ACÁCIO SILVA NETO

\title{
TENSÕES INDUZIDAS POR DESCARGAS ATMOSFÉRICAS EM REDES DE DISTRIBUIÇÃO DE BAIXA TENSÃO
}

\author{
Dissertação apresentada à Escola \\ Politécnica da Universidade de São Paulo \\ para obtenção do título de Mestre em \\ Engenharia.
}


ACÁCIO SILVA NETO

TENSÕES INDUZIDAS POR DESCARGAS ATMOSFÉRICAS EM REDES DE DISTRIBUIÇÃO DE BAIXA TENSÃO

Dissertação apresentada à Escola Politécnica da Universidade de São Paulo para obtenção do título de Mestre em Engenharia.

Área de Concentração:

Sistemas de Potência

Orientador:

Prof. Dr. Alexandre Piantini 
FICHA CATALOGRÁFICA

Silva Neto, Acácio

Tensões induzidas por descargas atmosféricas em redes de distribuição de baixa tensão / Acácio Silva Neto -- São Paulo, 2004.

$140 \mathrm{p}$.

Dissertação (Mestrado) - Escola Politécnica da Universidade de São Paulo. Departamento de Engenharia de Energia e Automação Elétricas

1. Redes de distribuição de energia elétrica 2. Potencial elétrico 3. Sistemas elétricos de potência I. Universidade de São Paulo. Escola Politécnica. Departamento de Engenharia de Energia e Automação Elétricas II.t 
Aos meus pais Acácio e Lázara, pelo incentivo em todos os momentos de minha vida. Obrigado por tudo. 


\section{AGRADECIMENTOS}

Ao meu orientador Prof. Dr. Alexandre Piantini pelo incentivo e apoio na realização deste trabalho.

Aos amigos Kodaira, Paulo e Thaís que tem colaborado com a minha formação profissional.

Ao Prof. Dr. Jorge Janiszewski pelos sábios conselhos.

Ao Instituto de Eletrotécnica e Energia que forneceu todas as condições para o desenvolvimento deste trabalho.

Às amigas da Biblioteca do IEE, Fátima, Lourdes e Penha, por todas as pesquisas que fizeram para enriquecer meu conhecimento.

Ao engenheiro Carlos Eduardo e à amiga Cíntia B. Lacerda pela ajuda na revisão dos textos.

E a todos que direta ou indiretamente colaboraram na realização deste trabalho. 


\section{RESUMO}

A utilização crescente de equipamentos eletro-eletrônicos sensíveis a interferências e a adoção de novos critérios para avaliação da qualidade da energia fornecida têm resultado em um aumento do número de pesquisas desenvolvidas com o objetivo de se obter informações a respeito das características das sobretensões em redes de baixa tensão. Isto motivou a realização deste trabalho, que teve por objetivo analisar as sobretensões causadas por descargas atmosféricas próximas a redes secundárias.

O estudo trata inicialmente das tensões transferidas para a rede de baixa tensão, via transformador, devido a tensões induzidas no primário. Para tal são utilizados resultados experimentais obtidos em modelo de linhas de distribuição em escala reduzida e também medições de tensões induzidas por descargas naturais em uma linha especialmente construída para estudo do fenômeno. Com o uso de um modelo de transformador de distribuição típico, de validade comprovada para avaliação de surtos transferidos, são analisadas as tensões transferidas para a rede secundária considerando-se diversas formas de onda no primário.

Posteriormente são calculadas as tensões induzidas nas redes de baixa tensão por descargas incidentes em suas proximidades através do "Extended Rusck Model" (ERM) - modelo de validade comprovada por meio de centenas de comparações entre tensões induzidas medidas e calculadas. $\mathrm{O}$ trabalho discute as influências, nas tensões induzidas, do modo de representação do transformador e das cargas conectadas ao secundário, valor da resistência de terra, amplitude e velocidade de propagação da corrente no canal, etc. A comparação entre as tensões induzidas em linhas convencionais e multiplexadas também é realizada. É analisado também o uso de dispositivos de proteção contra surtos na rede multiplexada tendo em vista a redução das amplitudes das tensões induzidas. Por fim são feitas comparações entre tensões induzidas e tensões transferidas via transformador à rede secundária considerando a mesma descarga atmosférica. 


\begin{abstract}
The growing use of electric and electronic equipment prone to electromagnetic interferences and the adoption of new criteria for evaluating the quality of the power supplied have increased the number of studies developed in order to obtain information regarding the characteristics of overvoltages on low-voltage networks. Such fact has motivated the development of this work, which aimed at analyzing overvoltages caused by lightning discharges near secondary networks.

The study first covers voltages transferred to the low-voltage network through the transformer due to induced voltages on its primary terminals. In order to accomplish that, experimental results obtained on a reduced scale model are used, as well as measurements of natural lightning induced voltages on a line specially built to study the phenomena. The voltages transferred to the secondary network, considering several waveforms on the primary, are analyzed by using a typical distribution transformer model, proven valid for evaluating transferred surges.
\end{abstract}

The study then presents the calculation of voltages induced on low-voltage networks by discharges on their vicinity through the "Extended Rusck Model" (ERM) - a model that has been validated by hundreds of comparisons between measured and calculated induced voltages. This work discusses the influences on induced voltages of the manner of representing the transformer and the loads connected to the secondary, as well as grounding resistance, amplitude and stroke current propagation speed, etc. Comparisons between lightning induced voltages on open wire lines and on lines with twisted conductors are also made. The use of surge protective devices on lines with twisted conductors is analyzed, and the reduction of induced voltage amplitudes is investigated. Finally, induced voltages and voltages transferred to the secondary network through a transformer are compared, considering the same lightning discharge. 


\section{SUMÁRIO}

LISTA DE FIGURAS

LISTA DE TABELAS

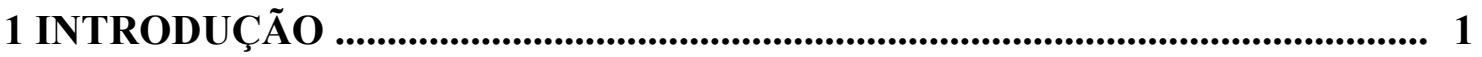

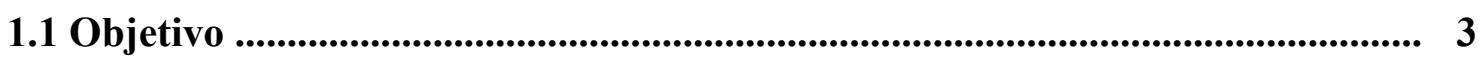

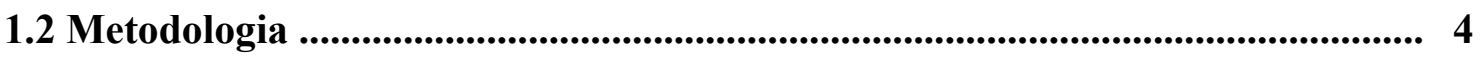

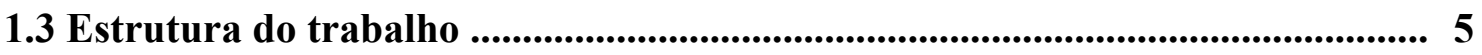

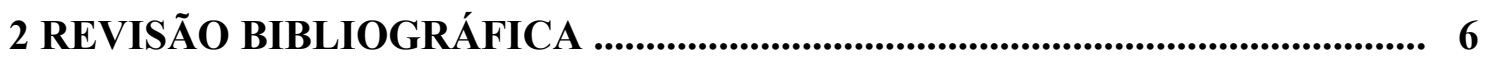

3 SURTOS TRANSFERIDOS VIA TRANSFORMADOR DEVIDO A

DESCARGAS ATMOSFÉRICAS PRÓXIMAS À REDE ................................. 29

3.1 Tensões induzidas em redes primárias .............................................................. 29

3.2 Tensões transferidas ao secundário via transformador ...................................... 40

4 TENSÕES INDUZIDAS NA REDE SECUNDÁRIA DEVIDO A

DESCARGAS ATMOSFÉRICAS .................................................................. 50

4.1. O modelo ERM ("Extended Rusck Model") .......................................................... 50

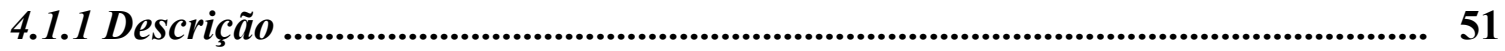

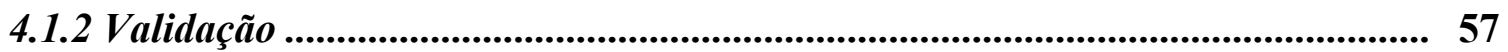

4.2 Configurações típicas de redes secundárias ..................................................... 59

4.3 Análise paramétrica ......................................................................................66

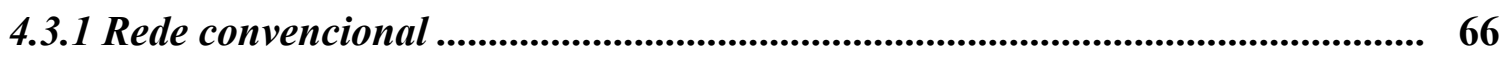

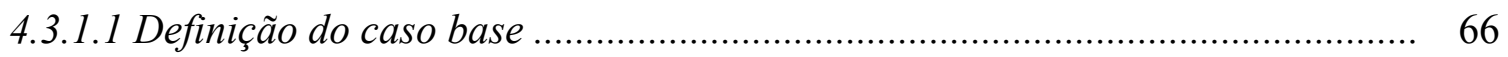

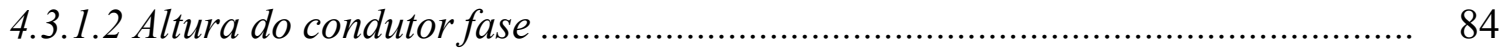

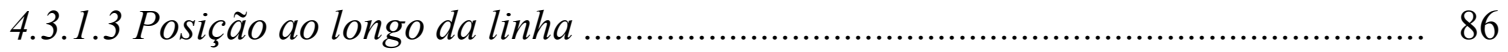

4.3.1.4 Amplitude da corrente da descarga de retorno ............................................. 87

4.3.1.5 Tempo de frente da corrente de descarga .................................................. 88

4.3.1.6 Tempo de queda da corrente de descarga ................................................... 90

4.3.1.7 Velocidade de propagação da corrente de descarga no canal ........................ 91

4.3.1.8 Distância do local de incidência da descarga à linha ................................... 93

4.3.1.9 Resistência de terra ............................................................................... 94 


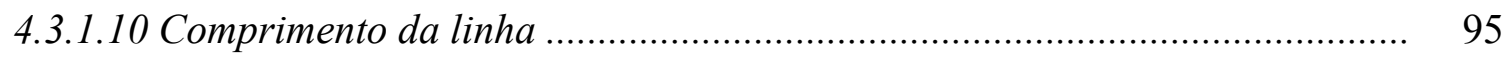

4.3.1.11 Distância entre pontos de aterramento do neutro ...................................... 97

4.3.1.12 Carga indutiva ...................................................................................... 98

4.3.1.13 Carga resistiva ........................................................................... 100

4.3.1.14 Carga capacitiva ............................................................................... 101

4.3.1.15 Comprimento do ramal de ligação ............................................................. 103

4.3.2 Rede multiplexada ........................................................................................ 104

4.3.2.1 Posição ao longo da linha ........................................................................ 111

4.3.2.2 Amplitude da corrente de descarga ........................................................... 112

4.3.2.3 Tempo de frente da corrente de descarga ................................................ 113

4.3.2.4 Resistência de terra ........................................................................... 114

4.3.3 Tensões induzidas em linhas com dispositivos de proteção contra surtos ....... 116

4.4 Comparação entre tensões transferidas ao secundário do transformador e as tensões induzidas em redes de baixa tensão .................................................... 120

5 CONCLUSÕES E PROPOSTAS DE TRABALHOS FUTUROS ....................... 125

REFERÊNCIAS BIBLIOGRÁFICAS ........................................................... 128 


\section{LISTA DE FIGURAS}

Fig. 2.1: Típicas sobretensões induzidas por descarga atmosféricas próximas a redes de baixa tensão [6]..

Fig. 2.2: Perfil ao longo da rede de BT (configuração 1) das amplitudes das tensões induzidas por descargas atmosféricas incidentes nas proximidades da linha (corrente da descarga $32 \mathrm{kA}, 5 / 50 \mu \mathrm{s}$ ) [7]

Fig. 2.3: Perfil ao longo da rede de BT (configuração 2) das amplitudes das tensões induzidas por descargas atmosféricas incidentes nas proximidades da linha (corrente da descarga $32 \mathrm{kA}, 5 / 50 \mu \mathrm{s}$ ) [7]......

Fig.2.4: Configuração da linha utilizada nas simulações [12]

Fig. 2.5: Tensões induzidas na rede secundária em função do tempo de frente $t f$ da corrente do "return stroke" [12]

Fig. 2.6: Modelo da impedância da unidade consumidora (adaptada de [8])...... 13

Fig. 2.7: Tensões induzidas na entrada do consumidor considerando quatro diferentes terminações (adaptada de [8]).....

Fig. 2.8: Configuração da rede de baixa tensão [13]

Fig. 2.9: Rede de distribuição aérea de baixa tensão e localização das descargas atmosféricas (adaptada de [13])

Fig. 2.10: Distribuição da máxima tensão induzida na rede de baixa tensão (sistema IT). Carga do consumidor: indutância de $10 \mu \mathrm{H}$ em série com capacitância de $100 \mathrm{nF}$ (adaptada de [13]).....

Fig. 2.11: Distribuição da máxima tensão induzida na rede de baixa tensão (sistema TN). Carga do consumidor: indutância de $10 \mu \mathrm{H}$ (adaptada de [13]).

Fig 2.12: Configuração das linhas experimentais (adaptada de [43])................ 20

Fig. 2.13: Configuração da linha experimental (adaptada de [45])..................... 21

Fig. 2.14: Formas de onda obtidas (adaptada de [45])...................................... 22

Fig. 2.15: Configuração de rede utilizada nas simulações (adaptada de [46])..... 22

Fig. 2.16: Visão geométrica da instalação elétrica. EF-IN e EF-OUT são antenas de medição de campo elétrico vertical interna e externamente à edificação, respectivamente (adaptada de [46]).

Fig. 2.17: Forma de onda do campo elétrico vertical medido interna e externamente à residência (adaptada de [46]).

Fig. 2.18: Tensão induzida medida e calculada com base no campo elétrico vertical externo indicado na Fig. 2.17 (adaptada de [46]).

Fig. 2.19: Tensões induzidas e campo elétrico vertical (adaptada de [46]). 
Fig 2.20: Descarga negativa nuvem-solo seguida de descarga intranuvem (adaptada de [47])...

Fig. 3.1: Configuração da rede do modelo reduzido - Caso 1 (adaptada de [34]). 31

Fig. 3.2: Tensão induzida medida no ponto M indicado na Fig. 3.1 (modelo reduzido - Caso 1). (adaptada de [34]). Corrente com amplitude de $34 \mathrm{kA}$

Fig. 3.3: Configuração da rede do modelo reduzido - Caso 2 (adaptada de [34]). 32

Fig. 3.4: Tensão induzida medida no ponto $\mathrm{M}$ indicado na Fig. 3.3 (modelo reduzido - Caso 2). (adaptada de [34]).Corrente com amplitude de $34 \mathrm{kA}$.

Fig. 3.5: Configuração da rede do modelo reduzido - Caso 3 (adaptada de [34]). 33

Fig. 3.6: Tensão induzida medida no ponto $\mathrm{M}$ indicado na Fig. 3.5 (modelo reduzido - Caso 3). (adaptada de [34]). Amplitude da corrente: 34 kA. 33

Fig. 3.7: Configuração da rede do modelo reduzido - Caso 4 (adaptada de [34]). 34

Fig. 3.8 Tensão induzida medida no ponto $\mathrm{M}$ indicado na Fig. 3.7 (modelo reduzido - Caso 4). (adaptada de [34]). Amplitude da corrente: 50 kA. 34

Fig. 3.9: Planta geral de localização dos sistemas de medição e aquisição. IPT Instituto de Pesquisas Tecnológicas e IEE - Instituto de Eletrotécnica e Energia [44]....

Fig. 3.10: Tensões induzidas na linha sem pára-raios em diferentes ocasiões. $\quad 38$ (escala real - casos 5 e 6 ) [50].

Fig. 3.11: Tensões induzidas na linha sem pára-raios sem diferentes ocasiões (escala real - casos 7 e 8 ) [50].

Fig. 3.12: Modelo de transformador de $30 \mathrm{kVA}$ para cálculo de surtos transferidos [29].

Fig 3.13: Configuração simulada. H1, H2 e H3 - terminais de alta tensão do transformador; $\mathrm{x} 1, \mathrm{x} 2, \mathrm{x} 3$ - terminais de baixa tensão do transformador; $\mathrm{n}$ - terminal neutro; V1 - tensão induzida no primário (fase-terra) por uma descarga atmosférica nas proximidades da linha; V2 - tensão nos terminais de baixa tensão do transformador (tensão transferida).

Fig. 3.14: Tensões transferidas para o secundário do transformador, na condição a vazio, considerando as tensões induzidas no primário obtidas através do estudo em escala reduzida

Fig. 3.15: Tensões transferidas para o secundário do transformador, na condição a vazio, considerando as tensões induzidas no primário obtidas através do estudo em escala real.

Fig. 3.16: Espectros da tensão no primário nos casos 7 e 8 e a curva de ganho do transformador. 
Fig. 3.17: Tensões transferidas ao secundário do transformador para diferentes condições de carga, considerando como tensão induzida no primário a onda relativa ao Caso 3 .

Fig. 4.1: Descarga atmosférica em uma estrutura metálica (adaptada de [27]).... 52

Fig. 4.2: Rampa de corrente se propagando ao longo do canal (adaptada de [27]).

Fig. 4.3: Rampa de corrente na estrutura metálica (adaptada de [27])

Fig. 4.4: Tensões induzidas em função da altura ht da estrutura metálica (adaptada de [27]).

Fig 4.5: Tensões induzidas U medida e calculada (adaptada de [27]). Caso 8102 [59].

Fig 4.6: Tensões induzidas U medida e calculada (adaptada de [27]). Caso 8202 [59].

Fig. 4.7: Estruturas de montagem de redes secundárias convencionais (adaptada de [85]).

Fig. 4.8: Cabo multiplexado.

Fig. 4.9: Traçados típicos de rede secundária (adaptada de $[65,75]$ ).

Fig. 4.10: Configuração da linha de baixa tensão monofásica sem neutro

Fig. 4.11: Tensão induzida (fase-terra) no ponto P indicado na Fig. 4.10 para diferentes alturas do condutor

Fig. 4.12: Configuração da linha de baixa tensão - dois condutores, sendo o mais alto aterrado no ponto médio da linha

Fig. 4.13: Tensões em relação ao terra no ponto $P$ para a configuração indicada na Fig. 4.12

Fig. 4.14: Comparação entre as tensões induzidas em relação ao terra nas configurações mostradas nas Figuras 4.10 e 4.12

Fig. 4.15: Configuração da linha de baixa tensão com transformador de $30 \mathrm{kVA} . \nabla$ - transformador

Fig. 4.16: Módulo das impedâncias de saída do modelo de transformador de 30 kVA e do circuito RLC paralelo utilizado como aproximação

Fig. 4.17: Tensões induzidas no ponto $P$ indicado na Figura 4.15 para $x d=0 \mathrm{~m} .73$

Fig. 4.18: Tensões induzidas no ponto $\mathrm{P}$ indicado na Figura 4.15 ..................... 75

Fig. 4.19: Configuração da linha de BT considerado transformador e carga no mesmo ponto

Fig. 4.20: Tensões induzidas no ponto P indicado na Figura 4.19 .................... 78

Fig. 4.21: Tensões induzidas no ponto $P$ indicado na Figura 4.19 ...................... 79

Fig. 4.22: Tensões induzidas no ponto $\mathrm{P}$ indicado na Figura 4.19. Considerando a corrente da descarga com tempo de frente $\mathrm{tf}=1 \mu \mathrm{s}$......................... 80

Fig. 4.23: Configuração da linha para diferentes modelos de carga ................... 81 
Fig. 4.24: Comparação entre tensões induzidas na configuração mostrada na Figura 4.23 para diferentes tipos de carga

Fig 4.25: Configuração da linha - Caso Base (xat =60 m)

Fig. 4.26: Tensões induzidas no ponto $\mathrm{P}$ indicado na Fig. 4.27. Caso base ........ 84

Fig. 4.27: Comportamento da tensão induzida em função da altura $\mathbf{h}$ do condutor fase. Configuração da linha mostrada na Figura 4.25

Fig 4.28: Configuração da linha - Caso base. Análise das tensões induzidas ao longo na linha

Fig. 4.29: Comportamento da tensão induzida em função das distâncias xd e x . 87

Fig. 4.30: Comportamento das tensões induzidas em função da amplitude I da corrente de descarga. Tensões calculadas no ponto $\mathrm{P}$ indicado na Figura 4.25

Fig. 4.31: Variação das tensões em função do tempo de frente tf da corrente de descarga. Tensões calculadas no ponto $\mathrm{P}$ indicado na Figura 4.25

Fig. 4.32: Variação das tensões induzidas em função do tempo de frente to da corrente de descarga

Fig. 4.33: Variação das tensões induzidas em função do coeficiente $\mathbf{b}$ da velocidade de propagação da corrente de descarga

Fig. 4.34: Variação das tensões induzidas em função da distância d da linha ao ponto de incidência da descarga atmosférica.

$\mathrm{I}=45 \mathrm{kA}, \mathrm{tf}=3 \mu \mathrm{s}$, to $=150 \mu \mathrm{s}$.

Fig. 4.35: Variação das tensões induzidas em função da resistência de terra Rat. 95

Fig 4.36: Configurações de linha para análise da influência do seu comprimento (vista superior)

Fig. 4.37: Variação das tensões induzidas (no ponto P) em função do comprimento da linha

Fig 4.38: Configurações de linha para análise da influência da distância entre pontos de aterramento do condutor neutro

Fig. 4.39: Variação das tensões induzidas em função do intervalo de aterramento do condutor neutro

Fig. 4.40: Variação das tensões induzidas em função da carga indutiva 99

Fig. 4.41: Variação das tensões induzidas em função da carga resistiva

Fig. 4.42: Variação das tensões induzidas em função da carga capacitiva 102

Fig. 4.43: Tensões induzidas (fase-terra) em diferentes pontos da linha em função do comprimento lr do ramal de ligação

Fig. 4.44: Variação das tensões induzidas fase-neutro em função do comprimento do ramal de ligação em diferentes pontos da linha

Fig. 4.45: Configuração de uma rede de BT multiplexada sem carga ou transformador instalado na linha

Fig. 4.46: Comparação entre tensões induzidas no ponto $\mathrm{P}(\mathrm{xd}=0 \mathrm{~m})$ das redes multiplexada (Fig. 4.45) e convencional (Fig 4.12). Caso simples, sem transformador ou cargas na linha

Fig. 4.47: Configuração da linha de BT multiplexada com transformador de $30 \mathrm{kVA}$ instalado em seu ponto central .

Fig. 4.48: Comparação entre tensões induzidas no ponto $\mathrm{P}(\mathrm{xd}=100 \mathrm{~m})$ na rede com transformador para as configurações multiplexada (Fig. 4.47) e convencional (Fig 4.15) 
Fig. 4.49: Comparação entre tensões induzidas fase-neutro no ponto $P$ $(\mathrm{xd}=100 \mathrm{~m})$ na rede com transformador de $30 \mathrm{kVA}$ para as configurações multiplexada (Fig. 4.47) e convencional (Fig 4.15)

Fig. 4.50: Configuração da linha de BT multiplexada com transformador de $30 \mathrm{kVA}$ instalado no seu ponto central e cargas ao longo da linha (configuração equivalente à mostrada na Fig. 4.25)

Fig. 4.51: Comparação entre tensões induzidas no ponto $\mathrm{P}$ na rede com transformador de $30 \mathrm{kVA}$ e cargas para as configurações multiplexada (Fig. 4.50) e convencional (Fig 4.25).

Resistência de terra Rat $=20 \Omega$

Fig. 4.52: Configuração de linha multiplexada para análise das tensões induzidas a $30 \mathrm{~m}$ de um ponto de aterramento do neutro.

Configuração equivalente à mostrada na Fig. 4.28-a

Fig. 4.53: Comparação entre tensões induzidas na rede com transformador e cargas para as configurações multiplexada (Fig. 4.52) e convencional (Fig 4.28-a)

Fig. 4.54: Comparação entre tensões induzidas no ponto $\mathrm{P}$ da rede com transformador para as configurações multiplexada (Fig. 4.50) e convencional (Fig 4.25). Amplitude da corrente I $=90 \mathrm{kA}$

Fig. 4.55: Comparação entre tensões induzidas no ponto $\mathrm{P}$ na rede com transformador para as configurações multiplexada (Fig. 4.50) e convencional (Fig 4.25). Tempo de frente da corrente da descarga $\mathrm{tf}=1,5 \mu \mathrm{s}$

Fig. 4.56: Comparação entre tensões induzidas no ponto $P$ na rede com transformador para as configurações multiplexada (Fig. 4.50) e convencional (Fig 4.25). Resistência de terra Rat $=200 \Omega$

Fig. 4.56: Comparação entre tensões induzidas no ponto $\mathrm{P}$ na rede com transformador para as configurações multiplexada (Fig. 4.50) e convencional (Fig 4.25). Resistência de terra Rat $=200 \Omega$ 


\section{LISTA DE TABELAS}

Tabela 4.1: Afastamento mínimo entre condutores e o solo. E: tensão nominal $[84,85] \ldots$

Tabela 4.2: Amplitudes máximas das tensões induzidas no condutor neutro (ponto P) para as configurações de redes multiplexada (Figs. $4.45 \mathrm{e}$ 4.47) e convencional (Figs. 4.12 e 4.15)..... 


\section{LISTA DE ABREVIATURAS E SIGLAS}

\begin{tabular}{|c|c|}
\hline ATP & "Alternative Transients Program" \\
\hline AWG & "American Wire Gage" \\
\hline BT & Baixa Tensão \\
\hline $\mathrm{CA}$ & Cabo de alumínio \\
\hline CAL & Cabo de alumínio liga \\
\hline CEB & Companhia Energética de Brasília \\
\hline CELG & Centrais Elétricas de Goiás S.A. \\
\hline CELPA & Centrais Elétricas do Pará S.A. \\
\hline CELTINS & Companhia de Energia Elétrica do Estado do Tocantins \\
\hline CEMAT & Centrais Elétricas Mato-Grossenses S.A. \\
\hline CEMIG & Companhia Energética de Minas Gerais \\
\hline CIGRE & "International Council on Large Electric Systems" \\
\hline CIRED & "International Conference and Exhibition on Electricity Distribution" \\
\hline COELBA & Companhia Elétrica da Bahia \\
\hline COPEL & Companhia Paranaense de Energia \\
\hline CPFL & Companhia Paulista de Força e Luz \\
\hline DPS & Dispositivos de Proteção contra Surtos \\
\hline EMTP & "Electromagnetic Transients Program" \\
\hline ENERSUL & Empresa Energética do Mato Grosso do Sul S.A. \\
\hline ERM & "Extended Rusck Model" \\
\hline GATDA & Grupo de Alta Tensão e Descarga Atmosféricas \\
\hline $\mathrm{HP}$ & Heweltt \& Packard \\
\hline IEE & Instituto de Eletrotécnica e Energia da USP \\
\hline IPT & Instituto de Pesquisas Tecnológicas \\
\hline LIOV & "Lightning-Induced OverVoltage" \\
\hline LLS & "Lightning Location System" \\
\hline LPATS & "Lightning Positioning and Tracking System" \\
\hline m.r.s. & modelo do "return stroke" \\
\hline NBI & Nível Básico de Isolamento \\
\hline NBR & Norma Brasileira \\
\hline
\end{tabular}


Pspice Software de simulação de circuitos

PVC "Poly Vinil Chloride"

TL "Transmission Line"

TN Alimentação (lado fonte) diretamente aterrado, massas (carcaças) das cargas ligadas ao ponto aterrado da fonte

TN-C Alimentação (lado fonte) diretamente aterrado, massas (carcaças) das cargas ligadas ao ponto aterrado da fonte por meio do condutor neutro

TN-S Alimentação (lado fonte) diretamente aterrado, massas (carcaças) das cargas ligadas ao ponto aterrado da fonte por meio do condutor de proteção

TNCS Alimentação (lado fonte) diretamente aterrado, massas (carcaças) das cargas ligadas ao ponto aterrado da fonte parte por meio do condutor de proteção e parte por meio do condutor neutro Alimentação (lado fonte) diretamente aterrado, massas (carcaças) das cargas ligadas a um terra próprio, independente da fonte

USP Universidade de São Paulo

XLPE Politileno Reticulado 


\section{LISTA DE SÍMBOLOS}

\begin{tabular}{|c|c|}
\hline$\nabla$ & transformador de distribuição \\
\hline • & carga da unidade consumidora (carga residencial) \\
\hline$\Delta \mathrm{z}$ & elemento no eixo z \\
\hline $\mathrm{A}_{\mathrm{i}}$ & vetor potencial \\
\hline $\mathrm{b}$ & razão entre a velocidade de propagação da onda de corrente no canal \\
\hline & de descarga e a velocidade da luz no vácuo \\
\hline bt & razão entre a velocidade de propagação da onda de corrente na \\
\hline & estrutura e a velocidade da luz no vácuo \\
\hline $\mathrm{C}$ & capacitância \\
\hline $\mathrm{c}$ & velocidade da luz no vácuo \\
\hline $\mathrm{E}$ & campo elétrico \\
\hline EF-IN & campo elétrico interno \\
\hline EF-OUT & campo elétrico externo \\
\hline h & altura dos condutores fases \\
\hline ht & altura da estrutura metálica \\
\hline hn & altura da base da nuvem \\
\hline hg & altura do condutor neutro \\
\hline $\mathrm{H} 1$ & terminal de alta tensão de transformador de distribuição trifásico \\
\hline $\mathrm{H} 2$ & terminal de alta tensão de transformador de distribuição trifásico \\
\hline H3 & terminal de alta tensão de transformador de distribuição trifásico \\
\hline $\mathrm{i}(\mathrm{z}, \mathrm{t})$ & corrente na altura $\mathrm{z}$ e no instante de tempo $\mathrm{t}$ \\
\hline Ic & corrente no canal de descarga \\
\hline Ic & corrente na imagem do canal de descarga \\
\hline It & corrente na estrutura metálica \\
\hline It' & corrente na imagem da estrutura metálica \\
\hline $\mathrm{L}$ & Indutância \\
\hline lr & comprimento do ramal de ligação \\
\hline M & local de medição da tensão induzida no modelo reduzido \\
\hline$n$ & neutro \\
\hline $\mathrm{P}$ & ponto de cálculo da tensão induzida \\
\hline
\end{tabular}


ponto de cálculo da tensão induzida na linha primária ponto de cálculo da tensão induzida na linha secundária carga elétrica distribuição linear de carga elétrica distância do condutor à estrutura metálica Resistência altura no tempo $t$ da frente de corrente no canal altura no tempo $t$ da frente de corrente na imagem do canal altura no tempo $t$ da frente de corrente na estrutura metálica altura no tempo $t$ da frente de corrente na imagem da estrutura metálica tempo maior que $t_{0}$ tempo no início do "return stroke" tempo de frente da corrente da descarga atmosférica tempo até zero valor da corrente da descarga atmosférica tensão induzida no ponto $\mathrm{x}$ e no tempo $\mathrm{t}$ Potencial escalar induzido distância entre o ponto de cálculo da tensão induzida e o ponto da linha mais próximo ao local de incidência da descarga atmosférica terminal de baixa tensão do transformador de distribuição trifásico terminal de baixa tensão do transformador de distribuição trifásico terminal de baixa tensão do transformador de distribuição trifásico distância entre a carga e a extremidade da linha 


\section{CAPÍTULO 1}

\section{INTRODUÇÃO}

Os efeitos das descargas atmosféricas são de grande importância para o setor elétrico devido à possibilidade de ocorrência de danos permanentes nos equipamentos utilizados no sistema e de desligamentos de linhas de transmissão e distribuição. Tais situações podem redundar em grandes prejuízos às empresas do setor e à sociedade. As descargas podem injetar surtos na rede elétrica basicamente de três formas: incidindo diretamente nos condutores (descargas diretas), atingindo algum ponto nas proximidades da linha (descargas indiretas) ou atingindo diretamente uma edificação.

As linhas de transmissão são normalmente dotadas de cabo guarda para proporcionar uma certa proteção quanto às descargas diretas nos condutores fase. Embora o cabo guarda seja instalado sobre os demais condutores, ainda há possibilidade de uma descarga atingir algum dos condutores fase, podendo ocasionar um desligamento na linha dependendo do nível de tensão do sistema, da intensidade e forma de onda da corrente da descarga e da presença ou não de dispositivos de proteção ao longo da linha. No caso da descarga atingir o cabo guarda ou o topo da torre, também existe a possibilidade de desligamento da linha devido ao "backflashover", isto é, descarga disruptiva na cadeia de isoladores em virtude do aumento da diferença de potencial entre a torre e os condutores fase. Quanto às descargas indiretas (próximas à linha), as linhas de transmissão com tensão nominal igual ou superior a $69 \mathrm{kV}$ raramente são afetadas, uma vez que sua isolação é em geral suficientemente alta para impedir uma descarga disruptiva nos isoladores e, conseqüentemente, o desligamento da linha.

Em relação às redes de distribuição, as descargas atmosféricas indiretas geralmente têm importância significativa na composição dos índices de qualidade da energia fornecida, uma vez que as tensões por elas induzidas podem atingir amplitudes superiores ao nível básico de isolamento (NBI) da linha. Além disso, deve-se também levar em conta seus altos índices de ocorrência. O uso crescente de equipamentos sensíveis faz com que a busca pela qualidade da energia fornecida seja 
cada vez mais importante. As descargas atmosféricas representam grande impacto para o sistema de distribuição de energia elétrica devido à configuração predominantemente aérea das linhas e a sua grande extensão. Estima-se que cerca de um terço dos desligamentos das redes de distribuição seja causado por descargas atmosféricas [1]. O Brasil é um dos países com maior incidência de raios no mundo dada sua dimensão territorial e sua localização entre os trópicos. De acordo com [2], entre 50 e 70 milhões de raios atingem o solo brasileiro a cada ano, causando prejuízos da ordem de $\mathrm{R} \$ 500$ milhões, afetando principalmente os setores elétrico, industrial e de telecomunicações.

Nesse contexto, as descargas atmosféricas são responsáveis por boa parte dos danos e das sobretensões em linhas de distribuição. Conforme mencionado, as sobretensões podem ser causadas por descargas diretas ou indiretas. Embora as amplitudes das solicitações causadas por descargas indiretas sejam menos severas que aquelas provocadas por descargas diretas, elas são de maior importância, pois ocorrem com maior freqüência. Além disso, como as tensões induzidas por descargas atmosféricas podem atingir amplitudes superiores a $300 \mathrm{kV}$, elas podem ocasionar desligamentos em linhas com tensão nominal inferior a $69 \mathrm{kV}$. De acordo com [3], cerca de $47 \%$ das falhas em transformadores de distribuição da CEMIG são provocadas por descargas atmosféricas, causando prejuízos da ordem de US\$ 1,83 milhões por ano. Esse é um dos motivos pelos quais as tensões induzidas por descargas atmosféricas em redes de distribuição primária vêm sendo pesquisadas há vários anos. Apesar disso, ainda existem divergências sobre o fenômeno, o que tem motivado também o desenvolvimento de estudos experimentais $[4,5]$.

Mais recentemente, com as privatizações do setor elétrico brasileiro e a adoção de novos critérios de qualidade para o fornecimento de energia, as concessionárias têm investido em programas de pesquisa e desenvolvimento nessa área. Do ponto de vista dos consumidores residenciais e comerciais, que recebem alimentação em baixa tensão $(110 / 220 / 380 \mathrm{~V})$, as sobretensões causadas por descargas atmosféricas têm papel relevante na qualidade da energia recebida, uma vez que essas sobretensões podem atingir valores superiores a $10 \mathrm{kV}$ [6-14]. As sobretensões nas redes 
secundárias devido a descargas atmosféricas podem ser transferidas do primário via transformador quando da ocorrência de descargas diretas ou próximas à rede primária. A ocorrência de descargas diretas na rede secundária é menos freqüente, pois sua instalação é feita em altura inferior à da rede primária, além de ficar, na maioria dos casos, sob a mesma. Ainda em relação aos surtos na rede secundária, eles também podem ser causados por descargas incidentes nas edificações. No caso de correntes de alta intensidade, haverá um aumento do potencial de terra no local da edificação atingida, o que poderá causar a transferência do surto à rede de baixa tensão em decorrência de descargas disruptivas ou pela atuação de dispositivos de proteção.

As tensões transferidas à rede secundária quando da incidência de descargas diretas no primário foram estudadas em [9, 15-24]. Embora existam vários trabalhos a respeito de tensões induzidas em redes primárias, as tensões induzidas em redes secundárias ainda não foram estudadas com grande profundidade, como pode ser observado pela escassez de publicações na área. O melhor conhecimento do comportamento das tensões induzidas nas redes secundárias é de grande importância para a melhoria da qualidade da energia, uma vez que essas tensões podem ter efeito significativo no desempenho das redes frente a descargas atmosféricas, em virtude de sua alta freqüência de ocorrência e do fato de poderem atingir amplitudes elevadas. A busca de um melhor entendimento da forma como os diversos parâmetros afetam suas amplitudes e formas de onda é, portanto, de fundamental importância.

\subsection{Objetivo}

Este trabalho visa a caracterização das tensões induzidas em redes de distribuição de baixa tensão por descargas atmosféricas indiretas. Essa caracterização consiste na determinação do comportamento das tensões induzidas considerando situações típicas, através de estudo sistemático no qual são avaliadas as influências dos parâmetros mais importantes quanto às suas amplitudes e formas de onda. $\mathrm{O}$ estudo contempla a análise de redes convencionais e multiplexadas, bem como os efeitos da instalação de dispositivos de proteção contra surtos na rede secundária. 


\subsection{Metodologia}

A teoria para o cálculo de tensões induzidas por descargas atmosféricas em linhas de distribuição é complexa e envolve um grande número de variáveis. Assim, para atingir o objetivo do trabalho, é fundamental o conhecimento do fenômeno das descargas atmosféricas e das características das redes de baixa tensão.

A parte inicial do trabalho refere-se à pesquisa bibliográfica, que proporciona uma visão geral dos surtos causados por descargas atmosféricas em redes de baixa tensão. Além de estudos a respeito de tensões induzidas por descargas nuvem-terra, também são apresentados alguns resultados de estudos sobre as tensões induzidas em redes secundárias por descargas intranuvem.

Posteriormente são tratadas as tensões transferidas do primário, via transformador, quando da ocorrência de descargas próximas à rede. Para essa avaliação, é necessário conhecer as características básicas das tensões induzidas nas redes primárias e os parâmetros mais importantes das descargas atmosféricas. Essa etapa do trabalho é desenvolvida utilizando-se o Modelo de Rusck Estendido ("Extended Rusck Model ERM"), proposto em [25] e aprimorado em [26], modelo este de validade comprovada por meio de comparações envolvendo experimentos em escalas real e reduzida [26-28]. A análise das tensões transferidas à rede secundária é realizada por meio de simulações utilizando para representação do transformador de distribuição o modelo desenvolvido pelo Grupo de Alta Tensão/Descargas Atmosféricas (GATDA / USP) [29-32].

A caracterização das tensões induzidas por descargas atmosféricas em linhas de baixa tensão é feita a partir de um estudo sistemático envolvendo a análise dos dados obtidos através de simulações computacionais. Tais simulações, realizadas através do ERM, contemplam diversas configurações de linha e valores para parâmetros, tais como a resistência de terra, a altura dos condutores, a forma de representação das cargas nas unidades consumidoras, etc. Os principais parâmetros das descargas 
atmosféricas, como a amplitude, forma de onda e velocidade de propagação da corrente e a distância da descarga à linha também são levados em consideração. As simulações computacionais são realizadas inicialmente para casos mais simples, de modo a verificar como cada variável envolvida no problema afeta a amplitude e a forma de onda da tensão induzida. Casos mais complexos, como a consideração de cargas e equipamentos como transformadores e dispositivos de proteção contra surtos, são analisados em seguida.

A metodologia utilizada possibilita, então, a caracterização das tensões induzidas na rede secundária para os principais casos de interesse, facilitando a tomada de decisões sobre as configurações de linhas de baixa tensão e a especificação de dispositivos de proteção de transformadores de distribuição e para utilização nas entradas das unidades consumidoras.

\subsection{Estrutura do Trabalho}

Quanto à estrutura deste trabalho, tem-se, no Capítulo 2, uma revisão bibliográfica a respeito das tensões induzidas por descargas atmosféricas em redes e instalações de baixa tensão. No Capítulo 3 são apresentados estudos a respeito de sobretensões transferidas do primário ao secundário do transformador quando da ocorrência de descargas próximas à rede de distribuição. O Capítulo 4 consiste em uma análise paramétrica das tensões induzidas em redes secundárias convencionais e multiplexadas, considerando também a utilização de dispositivos de proteção na rede de baixa tensão. As conclusões e propostas para trabalhos futuros são apresentadas no Capítulo 5. 


\section{CAPÍTULO 2}

\section{REVISÃO DA LITERATURA}

Este capítulo apresenta um resumo dos trabalhos considerados mais importantes quanto às tensões induzidas na rede secundária devido a descargas atmosféricas próximas a linhas de distribuição.

No trabalho realizado pela força-tarefa CIRED/CIGRE sobre proteção de redes de média e baixa tensão contra descargas atmosféricas [6], foram apresentadas discussões a respeito das sobretensões na rede secundária causadas tanto por descargas diretas quanto por descargas próximas à rede. Por meio de simulações realizadas com o programa LIOV-EMTP [33] verificou-se que, devido à presença do condutor neutro na rede de baixa tensão, o qual é aterrado em vãos regulares, as tensões induzidas nessas redes apresentam valores mais baixos que aqueles encontrados na rede primária. Ainda de acordo com o trabalho, a tensão induzida no condutor neutro é efetivamente limitada pelo aterramento e o valor máximo da tensão induzida ocorre no meio do vão (os menores valores de tensão ocorrem junto aos pontos de aterramento). As formas de onda das tensões induzidas na rede secundária são caracterizadas, segundo os autores, por oscilações amortecidas conforme mostrado na Figura 2.1. Outra afirmação do trabalho é que a tensão induzida no condutor fase é também limitada em valores baixos em virtude do grande acoplamento entre os condutores e o neutro. Esse acoplamento é elevado nas redes de baixa tensão (BT), principalmente em redes multiplexadas. Os valores de sobretensão na rede de BT apresentados não provocam, geralmente, disrupção nos isoladores porém, os valores são suficientemente altos para provocar danos nos aparelhos eletro-eletrônicos dos consumidores conectados a um ponto da linha próximo ao local de incidência da descarga atmosférica. 


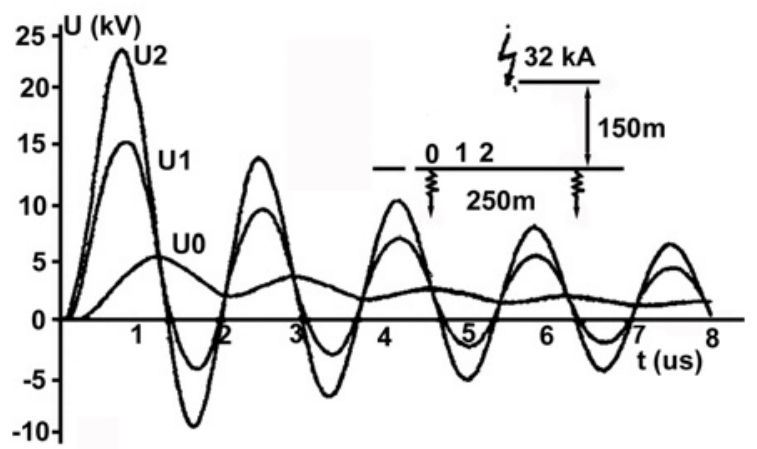

Fig. 2.1: Típicas sobretensões induzidas por descarga atmosféricas próximas a redes de baixa tensão [6].

Em outro trabalho apresentado no CIRED em 1997, Mirra et al [7] classificam os surtos na rede de baixa tensão causados por descargas atmosféricas como: sobretensões originadas na rede primária e transferidas via transformador, tensões induzidas diretamente na rede secundária por descargas atmosféricas próximas e sobretensões na rede secundária decorrentes de descargas diretas. Para cada tipo de situação foram realizadas simulações de modo a se determinar os valores de pico e as formas de onda das sobretensões em casos específicos, bem como para se identificar os parâmetros da rede de distribuição com maior influência sobre essas sobretensões. A determinação das sobretensões transferidas via transformador foi realizada, na maioria das simulações, através da utilização de um modelo capacitivo simples para o transformador de distribuição. O modelo de transformador utilizado foi ajustado e comparado através de um modelo físico de transformador implementado no “Electromagnetic Transient Program" (EMTP) que, segundo os autores, apresentou uma boa concordância entre valores de tensão e corrente medidos e simulados.

A validade do programa LIOV-EMTP utilizado para os cálculos das tensões induzidas em [33] foi verificado em [34]. O programa permite calcular tensões em redes com vários condutores, terminações e topologias em função dos seguintes parâmetros da descarga atmosférica: forma de onda da corrente na base do canal, velocidade e localização do "return stroke", ponto de observação da rede e parâmetros do solo. A rede aérea de baixa tensão estudada tinha o esquema TT e era constituída ora por dois, ora por quatro condutores torcidos (rede multiplexada). O condutor neutro era aterrado em intervalos variando entre $300 \mathrm{~m}$ a $400 \mathrm{~m}$. 
A rede de BT foi simulada por um feixe de quatro condutores com impedância característica de $500 \Omega$. A altura dos condutores era de $6,5 \mathrm{~m}$. As tensões induzidas observadas nessa rede de baixa tensão são idênticas às ilustradas na Figura 2.1, apresentando oscilações devido às reflexões nos pontos de aterramento do condutor neutro. O período das oscilações corresponde a duas vezes o tempo de tráfego das ondas de tensão entre os pontos de aterramento do neutro. O perfil das amplitudes das tensões induzidas ao longo de um alimentador típico de rede de baixa tensão é apresentado na Figura 2.2. O alimentador consiste em dois troncos partindo do transformador de distribuição. A impedância de aterramento do condutor neutro foi representada por resistores de $50 \Omega$.

A curva de sobretensão ao longo da rede de BT é caracterizada pelo fato de as maiores amplitudes ocorrerem no meio dos vãos localizados em frente ao local de incidência da descarga atmosférica. A Figura 2.3 apresenta o perfil das tensões induzidas ao longo de uma rede de baixa tensão com outra configuração. A rede representada na Figura 2.3 difere da apresentada na Figura 2.2 pelo acréscimo de quatro ramificações ao tronco principal superior da rede.

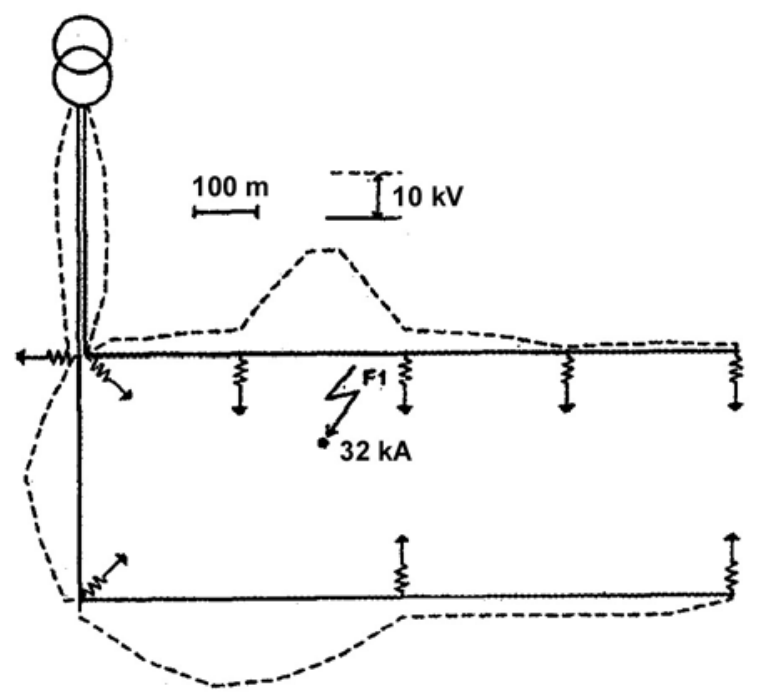

Fig. 2.2: Perfil ao longo da rede de BT (configuração 1) das amplitudes das tensões induzidas por descargas atmosféricas incidentes nas proximidades da linha (corrente da descarga $32 \mathrm{kA}, 5 / 50 \mu \mathrm{s}$ ) [7]. 


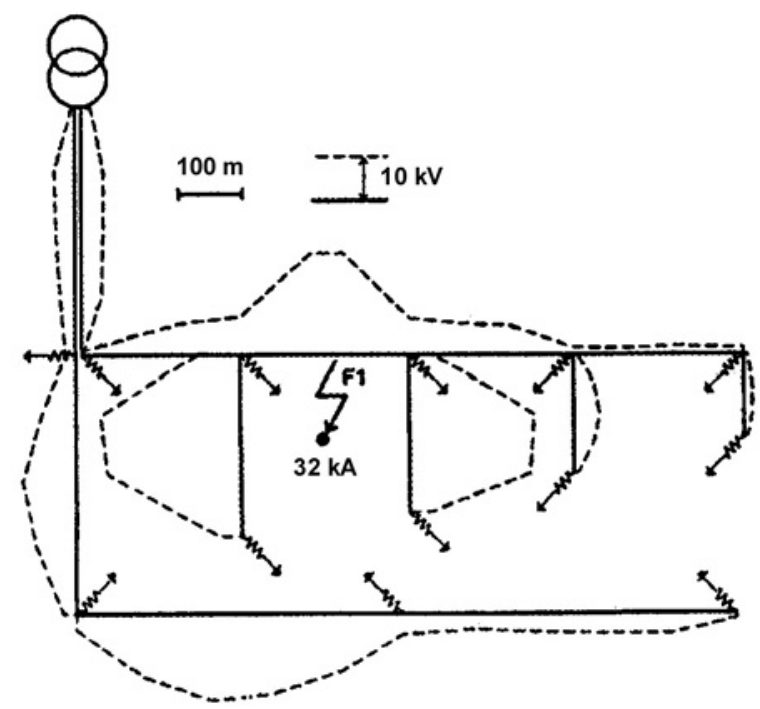

Fig. 2.3: Perfil ao longo da rede de BT (configuração 2) das amplitudes das tensões induzidas por descargas atmosféricas incidentes nas proximidades da linha (corrente da descarga $32 \mathrm{kA}, 5 / 50 \mu \mathrm{s}$ ) [7].

Segundo o trabalho, a adição de novos ramais na rede não provoca mudança nos valores de pico das sobretensões nos vãos adjacentes, uma vez que as contribuições dos vãos adjacentes para o valor de pico da sobretensão em um determinado vão podem ser desprezadas devido ao fato da impedância de terra é baixa quando comparada à impedância da linha.

No trabalho de Piantini et al [9] foi realizado um amplo estudo das sobretensões nas linhas secundárias ocasionadas por descargas atmosféricas, contemplando suas diversas origens, ou seja, sobretensões induzidas por descargas atmosféricas próximas à rede secundária, sobretensões induzidas na rede secundária devido às descargas entre nuvens, sobretensões devido a descargas atmosféricas diretas na rede secundária e sobretensões transferidas à rede secundária via transformador devido a descargas atmosféricas próximas à rede primária. Com enfoque às tensões induzidas na rede secundária, foram apresentados resultados e análises de simulações computacionais relativas às sobretensões induzidas na rede de BT. Através do modelo ERM desenvolvido em [25], e aprimorado e validado por meio de comparações com resultados experimentais obtidos em modelo em escalas real e reduzida [26-28], foram realizadas simulações variando os principais parâmetros que 
afetam as tensões induzidas para uma determinada configuração de linha, determinando-se a influência de cada parâmetro na amplitude e na forma de onda das tensões. A Figura 2.4 apresenta uma das configurações de linha utilizada nas simulações.

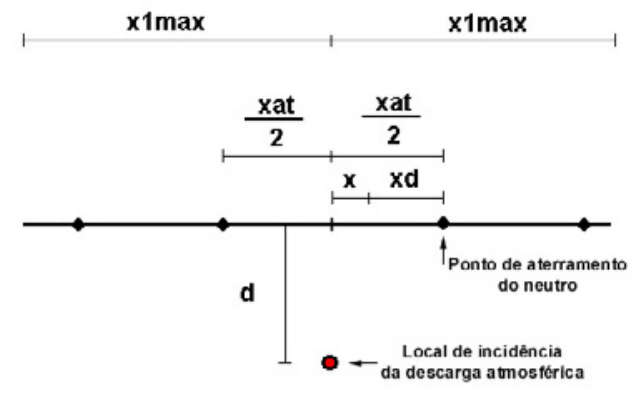

(a)

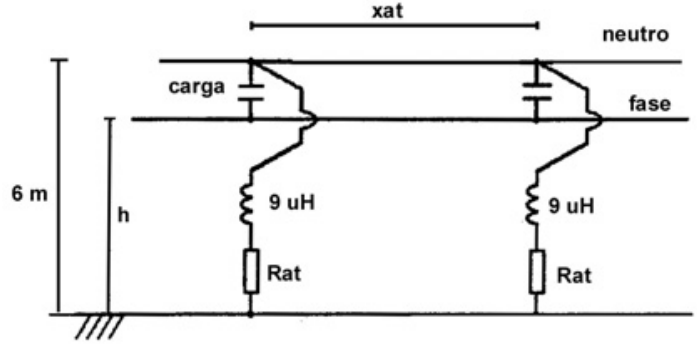

(b)

Fig.2.4: Configuração da linha utilizada nas simulações [12].

$\mathbf{x}=$ distância entre o ponto de cálculo da tensão e o ponto na linha mais próximo ao local de incidência da descarga.

$\mathbf{x d}=$ distância entre o ponto de cálculo da tensão e o ponto de aterramento do neutro mais próximo. a) vista superior

b) vista lateral

Os principais parâmetros analisados nessa linha foram a altura do condutor fase, o comprimento da linha, a posição ao longo da linha em que é calculada a tensão induzida, o valor da resistência de terra e a distância entre os pontos de aterramento do neutro. Foram avaliadas ainda as influências, nas tensões induzidas, da distância entre a linha e o local de incidência da descarga atmosférica, tempo de frente da corrente do "return stroke" e as características da carga (capacitiva, resistiva e indutiva).

A Figura 2.5 apresenta, a título de exemplo, as tensões induzidas na rede secundária considerando-se diferentes tempos de frente tf da corrente do "return stroke", para uma determinada configuração de linha. Como se pode observar, quanto menor o tempo de frente $t f$, maiores as amplitudes das tensões induzidas. Devido principalmente ao menor espaçamento entre os pontos de aterramento do condutor neutro (no caso, $60 \mathrm{~m}$ ), as tensões induzidas não apresentam a característica oscilatória observada em $[6,7]$. Dos resultados apresentados no trabalho, verifica-se 
que as amplitudes das tensões induzidas na linha de baixa tensão podem freqüentemente atingir valores superiores a $6 \mathrm{kV}$.

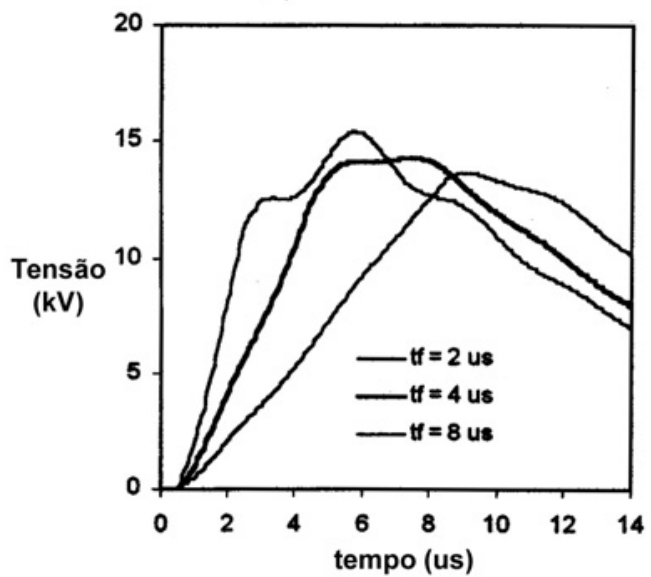

(a)

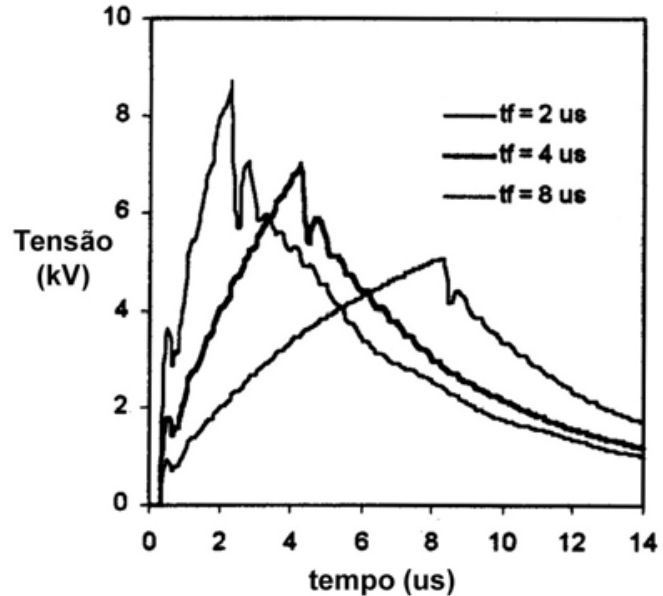

(b)

Fig. 2.5: Tensões induzidas na rede secundária em função do tempo de frente $t f$ da corrente do "return stroke" [12].

a) tensões fase-neutro

b) tensões neutro-terra

Ainda em relação ao trabalho desenvolvido pelos mesmos autores [9], foi realizado um levantamento bibliográfico a respeito de tensões induzidas por descargas atmosféricas em nuvem. Essas descargas podem ser divididas em intranuvem, internuvens e nuvem-ar, mas atualmente não existem dados experimentais que possam distinguir as características desses três tipos de descargas, pois medições de campos elétricos têm demonstrado uma similaridade considerável entre esses tipos de descargas [35]. Em virtude da utilização de componentes eletrônicos sensíveis nos equipamentos eletroeletrônicos atuais, estão surgindo suspeitas quanto à possibilidade das tensões induzidas provocadas por descargas desses tipos (doravante denominadas descargas em nuvem) causarem danos e redução da vida útil desses equipamentos. Embora as descargas em nuvem ocorram, em geral, com maior freqüência que as descargas nuvem-solo, esse fenômeno é ainda pouco estudado devido aos poucos impactos sobre o sistema elétrico, como desligamentos de linhas de distribuição e queima de transformadores.

Em [36], Rubinstein e Uman apresentam resultados de pesquisa a respeito de tensões induzidas por descargas atmosféricas em uma linha de distribuição não energizada 
com 448 m de comprimento. Foram efetuadas medições de tensões na linha com ambas as extremidades em aberto e também medições de campo elétrico em suas proximidades quando da ocorrência de descargas nuvem-solo e em nuvem. No caso de descargas em nuvem, a altitude da ocorrência foi superior a $5 \mathrm{~km}$, com ângulo de elevação de cerca de $40^{\circ}$. Foram registradas tensões induzidas oscilantes com amplitude máxima de $90 \mathrm{~V}$.

O trabalho de Hoidalen [8] apresenta resultados de cálculos de sobretensões na rede secundária provocadas por descargas atmosféricas indiretas, considerando o efeito das cargas. A modelagem das cargas da rede de BT, instalações dos consumidores e o lado de baixa dos transformadores de distribuição, foi feita com base em medições de impedâncias na faixa de $5 \mathrm{kHz}$ até $2 \mathrm{MHz}$, realizadas através de um analisador de redes marca HP, modelo 4195A. As impedâncias de entrada dos transformadores foram medidas entre as fases conectadas e o tanque, com o neutro ora conectado ao tanque, ora isolado. As impedâncias de entrada dos consumidores foram medidas na cabine de medição entre os condutores fase e o de proteção, com o condutor neutro conectado aos condutores fase (sistema IT) ou conectado ao condutor de proteção (sistema TN). Em ambos os casos o condutor de proteção era ligado ao sistema de aterramento e a alimentação do sistema estava desligada.

A unidade consumidora avaliada em [8] consistiu em um apartamento de $127 \mathrm{~m}^{2}$ com sete circuitos elétricos. Os sistemas de aquecimento de água, piso e ambiente foram desligados, que é uma situação típica no período do verão. As lâmpadas incandescentes foram substituídas por resistores que simulam a impedância dos filamentos das lâmpadas na condição normal de funcionamento. A Figura 2.6 apresenta o melhor circuito obtido para simular a impedância da unidade consumidora nos dois esquemas de alimentação estudados.

Os cálculos das tensões induzidas foram realizados utilizando como modelo da carga uma indutância ideal entre $2 \mu \mathrm{H}$ e $20 \mu \mathrm{H}$ no esquema TN. Para o esquema IT o modelo utilizado foi uma capacitância entre $20 \mathrm{nF}$ e $200 \mathrm{nF}$ em série com uma indutância com valor entre $2 \mu \mathrm{H}$ e $20 \mu \mathrm{H}$. A modelagem da impedância da instalação 
consumidora não foi realizada em detalhe devido à grande diferença entre instalações de baixa tensão, o que segundo o autor justifica o uso de um modelo mais simples.

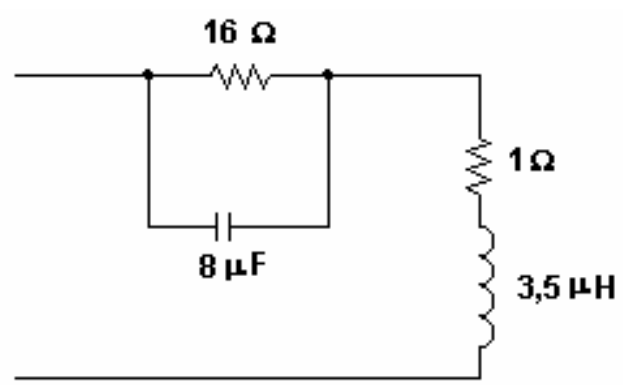

(a)

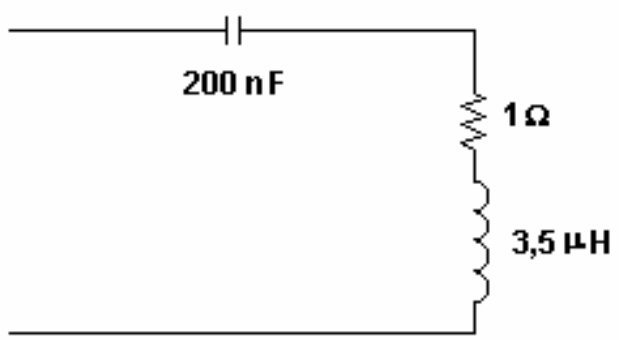

(b)

Fig. 2.6: Modelo da impedância da unidade consumidora (adaptada de [8]).

a) esquema de alimentação TN $\quad$ b) esquema de alimentação IT

Para a modelagem dos transformadores foram realizadas medições de impedância em 15 transformadores de distribuição com potências de $50 \mathrm{kVA}$ a $1250 \mathrm{kVA}$, tendo sido observadas grandes diferenças entre transformadores com e sem o neutro aterrado. Quando o neutro do transformador é aterrado, sua impedância vista pela rede de baixa tensão pode ser representada, como primeira aproximação, por uma pequena indutância da ordem de $4 \mu \mathrm{H}$ a $40 \mu \mathrm{H}$, enquanto para o caso do neutro do transformador isolado do terra a impedância pode ser representada por uma capacitância de $2 \mathrm{nF}$ a $20 \mathrm{nF}$. Essa aproximação é válida para a faixa de $10 \mathrm{kHz}$ a $500 \mathrm{kHz}$, que segundo o autor é suficiente para cálculos de sobretensões induzidas.

O modelo utilizado para o cálculo das tensões induzidas foi o proposto por Agrawal [37], tendo a linha sido considerada sem perdas pelo fato de seu comprimento ser menor que $1 \mathrm{~km}$. Foi assumido também que o campo elétrico não é afetado pela condutividade do solo, embora o modelo utilizado permita que os efeitos da condutividade do solo sejam considerados de forma a observar sua contribuição. Os cálculos das tensões induzidas foram realizados utilizando o "Alternative Transients Program" (ATP) para uma linha de baixa tensão com configuração simples. A rede de BT consistia em uma rede trifásica de $500 \mathrm{~m}$ de comprimento e altura de 6 m, com impedâncias características de $500 \Omega$ e $200 \Omega$ nos modos comum 
e diferencial, respectivamente. Em uma extremidade da linha foi conectado um transformador, representado por uma indutância de $10 \mu \mathrm{H}$. Na outra extremidade da linha, uma impedância (indutância de $2 \mu \mathrm{H}$ a $20 \mu \mathrm{H}$ no sistema TN e uma capacitância de $20 \mathrm{nF}$ a $200 \mathrm{nF}$ em série com uma indutância de $2 \mu \mathrm{H}$ a $20 \mu \mathrm{H}$ no sistema IT) representou a instalação de baixa tensão.

A descarga é localizada a $100 \mathrm{~m}$ do ponto médio da linha e possui forma de onda, na base do canal, conforme a função de Heidler [38], com $\operatorname{Im}=30 \mathrm{kA}, \tau 1=2 \mu \mathrm{s}$, $\tau 2=50 \mu$ s e $m=5$. Foi usado o Modelo de Linha de Transmissão (TL) [39] para descrever a propagação da corrente no canal, sendo assumida a velocidade de propagação de $1,1.10^{8} \mathrm{~m} / \mathrm{s}$. As figuras 2.7 -a e $2.7-\mathrm{b}$ apresentam os resultados dos cálculos das tensões induzidas na entrada de um consumidor para vários valores de carga, considerando os sistemas de alimentação TN e IT, respectivamente.
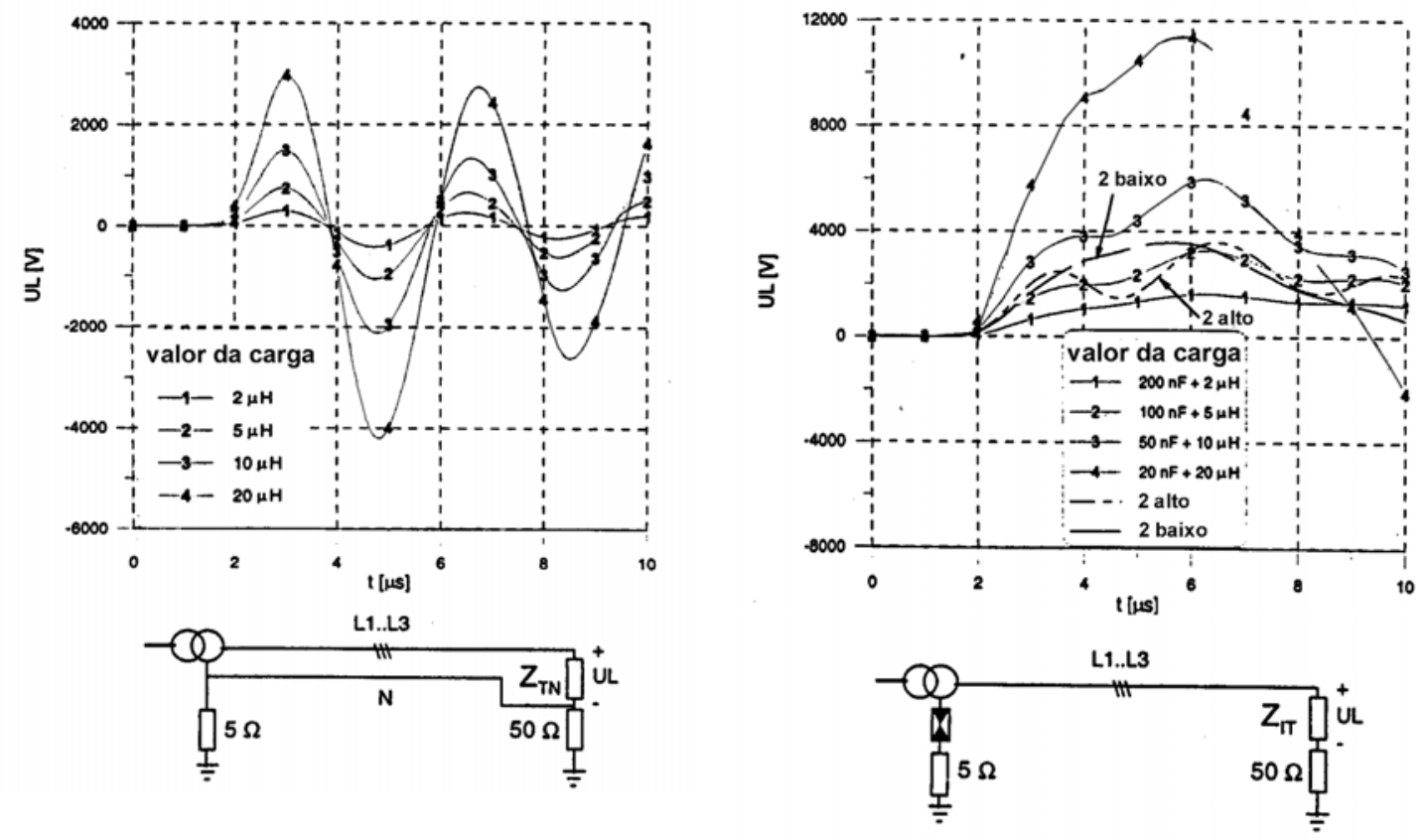

Fig. 2.7: Tensões induzidas na entrada do consumidor considerando quatro diferentes terminações (adaptada de [8]).
a) sistema $\mathrm{TN}$
b) sistema IT

A Figura 2.7 mostra que a amplitude da tensão induzida nos sistemas TN e IT é fortemente dependente da carga do consumidor. Em geral, cargas maiores (menor 
impedância) resultam em amplitudes menores de sobretensão. Foi verificado também que as sobretensões no sistema de alimentação com terra isolado (IT) são maiores que as relativas ao sistema TN. A menor amplitude da tensão induzida no sistema TN pode ser explicada pela presença do condutor neutro na rede de distribuição, pela baixa impedância das cargas dos consumidores e pelo aterramento do neutro do transformador.

Outro trabalho apresentado por Hoidalen et al [13] apresenta os distúrbios causados por descargas atmosféricas nas redes de baixa tensão. O trabalho consiste principalmente no cálculo e análise de tensões induzidas na rede de baixa tensão a partir de dados obtidos através do sistema de localização de descargas "Lightning Location System - LLS" da Noruega. Esse sistema de localização de descargas atmosféricas possui 12 sensores e utiliza também dados dos sistemas de localização de descargas da Dinamarca e da Suécia totalizando, então, 25 sensores. Uma linha aérea de distribuição em baixa tensão é utilizada como base para o cálculo das tensões induzidas, sendo sua configuração representada na Figura 2.8.

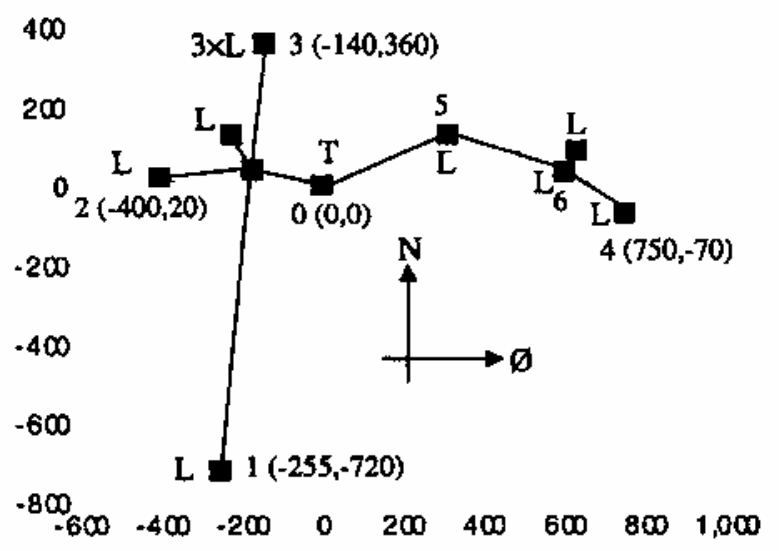

Fig. 2.8: Configuração da rede de baixa tensão [13].

L: instalação dos consumidores. T: Transformador. Unidade: metros.

A rede é trifásica do tipo IT, está localizada em uma área rural e possui 9 linhas, sendo a altura dos condutores igual a $6 \mathrm{~m}$. A impedância característica de modo comum dos condutores fase é assumida, por simplificação, como igual a $300 \Omega$. Foram realizados também cálculos de tensões induzidas para a rede de BT com 
configuração do tipo $\mathrm{TN}$, de forma a analisar o desempenho face a descargas atmosféricas dos dois tipos de alimentação. A impedância característica do condutor neutro para rede do tipo TN foi assumida como sendo igual a $500 \Omega$ e a impedância mútua entre o condutor fase e o neutro, igual a $200 \Omega$. O transformador de distribuição é trifásico e foi modelado por um capacitor de $10 \mathrm{nF}$ em série com uma indutância de $10 \mu \mathrm{H}$ para o sistema de alimentação IT ou com uma indutância de $10 \mu \mathrm{H}$ no caso do sistema TN. Esses valores são típicos para freqüências na faixa de $10 \mathrm{kHz}$ a $500 \mathrm{kHz}$, de acordo com medições realizadas em [8]. A resistência de terra foi assumida como igual a $50 \Omega \mathrm{em}$ ambos os casos.

As instalações consumidoras foram modeladas por um capacitor de $100 \mathrm{nF}$ para o sistema IT e por uma indutância de $10 \mu \mathrm{H}$ para o sistema TN. Esses valores também foram adotados em função das medições realizadas em [8]. A resistência de terra foi assumida como igual a $100 \Omega$ em ambos os casos. A tensão induzida foi calculada entre o condutor fase e o terminal de terra, ou seja, sobre a impedância da instalação de baixa tensão. Os cálculos das tensões induzidas foram realizados de acordo com o modelo de Agrawal [37], a partir do ponto de incidência das descargas atmosféricas e das amplitudes das correntes, parâmetros esses fornecidos pelo sistema LLS. Os tempos de frente e de meio valor são assumidos, para todas as simulações, como iguais a $2 \mu \mathrm{s}$ e $50 \mu \mathrm{s}$, respectivamente. O método de cálculo também assume que o canal da descarga é retilíneo e vertical, a corrente no canal se propaga com velocidade $v$ constante (modelo Linha de Transmissão - TL), apenas o campo do "return stroke" é considerado, o solo é homogêneo com condutividade e permeabilidade constantes, e as terminações da linha (carga) são assumidas simétricas, sendo estudadas apenas as tensões de modo comum.

A Figura 2.9 apresenta um mapa de localização de descargas ocorridas nas proximidades da linha em estudo. 


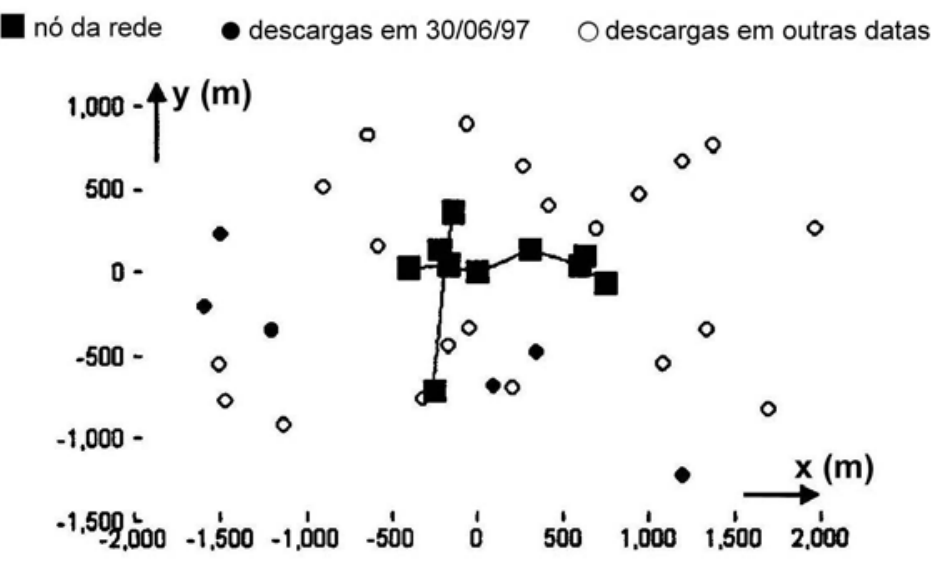

Fig. 2.9: Rede de distribuição aérea de baixa tensão e localização das descargas atmosféricas (adaptada de [13]).

Com base na estimativa do local de incidência da descarga e do respectivo valor de crista da corrente, foi apresentada a distribuição estatística para a máxima amplitude de tensão induzida na rede de baixa tensão para as seguintes terminações possíveis da linha: aberta, terminação casada e terminação com carga (modelada conforme apresentado anteriormente). As figuras 2.10 e 2.11 apresentam a distribuição estatística da máxima tensão induzida na rede de baixa tensão com configurações IT e TN, respectivamente. Para cada tipo de configuração de rede (IT ou TN) são indicadas probabilidades das tensões induzidas ultrapassarem os valores indicados na abscissa, considerando o solo tanto como condutor perfeito como também com condutividade de $1 \mathrm{mS} / \mathrm{m}$.

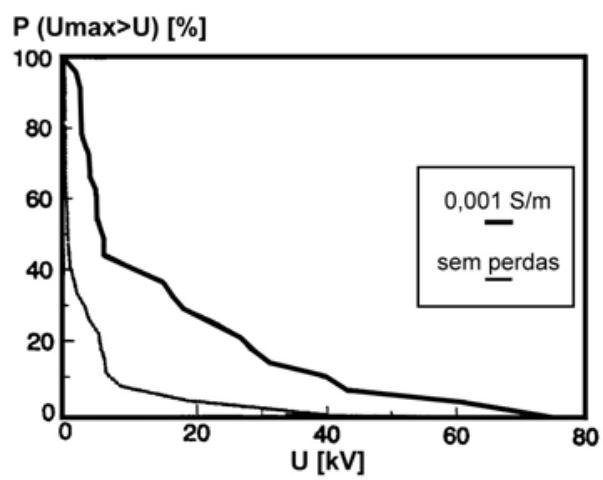

Fig. 2.10: Distribuição da máxima tensão induzida na rede de baixa tensão (sistema IT). Carga do consumidor: indutância de $10 \mu \mathrm{H}$ em série com capacitância de $100 \mathrm{nF}$ (adaptada de [13]). 


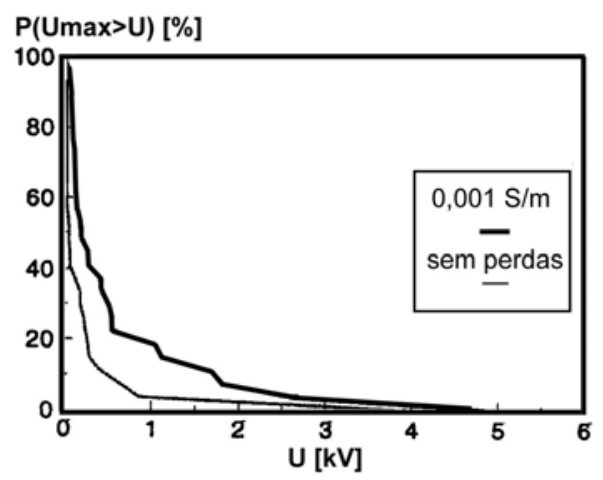

Fig. 2.11: Distribuição da máxima tensão induzida na rede de baixa tensão (sistema TN). Carga do consumidor: indutância de $10 \mu \mathrm{H}$ (adaptada de [13]).

Com os resultados apresentados nas figuras 2.10 e 2.11, concluiu-se que a amplitude da tensão induzida por descargas atmosféricas na rede de baixa tensão é dependente do esquema de alimentação (IT, TN) e que o sistema IT é o mais afetado pelas descargas indiretas. Entretanto, o autor diz que é preciso realizar mais estudos, especialmente a respeito dos vários sub-sistemas em uso atualmente, como TN-C, TN-S, TNC-S etc..

Conti et al [40] também estudaram as sobretensões na rede de baixa tensão provocadas por descargas atmosféricas diretas em linha secundária ou unidades consumidoras. No trabalho são apresentados também os surtos transferidos da rede primária para a secundária via transformador - utilizando o modelo desenvolvido pelo GATDA [22] - e as sobretensões induzidas na rede secundária provocadas por descargas atmosféricas incidentes nas proximidades da linha. O objetivo do trabalho foi analisar os parâmetros da rede de distribuição que influenciam essas sobretensões, permitindo assim a escolha de configurações de rede e de equipamentos de proteção de forma a minimizar os danos causados por descargas atmosféricas. A análise das tensões induzidas foi feita por meio de simulações computacionais para uma rede secundária de $150 \mathrm{~m}$ de comprimento e ocorrência de uma descarga atmosférica a $50 \mathrm{~m}$ do ponto central da linha, onde é calculada a tensão induzida. A forma de onda da corrente da descarga atmosférica (primeiro "stroke") utilizada nas simulações foi assumida como triangular $(1,2 / 50 \mu \mathrm{s})$, variando-se o valor de pico da corrente. Não foi apresentada no trabalho a velocidade de propagação da corrente da descarga considerada nas simulações. 
Com base nas simulações realizadas no trabalho, verificou-se que os parâmetros da descarga que mais influenciam as tensões induzidas são o valor de pico da corrente e seu tempo de subida. Os principais parâmetros da linha que influenciam as tensões induzidas são a altura dos condutores, a configuração da linha e a presença de pontos de conexão com a terra. Já o efeito de "blindagem" devido à presença do condutor neutro é de aproximadamente $20 \%$ para redes abertas (convencionais), enquanto as redes multiplexadas apresentam melhor desempenho quanto às tensões induzidas. A principal conclusão apresentada é que os resultados obtidos pelas simulações não devem ser generalizados em virtude da grande diversidade de topologias de redes existentes.

Silveira et al [41] fizeram um estudo das tensões induzidas em linhas de distribuição por descargas atmosféricas de modo a verificar como os principais parâmetros das descargas atmosféricas e da linha influenciam o comportamento das tensões induzidas. Para as redes de BT, foi realizada uma análise preliminar das sobretensões induzidas na linha no ponto de entrada de alimentação dos consumidores. Para essa avaliação, foram realizados cálculos de tensões induzidas utilizando o modelo descrito em [42], considerando uma descarga atmosférica incidente a $50 \mathrm{~m}$ do ponto central de uma linha típica. Segundo os autores, observou-se que a redução da impedância da carga tem o efeito de diminuir a tensão induzida fase-neutro sobre a mesma, embora a amplitude da sobretensão na entrada de serviço do consumidor seja alta nos dois casos analisados no artigo.

Um estudo interessante a respeito das tensões induzidas em redes de BT com cabos multiplexados foi iniciado por Gruber et al [43], que consiste em comparar as tensões induzidas medidas em duas linhas experimentais com diferentes condições de aterramento do condutor neutro. Desse modo os autores pretendem determinar o desempenho das redes de BT para cada configuração de rede e de aterramento adotada. As redes estudadas são trifásicas com os condutores fase de alumínio, com seção de $35 \mathrm{~mm}^{2}$ e isoladas por uma camada de polietileno de $1,5 \mathrm{~mm}$ de espessura. Os condutores fase são torcidos sobre condutor neutro, que tem como função 
adicional a sustentação dos mesmos. O condutor neutro pode ter duas configurações: isolado como os condutores fase ou nu. Os condutores são instalados a uma altura típica de $10 \mathrm{~m}$ acima do solo e a cada dois postes é instalada uma caixa de derivação para os consumidores. Primeiramente o condutor neutro é aterrado a cada caixa de distribuição, sendo posteriormente aterrado apenas no poste onde é instalado o transformador e nos dois postes adjacentes. As duas redes foram instaladas conforme apresentado na Figura 2.12.

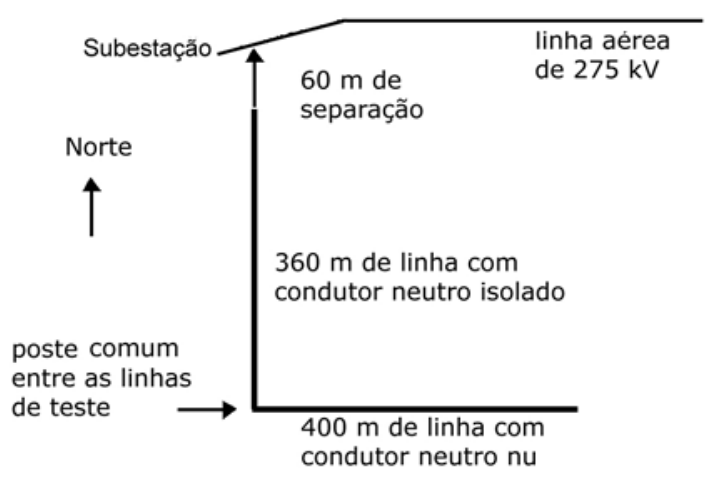

Fig 2.12: Configuração das linhas experimentais (adaptada de [43])

A configuração "em L" da rede, segundo os autores, permite uma comparação das tensões induzidas atribuídas aos diferentes componentes do campo elétrico horizontal. Serão utilizados como dados de entrada para o cálculo das tensões induzidas os valores informados pelo sistema de localização de descargas atmosféricas "Lightning Positioning and Tracking System" (LPATS).

Com a intenção de um melhor entendimento do mecanismo das tensões induzidas, Galván et al $[44,45]$ realizaram um interessante trabalho de pesquisa com o objetivo de estimar a resposta de uma instalação de baixa tensão a pulsos de campos eletromagnéticos originados por descargas elétricas preliminares ao "return stroke". Os experimentos desenvolvidos consistiram na obtenção de formas de onda do campo elétrico no domínio do tempo e das correspondentes tensões induzidas em pequenas redes elétricas experimentais. Em [45], as duas redes elétricas eram isoladas do sistema de alimentação, sendo uma instalada em campo aberto e outra no interior de uma residência de madeira, conforme apresentado na Figura 2.13. 


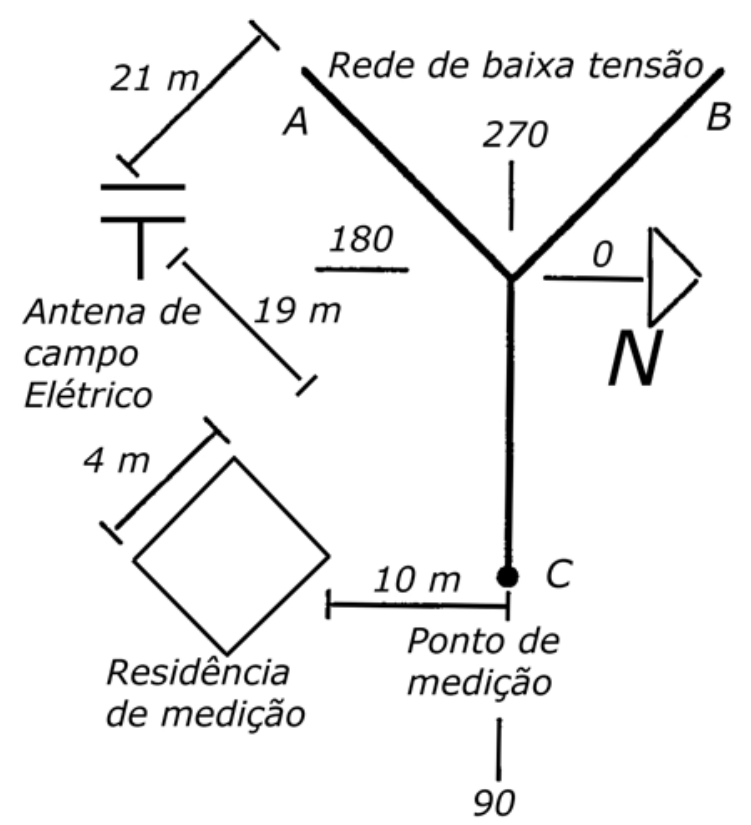

Fig. 2.13: Configuração da linha experimental (adaptada de [45]).

A metodologia proposta pelos autores para o cálculo da tensão induzida em uma instalação de baixa tensão consiste na modelagem da rede a partir da medição do campo elétrico vertical e da correspondente tensão induzida da rede de baixa tensão. Pela identificação de pequenos pulsos com comportamento semelhante a um degrau (tempo de subida da ordem de $50 \mathrm{~ns}$ ) no campo elétrico medido, é possível, então, encontrar a resposta ao degrau da rede em estudo, uma vez que a tensão induzida por esses pulsos também é medida. Aplicando o teorema da convolução ou a integral de Duhamel, encontra-se a resposta da rede (tensão induzida) para qualquer campo elétrico a ela aplicado. Os resultados apresentados no artigo tiveram concordância variável em relação às formas de onda ou aos picos de tensão induzida medida e calculada, dependendo da qualidade (identificação de pulsos e campo elétrico com comportamento próximo ao degrau) dos sinais utilizados para modelagem da rede em Y. A Figura 2.14 apresenta resultados de medições do campo elétrico, como também das tensões induzidas medida e calculada. 


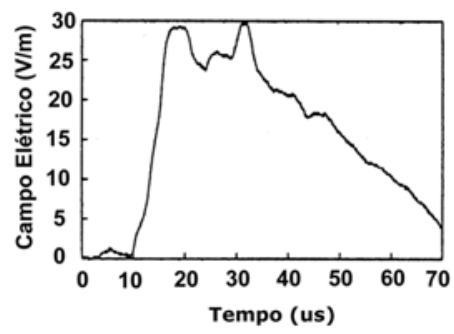

(a)

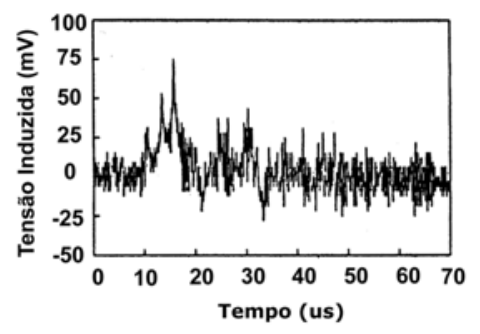

(b)

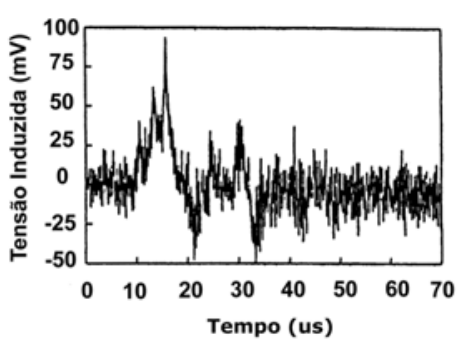

(c)

Fig. 2.14: Formas de onda obtidas (adaptada de [45]).

a) campo elétrico vertical devido ao "return stroke"

b) tensão induzida na rede em configuração $Y$

c) tensão induzida calculada

Em [46], Galván e Cooray também estudaram as tensões induzidas em instalações elétricas de BT causadas por campos eletromagnéticos provocados por descargas atmosféricas. O objetivo do trabalho foi obter dados experimentais que permitissem avaliar as tensões induzidas em redes de baixa tensão e o método utilizado para o cálculo dessas tensões desenvolvido pelos pesquisadores de acordo com a teoria de Agrawal el al [37]. A partir da medição do campo elétrico vertical foram realizadas simulações computacionais considerando diferentes dimensões para a rede apresentada na Figura 2.15. Para cada configuração de rede ou carga foram realizadas simulações de tensões induzidas considerando 4 diferentes valores da condutividade do solo: infinita; $0,01 \mathrm{~S} / \mathrm{m} ; 0,001 \mathrm{~S} / \mathrm{m}$ e $0,0001 \mathrm{~S} / \mathrm{m}$.

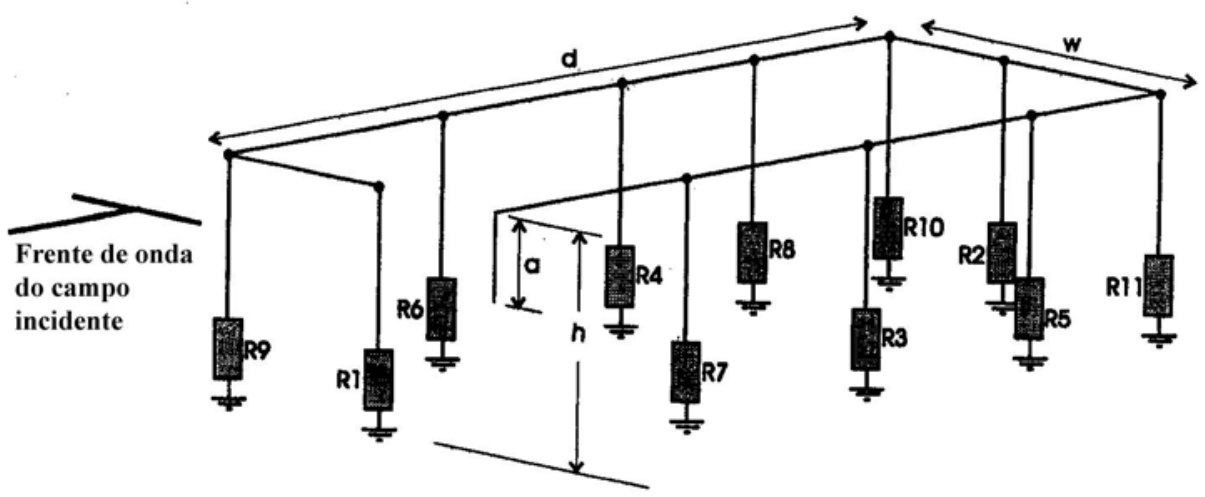

Fig. 2.15: Configuração de rede utilizada nas simulações (adaptada de [46]).

Com o objetivo de validar os resultados obtidos nos cálculos das tensões induzidas, foi construída uma rede de condutores no interior de uma residência de madeira. A 
rede era constituída de um condutor horizontal localizado a 2,3 m do solo e de três condutores verticais ligados a ele, conforme esquematizado na Figura 2.16.

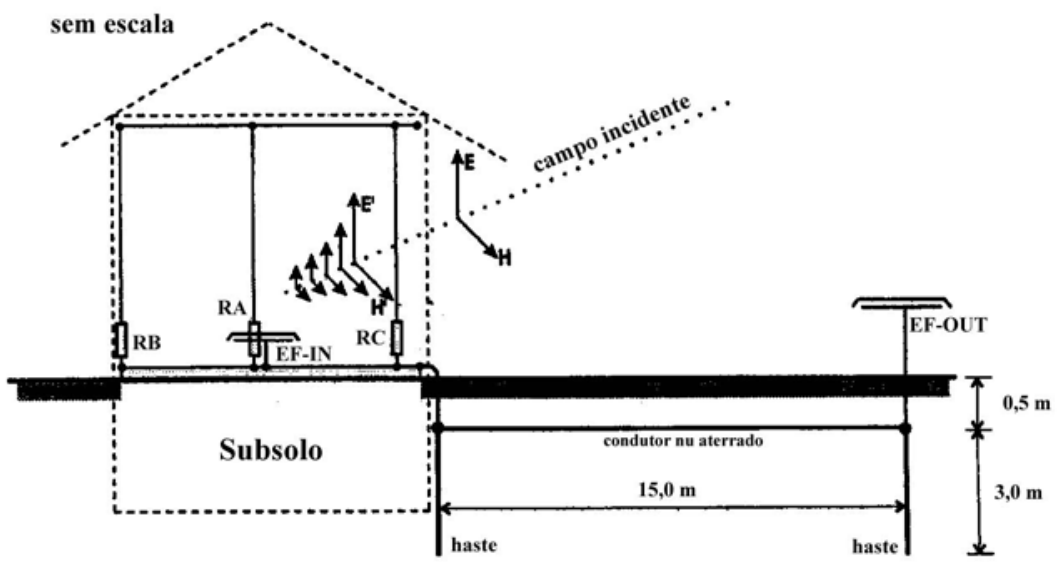

Fig. 2.16: Visão geométrica da instalação elétrica. EF-IN e EF-OUT são antenas de medição de campo elétrico vertical interna e externamente à edificação, respectivamente (adaptada de [46]).

A tensão induzida era medida sobre o resistor RC indicado na Figura 2.16, que estava conectado a um dos fios verticais da rede. O campo elétrico vertical era medido simultaneamente no interior e no exterior da residência por meio de antenas de placas paralelas. A condutividade do solo medida no local do experimento foi de $0,025 \mathrm{~S} / \mathrm{m}$. Foram realizados vários registros de tensões induzidas por descargas atmosféricas, mas somente um caso foi apresentado. Para o caso discutido no artigo, a medição ocorreu com RC igual a $50 \Omega$ e RA e RB desconectados do circuito (circuito aberto). A Figura 2.17 apresenta os campos elétricos verticais medidos no exterior e no interior da residência. A tensão induzida calculada tendo como dado de entrada o campo elétrico vertical medido no exterior da edificação é apresentada na Figura 2.18. O cálculo da tensão induzida leva também em consideração o campo elétrico horizontal, que é calculado de acordo com a formulação de "wave-tilt" [35]. 


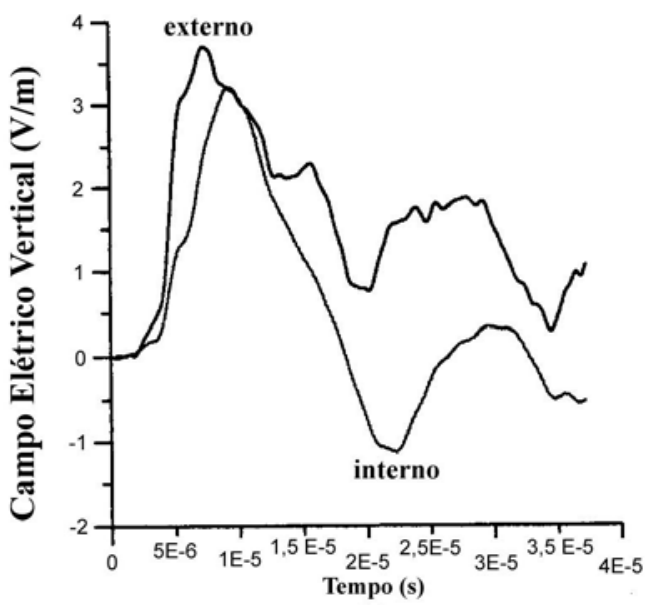

(a)

Fig. 2.17: Forma de onda do campo elétrico vertical medido interna e externamente à residência (adaptada de [46]).

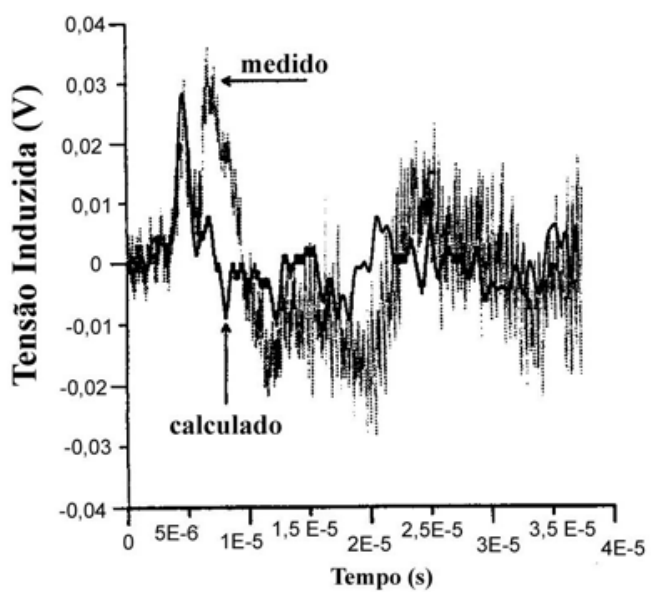

(b)

Fig. 2.18: Tensão induzida medida e calculada com base no campo elétrico vertical externo indicado na Fig. 2.17 (adaptada de [46]).

Pode ser observado na Figura 2.18 que apenas o primeiro pico da tensão induzida foi bem reproduzido. Em função disso, foi repetido o cálculo da tensão induzida utilizando-se o campo elétrico vertical medido no interior da residência como dado de entrada. O resultado desse novo cálculo é apresentado na Figura 2.19-a, que resulta em melhor concordância que a do caso anterior. As diferenças entre os valores medidos e calculados podem ser explicadas pelo fato de a amplitude do campo elétrico medido no centro da instalação não ser necessariamente igual à amplitude do campo elétrico no local de instalação do condutor. Segundo os autores, a forma de onda da tensão induzida é similar à derivada do campo elétrico vertical no 
tempo quando a impedância no ponto de medição é baixa (inferior a $50 \Omega$ ) e as outras cargas estão desconectadas do circuito. Essa afirmação foi corroborada pela comparação da forma de onda da derivada do campo elétrico vertical em relação ao tempo com a forma de onda da tensão induzida, apresentada na Figura 2.19-b.

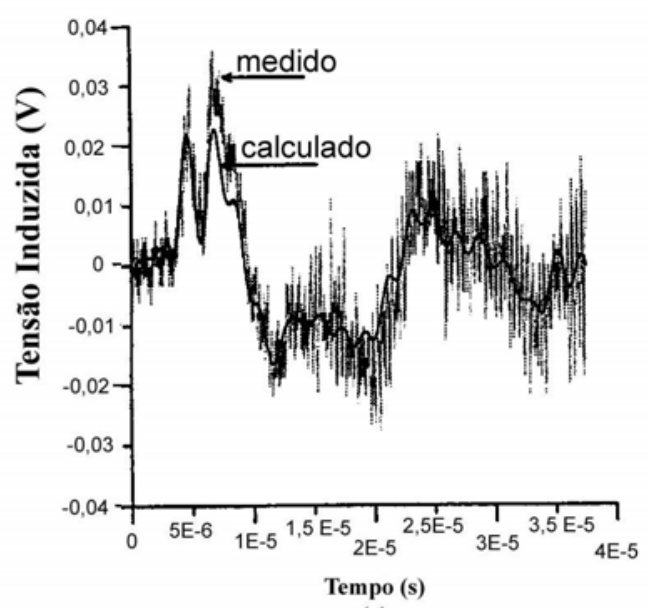

(a)

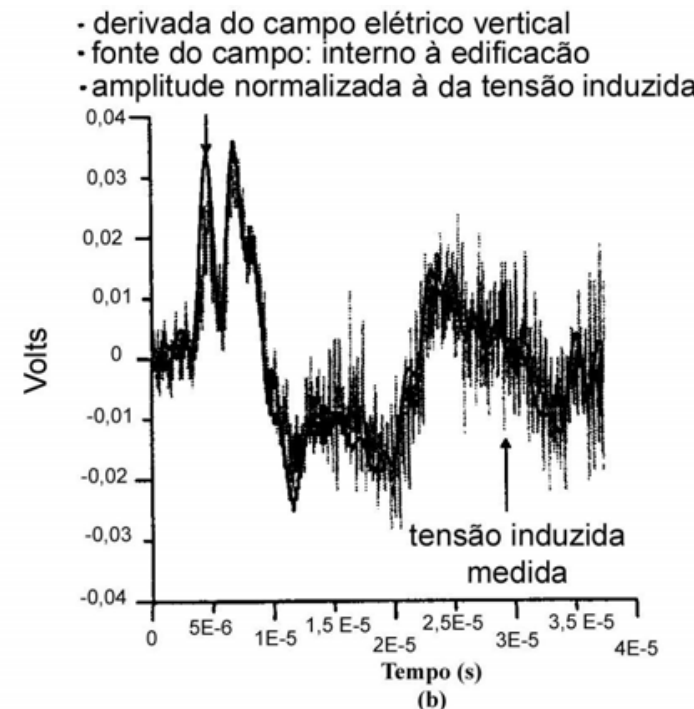

(b)

Fig. 2.19: Tensões induzidas e campo elétrico vertical (adaptada de [46]).

a) comparação entre a tensão induzida medida e a calculada usando o campo elétrico vertical interno à estrutura

b) comparação da forma de onda da tensão induzida medida com a derivada do campo elétrico vertical no tempo

As principais conclusões do trabalho, obtidas a partir de várias simulações computacionais, são que as tensões induzidas nas instalações de baixa tensão são fortemente dependentes da carga conectada à rede, o aumento do número de condutores verticais instalados na rede reduz a amplitude da tensão induzida no ponto de interesse e que o uso do campo elétrico vertical medido no interior da estrutura para a avaliação da tensão induzida representa melhor resultado devido à atenuação e distorção que a estrutura impõe ao campo elétrico incidente na rede de BT.

Outro trabalho na área de tensões induzidas por descargas atmosféricas em instalações de baixa tensão foi realizado por Silfverskiöld et al [47], que estudaram as tensões induzidas durante o ciclo completo de descargas nuvem - solo (de ambas 
as polaridades) e de descargas intranuvem. O objetivo do trabalho era investigar as tensões induzidas em uma instalação de baixa tensão em decorrência do acoplamento direto de campos eletromagnéticos originados por descargas atmosféricas, na ausência das sobretensões vindas da rede de distribuição. Para isso foi utilizada uma instalação experimental em que foram realizadas medições de tensões induzidas por descargas atmosféricas. Essa instalação foi montada dentro de uma residência de $100 \mathrm{~m}^{2}$ e tinha seis ramos principais com $10 \mathrm{~m}$ a $30 \mathrm{~m}$ de comprimento e 15 subramos com pelo menos $5 \mathrm{~m}$ de comprimento distribuídos em seis cômodos. A instalação possuía 3 condutores fase, 1 condutor neutro e 1 condutor de proteção, ou seja, tinha a configuração TNS (condutor neutro separado do condutor de proteção). Junto com a tensão induzida era realizada, também, a medição do campo elétrico no exterior da residência, de modo a relacionar as diferentes fases das descargas atmosféricas com as tensões induzidas na instalação. Na Figura 2.20 são apresentadas, a título de exemplo, medições do campo elétrico vertical e da correspondente tensão induzida provocada por uma descarga atmosférica a $24 \mathrm{~km}$ de distância da instalação experimental.

Foi analisada, para cada estágio da descarga atmosférica (descargas preliminares, "return stroke", "strokes" subseqüentes etc.), a relação entre o campo elétrico medido e a tensão induzida. Verificou-se que os pulsos bipolares de campo elétrico resultantes das descargas preliminares ou descargas intranuvem produzem tensões induzidas com amplitudes semelhantes às produzidas pelo "return stroke". Esses pulsos bipolares de campo elétrico são em maior número que os "return strokes" e seus efeitos podem causar interferências nos equipamentos ligados à instalação de baixa tensão, como por exemplo, equipamentos de automação residencial que utilizem a rede como canal de comunicação. Embora o valor da amplitude da tensão induzida medida tenha sido baixo (aproximadamente $100 \mathrm{~V}$ pico a pico), os autores estimam que valores acima de $400 \mathrm{~V}$ possam ser observados caso descargas atmosféricas ocorram a poucos quilômetros de distância da instalação. 


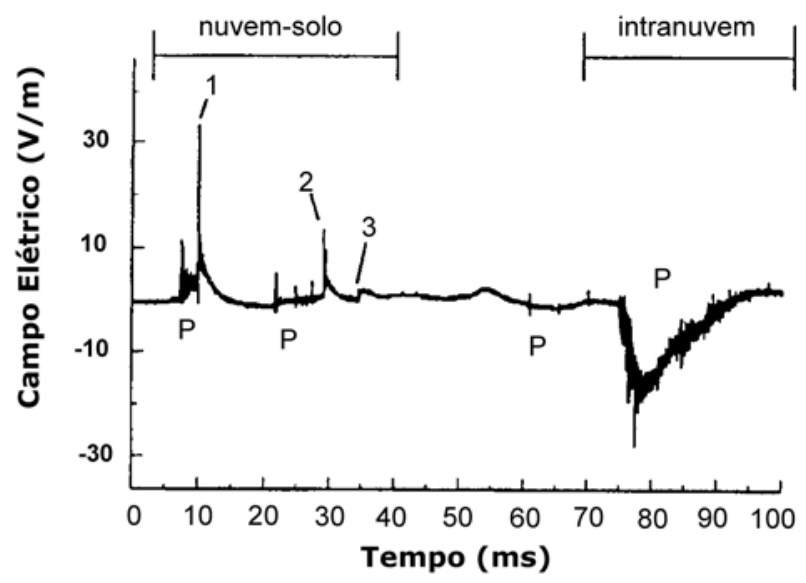

(a)

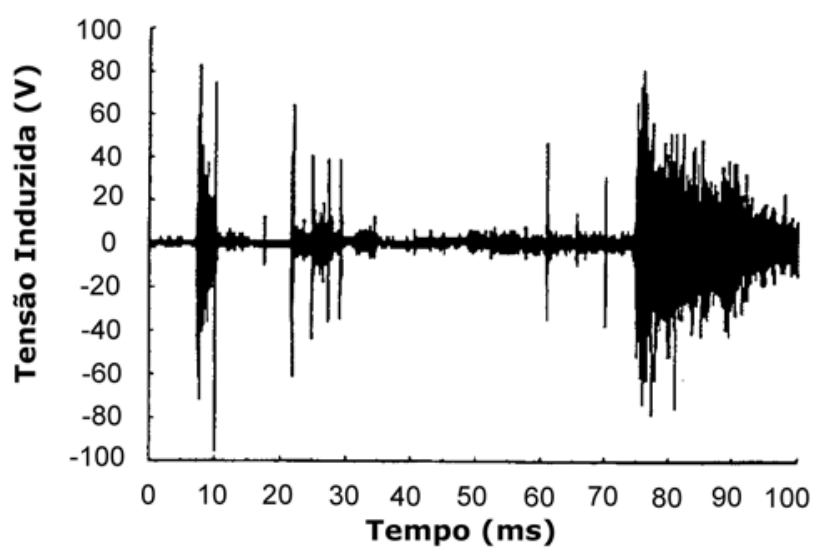

(b)

Fig 2.20: Descarga negativa nuvem-solo seguida de descarga intranuvem (adaptada de [47]).

a) campo elétrico vertical. Os "return strokes" são numerados como 1, 2 e 3. A letra "P" indica grupos de pulso na escala de microsegundos.

b) tensão induzida no modo comum na instalação elétrica residencial de baixa tensão. Medição simultânea ao campo elétrico vertical indicado na Fig. 2.20-a.

Em [48] foi realizado um estudo de avaliação das sobretensões induzidas nas redes de distribuição secundárias devido a descargas atmosféricas indiretas. Foram realizadas diversas simulações computacionais de forma a determinar a influência de uma série de parâmetros nas tensões induzidas. Foi considerada a incidência de uma descarga atmosférica a $50 \mathrm{~m}$ do centro de um vão de $150 \mathrm{~m}$ de comprimento de uma linha de baixa tensão monofásica. A forma de onda da corrente injetada na base do canal (com $900 \mathrm{~m}$ de comprimento) foi triangular $(1 \mu \mathrm{s} / 50 \mu \mathrm{s})$, com amplitude de $1 \mathrm{kA}$, sendo o modelo utilizado para o cálculo das tensões induzidas descrito em [42]. Nas simulações, a velocidade de propagação da corrente do "return stroke" foi 
admitida como igual a $75 \%$ ou a $100 \%$ da velocidade da luz no vácuo, valores estes excessivamente elevados. Através das simulações, concluiu-se que a presença do condutor neutro na rede de distribuição influencia no sentido de provocar redução da tensão induzida no condutor fase. Em relação à resistência de terra, concluiu-se no artigo que este parâmetro não é relevante para a redução das amplitudes das tensões induzidas mas sim a presença das conexões do condutor neutro à terra.

Neste Capítulo foram apresentados os trabalhos mais relevantes a respeito das tensões induzidas em linhas de baixa tensão, tanto devido a descargas ao solo quanto a descargas intranuvem. Conforme apresentado, há poucas publicações com o enfoque no tema específico deste trabalho, que trata do comportamento das tensões induzidas em redes de baixa tensão quando da ocorrência de descargas atmosféricas nas suas proximidades. Essa situação mostra a importância da realização de mais estudos nessa área com o objetivo de se melhor entender o fenômeno das tensões induzidas em redes secundárias, e foi um dos fatores que motivaram o desenvolvimento deste trabalho. 


\section{CAPÍTULO 3}

\section{SURTOS TRANSFERIDOS VIA TRANSFORMADOR DEVIDO A DESCARGAS ATMOSFÉRICAS PRÓXIMAS À REDE}

As sobretensões na rede primária causadas por descargas atmosféricas diretas ou indiretas são transferidas ao secundário através dos transformadores de distribuição. Este capítulo apresenta um estudo das características dos surtos transferidos ao secundário do transformador devido a tensões induzidas na rede primária. As tensões transferidas são calculadas por meio de simulações computacionais utilizando o modelo de transformador desenvolvido pelo GATDA/USP, sendo as formas de onda de tensões induzidas em redes primárias obtidas por meio de experimentos em escalas real e reduzida. O objetivo desse capítulo é dar uma visão geral das características dessas tensões transferidas e compará-las com as tensões induzidas nas redes secundárias, assunto esse discutido no Capítulo 4. Um estudo detalhado dos surtos transferidos às redes de baixa tensão via transformador, para o caso de descargas diretas na rede primária, é apresentado em [23].

\subsection{Tensões induzidas em redes primárias}

O mecanismo de indução nas redes de distribuição primária é o mesmo das redes de baixa tensão. Entretanto, devido às suas diferentes características das redes, as tensões induzidas apresentam comportamentos distintos nos dois casos. Embora as tensões induzidas nas linhas de classe $15 \mathrm{kV}$ sejam estudadas já há algum tempo, ainda existem divergências sobre $o$ fenômeno, o que tem motivado o desenvolvimento de estudos teóricos e experimentais $[4,49,50,51]$.

Em [49] foi desenvolvido um modelo em escala reduzida para o estudo do desempenho de linhas aéreas de distribuição face a descargas atmosféricas, incluindo a análise dos diferentes métodos de proteção. Experimentos em escala reduzida apresentam a vantagem de permitir a obtenção de um grande número de registro de 
tensões induzidas e correntes de descarga em um ambiente controlado, sendo conhecidos os principais parâmetros de influência nas tensões.

O fator de escala para comprimentos do modelo desenvolvido em [49] foi igual a 1:50, o que permitia a simulação de linhas de distribuição reais com até $1,4 \mathrm{~km}$ de comprimento. A escolha desse fator de escala é feita em função dos sistemas de geração e medição disponíveis, além da possibilidade de se simular adequadamente as situações desejadas.

A linha de distribuição foi simulada por intermédio de condutores de cobre com 0,4 mm de diâmetro e $28 \mathrm{~m}$ de comprimento, sustentados por estruturas de PVC espaçadas de $60 \mathrm{~cm}$ e com forma tal que permitia a representação de linhas de diferentes configurações. Essas dimensões correspondem a uma linha real de 1,4 km de comprimento, com condutores de 2,0 cm de diâmetro e postes espaçados de $30 \mathrm{~m}$. A linha era casada em ambas as extremidades, de maneira a se evitar reflexões. $O$ plano de terra do modelo possuía uma área total de $28 \times 9 \mathrm{~m}^{2}$ e foi construído com placas de alumínio de $0,5 \mathrm{~mm}$ de espessura, simulando um solo com condutividade perfeita.

A representação do "return stroke" (m.r.s.) foi feita utilizando-se o modelo da linha de transmissão [39]. O modelo foi construído dispondo-se helicoidalmente um condutor em um tubo, de forma que, ao variar o espaçamento entre as espiras, pôdese ajustar os parâmetros L (indutância) e C (capacitância) do canal a fim de se obter o valor desejado para a velocidade de propagação da corrente. A simulação do canal foi feita então através de um fio de cobre de $0,7 \mathrm{~mm}$ de diâmetro enrolado em uma haste de PVC (323 espiras por metro) de diâmetro igual a 25,4 mm e com $12 \mathrm{~m}$ de altura, o que correspondia a um canal real com comprimento de $600 \mathrm{~m}$.

Esse experimento possibilitou a variação de muitos parâmetros, como por exemplo, a forma de onda e a localização da descarga simulada, a configuração da linha de distribuição, o ponto onde era observada a tensão induzida, etc.. As aplicações de correntes realizadas permitiram a comparação direta entre tensões induzidas medidas 
em duas linhas de distribuição, uma de referência (sem proteção) e outra de teste, dotada de dispositivos de proteção [26]. Em [34] são apresentadas comparações entre formas de onda de tensões induzidas no modelo reduzido [49] e calculadas pelo modelo descrito em [33]. As figuras 3.1 a 3.8 apresentam algumas configurações de redes de distribuição primária simuladas no modelo reduzido e as respectivas formas de onda de tensões induzidas medidas. As escalas de comprimento, tempo e tensão das figuras estão referenciadas ao sistema em escala real.

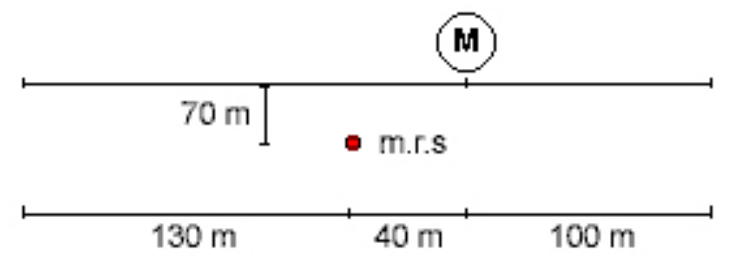

Fig. 3.1: Configuração da rede do modelo reduzido - Caso 1 (adaptada de [34]).

M: ponto de medição da tensão.

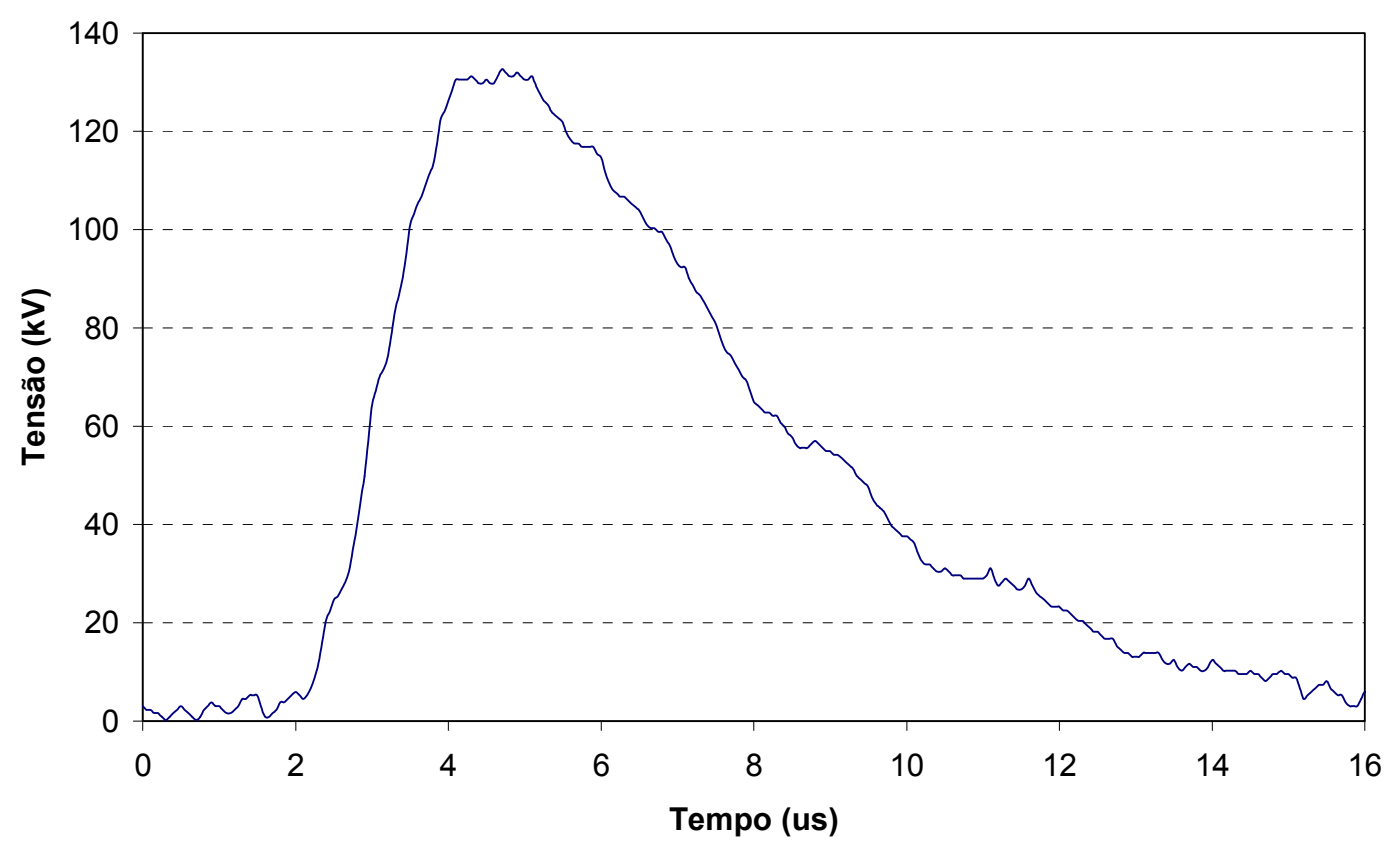

Fig. 3.2: Tensão induzida medida no ponto M indicado na Fig. 3.1 (modelo reduzido - Caso 1). (adaptada de [34]). Corrente com amplitude de $34 \mathrm{kA}$ 


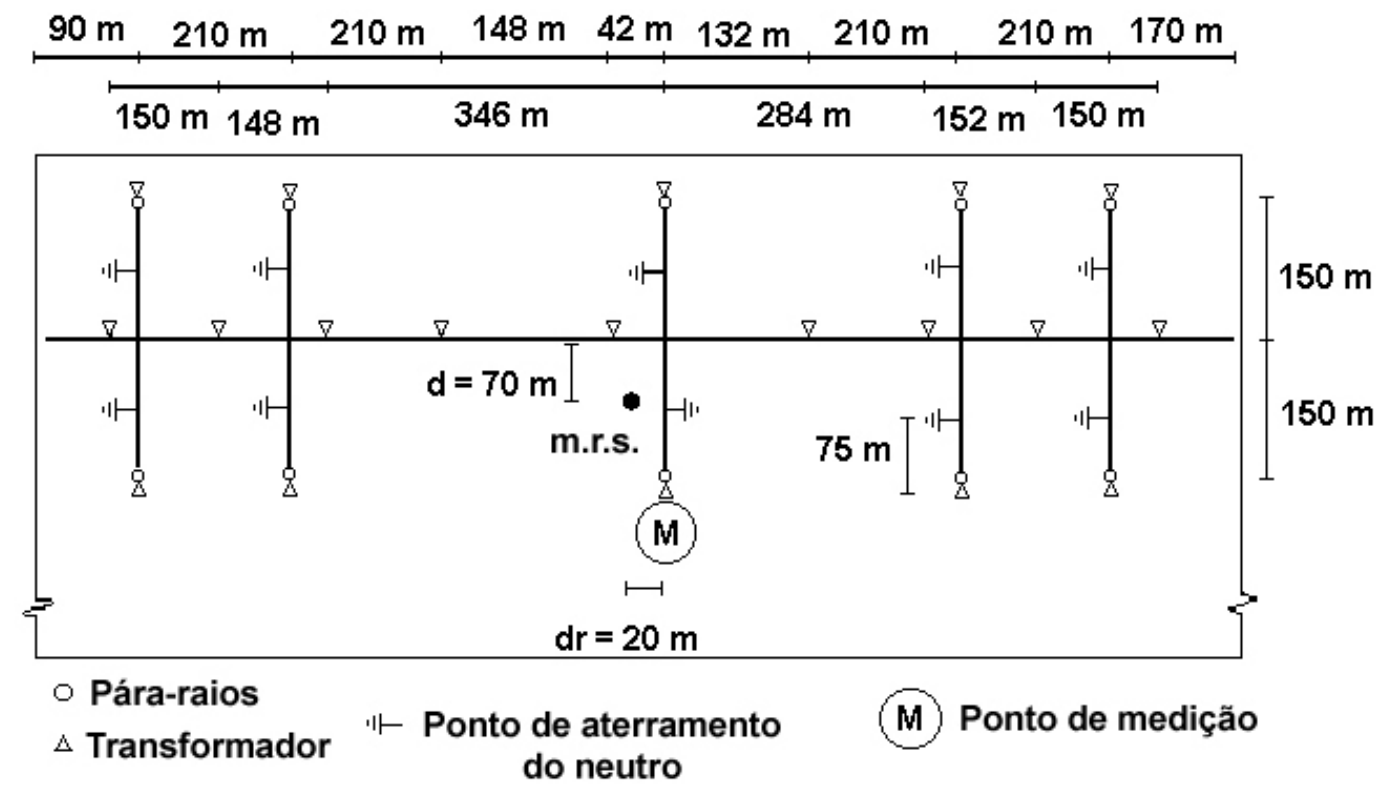

Fig. 3.3: Configuração da rede do modelo reduzido - Caso 2 (adaptada de [34]).

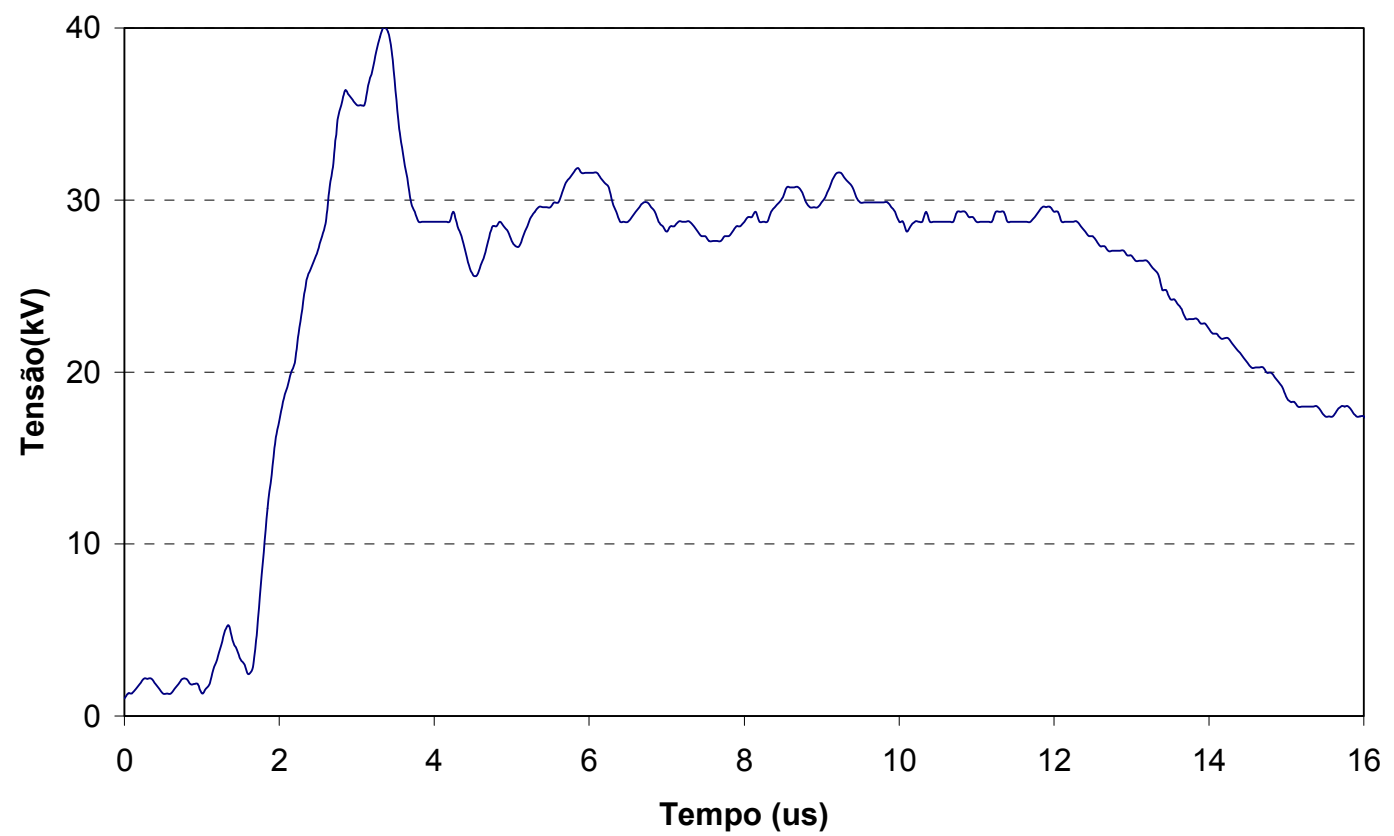

Fig. 3.4: Tensão induzida medida no ponto M indicado na Fig. 3.3 (modelo reduzido - Caso 2). (adaptada de [34]).Corrente com amplitude de $34 \mathrm{kA}$. 


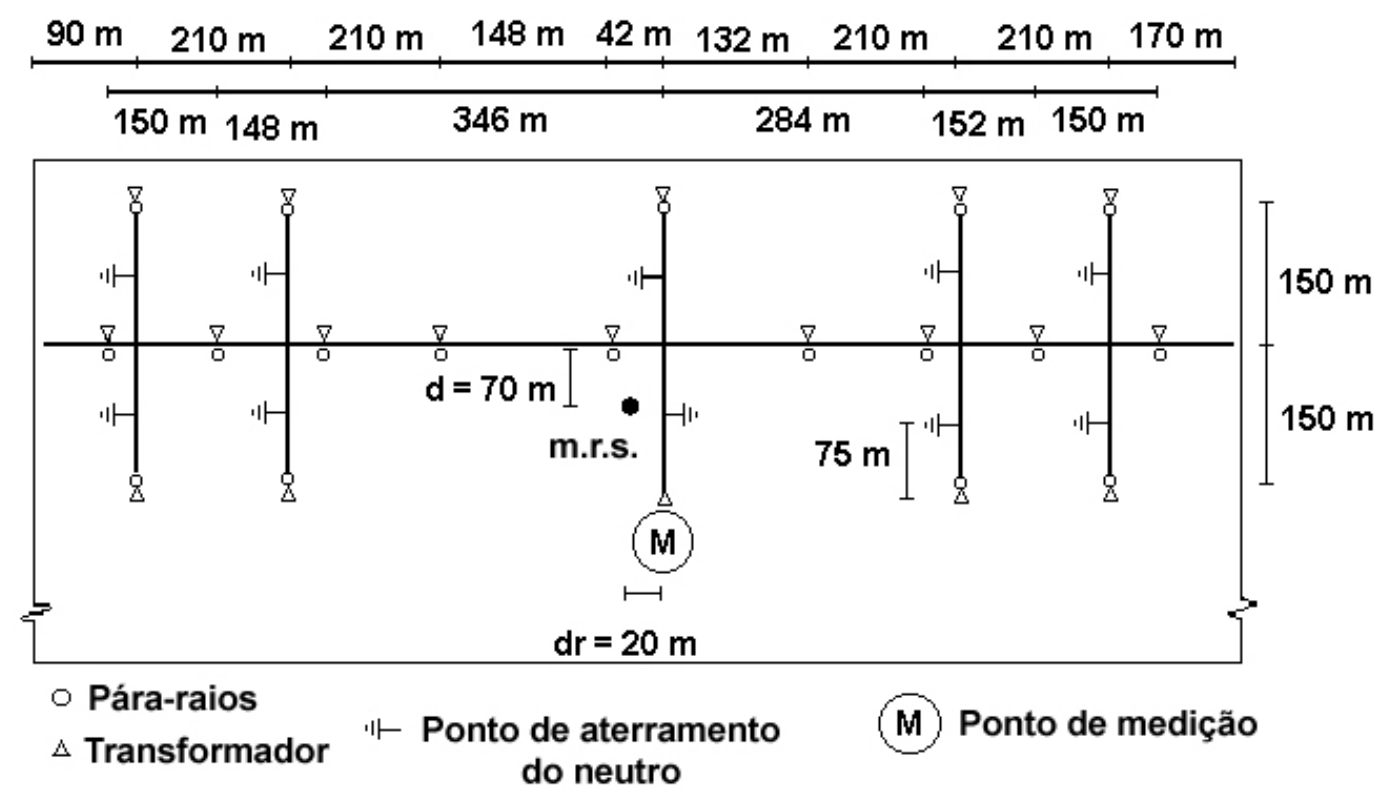

Fig. 3.5: Configuração da rede do modelo reduzido - Caso 3 (adaptada de [34]).

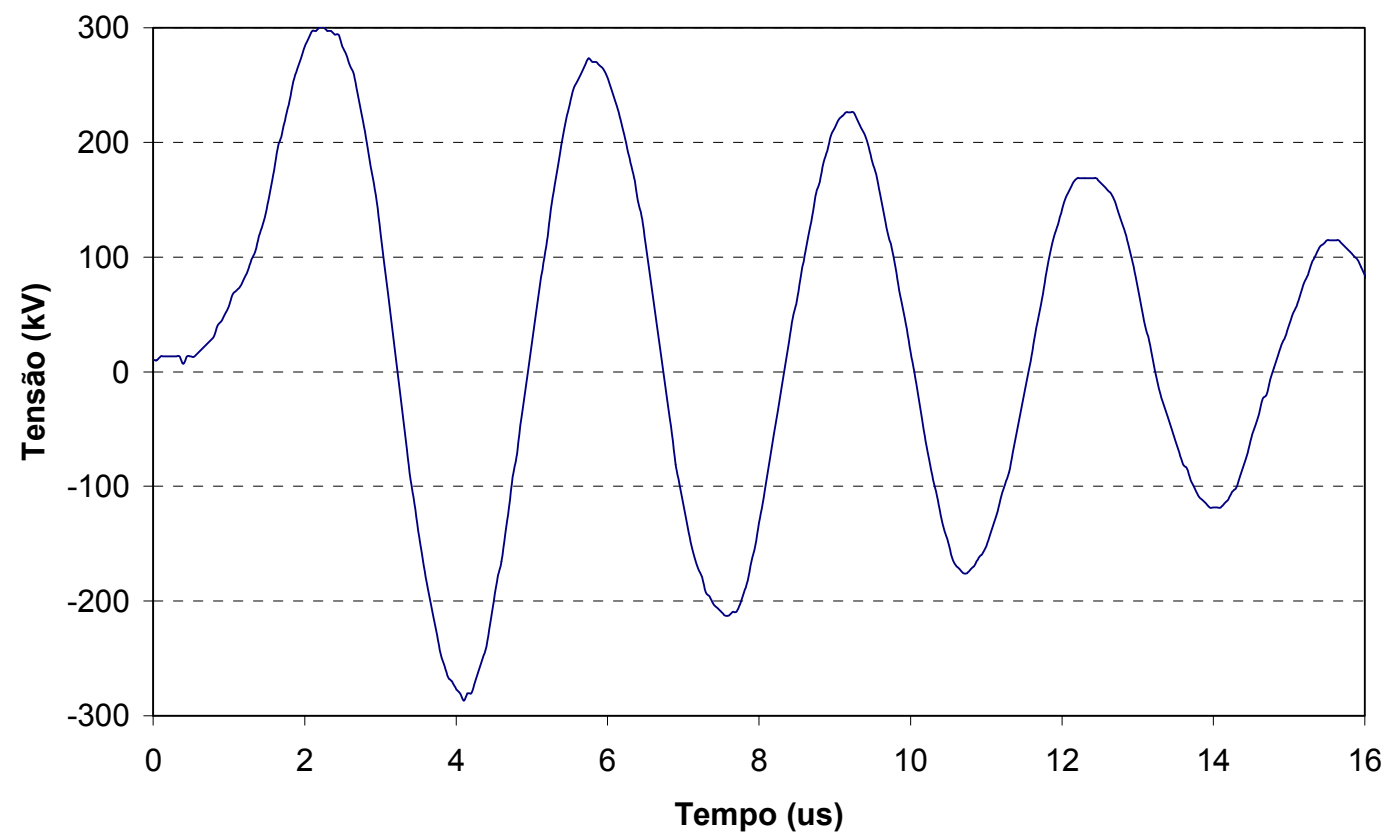

Fig. 3.6: Tensão induzida medida no ponto $M$ indicado na Fig. 3.5 (modelo reduzido - Caso 3). (adaptada de [34]). Amplitude da corrente: $34 \mathrm{kA}$. 


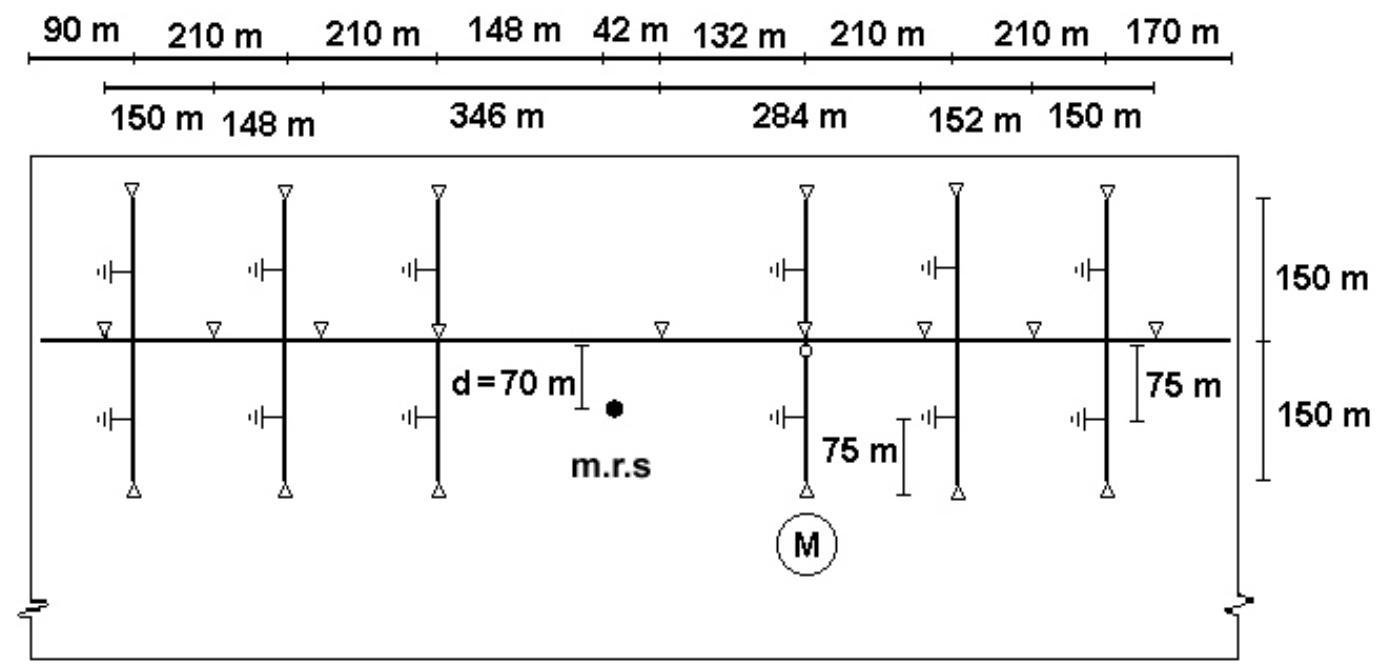

$\begin{array}{lll}\text { - Pára-raios } & \Perp \text { Ponto de aterramento } \\ \text { do neutro } & \text { (M) Ponto de medição }\end{array}$

Fig. 3.7: Configuração da rede do modelo reduzido - Caso 4 (adaptada de [34]).

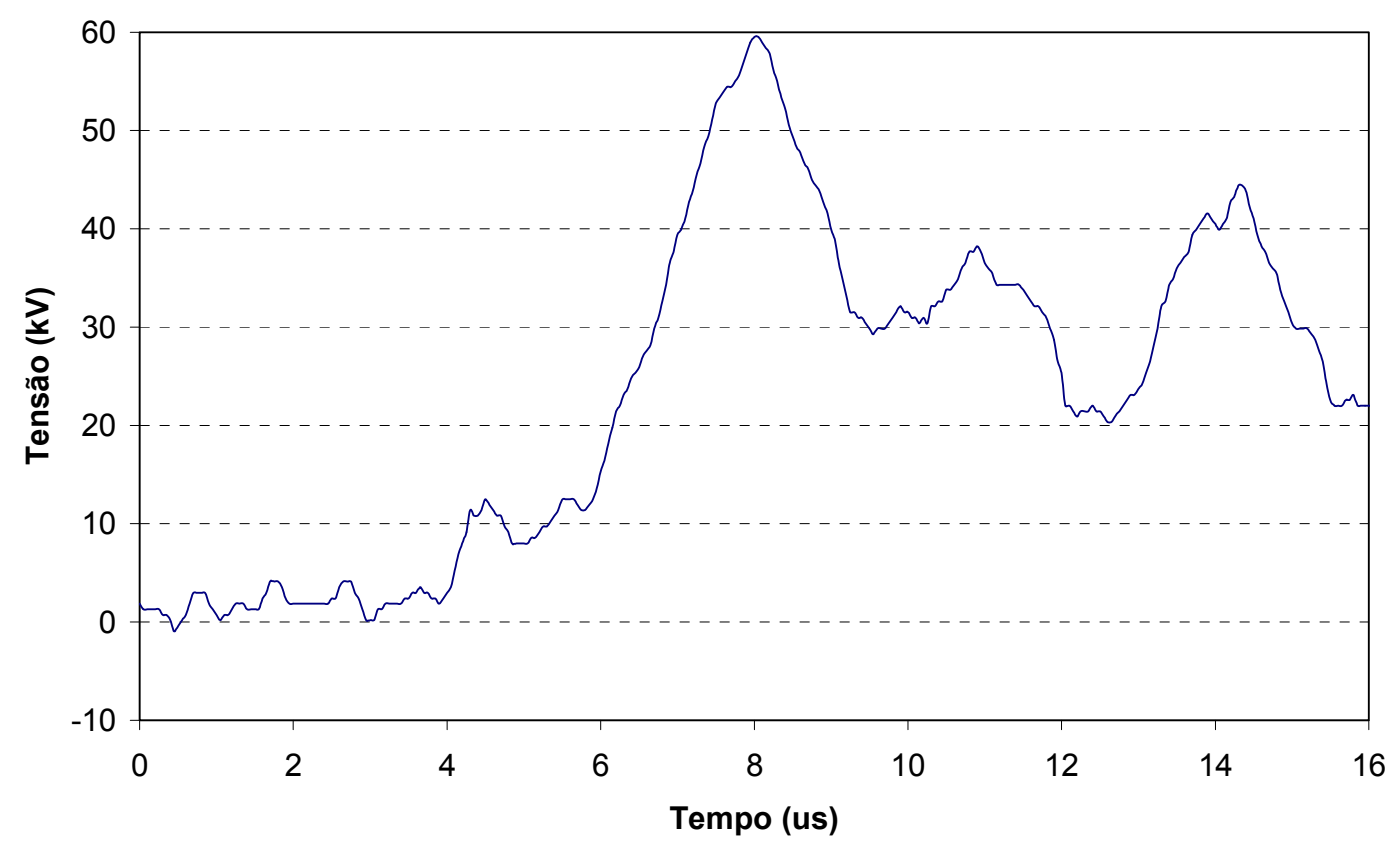

Fig. 3.8 Tensão induzida medida no ponto M indicado na Fig. 3.7 (modelo reduzido - Caso 4). (adaptada de [34]). Amplitude da corrente: $50 \mathrm{kA}$. 
A Figura 3.2 apresenta uma forma de onda típica de tensão induzida para uma linha de configuração simples (Caso 1, Figura 3.1), com 270 m de comprimento, sem páraraios ou transformadores, na ocorrência de uma descarga atmosférica com amplitude de 34 kA a 70 m de distância da linha. Uma rede com configuração mais complexa, com transformadores instalados no tronco principal e nos ramais, é apresentada na Figura 3.3. Nessa configuração, foram instalados pára-raios nos transformadores localizados nos ramais da rede, inclusive no transformador onde foi realizada a medição. A tensão induzida medida nessa rede, indicada na Figura 3.4, foi limitada pela presença de pára-raios próximos ao ponto de medição. Uma outra configuração da rede, agora com pára-raios instalados também no tronco principal, é indicada na Figura 3.5, sendo a tensão induzida medida mostrada na Figura 3.6. Nota-se que para essa configuração a tensão induzida medida no ponto $M$ apresenta característica oscilatória. Por fim, a Figura 3.7 apresenta uma rede primária com apenas um pára-raios instalado ao longo do alimentador principal. A tensão induzida para esse caso é mostrada na Figura 3.8.

Embora o uso de modelos em escala reduzida possibilite a obtenção de um grande número de dados, a comprovação final de qualquer modelo matemático complexo deve ser feita com base em resultados de campo. Isso motivou o desenvolvimento de uma pesquisa experimental $[4,50,51]$, em que foi construído um sistema em escala real para a obtenção de registros de tensões induzidas e de correntes de descargas. Um dos objetivos da pesquisa é a comprovação da validade do modelo matemático para cálculo de tensões induzidas em linhas aéreas denominado "Extended Rusck Model" (ERM) desenvolvido em [25-27]. O estudo tem também por finalidade a avaliação da eficácia do pára-raios como dispositivo de proteção contra descargas atmosféricas. Destaca-se aqui o pioneirismo do trabalho, pois com exceção da pesquisa desenvolvida em [26], através de modelo em escala reduzida, em nenhum outro estudo experimental o efeito da utilização de pára-raios na redução das tensões induzidas foi determinado diretamente. Assim, além de possibilitar uma avaliação direta da eficácia do sistema de proteção utilizado, os resultados obtidos permitirão a realização de comparações entre as tensões induzidas medidas na linha e as tensões calculadas através do modelo matemático desenvolvido em [25]. Tais resultados 
representarão uma importante contribuição para o estado da arte do fenômeno, tendo em vista a escassez de dados de campo envolvendo registros simultâneos de tensões induzidas e correntes de descargas.

A metodologia empregada em $[4,50,51]$ também poderá ser aplicada na obtenção de subsídios para definição de critérios de instalação de pára-raios em transformadores de redes urbanas. Além disso, a pesquisa permitirá que seja analisado o desempenho de linhas de distribuição de média tensão, com proteção e sem proteção, face a descargas atmosféricas. Com base nesses resultados, serão definidos critérios para a utilização das técnicas mais eficazes que podem ser adotadas tendo em vista a melhoria do desempenho das linhas.

O sistema de obtenção de dados relativos a tensões induzidas e correntes de descargas foi implantado no campus da Universidade de São Paulo, em São Paulo. A Figura 3.9 mostra a localização dos principais componentes do sistema.

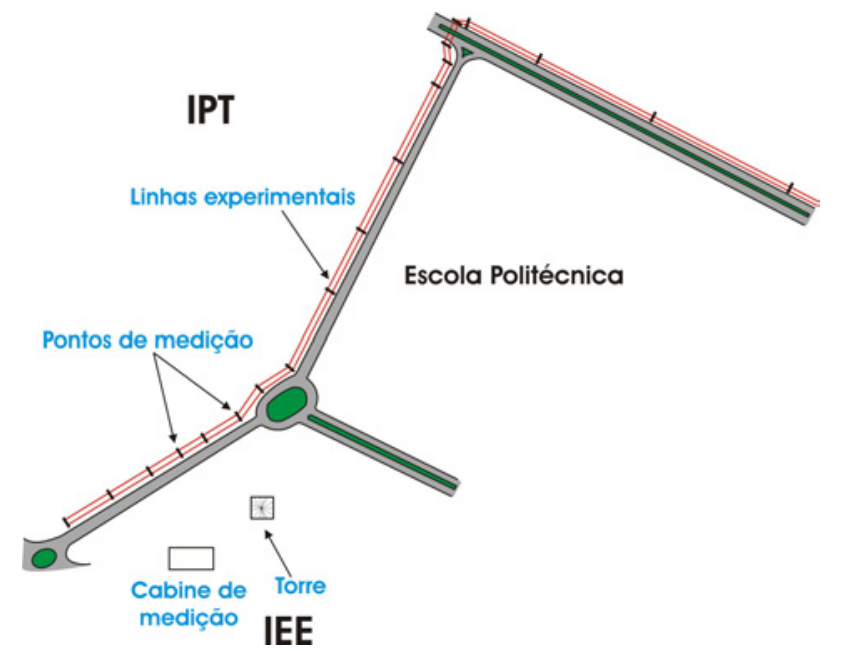

Fig. 3.9: Planta geral de localização dos sistemas de medição e aquisição. IPT: Instituto de Pesquisas Tecnológicas; IEE: Instituto de Eletrotécnica e Energia [44].

O trabalho prevê a obtenção de registros simultâneos das correntes de descargas atmosféricas incidentes em uma torre (com 62,5 $\mathrm{m}$ de altura) e das correspondentes tensões induzidas em duas linhas de distribuição monofásicas situadas nas proximidades da mesma. Mesmo que não ocorra uma descarga direta na torre, são 
registradas as tensões induzidas por descargas próximas às linhas. Na base da torre foram instalados um resistor "shunt" e um osciloscópio, que compõem o sistema de medição de corrente. A utilização de cruzetas de tamanho superior ao convencional permitiu a instalação de duas linhas, em uma das quais foram instalados pára-raios em pontos estratégicos; a outra está desprovida de qualquer tipo de proteção. Nos postes foram instalados divisores de tensão e osciloscópios, que compõem o sistema de medição da tensão. Nas proximidades da torre, foi construída uma cabine blindada onde ficam os equipamentos responsáveis pelo gerenciamento e controle da aquisição e do armazenamento dos dados e pelo acionamento do sistema.

O sistema foi implantado em março de 2002 e já foram obtidos vários registros de tensões induzidas tanto na linha de referência (sem pára-raios) quanto na linha de teste (com pára-raios). As figuras 3.10 e 3.11 apresentam 4 formas de onda de tensões induzidas registradas pelo sistema, na linha sem pára-raios, em diferentes ocasiões. 


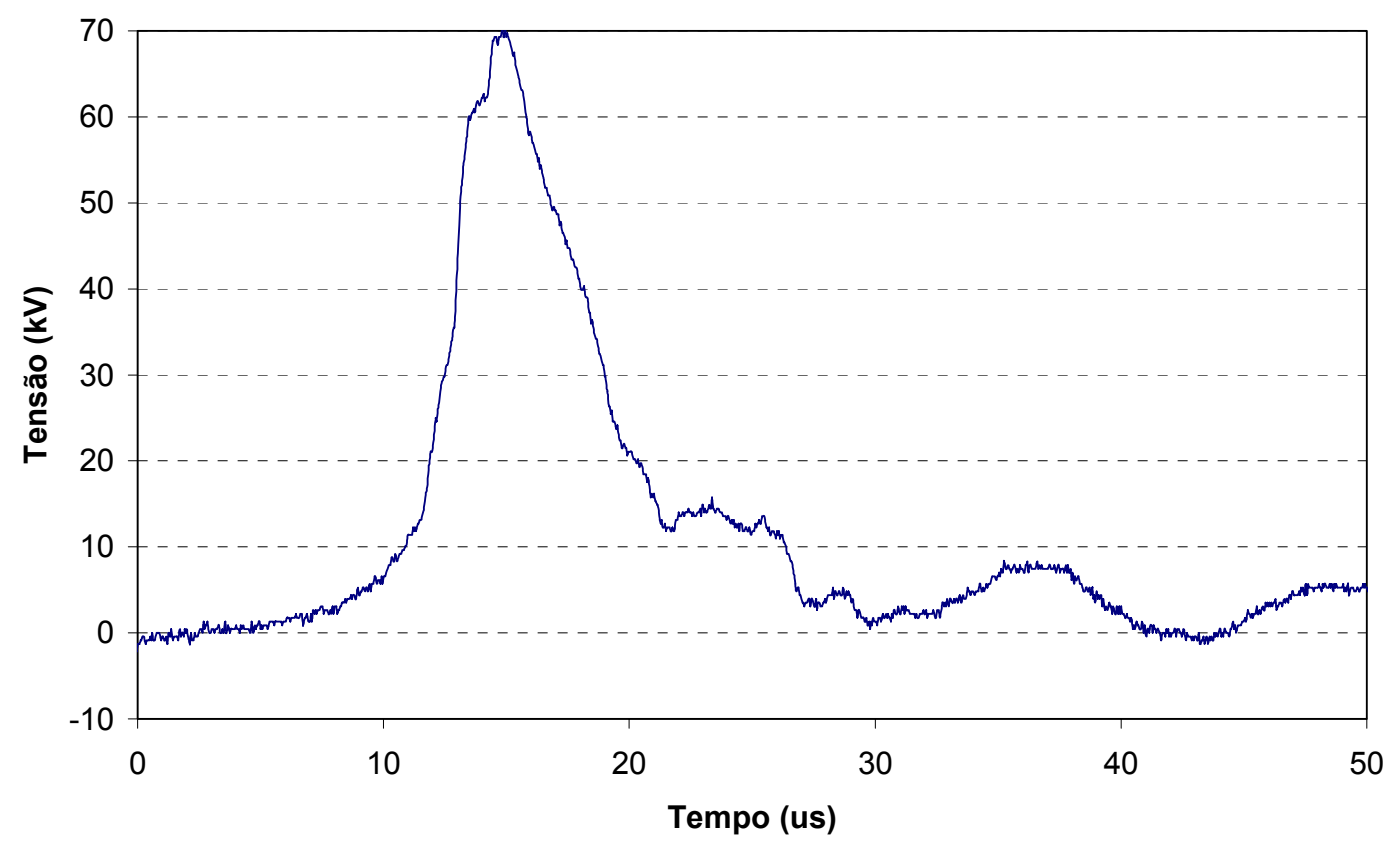

(a)

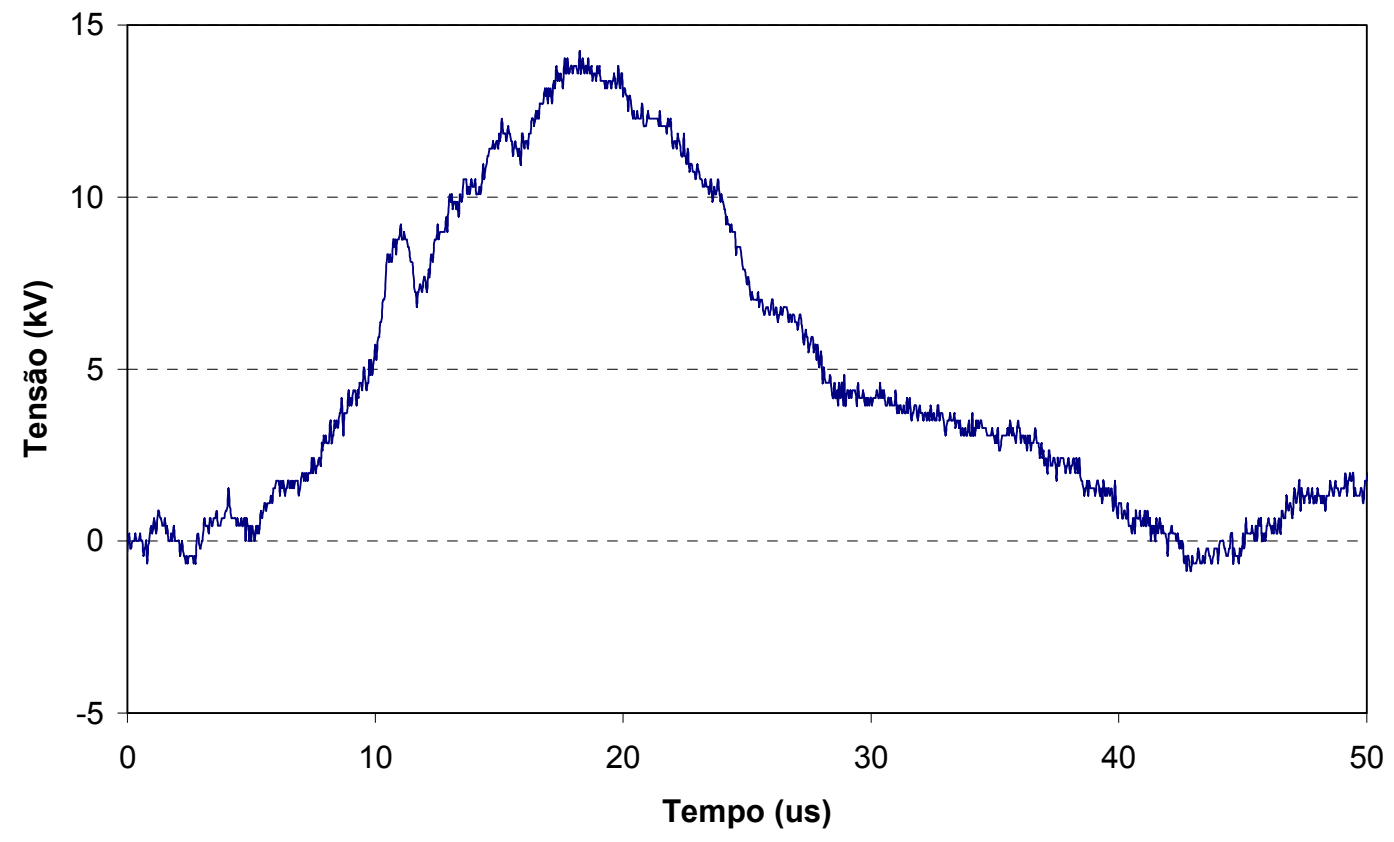

(b)

Fig. 3.10: Tensões induzidas na linha sem pára-raios em diferentes ocasiões (escala real-casos 5 e 6) [50].
a) Caso 5
b) Caso 6 


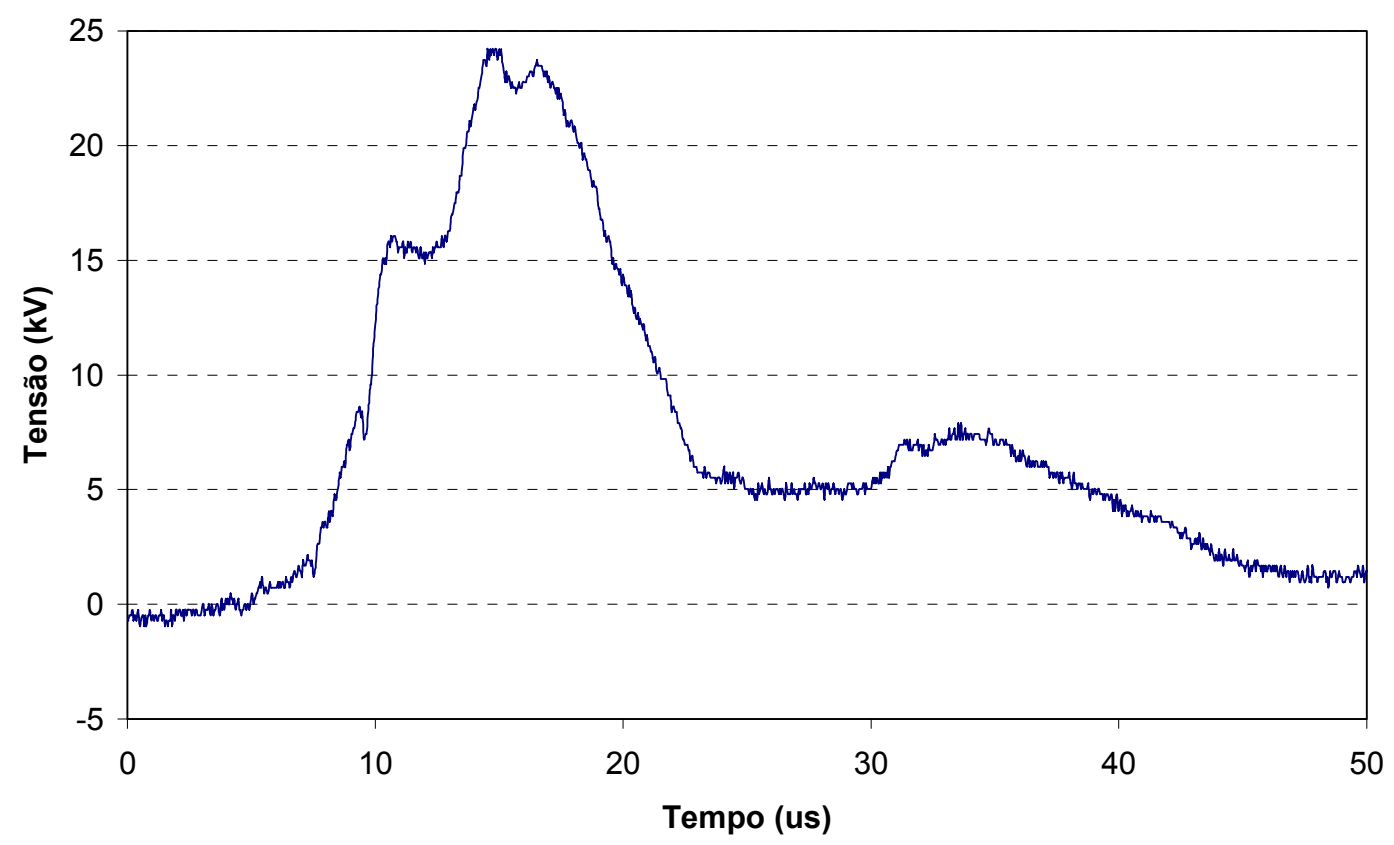

(a)

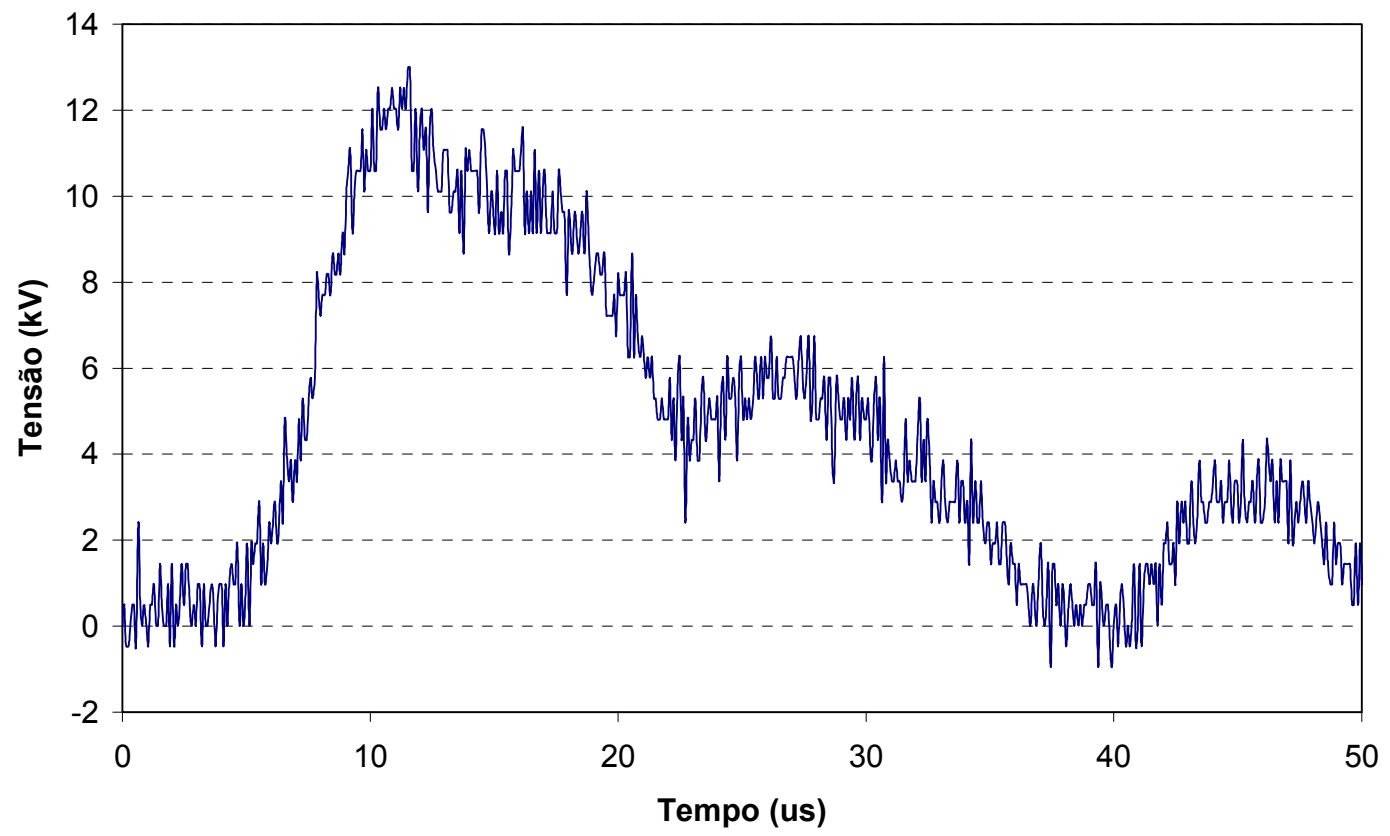

(b)

Fig. 3.11: Tensões induzidas na linha sem pára-raios sem diferentes ocasiões (escala real - casos 7 e 8) [50].
a) Caso 7
b) Caso 8 


\subsection{Tensões transferidas ao secundário via transformador}

Para realizar a análise das tensões transferidas da rede primária para a secundária via transformador, é necessário também um modelo confiável do transformador em questão. Em [52] foram calculadas as tensões transferidas ao secundário de um transformador a vazio utilizando o modelo descrito no trabalho e um programa para cálculo de resposta [53] que utiliza a função de transferência do transformador medida em laboratório. Pode-se dizer que a tensão transferida calculada desse modo é equivalente a uma medição, uma vez que a função de transferência do transformador foi obtida em laboratório e contempla toda a faixa de freqüências dos impulsos "aplicados" ao primário. As tensões induzidas na rede primária usadas para calcular as tensões transferidas foram obtidas através do modelo ERM ("Extended Rusck Model") [25, 27, 28], descrito no Capítulo 4. Os resultados das comparações entre as tensões "medidas" e as calculadas pelo modelo do transformador proposto apresentaram ótima concordância.

Neste trabalho, são calculadas as tensões transferidas para o secundário de um transformador típico de distribuição, trifásico, $13,8 \mathrm{kV}-220 / 127 \mathrm{~V}, 30 \mathrm{kVA}$, conexão delta-estrela, utilizando as tensões induzidas medidas apresentadas no item anterior e o modelo de transformador desenvolvido em [20, 21, 29-32]. O modelo de transformador desenvolvido pelo GATDA/USP é simples, confiável e possibilita a análise das tensões transferidas ao secundário do transformador para diferentes condições de carga.

A metodologia desenvolvida em [20, 21, 29-32] contemplou a obtenção de modelos de transformadores trifásicos de potências de $30 \mathrm{kVA}, 45 \mathrm{kVA}, 75 \mathrm{kVA}, 112,5 \mathrm{kVA}$ e $225 \mathrm{kVA}$, todos $13,8 / 0,220 \mathrm{kV}$ e com ligação delta-estrela. Na Figura 3.12, é mostrado o modelo de transformador de $30 \mathrm{kVA}$ desenvolvido, sendo o nó " 1 " o primário e o nó “2” o secundário do transformador. O modelo é monofásico equivalente e, portanto, pode ser usado para calcular tensões transferidas aos enrolamentos de baixa do transformador admitindo-se que as tensões induzidas nos 
seus terminais de alta tensão são aproximadamente iguais nas três fases. De fato, as tensões induzidas na rede primária são aproximadamente iguais nas três fases, pois o espaçamento entre os seus condutores é geralmente muito menor que a distância da linha ao local de incidência da descarga atmosférica.

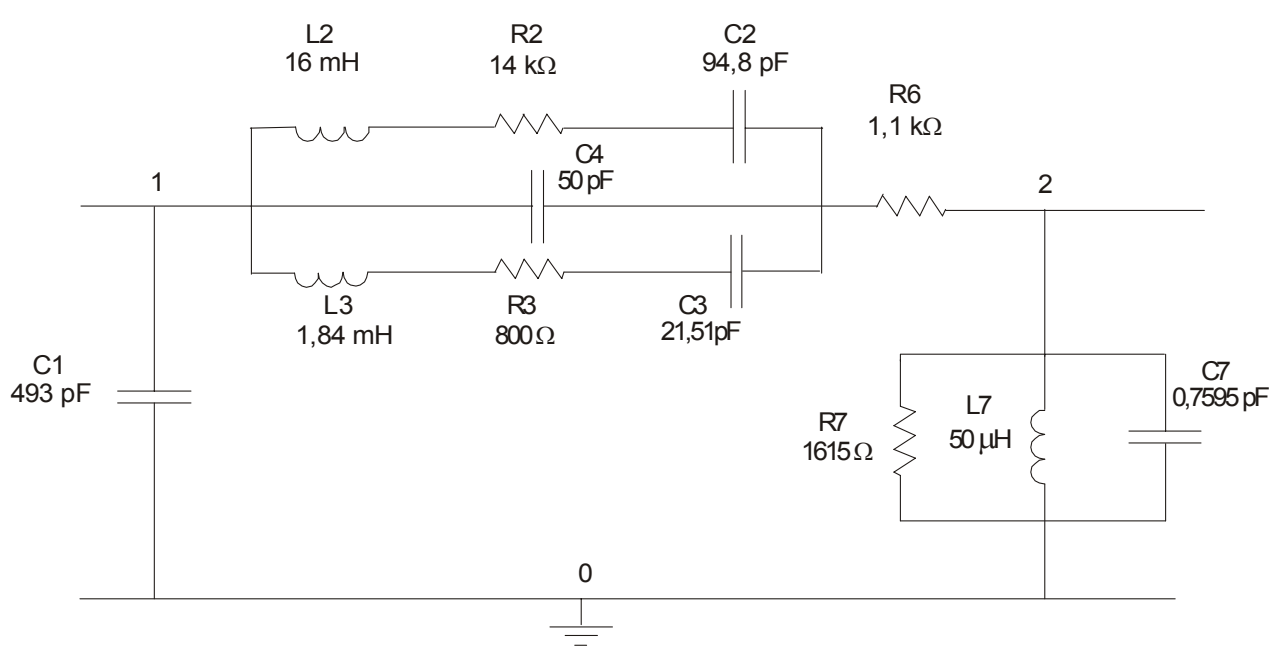

Fig. 3.12: Modelo de transformador de $30 \mathrm{kVA}$ para cálculo de surtos transferidos [29].

A Figura 3.13 ilustra uma rede primária ligada a um transformador de distribuição na condição de carga. Na ocorrência de uma descarga atmosférica indireta, tensões serão induzidas na linha e transferidas ao secundário do transformador. Considerouse, nas simulações, que as tensões nos terminais de alta do transformador são iguais às tensões fase-terra mostradas anteriormente, o centro estrela do secundário é ligado à carcaça do transformador e o solo é condutor perfeito. Também foi assumido que o condutor de descida do aterramento possui resistência e indutância desprezíveis. Para efeito de simplificação, as tensões transferidas foram calculadas diretamente no secundário do transformador, sem ligação deste à rede secundária. Os cálculos foram feitos no simulador computacional PSpice [54] inserindo uma fonte de tensão associada ao arquivo da tensão induzida entre os nós "1" e "0" do modelo de transformador. Foram simulados, inicialmente, os quatros casos de tensões induzidas medidas no modelo em escala reduzida e os quatro casos de tensões induzidas medidas no modelo em escala real apresentados anteriormente. Posteriormente foi efetuada uma análise da variação da tensão transferida ao secundário do transformador, sob diferentes condições de carregamento, para uma determinada forma de onda de tensão no primário. 
rede primária

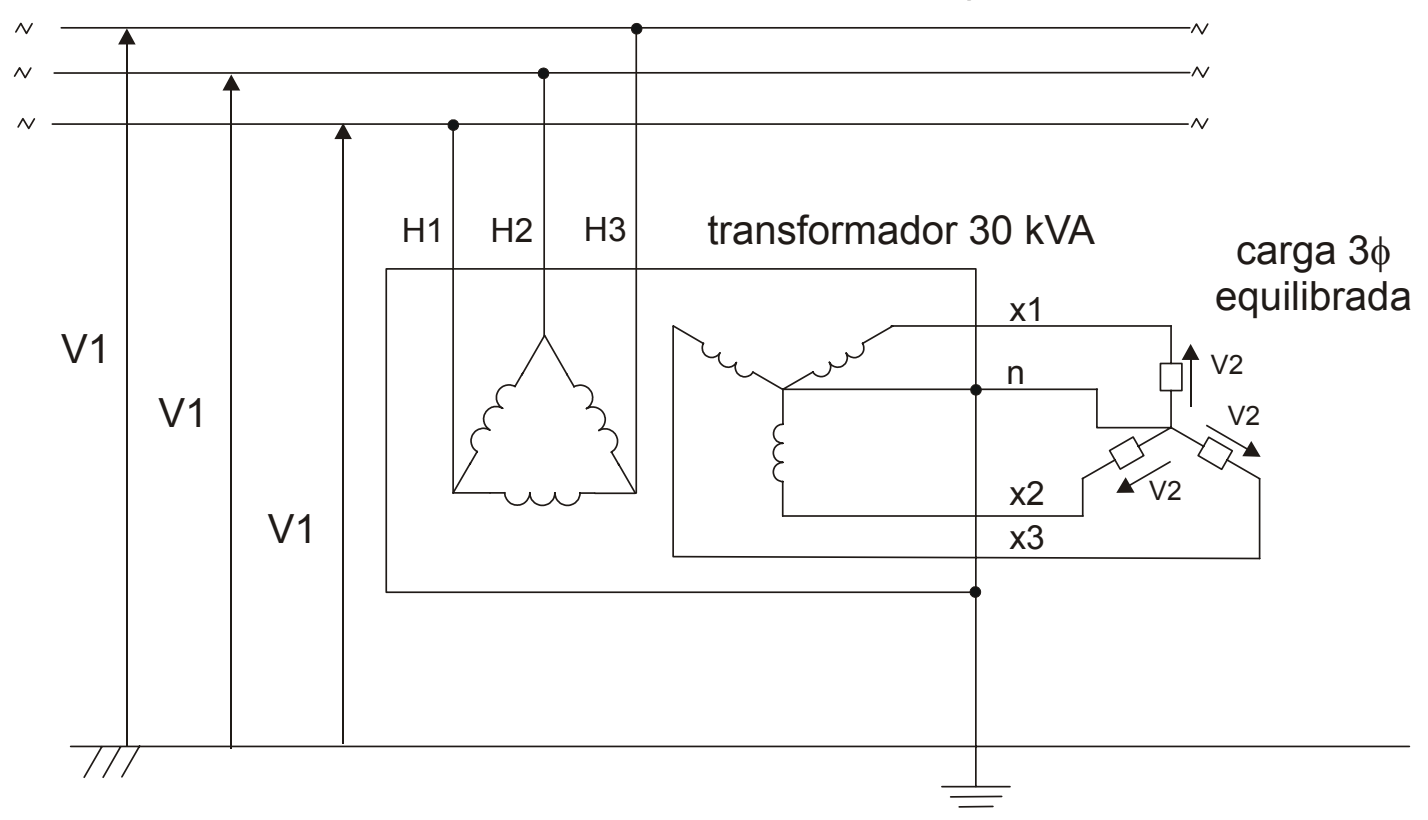

Fig 3.13: Configuração simulada. H1, H2 e H3 - terminais de alta tensão do transformador;

$\mathrm{x} 1, \mathrm{x} 2, \mathrm{x} 3$ - terminais de baixa tensão do transformador; $\mathrm{n}$ - terminal neutro;

V1 - tensão induzida no primário (fase-terra) por uma descarga atmosférica nas proximidades da linha; V2 - tensão nos terminais de baixa tensão do transformador (tensão transferida).

A Figura 3.14 apresenta as tensões transferidas calculadas utilizando o modelo de transformador de $30 \mathrm{kVA}$ na condição a vazio para as tensões induzidas na rede primária registradas no modelo em escala reduzida (tensões no primário também mostradas). Nota-se que as tensões transferidas ao secundário do transformador apresentam característica oscilatória, com freqüência fundamental na faixa de $300 \mathrm{kHz}$ a $800 \mathrm{kHz}$. Para os casos apresentados, à exceção do Caso 3, as tensões transferidas apresentam valores de amplitude inferiores a $0,8 \mathrm{kV}$. Embora o valor máximo da tensão no primário do transformador no Caso 3 tenha sido aproximadamente o dobro daquele referente ao Caso 1, a tensão transferida no Caso 3 é aproximadamente 5 vezes maior que a tensão transferida no Caso 1. Isto ocorre porque a tensão transferida é dependente tanto da amplitude do sinal de entrada (tensão no primário) quanto do seu espectro de freqüências. Para sinais de entrada com mesma forma de onda, a tensão transferida é diretamente proporcional à amplitude dos mesmos. Para tensões no primário com mesma amplitude, mas com 
diferentes formas de onda, as amplitudes das tensões transferidas podem ser diferentes, devido aos diferentes espectros de freqüências dos sinais de entrada.
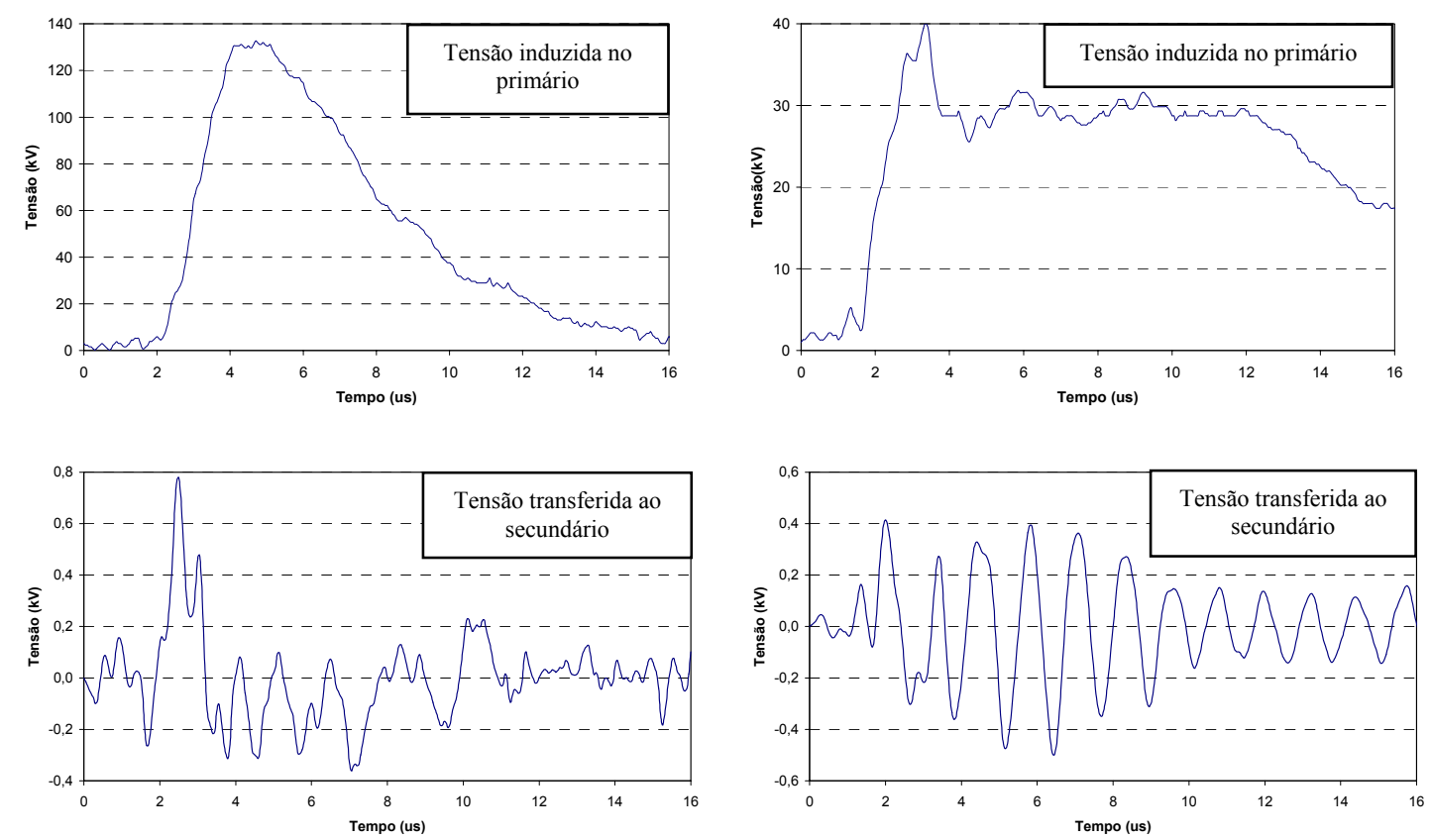

(a)

(b)
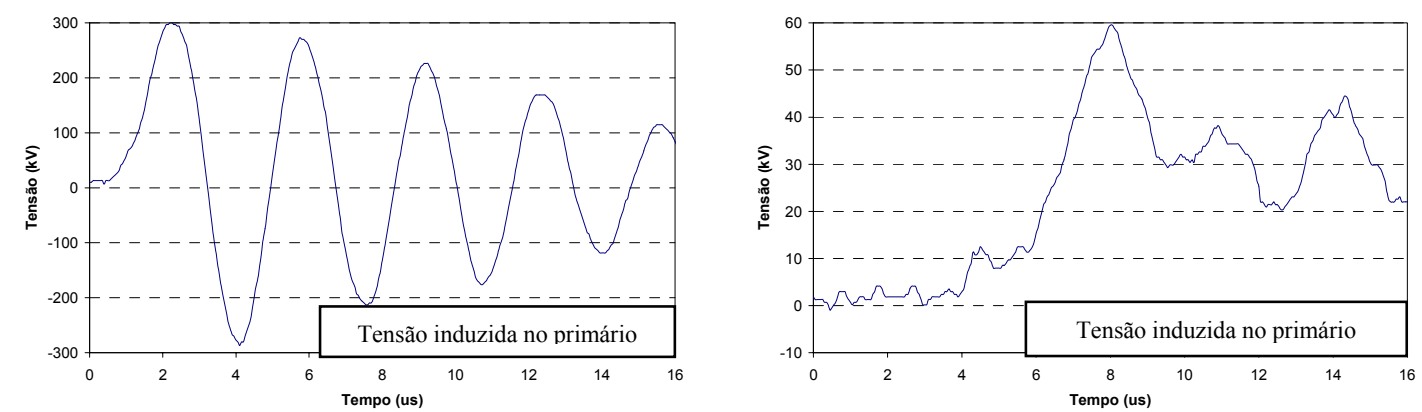

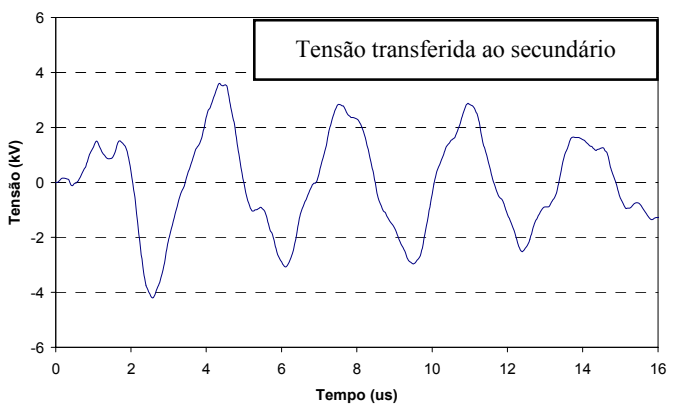

(c)

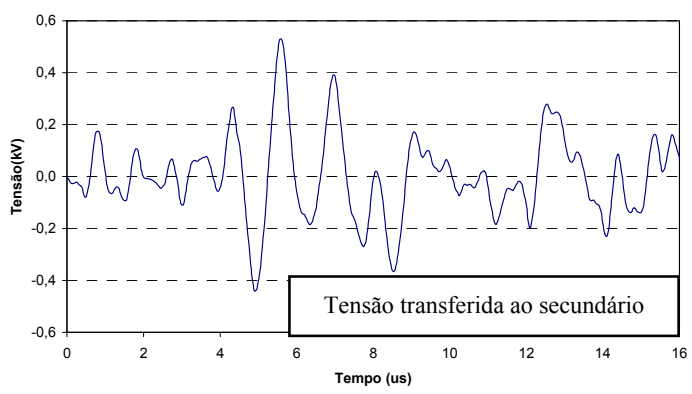

(d)

Fig. 3.14: Tensões transferidas para o secundário do transformador, na condição a vazio, considerando as tensões induzidas no primário obtidas através do estudo em escala reduzida.
a) Caso 1
b) Caso 2
c) Caso 3
d) Caso 4 
Na Figura 3.15 têm-se os resultados de cálculos das tensões transferidas ao secundário do transformador, na condição a vazio, para as tensões induzidas na rede primária registradas no modelo em escala real (tensões no primário também indicadas). Observa-se também a característica oscilatória das tensões transferidas, com freqüência fundamentais na faixa de $300 \mathrm{kHz}$ a $800 \mathrm{kHz}$.

Nos casos apresentados na Figura 3.15, fica também evidente a dependência da tensão transferida com a forma de onda da tensão no primário. Comparando as relações tensão no secundário pela tensão no primário nos casos 6 e 8 (figuras 3.15-b e 3.15-d, respectivamente), obtém-se os valores 0,1/14 (Caso 6) e 0,2/13 (Caso 8). Nesses dois casos, observa-se praticamente a mesma amplitude da tensão induzida na rede primária, mas a amplitude da tensão transferida para o secundário no Caso 8 é praticamente o dobro daquela correspondente ao Caso 6. Esse efeito também pode ser constatado ao se observar as tensões no primário e no secundário do transformador nos casos 7 e 8 (figuras 3.15-c e 3.15-d, respectivamente). A tensão no primário do transformador no Caso 7 é praticamente o dobro da tensão no Caso 8, mas essa relação não se mantém nas tensões transferidas ao secundário, que apresentam amplitudes semelhantes. Isto pode ser explicado pelos espectros de freqüências das tensões dos casos 7 e 8 e pela curva de resposta do transformador em função da freqüência (medida em laboratório), todas mostradas na Figura 3.16. Para melhor visualização, o módulo do espectro da tensão do Caso 8 foi normalizado e o módulo do espectro da tensão correspondente ao Caso 7 foi referenciado ao módulo do espectro do Caso 8. 

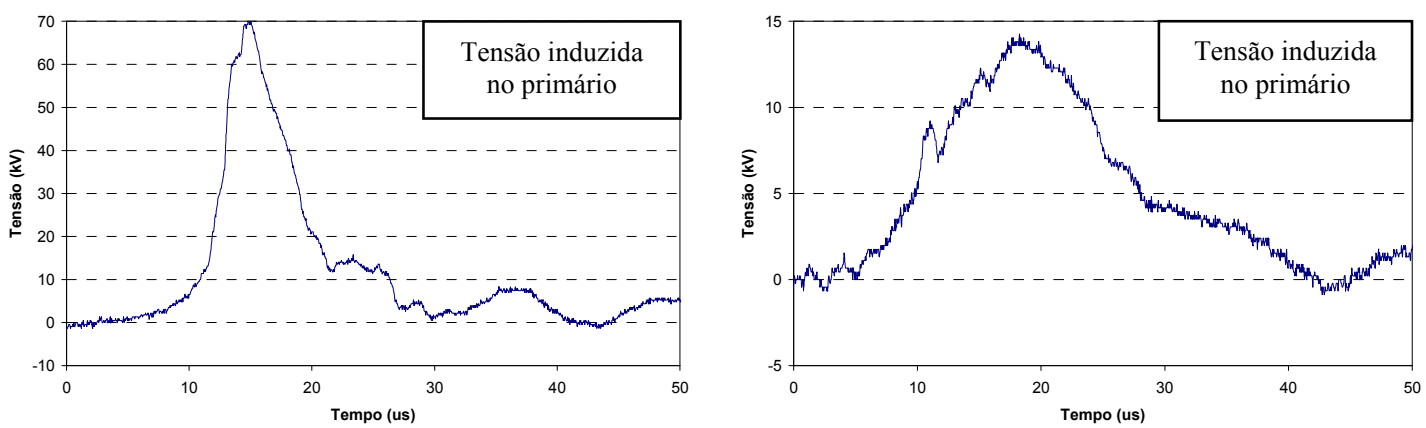

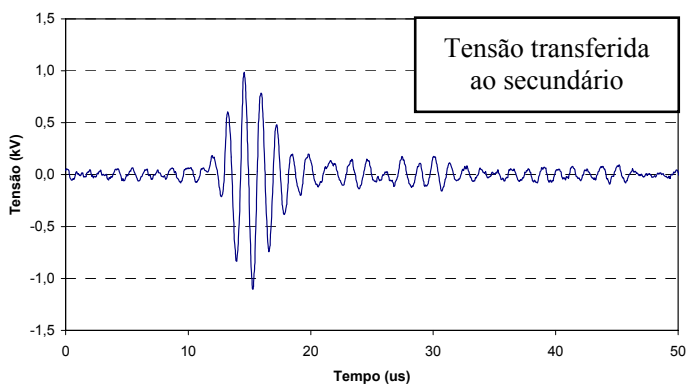

(a)
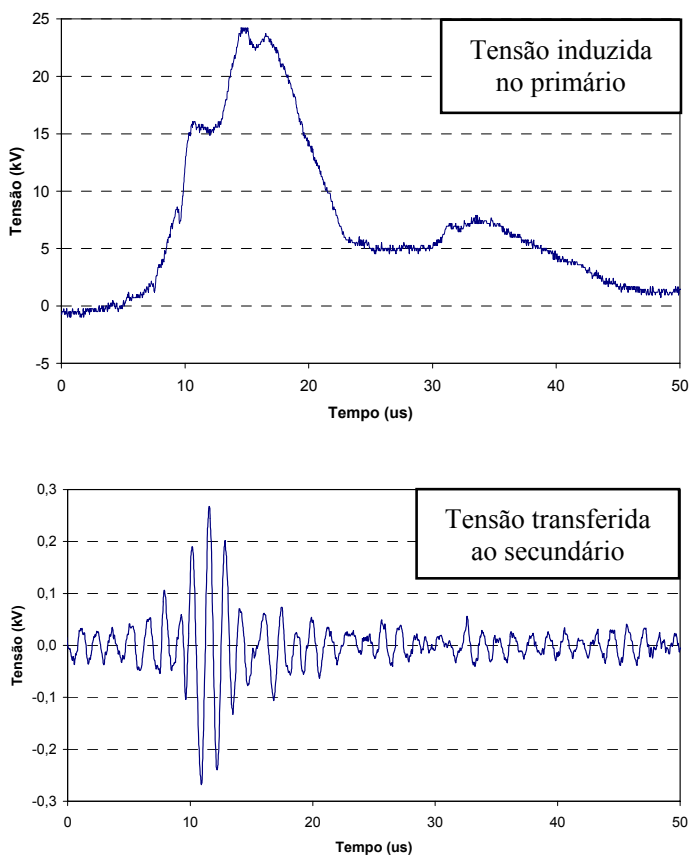

(c)

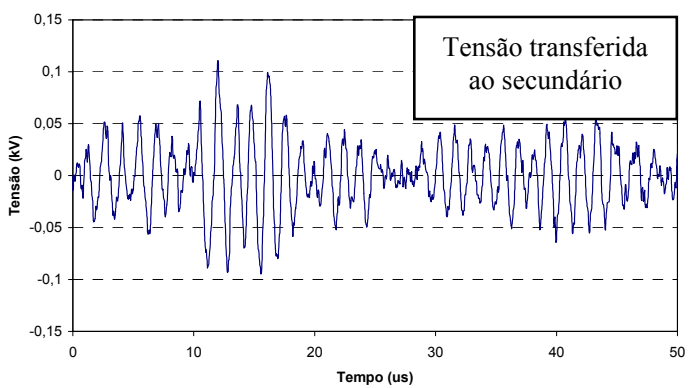

(b)
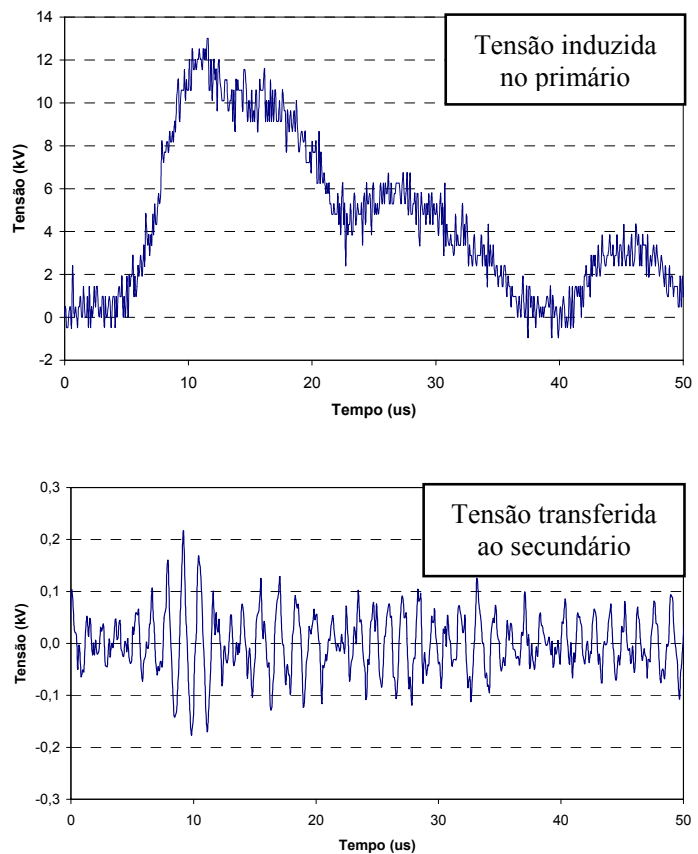

(d)

Fig. 3.15: Tensões transferidas para o secundário do transformador, na condição a vazio, considerando as tensões induzidas no primário obtidas através do estudo em escala real.
a) Caso 5
b) Caso 6
c) Caso 7
d) Caso 8

Verifica-se que as amplitudes dos componentes do surto referente ao Caso 7 são muito maiores que aqueles relativos ao Caso 8 até a freqüência de $300 \mathrm{kHz}$. Como o 
ganho do transformador é muito baixo até $400 \mathrm{kHz}$, a diferença de amplitude entre os sinais de entrada não tem muita importância na tensão transferida. Para a faixa em que o ganho do transformador é considerável, dos $500 \mathrm{kHz}$ aos $1200 \mathrm{kHz}$, o módulo da tensão no primário no Caso 7 continua maior que no Caso 8 , mas com pequena diferença. Esse comportamento explica o fato de as diferenças entre as amplitudes das tensões transferidas serem muito menores que aquelas correspondentes às tensões no primário do transformador.

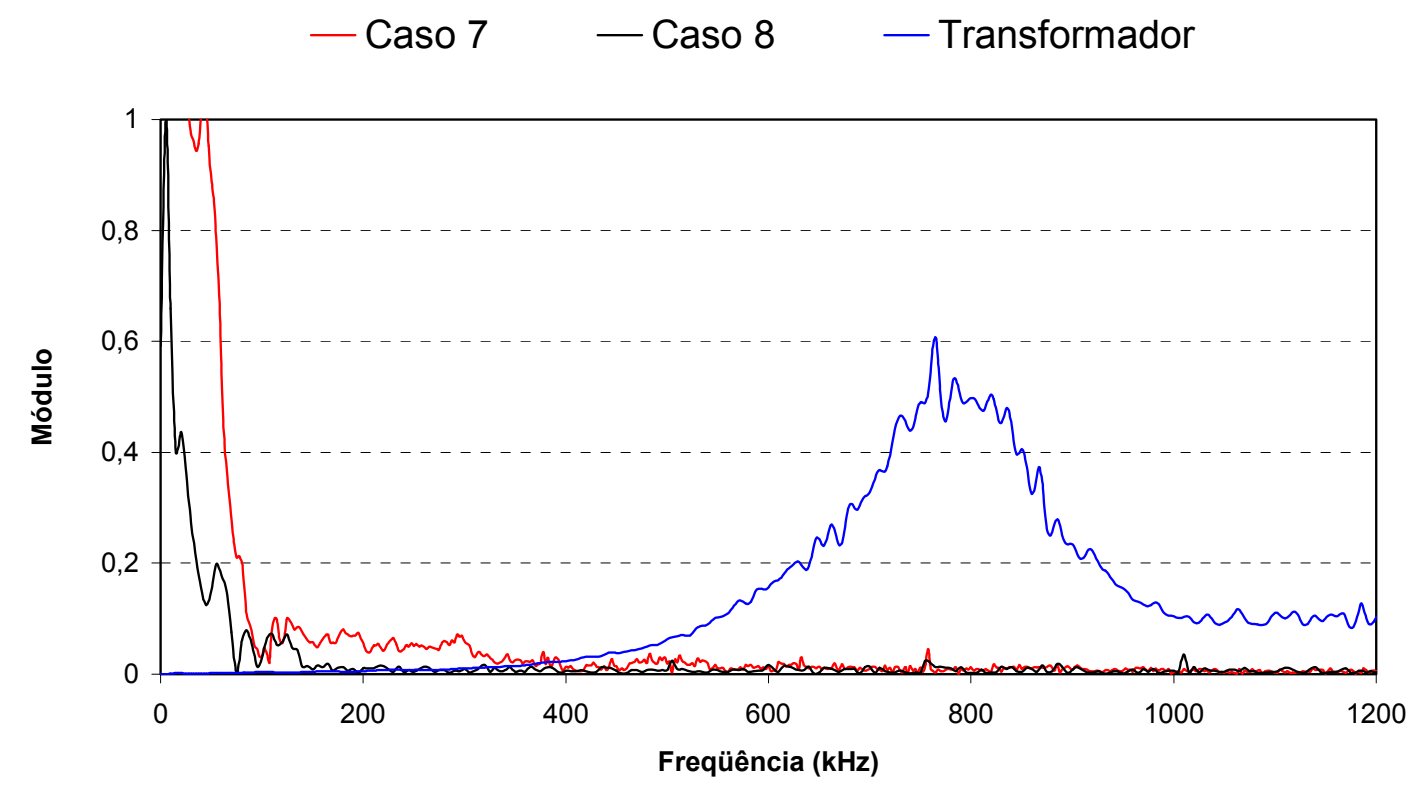

Fig. 3.16: Espectros da tensão no primário nos casos 7 e 8 e a curva de ganho do transformador.

O modelo de transformador utilizado nessas simulações permite também a avaliação dos surtos transferidos ao secundário com o transformador na condição sob carga. Mesmo para formas de onda não normalizadas o modelo apresentou bons resultados quando da comparação entre tensões calculadas e medidas em laboratório, tanto na condição a vazio quanto em diferentes condições de carregamento [29, 30]. Em vista dessa característica do modelo, foram realizadas simulações de tensões transferidas para o secundário do transformador considerando cargas resistivas, capacitivas e indutivas. A carga de um transformador de $30 \mathrm{kVA}$ na sua condição de carregamento nominal é equivalente a uma impedância de 1,67 $\Omega$. Uma carga de valor muito baixo de impedância conectada à baixa tensão do transformador resultaria em valores também baixos de tensões transferidas ao secundário. Para verificar a variação da 
tensão transferida ao secundário com a carga, foram consideradas cargas mais leves, de impedâncias iguais a $320 \Omega$ e $16 \Omega$. Para isso foram utilizadas resistências $(\mathrm{R})$ de valores iguais à impedância desejada, indutâncias (L) de $20 \mu \mathrm{H}$ e $2 \mu \mathrm{H}$ e capacitâncias (C) de $2 \mathrm{nF}$ e $20 \mathrm{nF}$. Uma carga indutiva de $20 \mu \mathrm{H}$ a $2 \mu \mathrm{H}$ pode representar a carga de um consumidor, conforme visto em [8]. Indutâncias de $20 \mu \mathrm{H}$ e $2 \mu \mathrm{H}$ apresentam, respectivamente, impedâncias de $320 \Omega$ e $16 \Omega$ na freqüência de $800 \mathrm{kHz}$. Os valores de capacitância também foram escolhidos para representarem o dual das cargas indutivas. Utilizando a tensão induzida obtida no Caso 3 do modelo reduzido (Figura 3.6) como tensão no primário do transformador, foram realizadas simulações de tensões transferidas ao lado de baixa tensão do transformador para as cargas descritas acima. A tensão aplicada no primário do transformador, a tensão transferida ao secundário com o transformador a vazio e com os diversos tipos de cargas são mostradas na Figura 3.17.

Comparando as tensões transferidas com o transformador a vazio (Figura 3.17-b) e com carga resistiva de $320 \Omega$ (Figura 3.17-c), verifica-se que a forma de onda sofre pouca alteração e o módulo do valor máximo se reduz de aproximadamente $25 \%(1 \mathrm{kV})$. A redução da amplitude da tensão transferida é mais sentida quando a impedância de carga resistiva é reduzida em 20 vezes (resistência igual a 16 $\Omega$ ), fazendo com que o módulo do valor máximo seja reduzido para $0,5 \mathrm{kV}$, como indicado na Figura 3.17-d. Embora a amplitude da tensão transferida tenha sido reduzida em aproximadamente 6 vezes, a forma de onda foi pouco modificada, devido principalmente ao fato da carga ser resistiva. Quando uma carga indutiva de $20 \mu \mathrm{H}$ foi colocada, a forma de onda da tensão transferida (Figura 3.17-e) sofreu uma deformação em relação à forma de onda da tensão transferida a vazio e o valor de crista foi reduzido para aproximadamente $1 \mathrm{kV}$. Com a diminuição da indutância de $20 \mu \mathrm{H}$ para $2 \mu \mathrm{H}$ observa-se uma redução de cerca de $50 \%$ na amplitude da tensão transferida (Figura 3.17-f), acompanhada de uma deformação da forma de onda aumento da freqüência fundamental. A tensão transferida com carga capacitiva de $2 \mathrm{nF}$ é apresentada na Figura 3.17-g. 


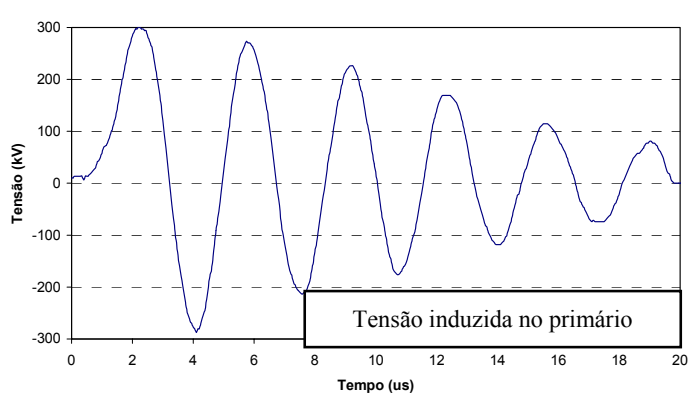

(a)

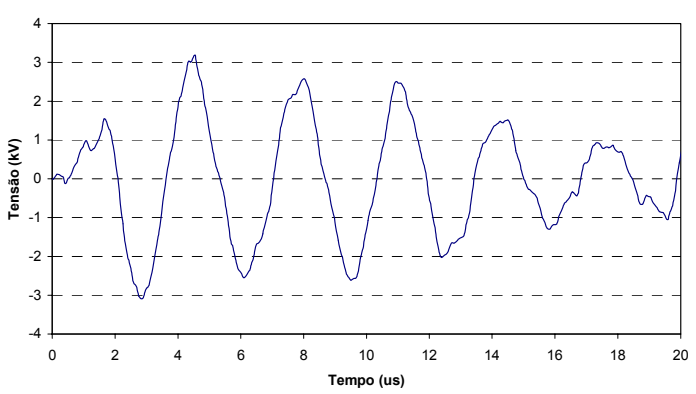

(c)

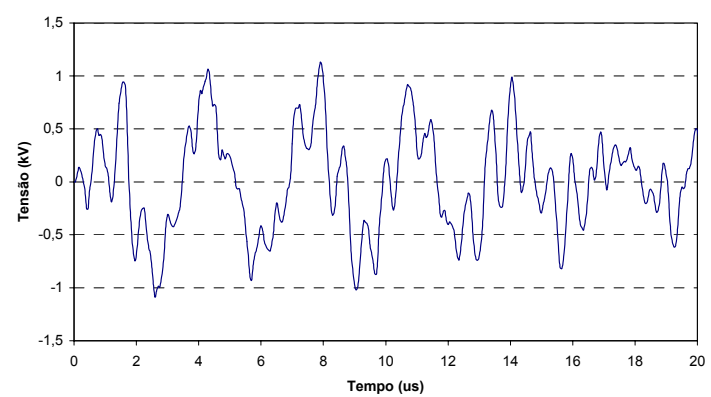

(e)

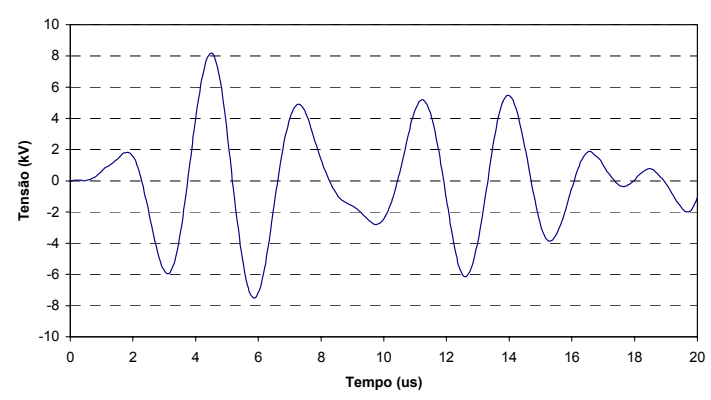

(g)

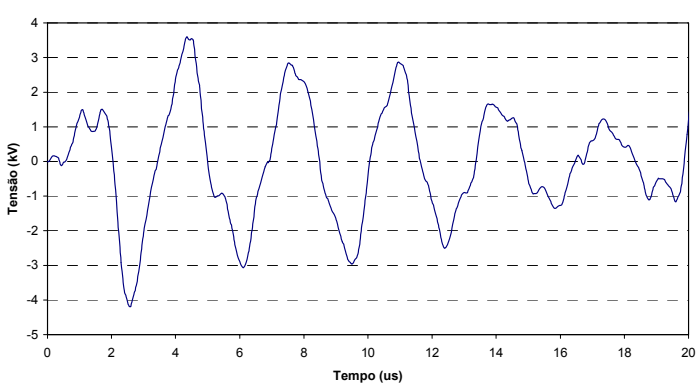

(b)

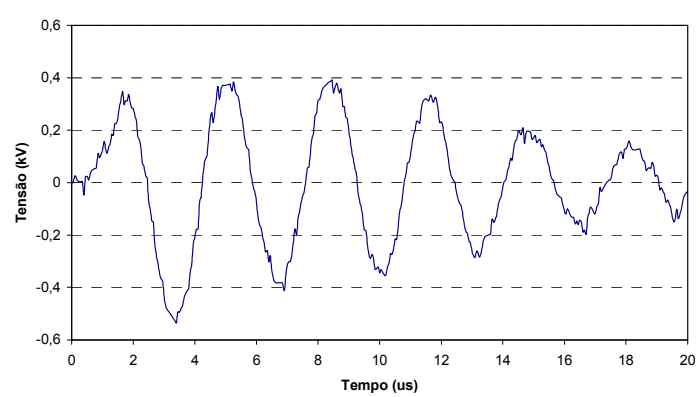

(d)

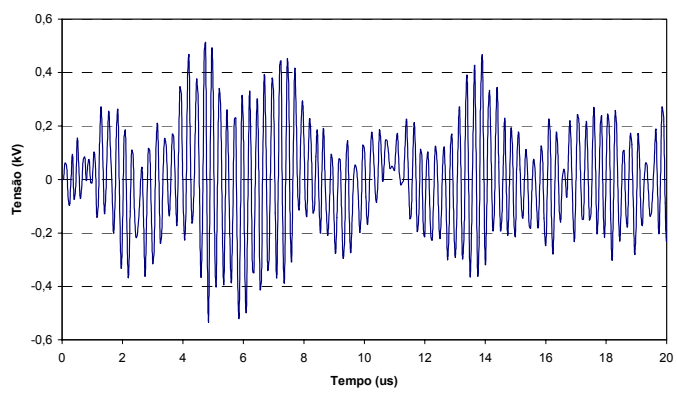

(f)

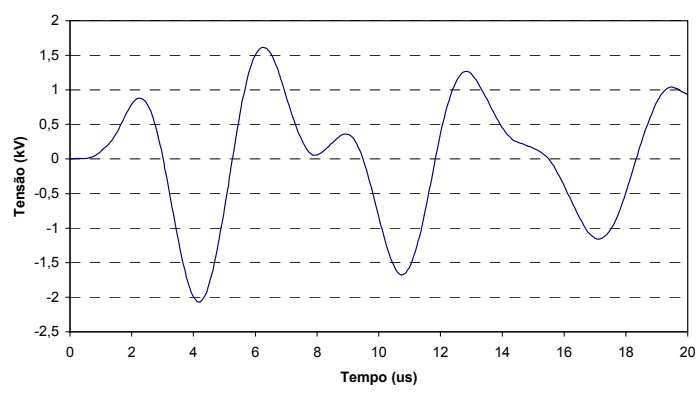

(h)

Fig. 3.17: Tensões transferidas ao secundário do transformador para diferentes condições de carga, considerando como tensão induzida no primário a onda relativa ao Caso 3.

a) tensão no primário (Caso 3)

d) Carga: $R=16 \Omega$ b) transformador em vazio

e) Carga: $\mathrm{L}=20 \mu \mathrm{H}$ c) Carga: $R=320 \Omega$

f) Carga: $\mathrm{L}=2 \mu \mathrm{H}$
g) Carga: $\mathrm{C}=2 \mathrm{nF}$
h) Carga: $\mathrm{C}=20 \mathrm{nF}$ 
Com a carga capacitiva de $2 \mathrm{nF}$ a forma de onda da tensão transferida sofreu nova deformação e, ao contrário do que ocorreu com as cargas resistiva e indutiva, a amplitude da tensão transferida ao secundário aumentou em relação à amplitude da tensão transferida na condição em vazio. Isto ocorre devido à ressonância entre a carga e o transformador. Aumentando-se o valor da capacitância para $20 \mathrm{nF}$ nota-se uma redução no valor da tensão transferida, como mostrado na Figura 3.17-h. Podese dizer que as amplitudes das tensões transferidas diminuem com o aumento de carga resistiva. Porém, para cargas capacitivas ou indutivas, a tensão transferida para esses casos pode apresentar amplitudes maiores ou menores que as transferidas na condição do transformador a vazio, dependendo do valor da carga, da forma de onda da tensão induzida no primário e do tipo de transformador analisado.

Neste capítulo foram apresentadas formas de onda típicas de tensões induzidas medidas em redes de distribuição primárias experimentais, tanto em escala reduzida quanto em escala real, possibilitando o conhecimento das características dessas tensões. Através do modelo de transformador desenvolvido pelo GATDA, foram calculadas as tensões transferidas para o lado de baixa tensão do transformador considerando-se diversas condições de carregamento. Observou-se que as tensões transferidas podem apresentar amplitudes elevadas e possuem em geral característica oscilatória. Tanto a amplitude como a forma de onda da tensão no secundário do transformador dependem da amplitude e forma de onda da tensão induzida na rede primária, do tipo de transformador e de seu carregamento. 


\section{CAPÍTULO 4}

\section{TENSÕES INDUZIDAS NA REDE SECUNDÁRIA DEVIDO A DESCARGAS INDIRETAS}

Este capítulo descreve inicialmente, o modelo "Extended Rusck Model" (ERM), utilizado neste trabalho para o cálculo das tensões induzidas em linhas de baixa tensão, mostrando a sua validade através de comparações entre tensões medidas e calculadas. Posteriormente são descritas as características construtivas das redes de baixa tensão de algumas concessionárias de energia brasileiras. Por fim, é realizada uma análise paramétrica das tensões induzidas em linhas de baixa tensão a partir da determinação das suas amplitudes e formas de onda considerando situações típicas e avaliando as influências dos parâmetros mais importantes relativos a essas tensões.

\subsection{O Modelo ERM (“Extended Rusck Model”)}

A grande freqüência de ocorrência de sobretensões induzidas por descargas atmosféricas em linhas de distribuição aumenta sua importância e tem motivado várias pesquisas [25-28, 55-58], principalmente sobre a procura de um modelo simples e prático que possa ser usado para a análise do desempenho de linhas de distribuição frente a esse fenômeno. As teorias existentes divergem em vários aspectos devido à complexidade do fenômeno e pelo fato de existirem poucos registros de formas de ondas de tensões induzidas junto com os respectivos parâmetros relevantes para o cálculo dessas tensões. Em [59, 60], Yokoyama et al apresentaram algumas formas de onda de tensão induzida em uma linha de distribuição quando da ocorrência de descargas em uma torre situada a $200 \mathrm{~m}$ de distância da linha. A tensão induzida e a corrente de descarga foram medidas simultaneamente.

Embora existam vários modelos para o cálculo de tensões induzidas, foi utilizado neste trabalho o modelo "Extended Rusck Model" (ERM) para caracterizar as tensões induzidas na rede secundária pelo fato deste modelo já ter sido validado 
através de várias comparações entre tensões induzidas medidas e calculadas envolvendo experimentos em escalas real e reduzida [25-28].

\subsubsection{Descrição}

Os estudos desenvolvidos em [61] mostram que o modelo de Rusck [58] leva a resultados coerentes, que podem ser justificados através dos campos eletromagnéticos associados com o fenômeno. Entretanto esta teoria não leva em consideração a incidência de descargas atmosféricas em estruturas metálicas e com isso não gera bons resultados quando as tensões calculadas são comparadas com as apresentadas em [59, 60]. Além disso, o comprimento do canal e da linha é considerado infinito e o efeito do "leader" ascendente não é considerado.

O ERM é baseado na teoria de Rusck, mas com algumas modificações para se considerar o tamanho finito do canal e da linha, e também o formato da linha de distribuição. O campo elétrico não é considerado constante na região entre a linha e a terra, uma aproximação adotada em [58]. Além disso, é possível considerar o caso de descargas atmosféricas em objetos metálicos nas vizinhanças da linha e também a ocorrência de "leader" ascendente [28]. Para o caso de uma excitação de campo eletromagnético irradiado por um canal perpendicular ao plano da terra, é possível demonstrar que o ERM e o modelo de Agrawal et al [37] são equivalentes.

Considere-se a Figura 4.1, que apresenta esquematicamente uma estrutura atingida por uma descarga, incluindo a imagem correspondente. Também estão representadas a distribuição linear de cargas $\left(\mathbf{q}_{\mathbf{0}}\right)$ e a corrente no canal e na estrutura em dois instantes: no início do "return stroke" $\left(\mathbf{t}_{\mathbf{0}}\right)$ e no tempo $\mathbf{t}$ (maior que $\mathbf{t}_{\mathbf{0}}$ ). O solo é considerado um plano condutor perfeito e a linha, de altura $\mathbf{h}$, está situada a uma distância $\mathbf{r}_{0}$ da estrutura metálica. 


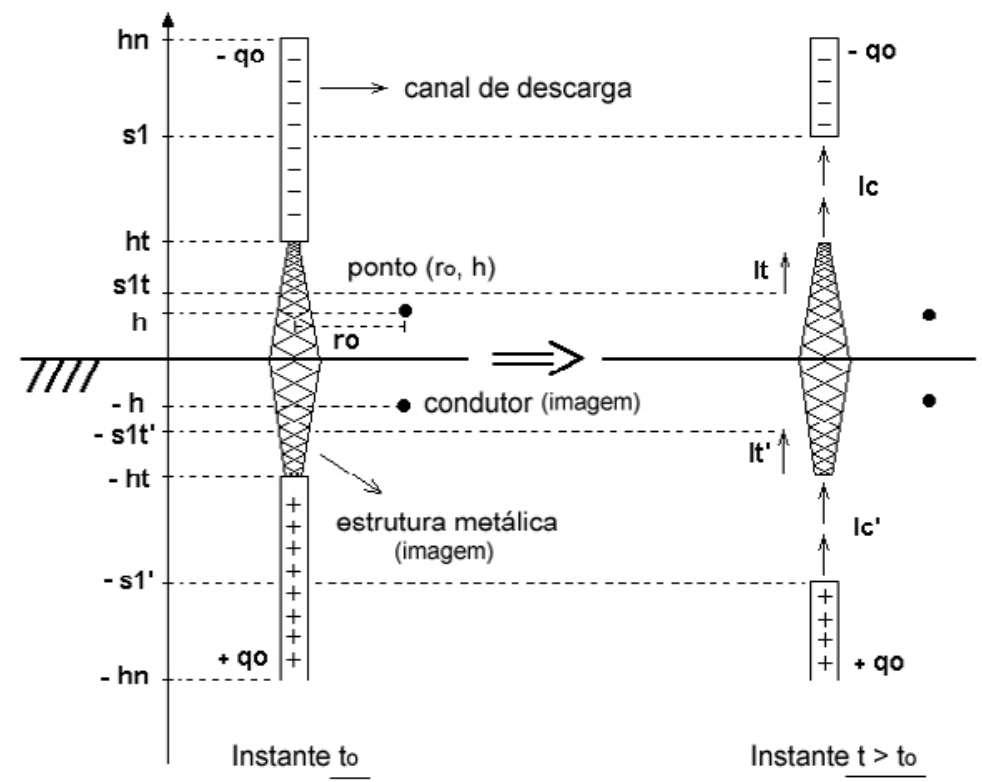

Fig. 4.1: Descarga atmosférica em uma estrutura metálica (adaptada de [27]).

Ic e Ic': correntes no canal de descarga e na sua imagem, respectivamente;

It e It': correntes na estrutura e na sua imagem, respectivamente;

hn: altura da base da nuvem;

ht: altura da estrutura metálica;

$\mathbf{s}_{1}$ e $\mathbf{s}_{1}$ ': respectivamente, altura no instante $\mathbf{t}$, da frente de corrente no canal e sua imagem; $\mathbf{s}_{\mathbf{1}} \mathbf{t}$ e $\mathbf{s}_{\mathbf{1}} \mathbf{t}$ ': respectivamente, altura no instante $\mathbf{t}$, da frente de corrente na estrutura metálica e sua imagem;

$\mathbf{q}_{\mathbf{0}}$ : densidade linear de cargas no canal.

As tensões induzidas são decompostas em seus componentes associados às cargas do canal (componente eletrostático) e às correntes que se propagam no canal e na estrutura (componente magnético). Para um degrau de corrente, o potencial escalar induzido $\mathbf{V}_{\mathbf{i}}$ em um ponto da linha distante $\mathbf{x}$ do ponto mais próximo da estrutura pode ser expresso por:

$V i(x, t)=\frac{1}{4 . \pi \cdot \varepsilon_{0}} \int_{s_{1}}^{h n} \frac{-q_{0} \cdot d s}{\sqrt{(s-h)^{2}+x^{2}+r_{0}^{2}}} \cdot u\left(t-t_{0}\right)+\frac{1}{4 \cdot \pi \cdot \varepsilon_{0}} \int_{s^{\prime}}^{h n} \frac{q_{0} \cdot d s}{\sqrt{(s+h)^{2}+x^{2}+r_{0}^{2}}} \cdot u\left(t-t^{\prime}{ }_{0}\right)$

em que $\mathbf{t}_{\mathbf{0}}$ e $\mathbf{t}_{\mathbf{0}}$ ' referem-se aos tempos de propagação das ondas eletromagnéticas do topo da estrutura e do topo da imagem, respectivamente, até o ponto x. Assim, 
$t_{0}=\frac{\sqrt{(h t-h)^{2}+x^{2}+r_{0}^{2}}}{c}$

sendo c a velocidade de propagação da luz no vácuo. O tempo to' pode ser obtido analogamente. O limite de integração $\mathbf{s}_{1}$ é obtido de:

$t=\frac{\left(s_{1}-h t\right)}{b . c}+\frac{\sqrt{\left(s_{1}-h\right)^{2}+x^{2}+r_{0}^{2}}}{c},\left(\mathbf{t}>\mathbf{t}_{\mathbf{0}}{ }^{\prime}\right)$

com $\mathbf{s}_{\mathbf{1}}=\mathbf{h t}$ para $\mathbf{t}=\mathbf{t}_{\mathbf{0}} ; \mathbf{s}_{\mathbf{1}}$ ' é encontrado de forma similar. O parâmetro $\mathbf{b}$ representa a razão entre a velocidade de propagação no canal e a velocidade da luz c.

O potencial escalar induzido $\mathbf{V}(\mathbf{x}, \mathbf{t})$ de um ponto de uma linha infinita é calculado de acordo com suas equações diferenciais, considerando $\mathbf{V}_{\mathbf{i}}$ como uma fonte distribuída [25]:

$V(x, t)=\left[V_{1}(x, t)+V_{2}(x, t)\right] \cdot u\left(t-t_{0}\right)$

com

$V_{1}(x, t)=\frac{1}{2 \cdot c} \int_{-\infty}^{x} \frac{\partial V i}{\partial t} \cdot\left(x^{\prime}, t-\frac{\left(x-x^{\prime}\right)}{c}\right) \cdot d x^{\prime}$

e

$V_{2}(x, t)=\frac{1}{2 \cdot c} \int_{x}^{x \infty} \frac{\partial V i}{\partial t} \cdot\left(x^{\prime}, t-\frac{\left(x^{\prime}-x\right)}{c}\right) \cdot d x^{\prime}$

Aplicando o teorema da superposição nos resultados acima, uma expressão equivalente pode ser obtida para uma função rampa. Dessa maneira, qualquer forma de onda de corrente pode ser considerada, uma vez que ela pode ser aproximada por um somatório de funções rampa deslocadas. 
O componente magnético associado com a corrente do canal e sua imagem é obtido através da determinação do vetor potencial $\mathbf{A}_{\mathbf{i}}$. A Figura 4.2 ilustra uma rampa de corrente com taxa de crescimento $\mathbf{m}$ propagando-se ao longo do canal. No instante $\mathbf{t}$, a frente de onda da corrente alcança a altura $\mathbf{s}_{\mathbf{1}}(\mathbf{t})$ no canal, que é dividido em $\mathbf{n}$ elementos de tamanho $\Delta \mathbf{z}$ entre ht e $\mathbf{s}_{\mathbf{1}}(\mathbf{t})$.

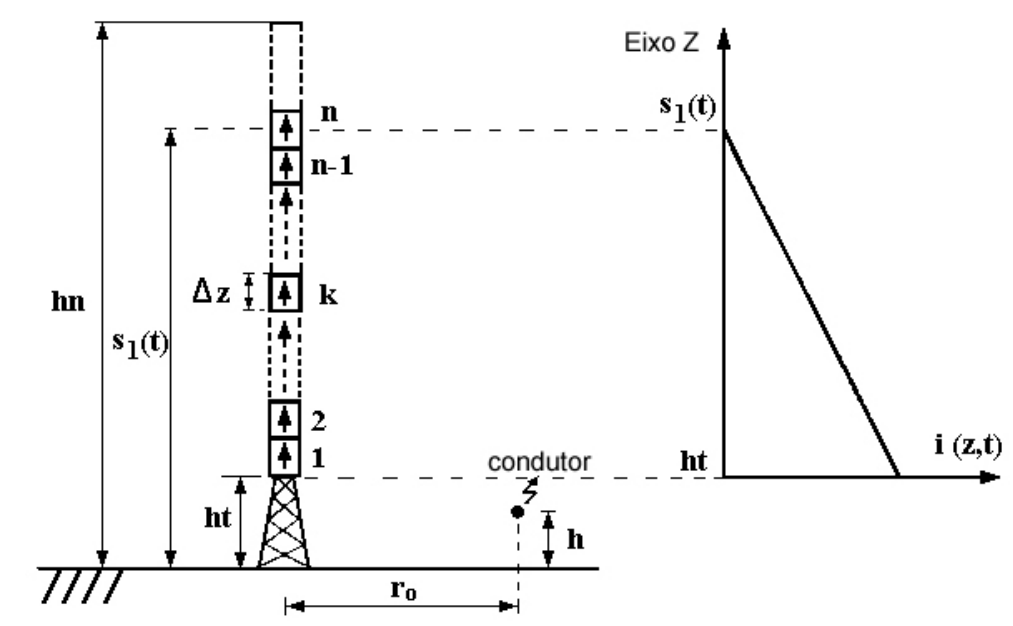

Fig. 4.2: Rampa de corrente se propagando ao longo do canal (adaptada de [27]).

(imagem não mostrada) $\mathbf{s}_{1}(\mathrm{t})$ : altura do elemento $\mathbf{n}$

$\mathbf{i}(\mathbf{z}, \mathbf{t})$ : corrente no canal $($ taxa de crescimento $=\mathbf{m})$

Para um tempo $\mathbf{t}>\mathbf{t}_{\mathbf{0}}$, o vetor potencial $\mathbf{A}_{\mathbf{i}}{ }^{\mathbf{\prime}}(\mathbf{x}, \mathbf{t})$ em um ponto da linha devido à corrente no canal, no limite, quando $\Delta \mathbf{z}$ tende a zero, é

$A i^{\prime}(x, t)=\frac{\mu_{0}}{4 . \pi} \cdot \frac{m}{b . c} \int_{h t}^{s_{1}(t)}\left(\frac{b \cdot c . t-z+h t-b \cdot \sqrt{(z-h)^{2}+x^{2}+r_{0}^{2}}}{\sqrt{(z-h)^{2}+x^{2}+r_{0}^{2}}}\right) \cdot d z$

A expressão correspondente para $\mathbf{A}_{\mathbf{i}}{ }^{\prime}$ '(x,t), associada com a imagem do canal de corrente, pode ser obtida de maneira similar e, então

$A i(x, t)=A i^{\prime}(x, t) \cdot u\left(t-t_{0}\right)+A i^{\prime \prime}(x, t) \cdot u\left(t-t^{\prime}{ }_{0}\right)$ 
Para o componente magnético referente à corrente ao longo da estrutura metálica (associado com o vetor potencial Ait), a análise é análoga. No entanto, embora ambas as correntes tenham a mesma amplitude e a mesma polaridade, a propagação ao longo da estrutura metálica é realizada do topo para a base, com velocidade próxima à da luz. Reflexões de corrente na base não são consideradas. A Figura 4.3 mostra uma rampa de corrente propagando-se através da estrutura metálica de altura ht. No instante t, a frente de onda de corrente alcança a altura $\mathbf{s}_{1} \mathbf{t}(\mathbf{t})$ na estrutura, que é então dividida em $\mathbf{n}$ elementos de tamanho $\Delta \mathbf{z}$ entre $\mathbf{s}_{\mathbf{1}} \mathbf{t}(\mathbf{t})$ e ht.

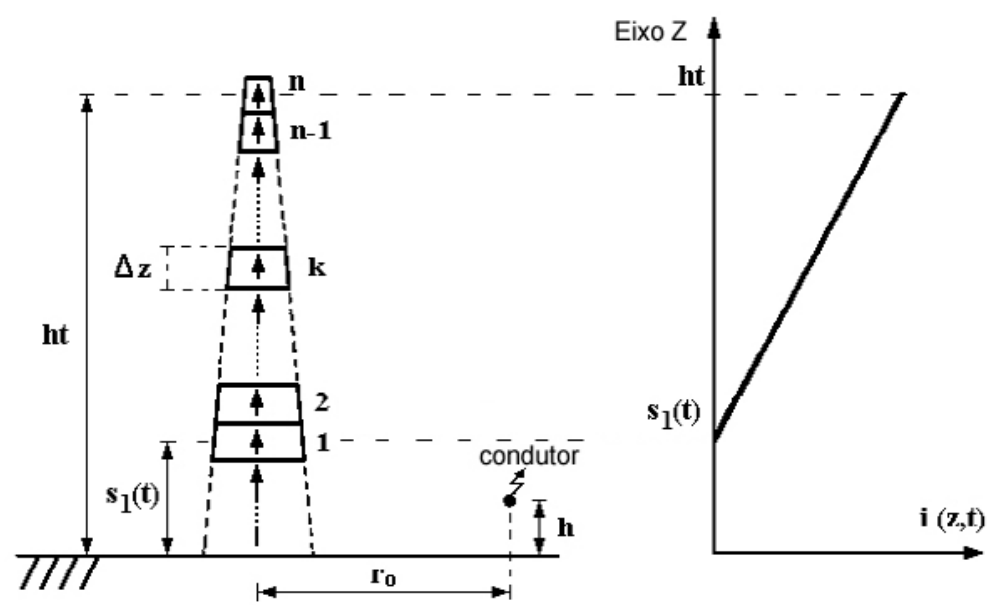

Fig. 4.3: Rampa de corrente na estrutura metálica (adaptada de [27]).

(imagem não mostrada)

Para $\mathbf{t}>\mathbf{t}_{\mathbf{0}}$, no limite $(\Delta \mathbf{z} \rightarrow \mathbf{0})$ o vetor potencial em um ponto da linha, associado à corrente na estrutura, pode ser escrito como:

$\operatorname{Ait}^{\prime}(x, t)=\frac{\mu_{0}}{4 \cdot \pi} \cdot \frac{m}{b t \cdot c} \int_{s_{1} t(t)}^{h t} \frac{\left(\text { bt.c.t }+z-h t-b t \cdot \sqrt{(z-h)^{2}+x^{2}+r_{0}^{2}}\right)}{\sqrt{(z-h)^{2}+x^{2}+r_{0}^{2}}} \cdot d z$

sendo bt a razão entre a velocidade de propagação da corrente na estrutura e a velocidade da luz no vácuo (nas simulações, foi atribuído o valor 0,9999 para bt). Considerando, de maneira similar, a corrente na imagem da estrutura com sua correspondente Ait'’(x,t), tem-se: 
$\operatorname{Ait}(x, t)=\operatorname{Ait}^{\prime}(x, t) \cdot u\left(t-t_{0}\right)+\operatorname{Ait}^{\prime \prime}(x, t) \cdot u\left(t-t_{0}{ }^{\prime}\right)$

A tensão induzida $\mathbf{U}(\mathbf{x}, \mathbf{t})$ em um ponto da linha é então calculada somando os componentes eletrostático e magnético do canal e da estrutura:

$U(x, t)=V(x, t)+\int_{0}^{h} \frac{\partial A i(x, t)}{\partial t} \cdot d z+\int_{0}^{h} \frac{\partial A i t(x, t)}{\partial t} \cdot d z$

As tensões induzidas em uma linha devido a descargas atmosféricas em estruturas metálicas próximas são caracterizadas por uma maior dependência da forma de onda da corrente em relação ao caso de descargas ao solo. Isto ocorre devido ao componente de tensão associado à corrente que se propaga ao longo da estrutura, que tem uma grande taxa de crescimento no instante correspondente a $\mathbf{s}_{\mathbf{1}} \mathbf{t}=\mathbf{0}$ (quando a frente de onda de corrente alcança a base da estrutura). No caso de descargas no solo, o componente associado às cargas do canal normalmente predomina e a variação de tensão é menos brusca.

A influência dos componentes eletrostático e magnético associados ao canal diminui à medida que a altura ht da estrutura aumenta. Por outro lado, o efeito do componente magnético associado à corrente ao longo da estrutura aumenta com ht, devido à maior velocidade de propagação $(\mathbf{b t} \cong \mathbf{1})$. Entretanto, quando a corrente alcança a base da estrutura, esse componente torna-se constante (para forma de onda tipo rampa) e a tensão induzida sofre uma variação significativa. Assim, para frente de onda de corrente em degrau, o componente magnético predomina e a amplitude de tensão aumenta com o aumento de ht, sendo que para frentes de onda de correntes mais lentas a tensão diminui com ht devido ao predomínio do componente eletrostático.

As simulações apresentadas na Figura 4.4, utilizando o modelo ERM, ilustram a influência da altura da estrutura nas amplitudes e formas de onda das tensões induzidas. A corrente do canal foi simulada como uma forma de onda triangular, com amplitude de $50 \mathrm{kA}$, tempo de frente de $3 \mu$ s e tempo de meio valor de $50 \mu \mathrm{s}$. A 
velocidade de propagação da corrente ao longo do canal foi assumida como igual a $30 \%$ da velocidade da luz no vácuo. A linha, com $10 \mathrm{~m}$ de altura e $5 \mathrm{~km}$ de comprimento, com as duas extremidades casadas. A estrutura metálica estava situada a $50 \mathrm{~m}$ da linha, no ponto médio da mesma. A altura da base da nuvem foi de $3 \mathrm{~km}$ e as tensões foram calculadas no ponto da linha mais próximo à estrutura.

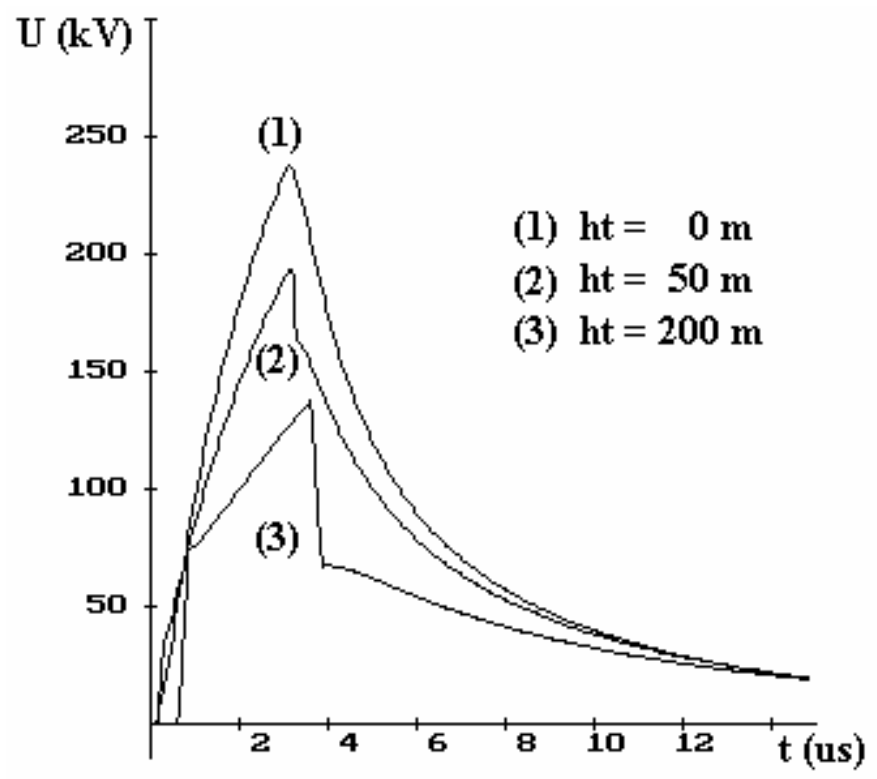

Fig. 4.4: Tensões induzidas em função da altura ht da estrutura metálica (adaptada de [27]).

\subsubsection{Validação}

Embora a adequabilidade do ERM e do modelo de Agrawal et al já tenham sido comprovadas por comparações entre resultados teóricos e experimentais [25-28, 34, 55], outros métodos ainda continuam sendo usados para cálculos computacionais de tensões induzidas por descargas atmosféricas em linhas de distribuição. Nas figuras 4.5 e 4.6, as tensões calculadas por quatro modelos [27, 56-58] são comparadas com as respectivas formas de onda medidas no experimento realizado por Yokoyama et al [59]. O experimento japonês foi o primeiro a obter medições simultâneas da corrente da descarga (em uma torre de $200 \mathrm{~m}$ de altura) e as respectivas tensões induzidas em uma linha experimental de $820 \mathrm{~m}$ de comprimento e distante $200 \mathrm{~m}$ da torre. Os modelos de Chowdhuri e Liew-Mar levam a tensões induzidas com forma de onda bipolar, com valor inicial negativo para o caso 
indicado na Figura 4.5 e positivo para o caso mostrado na Figura 4.6. É relevante mencionar também que a diferença entre esses dois modelos diz respeito meramente ao tratamento dado ao componente magnético da tensão induzida. Nenhum deles leva em conta o efeito das cargas induzidas na linha durante a fase do "stepped leader". Como discutido em [61], esse efeito não pode ser desprezado, uma vez que a velocidade média do "stepped leader" é pequena o suficiente para que cargas positivas da terra migrem para a linha, mantendo-a no potencial da terra até o começo do "return stroke".

Embora as reflexões nas extremidades da torre não tenham sido consideradas, obteve-se maior concordância quando a tensão induzida medida foi comparada com a tensão calculada pelo ERM, uma vez que a presença da torre e os comprimentos finitos da linha e do canal foram considerados. Muitas outras comparações entre tensões induzidas medidas e calculadas, usando na maioria das vezes dados obtidos de experimentos em modelo em escala reduzida, comprovaram a validade do ERM para cálculos de tensões induzidas por descargas atmosféricas.
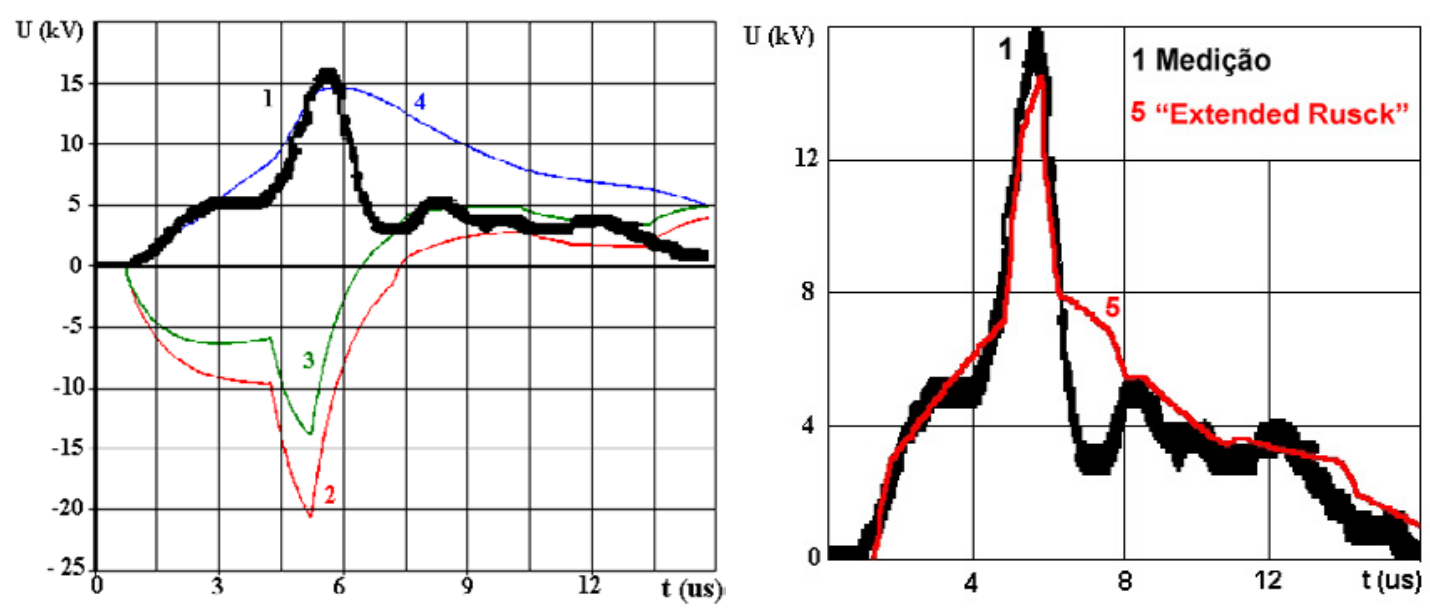

Fig 4.5: Tensões induzidas U medida e calculada (adaptada de [27]). Caso 81-02 [59].
1: Yokoyama et al (medido);
2: Chowdhuri [56];
3: Liew-Mar [57];

4: Rusck [58]; 5: ERM [25]. 

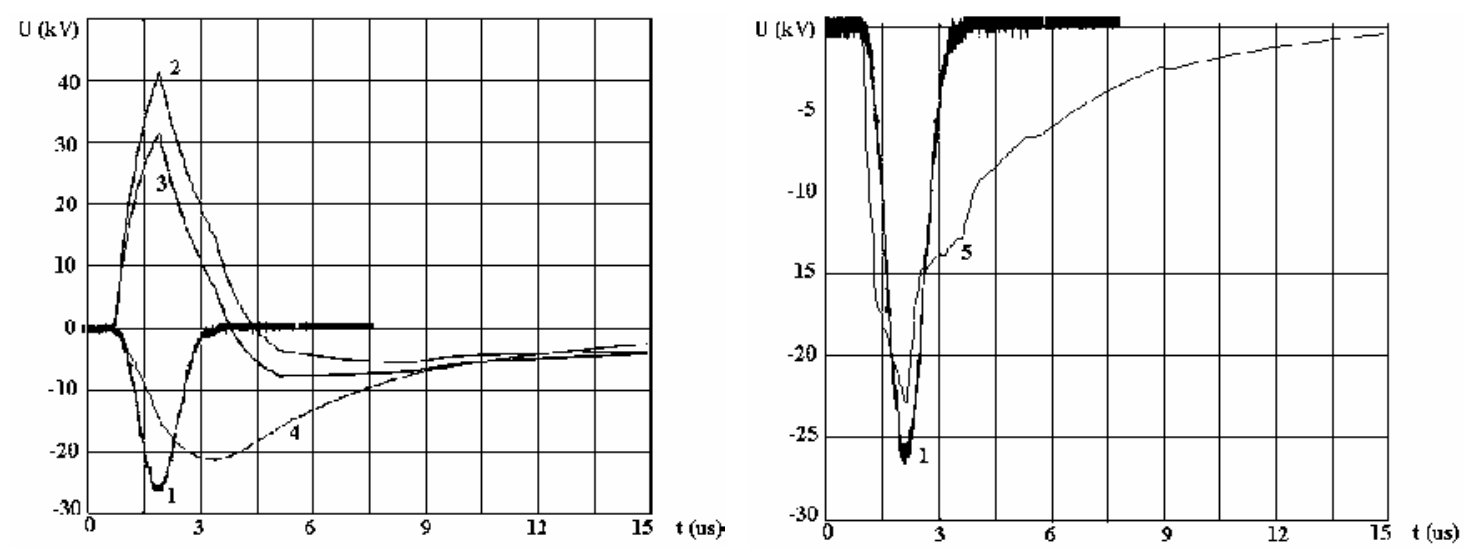

Fig 4.6: Tensões induzidas U medida e calculada (adaptada de [27]). Caso 82-02 [59].

1: Yokoyama et al (medido); $\quad 2$ : Chowdhuri [56]; 3: Liew-Mar [57]; 4: Rusck [58]; 5: ERM [25].

Neste item, o modelo estendido de Rusck (ERM) foi comparado a outros métodos normalmente utilizados e foi mostrado que ele leva a melhores concordâncias com as formas de onda de tensão induzida medidas no Japão por Yokoyama et al.

Em função dos bons resultados obtidos, tal modelo será utilizado no item 4.3 para a avaliação do efeito de diversos parâmetros nas tensões induzidas em linhas de baixa tensão.

\subsection{Configurações típicas de redes secundárias}

As redes secundárias são as linhas que alimentam os consumidores em baixa tensão (BT), ligadas ao secundário de transformadores de distribuição, que podem ser trifásicos ou monofásicos. A tensão normalizada para a rede secundária pode ser $120 / 208 \mathrm{~V}, 127 / 220 \mathrm{~V}$ ou 220/380 V para transformadores trifásicos com secundário em estrela aterrada, e $115 / 230 \mathrm{~V}$ ou $120 / 240 \mathrm{~V}$ para transformadores trifásicos com secundário em delta com neutro. Em redes secundárias trifásicas são utilizados nas linhas de baixa tensão 4 condutores, sendo 3 correspondentes às fases e o quarto condutor ao neutro. Nas redes monofásicas, as linhas são constituídas geralmente por três condutores, dois fases e um neutro. Em ambos os casos, o condutor neutro é multiaterrado e comum à rede primária. As redes secundárias utilizadas pelas concessionárias de energia podem ser do tipo convencional ou multiplexada. Na rede 
convencional são utilizados condutores não isolados instalados verticalmente, ao passo que na rede multiplexada são utilizados cabos fase isolados e torcidos ao redor de um condutor nu, que possui duas funções: sustentação da rede (cabo mensageiro) e neutro.

Para caracterizar as tensões induzidas em linhas de baixa tensão por descargas atmosféricas é necessário o conhecimento das características das redes de BT. Foi realizado, portanto, um trabalho de pesquisa sobre as configurações das redes de baixa tensão em concessionárias de energia elétrica. Foram pesquisados documentos das seguintes companhias: Centrais Elétricas de Goiás S.A. - CELG [64, 65], Empresa Energética do Mato Grosso do Sul S.A. - ENERSUL [66, 67], Companhia Energética de Brasília - CEB [68], Companhia de Energia Elétrica do Estado do Tocantins - CELTINS [69], Centrais Elétricas do Pará S.A. - CELPA [70], Centrais Elétricas Mato-Grossenses S.A. - CEMAT [71, 72], Companhia Elétrica da Bahia COELBA [73, 74], Companhia Paranaense de Energia - COPEL [75], Eletropaulo [76, 77], Companhia Paulista de Força e Luz - CPFL [78-81], Elektro [82] e Bandeirante Energia S.A. [83]. A descrição da rede da Companhia Energética de Minas Gerais - CEMIG foi obtida de [19].

As linhas secundárias em áreas urbanas são geralmente instaladas sob a linha primária quando da presença da mesma, sendo os postes compartilhados entre as linhas. O afastamento mínimo entre a linha secundária e a linha primária de classe $15 \mathrm{kV}$ é de $80 \mathrm{~cm}$, e de $100 \mathrm{~cm}$ para redes de classe $35 \mathrm{kV}$ [84]. Os postes são instalados tipicamente com distâncias entre vãos na faixa de $30 \mathrm{~m}$ a $40 \mathrm{~m}$.

A altura mínima entre os condutores da rede e o solo é geralmente na faixa de 3,5 m a 6,0 m dependendo da localização (tipo de logradouro) da linha. A Tabela 4.1 apresenta a distância entre os condutores e o solo para diferentes classes de tensão e localização da linha. Embora possam ser encontrados afastamentos diferentes para cada tipo de logradouro entre as concessionárias, os valores utilizados pelas concessionárias devem estar de acordo com a norma NBR 5433/5434 [84, 85]. 
Tabela 4.1: Afastamento mínimo entre condutores e o solo. E: tensão nominal [84, 85].

\begin{tabular}{|c|c|c|c|c|}
\hline & \multicolumn{4}{|c|}{ Distância mínima (mm) } \\
\hline Natureza do logradouro & $\begin{array}{c}\text { Circuito de comunicação e } \\
\text { cabos aterrados }\end{array}$ & $\begin{array}{c}\mathrm{E} \leq \\
600 \mathrm{~V}\end{array}$ & $\begin{array}{c}600 \mathrm{~V}<\mathrm{E} \\
\leq 15000 \mathrm{~V}\end{array}$ & $\begin{array}{c}15000 \mathrm{~V}<\mathrm{E} \\
\leq 35000 \mathrm{~V}\end{array}$ \\
\hline Rodovias & 6000 & 6000 & 7000 & 7000 \\
\hline $\begin{array}{c}\text { Ruas e avenidas } \\
\text { Entrada de prédios e demais } \\
\text { locais de uso restrito a veículos }\end{array}$ & 5000 & 5500 & 6000 & 6000 \\
\hline $\begin{array}{c}\text { Ruas e vias exclusivas a } \\
\text { pedestres }\end{array}$ & 3500 & 4500 & 6000 & 6000 \\
\hline Ferrovias & 6000 & 3500 & 5500 & 5500 \\
\hline
\end{tabular}

$\mathrm{Na}$ rede convencional os condutores são dispostos verticalmente, geralmente com separação entre condutores de $20 \mathrm{~cm}$, sendo o condutor neutro instalado acima dos condutores fase. A linha de baixa tensão é montada sobre suportes isolados denominados estribos, que podem ser duplos ou simples. A Figura 4.7 representa uma estrutura de montagem de uma linha de baixa tensão, com afastamento entre os condutores de $20 \mathrm{~cm}$. A COELBA, por exemplo, admite o uso de redes secundárias com espaçamento entre postes de até $80 \mathrm{~m}$, desde que seja utilizado espaçamento duplo - $40 \mathrm{~cm}$ entre os condutores [74]. Nesse caso, a rede deve ser montada em armações secundárias de 1 estribo. A montagem dos condutores nas estruturas é efetuada de cima para baixo e respeitando a seguinte ordem: neutro, fase A, fase B e fase C. Mesmo no caso de circuitos sem todas as fases, a posição e o espaçamento relativo entre neutro e fases é respeitada.

Os condutores utilizados na rede secundária de distribuição são cabos de alumínio (CA), nas bitolas $2 \mathrm{AWG}, 1 / 0 \mathrm{AWG}$ e 2/0 AWG (aproximadamente 33,6 mm², $53,5 \mathrm{~mm}^{2}$ e $67,4 \mathrm{~mm}^{2}$ respectivamente) [64]. A ligação entre o secundário do transformador ao barramento é feita com cabo isolado em XLPE (Polietileno Reticulado), seção de $50 \mathrm{~mm}^{2}$, para potências de $112,5 \mathrm{kVA}$. 

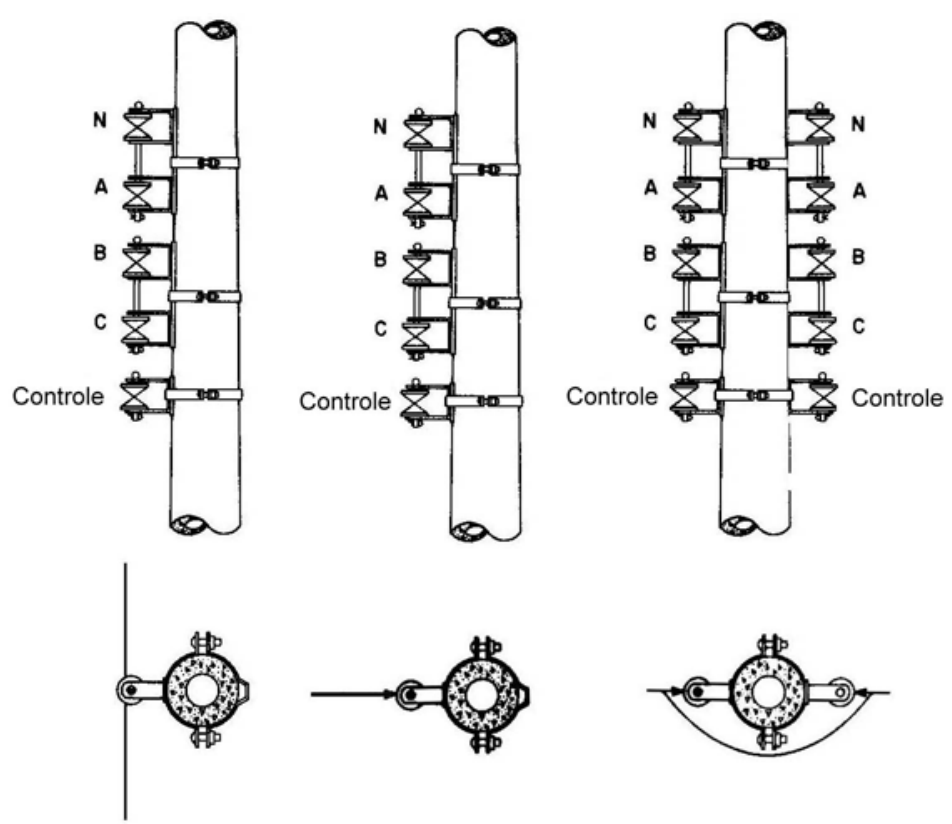

Fig. 4.7: Estruturas de montagem de redes secundárias convencionais (adaptada de [85]).

As linhas multiplexadas são formadas por um cabo mensageiro nu, que tem a função mecânica (sustentação) e elétrica (condutor neutro), e por cabos fase isolados e torcidos ao redor do mensageiro, conforme ilustrado na Figura 4.8. Os ramais de ligação são conectados à linha multiplexada por meio de "rabichos" conectados à rede. Os condutores fase são de alumínio $\mathrm{CA}$ isolados em polietileno reticulado $\left(\mathrm{XLPE}-90^{\circ} \mathrm{C}\right.$ ) para $0,6 / 1 \mathrm{kV}$ e o condutor mensageiro é de liga de alumínio (CAL liga 6201), geralmente nas seguintes formações:

- circuitos monofásicos: $2 \times 1 \times 35+35 \mathrm{~mm}^{2}$

$$
2 \times 1 \times 70+70 \mathrm{~mm}^{2}
$$

- circuitos trifásicos: $3 \times 1 \times 35+35 \mathrm{~mm}^{2}$

$$
\begin{aligned}
& 3 \times 1 \times 70+70 \mathrm{~mm}^{2} \\
& 3 \times 1 \times 120+70 \mathrm{~mm}^{2}
\end{aligned}
$$




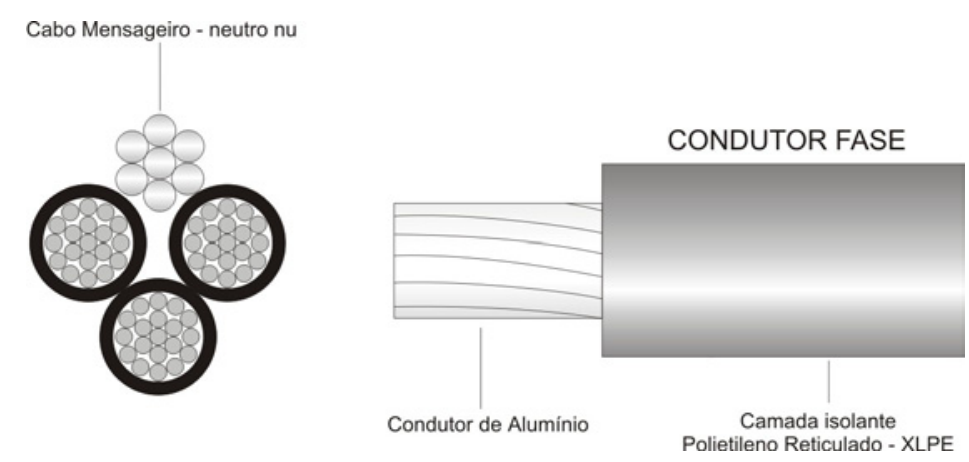

(a)

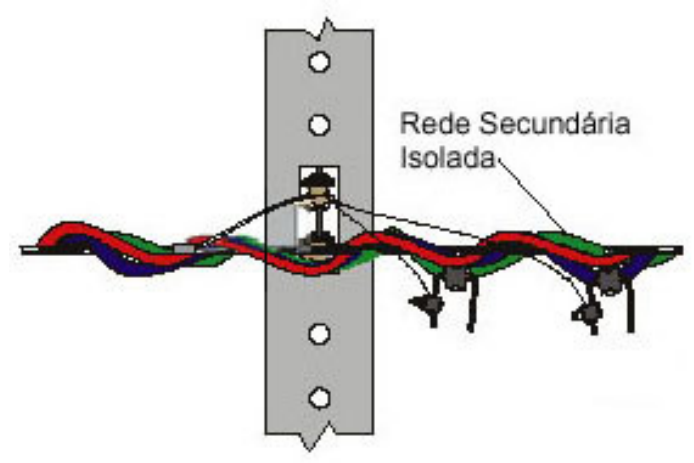

(b)

Fig. 4.8: Cabo multiplexado.

a) detalhe dos condutores [86].

b) detalhe da montagem do cabo no poste (adaptada de [72]).

O condutor neutro contínuo da rede de distribuição primária é comum à rede secundária, aterrado em intervalo padrão (multiaterrado) e interligado à malha de terra da subestação. A função do aterramento do condutor neutro e demais equipamentos elétricos é proteger as pessoas e os equipamentos, assegurando o bom funcionamento dos equipamentos de proteção do sistema elétrico [81]. A distância típica entre os intervalos de aterramento do neutro se encontra na faixa de $150 \mathrm{~m}$ a $300 \mathrm{~m}$. Para distâncias entre pontos de aterramento iguais a $300 \mathrm{~m}$, fica garantido que nenhum ponto da rede de distribuição secundária fique afastado mais que $200 \mathrm{~m}$ de um ponto de aterramento. Todo final de rede é aterrado. $\mathrm{O}$ valor máximo admissível da resistência do ponto de aterramento do neutro depende do local onde o aterramento está sendo feito. Em locais onde também se faz aterramentos de outros equipamentos, como por exemplo transformadores, equipamentos especiais, páraraios, etc., admite-se um valor máximo de resistência de terra menor que em locais 
onde se faz apenas o aterramento do neutro. Em regiões onde a rede não é blindada por estruturas, portanto mais sujeita a descargas atmosféricas, admite-se um valor máximo de resistência de terra menor que em locais menos sujeitas a descargas. Em geral cada companhia de energia elétrica adota os seus valores máximos de resistência de terra permitidos de acordo com cada caso. Os valores máximos admitidos se encontram tipicamente na faixa de $10 \Omega$ a $240 \Omega$, sendo adotados valores de resistência de terra mais baixos para locais ou equipamentos mais críticos. O aterramento é normalmente efetuado com uma ou mais hastes de aço-cobreada ("copperweld"), dependendo da resistência de terra desejada.

Nas redes urbanas, a alimentação dos consumidores em baixa tensão é feita através de um ramal de ligação, que compreende os condutores e acessórios instalados entre o ponto de derivação da rede da concessionária e o ponto de entrega de energia. Sua instalação e manutenção são de responsabilidade da concessionária. O comprimento máximo do ramal de ligação é, geralmente, de $30 \mathrm{~m}$, podendo chegar a $35 \mathrm{~m}$ em final de linha. A derivação do ramal de ligação é preferencialmente realizada nos postes, podendo ser utilizados tanto cabos isolados quanto cabos não isolados. A entrada do ramal da unidade consumidora possui um ponto de aterramento, onde são conectados o condutor neutro e a caixa metálica do medidor [83].

Uma das características das redes secundárias urbanas é a grande diversidade de configurações de montagem e traçado das linhas, uma vez que os loteamentos nem sempre obedecem a um padrão. As redes de baixa tensão são projetadas de modo a minimizar os custos anuais de investimento inicial, ampliações, modificações e perdas, dentro do horizonte do projeto (10 anos, normalmente). A máxima queda de tensão admitida na rede secundária é de $5 \%$ [68]. Para atender essas especificações, as redes secundárias são geralmente curtas (de 100 m a 400 m) e não interligadas. Em regiões com baixa demanda, uma linha mais longa é inicialmente construída, com previsão de secionamento no quinto ano, quando o limite dos condutores é atingido. Assim aumenta-se a capacidade da rede sem a substituição dos condutores previamente instalados [68]. As configurações típicas de redes secundárias urbanas são ilustradas na Figura 4.9. 
Em áreas rurais, as redes secundárias não possuem traçado como o indicado anteriormente. Como as cargas consumidoras são geralmente mais afastadas entre si, é efetuada uma derivação monofásica ou trifásica no ramal principal da rede primária, que se estende até o transformador de distribuição, sendo este instalado em um ponto mais próximo do centro da carga a ser alimentada [19].
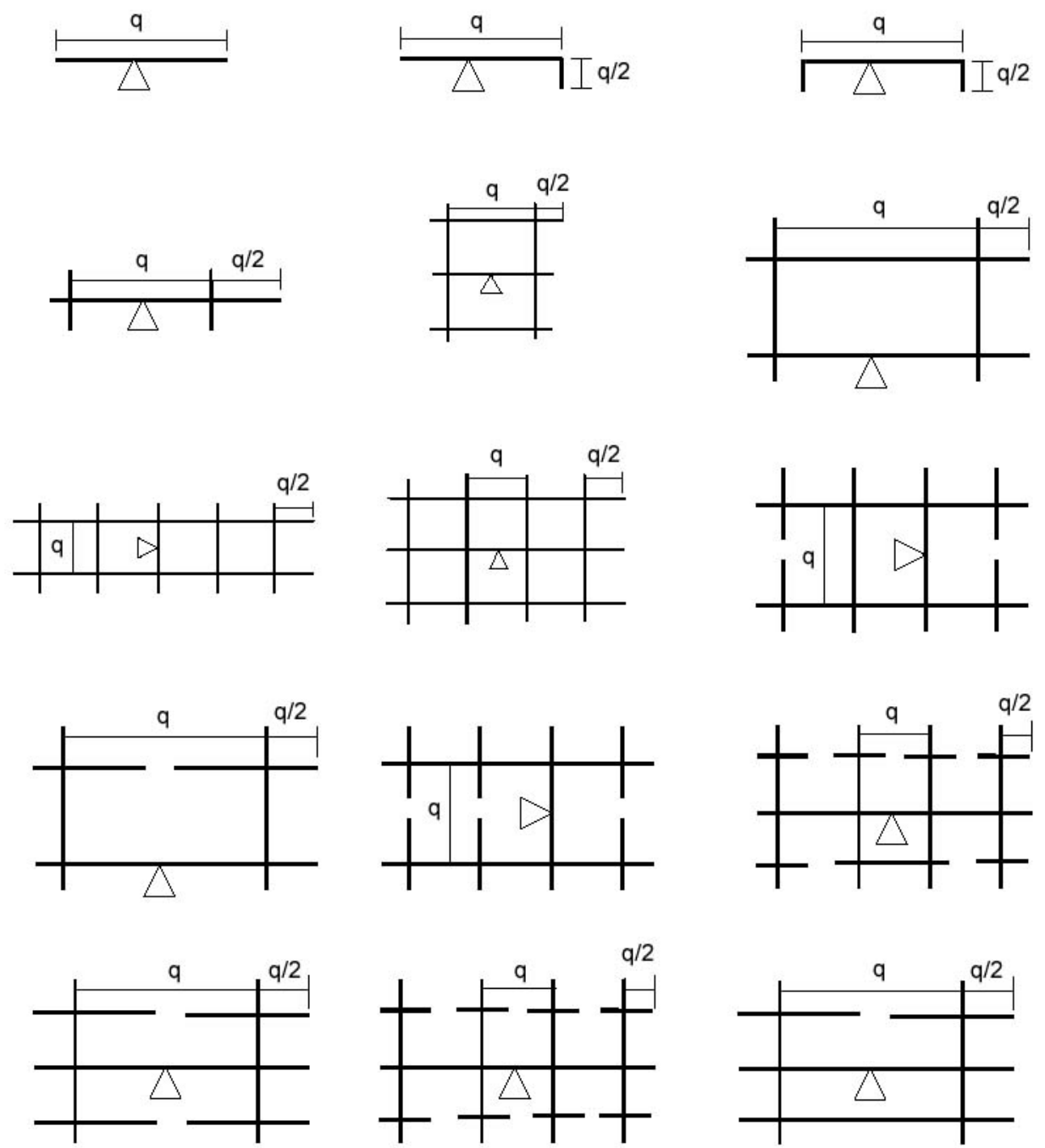

Fig. 4.9: Traçados típicos de rede secundária (adaptada de [65, 75]).

$(\Delta=$ transformador; $\mathrm{q}=100 \mathrm{~m})$ 


\subsection{Análise paramétrica}

Neste item são apresentados os resultados de uma análise paramétrica desenvolvida com o objetivo de avaliar as características das tensões induzidas na rede secundária em decorrência da incidência de descargas atmosféricas indiretas. Essa avaliação é realizada para redes convencionais e multiplexadas. Os dispositivos de proteção contra surtos (DPS) são analisados quanto à sua eficiência na redução das tensões induzidas nas linhas de BT. Os cálculos das tensões induzidas são inicialmente realizados para uma linha de distribuição secundária convencional simples monofásica, sem condutor neutro - tendo em vista o melhor entendimento do fenômeno. Posteriormente, as presenças do condutor neutro, do transformador de distribuição e das cargas dos consumidores são consideradas, com o objetivo de se definir um caso típico de rede de baixa tensão, denominado caso base, que é analisado no trabalho. A partir do caso base são analisados os efeitos dos principais parâmetros da linha e das descargas atmosféricas nas tensões induzidas.

\subsubsection{Rede convencional}

Conforme visto no item 4.2, a rede de baixa tensão convencional é formada por dois a quatro condutores nus (condutor neutro mais os condutores fase) montados verticalmente em isoladores cerâmicos. A rede de baixa tensão possui uma grande variedade de configurações, o que inviabiliza um estudo para todos os casos possíveis. Porém, é possível escolher uma determinada configuração que represente uma parcela significativa das redes instaladas. Assim, a partir dessa configuração básica, é realizada a análise paramétrica contemplando as principais variáveis de interesse em relação às tensões induzidas nas redes de baixa tensão.

\subsubsection{Definição do caso base}

A forma de onda e a amplitude da tensão induzida em uma linha de distribuição depende da configuração da rede e dos parâmetros da descarga atmosférica, como por exemplo, a amplitude, tempos de frente e de cauda da corrente, distância da 
descarga à linha etc. Uma linha monofásica, sem neutro e com comprimento infinito é a configuração mais simples possível para o cálculo de tensão induzida. É possível o cálculo de tensões induzidas em linhas de comprimento finito desde que o modelo matemático utilizado para tal considere as reflexões nas extremidades da linha, como no modelo ERM [25-28]. Nas simulações apresentadas a seguir são consideradas linhas de comprimentos finitos e "casadas", isto é, terminadas com um resistor de aterramento com resistência igual à impedância característica da linha. $\mathrm{O}$ uso de linhas "casadas" nas simulações facilita a análise dos resultados, uma vez que não ocorrem reflexões nas extremidades. Os efeitos de diferentes terminações da linha no local onde se efetuou o cálculo das tensões induzidas não são significativos quando são consideradas várias cargas ao longo da linha. Desta forma, as reflexões que porventura venham a ocorrer são devido às cargas e aos aterramentos ao longo do condutor neutro.

A Figura 4.10 apresenta a configuração de uma linha de baixa tensão monofásica sem neutro, com condutor de $1 \mathrm{~cm}$ de diâmetro instalado a uma altura $\mathbf{h}$ do solo, com $300 \mathrm{~m}$ de comprimento e casada em ambas as extremidades. Na ocorrência de uma descarga atmosférica a uma distância $\mathbf{d}$ igual a $50 \mathrm{~m}$ do ponto médio da linha, com amplitude de $45 \mathrm{kA}$ e forma de onda triangular com tempo de frente tf igual a $3 \mu \mathrm{s}$ e tempo até zero to igual a $150 \mu \mathrm{s}$, tensões são induzidas na medida que os campos eletromagnéticos chegam aos diversos pontos da linha. A combinação de todas as ondas de tensão em um determinado ponto de observação e instante de tempo (referente à corrente da descarga) resulta na tensão induzida total no local observado. O comprimento do canal da descarga foi adotado igual a $3 \mathrm{~km}$ e a velocidade de propagação da corrente no canal igual a $30 \%$ da velocidade da luz no vácuo. As tensões induzidas no ponto $\mathrm{P}$ para configuração indicada na Figura 4.10, considerando duas alturas do condutor, são apresentadas na Figura 4.11. Conforme observado na figura, a tensão induzida é diretamente proporcional à altura do condutor, uma vez que todos os demais parâmetros foram mantidos constantes. Para um condutor instalado a $6,8 \mathrm{~m}$ do solo a amplitude da tensão induzida foi de $141 \mathrm{kV}$, enquanto para o condutor instalado a $6,4 \mathrm{~m}$ foi de $133 \mathrm{kV}$. As formas de onda das tensões induzidas apresentam tempo de frente de aproximadamente $3 \mu$ s e tempo de 
cauda (50\% do valor de crista) de aproximadamente $5 \mu \mathrm{s}$. Vale observar que, nas condições das simulações, as tensões induzidas atingem o seu valor máximo aproximadamente no mesmo instante em que a amplitude da corrente de descarga é máxima.

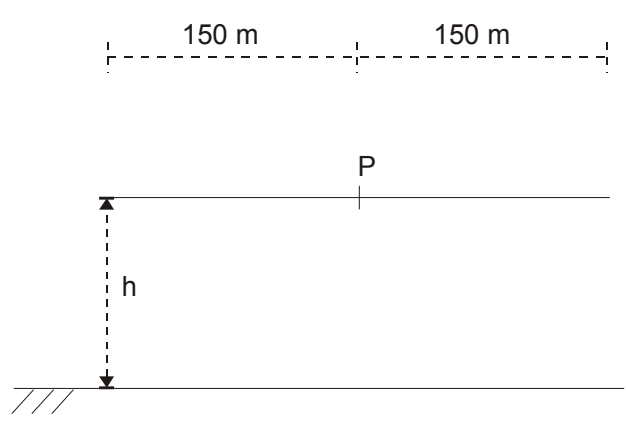

(a)

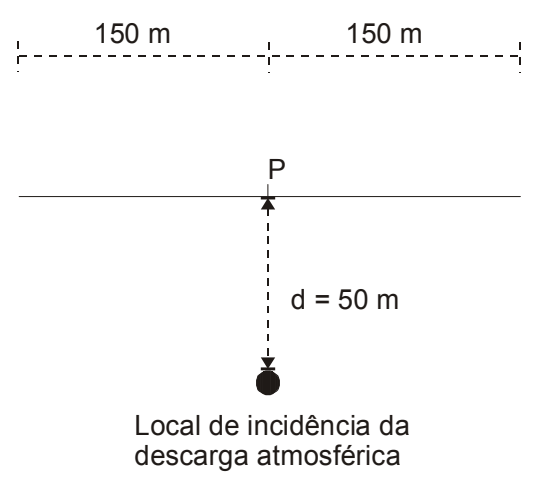

(b)

Fig. 4.10: Configuração da linha de baixa tensão monofásica sem neutro. $\mathrm{P}$ - Ponto de cálculo da tensão induzida.
a) vista lateral
b) vista superior

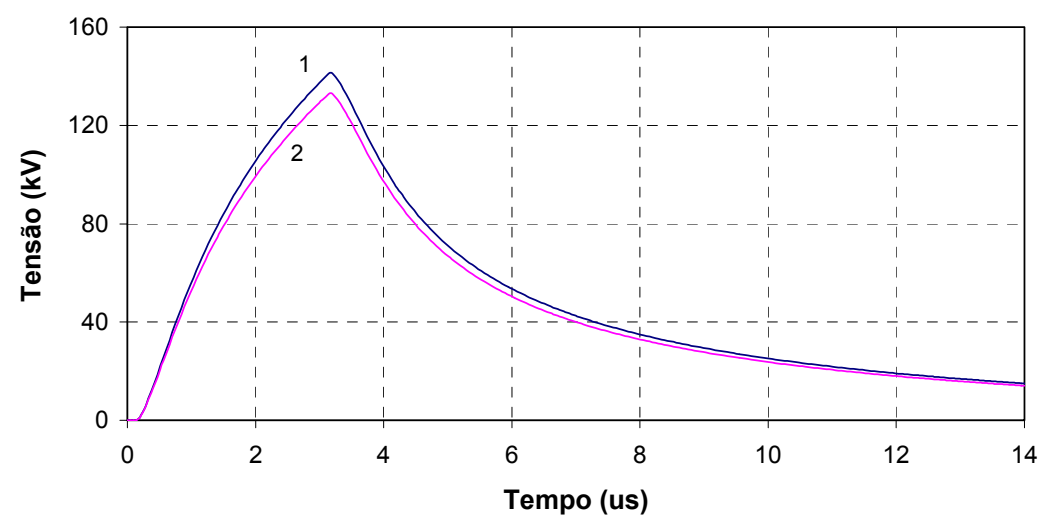

Fig. 4.11: Tensão induzida (fase-terra) no ponto P indicado na Fig. 4.10 para diferentes alturas do condutor

1- Condutor instalado a $6,8 \mathrm{~m}$ do solo $\quad 2$ - Condutor instalado a $6,4 \mathrm{~m}$ do solo

Considere-se agora uma linha com dois condutores, sendo um a $6,8 \mathrm{~m}$ do solo e outro a 6,4 m, conforme esquematizado na Figura 4.12. O condutor mais alto é aterrado no ponto central da linha e é denominado condutor neutro (n). O valor adotado para a resistência de terra no ponto de aterramento do condutor neutro é igual a $20 \Omega$ e a indutância do condutor de descida do aterramento do neutro foi considerada igual a 
17,5 $\mu \mathrm{H}$. O condutor fase é instalado abaixo do condutor neutro, com separação entre condutores igual a $40 \mathrm{~cm}$. Mantendo-se inalterados os demais parâmetros da linha e da descarga atmosférica foram calculadas as tensões induzidas no ponto P indicado na Figura 4.12 em ambos os condutores na ocorrência de uma descarga atmosférica no local indicado. As tensões induzidas calculadas no ponto $\mathrm{P}$ são mostradas na Figura 4.13.

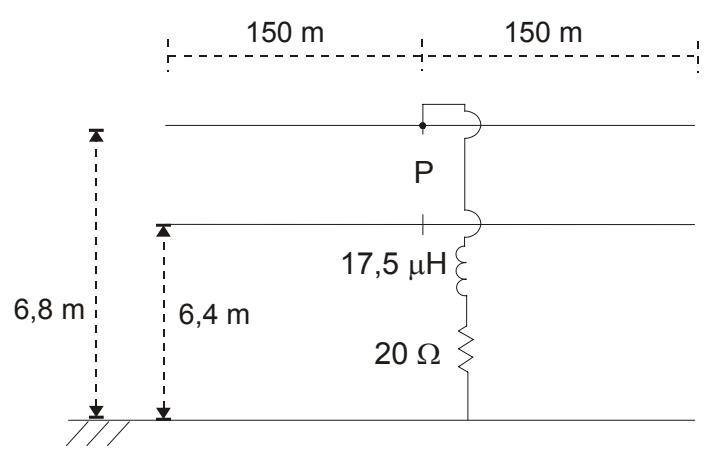

(a)

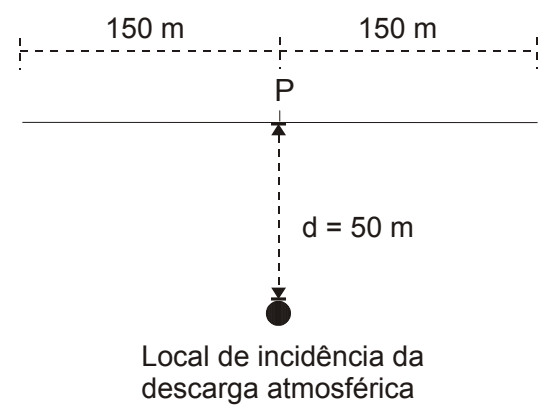

(b)

Fig. 4.12: Configuração da linha de baixa tensão - dois condutores, sendo o mais alto aterrado no ponto médio da linha.
a) vista lateral
b) vista superior

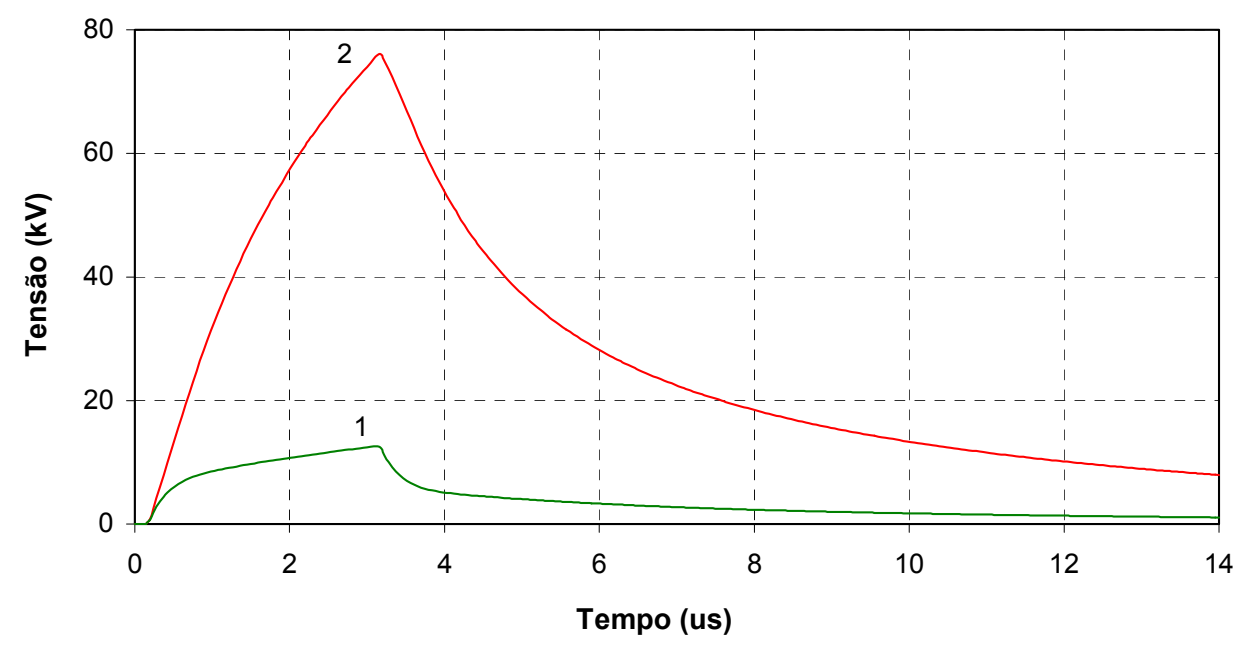

Fig. 4.13: Tensões em relação ao terra no ponto P para a configuração indicada na Fig. 4.12.

1- Condutor situado a $6,8 \mathrm{~m}$ do solo (condutor aterrado)

2- Condutor situado a $6,4 \mathrm{~m}$ do solo (sem ligação à terra) 
As amplitudes das tensões induzidas em relação ao terra foram de aproximadamente $12 \mathrm{kV}$ e $76 \mathrm{kV}$ nos condutores situados a $6,8 \mathrm{~m}$ e $6,4 \mathrm{~m}$ do solo, respectivamente. A tensão induzida no condutor a $6,8 \mathrm{~m}$ é significativamente reduzida (diferença de $91 \%$ ) quando comparada com um condutor não aterrado localizado à mesma altura (curva 1 na Figura 4.11). Isso ocorre devido à conexão do condutor ao solo através de uma baixa impedância de terra $(17,5 \mu \mathrm{H}$ em série com $20 \Omega)$, enquanto a impedância característica da linha é de aproximadamente $400 \Omega$. A tensão induzida (em relação ao terra) no condutor situado a $6,4 \mathrm{~m}$ do solo sofreu uma redução considerável (41\%) quando comparada com aquela relativa ao condutor de mesma altura sem a presença do condutor aterrado (curva 2 na Figura 4.11) devido ao acoplamento entre os condutores, fenômeno este demonstrado em [25]. A Figura 4.14 mostra a comparação das tensões induzidas nos condutores para as configurações indicadas nas Figuras 4.10 e 4.12. Como observado na Figura 4.14, os tempos de crista e cauda das tensões induzidas praticamente não sofreram alterações de uma configuração para outra.

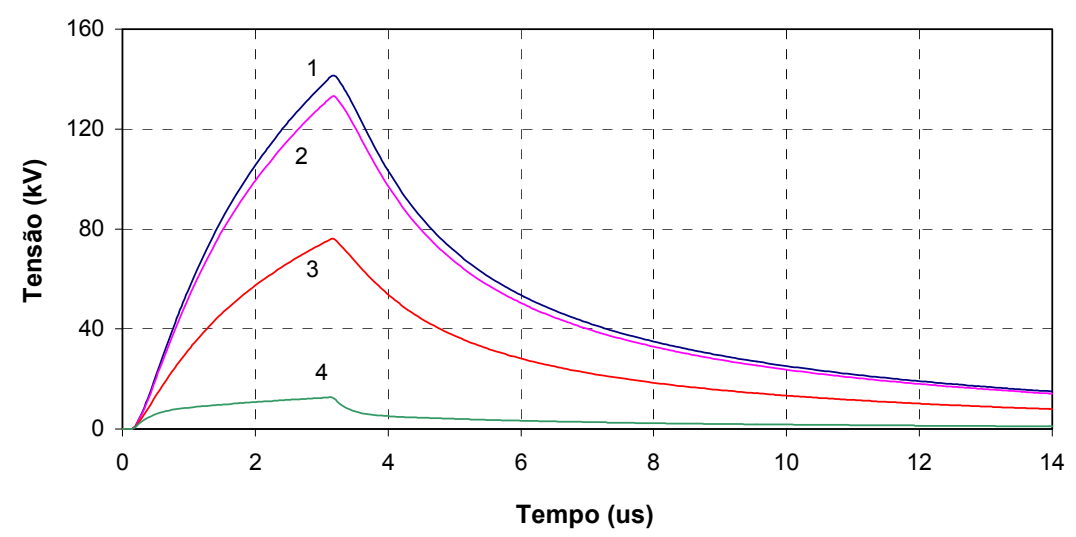

Fig. 4.14: Comparação entre as tensões induzidas em relação ao terra nas configurações mostradas nas Figuras 4.10 e 4.12.

1- Tensão no ponto $P$ em um condutor não aterrado a 6,8 $\mathrm{m}$ de altura (curva 1 na Fig. 4.11)

2- Tensão no ponto P em um condutor não aterrado 6,4 m de altura (curva 2 na Fig. 4.11)

3- Tensão no ponto $\mathrm{P}$ em um condutor não aterrado a $6,4 \mathrm{~m}$ de altura na presença de um condutor aterrado a 6,8 $\mathrm{m}$ de altura (curva 2 na Fig. 4.13)

4- Tensão no ponto $\mathrm{P}$ em um condutor aterrado a 6,8 $\mathrm{m}$ de altura (curva 1 na Fig. 4.13) 
A rede de distribuição em baixa tensão é alimentada por um transformador que é geralmente instalado no centro da linha ou da rede, conforme mostrado na Figura 4.9. Em relação aos surtos na rede de BT provocados por descargas indiretas, o secundário do transformador se comporta como uma carga para a linha e sua influência deve ser considerada na avaliação das tensões induzidas na linha. Em [8] o secundário do transformador foi representado por uma indutância de $10 \mu \mathrm{H}$ entre os condutores fase e neutro que, segundo o autor do trabalho, pode representar a impedância de saída de um transformador de distribuição típico. Em [20, 21, 24, 29 32] o GATDA desenvolveu uma metodologia para modelagem de transformadores de distribuição para altas freqüências na condição de carga. Nesses trabalhos, foram desenvolvidos modelos de transformadores de distribuição trifásicos com potências de $30 \mathrm{kVA}, 45 \mathrm{kVA}, 75 \mathrm{kVA}, 112,5 \mathrm{kVA}$ e $225 \mathrm{kVA}$, sendo o modelo do transformador de potência igual a $30 \mathrm{kVA}$ apresentado na Figura 3.12.

Com o objetivo de avaliar a influência do transformador de distribuição nas tensões induzidas nas redes de BT, foi realizada uma simulação considerando a presença do mesmo instalado no centro de uma linha, conforme esquematizado na Figura 4.15. A impedância de saída dos modelos dos transformadores desenvolvidos pelo GATDA apresentam grande concordância com a respectiva impedância medida em laboratório. Verificou-se também que essa impedância pode ser representada através de um circuito RLC paralelo. No caso do transformador de $30 \mathrm{kVA}$, os valores determinados para os parâmetros foram: $\mathrm{R}=1100 \Omega, \mathrm{L}=48 \mu \mathrm{H}$ e $\mathrm{C}=0,76 \mathrm{nF}$. A comparação entre os módulos da impedância de saída do transformador e do circuito simplificado é mostrada na Figura 4.16. Observa-se que o circuito RLC paralelo pode substituir o modelo do transformador na representação da impedância do mesmo vista pela linha de BT. 


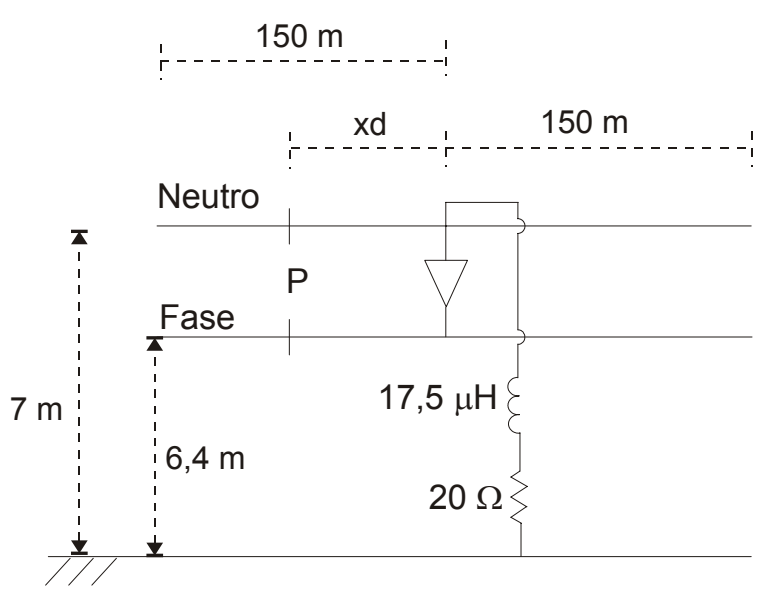

(a)

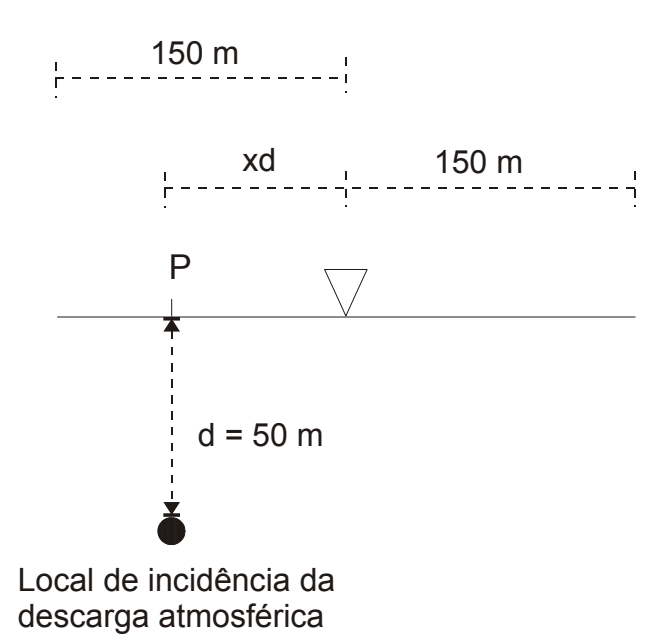

(b)

Fig. 4.15: Configuração da linha de baixa tensão com transformador de $30 \mathrm{kVA}$. $\nabla$ - transformador.

a) vista lateral

b) vista superior

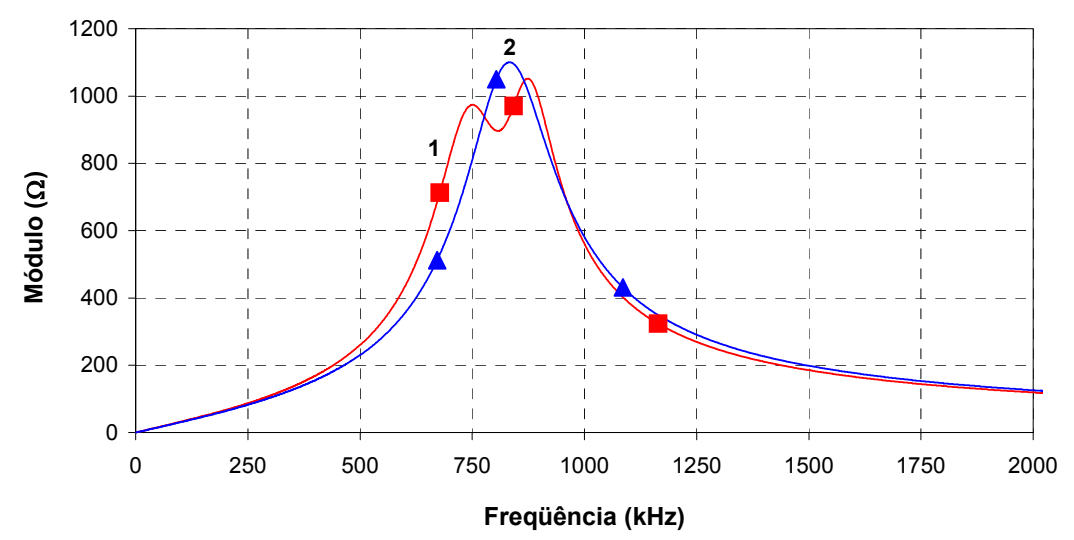

Fig. 4.16: Módulo das impedâncias de saída do modelo de transformador de 30 kVA e do circuito RLC paralelo utilizado como aproximação.

1 - Impedância de saída do modelo de transformador de 30 kVA.

2 - Impedância do circuito RLC paralelo.

As tensões induzidas no ponto $\mathrm{P}$ indicado na Figura 4.15, para o caso de $\mathrm{xd}=0 \mathrm{~m}$, com e sem transformador no ponto central da linha são mostradas na Figura 4.17. Nas simulações o transformador (quando existente) foi modelado através do circuito simplificado e os demais parâmetros da linha e da corrente da descarga não foram alterados. 


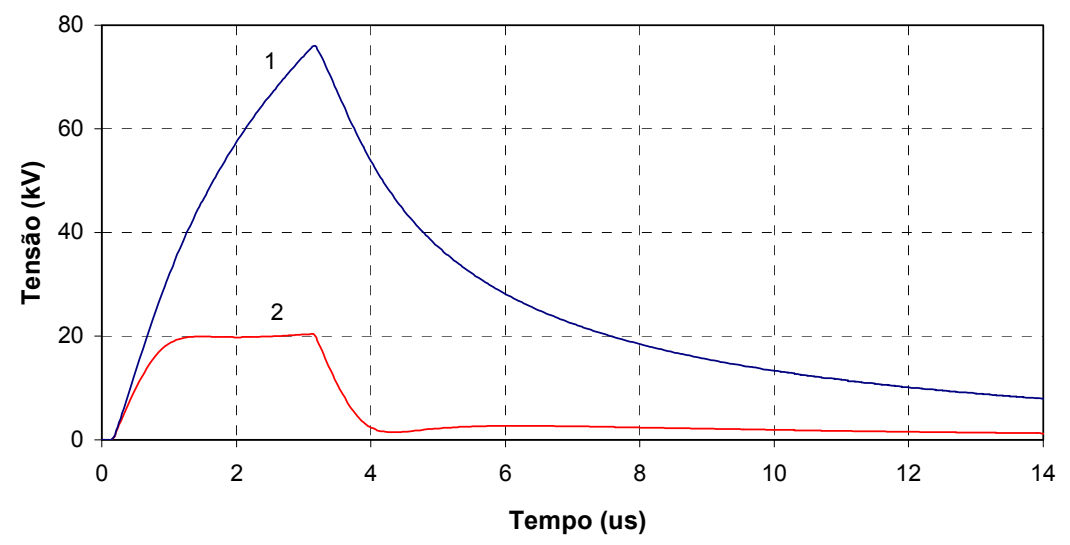

(a)

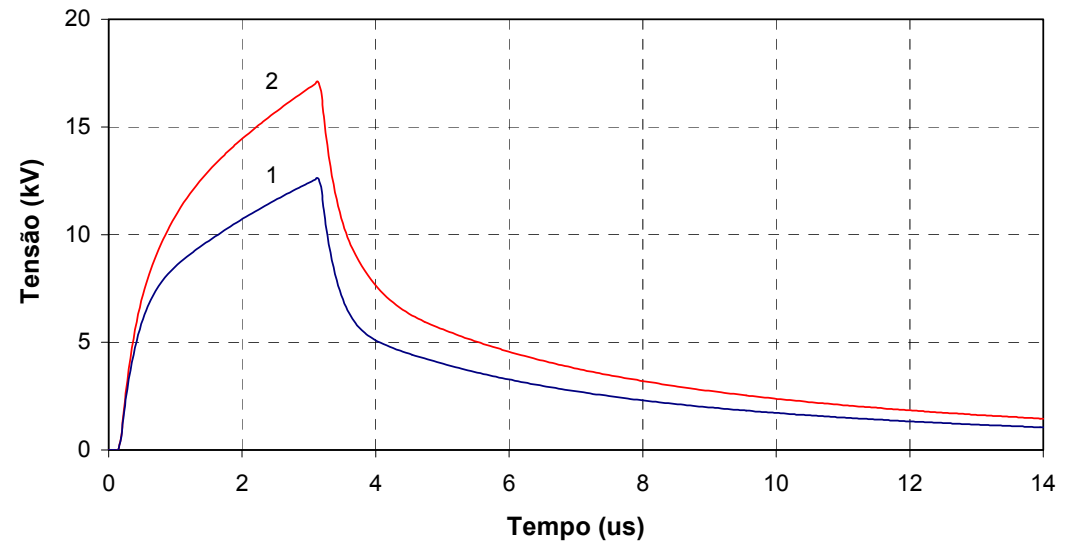

(b)

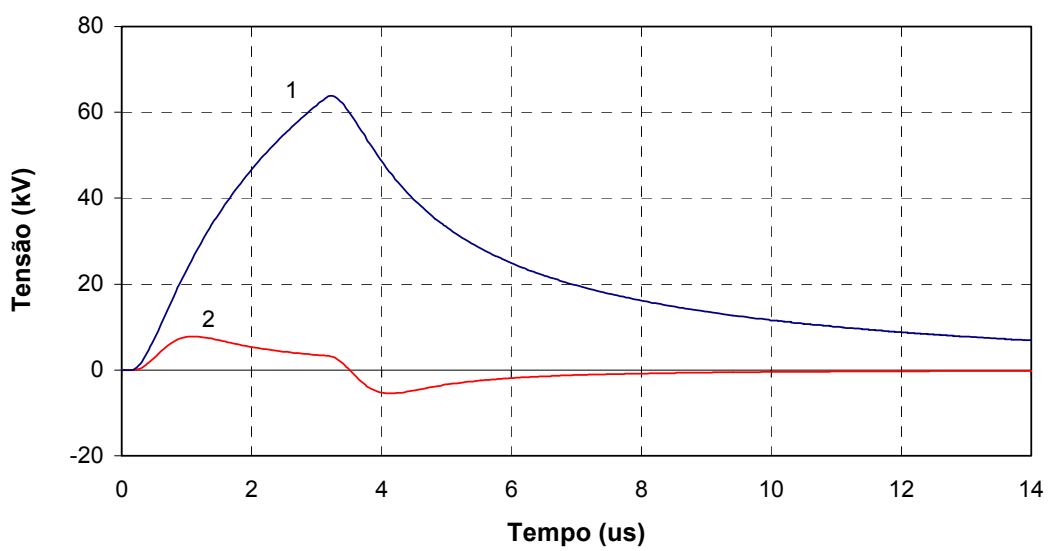

(c)

Fig. 4.17: Tensões induzidas no ponto $\mathrm{P}$ indicado na Figura 4.15 para $\mathrm{xd}=0 \mathrm{~m}$. 1 - Linha sem transformador 2 - Linha com transformador
a) tensões fase-terra
b) tensões neutro-terra
c) tensões fase-neutro 
Quando se considera a presença do transformador, a amplitude da tensão induzida fase-terra é reduzida a $20 \mathrm{kV}$ e apresenta a forma de onda indicada na Figura 4.17-a. A amplitude e forma de onda da tensão fase-terra é função da carga conectada entre os condutores fase e neutro, dos parâmetros da linha e da corrente de descarga (tempo de frente, cauda, local de incidência etc.). Enquanto a tensão fase-terra diminuiu com a adição do transformador à linha, a tensão neutro-terra sofreu uma elevação em relação ao caso anterior, como mostrado na Figura 4.17-b. Isso ocorreu porque a ligação entre os dois condutores através da impedância do transformador tende a aproximar os potenciais dos mesmos, reduzindo dessa forma os valores das tensões fase-neutro, principalmente nos pontos próximos ao transformador. A comparação das tensões fase-neutro com e sem o transformador instalado na linha é mostrada na Figura 4.17-c. Observa-se que a tensão fase-neutro no ponto $\mathrm{P}$ apresenta uma incursão negativa quando se considera o transformador na linha.

Como indicado na Figura 4.15, as tensões induzidas mostradas anteriormente foram calculadas na linha no local onde o transformador é instalado $(\mathrm{xd}=0 \mathrm{~m})$. Outra situação a ser analisada é a tensão induzida na linha a uma distância $\mathrm{xd}=100 \mathrm{~m}$ do transformador, mantendo-se todos os parâmetros restantes inalterados. As tensões induzidas na linha, calculadas no ponto P, são comparadas na Figura 4.18 para os casos de $x d=0 \mathrm{~m}$ e $x d=100 \mathrm{~m}$. Na Figura 4.18-a são comparadas as tensões faseterra para as configurações citadas. No ponto P a $100 \mathrm{~m}$ do transformador, a tensão fase-terra apresenta amplitude maior que aquela referente ao caso do ponto $\mathrm{P}$ próximo ao transformador $(\mathrm{xd}=0 \mathrm{~m})$. Isso ocorre porque no caso em que $\mathrm{xd}=100 \mathrm{~m}$, a tensão induzida é observada em um ponto onde não existe ligação entre os condutores fase e neutro. As tensões nos condutores neutros (tensões neutroterra) nos dois casos têm comportamentos semelhantes, conforme pode ser observado na Figura 4.18-b. Como o condutor neutro está situado em uma altura superior ao condutor fase, a tensão sobe mais rapidamente (taxa de crescimento maior) que a tensão no condutor fase, até que os efeitos da presença do transformador e do aterramento do condutor neutro sejam "sentidos" no ponto de cálculo da tensão induzida $(x d=100 \mathrm{~m})$. Nesse instante ocorre uma variação brusca da tensão no 
condutor neutro. Como a variação da tensão no condutor fase é menor, esta acaba por superar aquela.

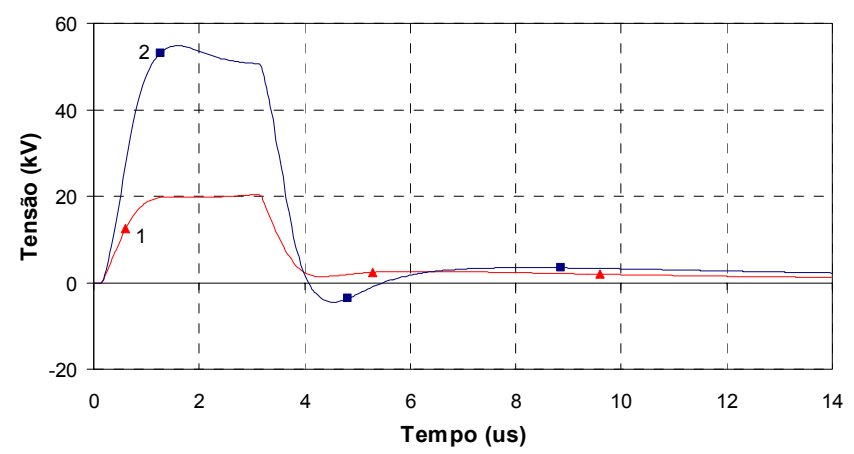

(a)

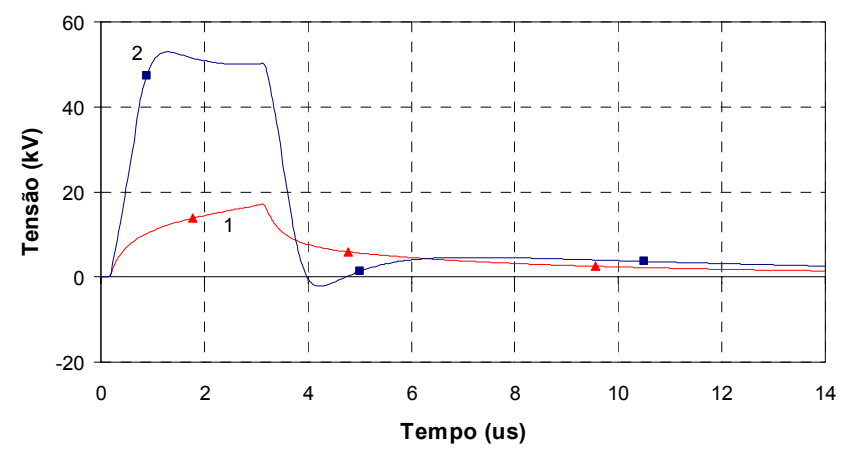

(b)

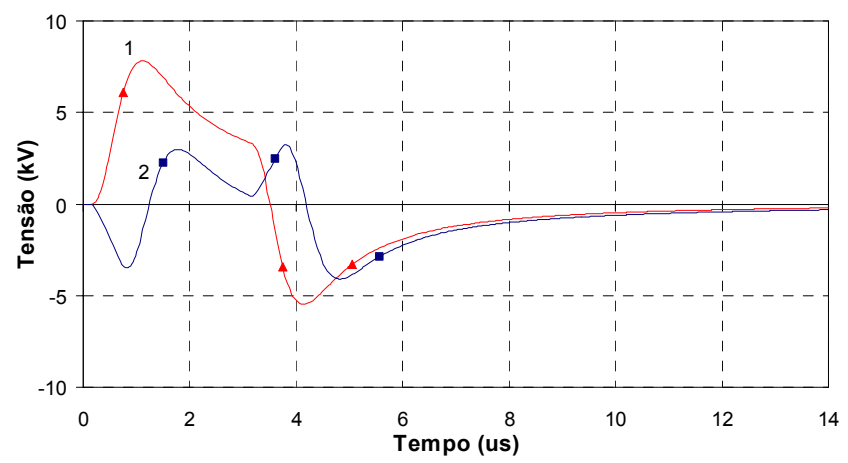

(c)

Fig. 4.18: Tensões induzidas no ponto $P$ indicado na Figura 4.15.

$$
1-\mathrm{xd}=0 \mathrm{~m} \quad 2-\mathrm{xd}=100 \mathrm{~m}
$$
a) tensões fase-terra
b) tensões neutro-terra
c) tensões fase-neutro

O tempo para que os efeitos do transformador e do aterramento do condutor neutro comecem a chegar no ponto de cálculo da tensão induzida é o tempo de propagação da onda de tensão do ponto de aterramento ao local de observação da tensão 
induzida. A tensão fase-neutro para $\mathrm{xd}=100 \mathrm{~m}$, indicada na Figura 4.18-c, é negativa nos instantes iniciais fato de a amplitude da tensão no condutor neutro ser maior que a do condutor fase, devido à sua maior altura e à distância do ponto $\mathrm{P}$ ao ponto de aterramento do condutor neutro. No instante de tempo igual a $3 \mu \mathrm{s}$, a corrente de descarga atinge o seu pico e começa a cair. Assim, como a taxa de crescimento da tensão induzida no condutor neutro é maior que a do condutor fase nos instantes iniciais (devido à maior altura do condutor), ela decresce mais rapidamente (maior taxa de decrescimento) que no condutor fase. Esse efeito pode ser observado pela elevação da tensão induzida fase-neutro quando $\mathrm{xd}=100 \mathrm{~m}$ nos instantes entre $3 \mu$ s e 3,6 $\mu$ s na Figura 4.18-c.

A rede de baixa tensão alimenta as cargas dos consumidores, cuja modelagem é complexa em virtude da grande diversidade de cargas existentes em uma instalação de baixa tensão. Em [8] foi realizado um estudo do comportamento da impedância de uma determinada instalação consumidora em função da freqüência, cujo modelo encontrado para a unidade avaliada é mostrado na Figura 2.6-a (sistema TN). Segundo o autor do trabalho, esse modelo pode ser aproximado por um indutor de 3,5 $\mu \mathrm{H}$. Os consumidores são conectados à linha de BT por meio de um ramal de ligação cuja impedância deve ser levada em conta. Considerando um ramal com $40 \mathrm{~m}$ de comprimento, a impedância associada ao seu condutor fase pode ser representada por uma indutância de $50 \mu \mathrm{H}$, considerando os valores típicos de indutância por unidade de comprimento indicados em [87]. Nas simulações em que se considerou a presença de cargas, foi adotada a aproximação indicada na Figura 4.19 (para o caso de uma única carga), onde o transformador (instalado no centro da linha) é representado pelo circuito RLC paralelo citado anteriormente e os potenciais do condutor neutro na saída do ramal e na carga são iguais. 


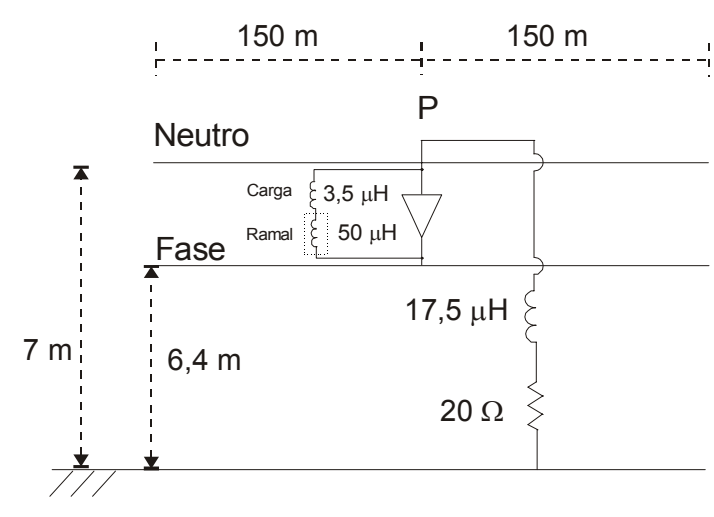

(a)

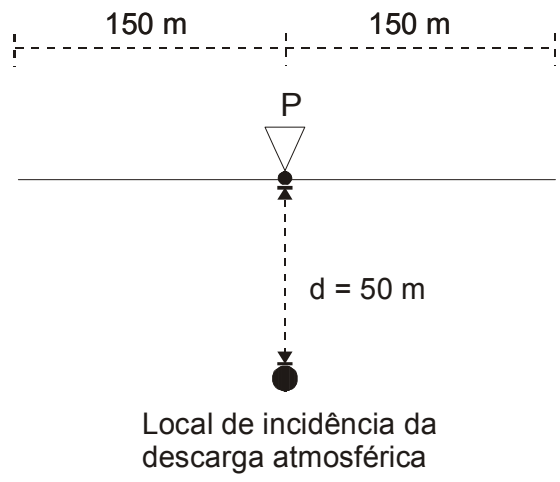

(b)

Fig. 4.19: Configuração da linha de BT considerado transformador e carga no mesmo ponto.

$$
\nabla \text { - transformador }
$$

a) vista lateral
- - carga

b) vista superior

As tensões induzidas calculadas no ponto P indicado na Figura 4.19, para os casos com e sem carga em paralelo ao transformador, são indicadas na Figura 4.20. Como pode-se observar, a adição de uma carga de 3,5 $\mu \mathrm{H}$ na linha (considerando também o ramal de ligação) provocou uma redução da amplitude da tensão induzida fase-terra no ponto onde o transformador e a carga são instalados. Isso ocorre devido à menor impedância entre os condutores fase e neutro. A tensão neutro-terra (não mostrada nesse caso) praticamente não sofre variação com a adição da carga na linha. A amplitude e forma de onda da tensão fase-neutro é mostrada na Figura 4.20-b. Nesse caso, conclui-se que a modelagem do transformador e da carga consumidora (incluindo o ramal de ligação) tem papel importante quanto às amplitudes e formas de onda das tensões induzidas nas redes de baixa tensão. 


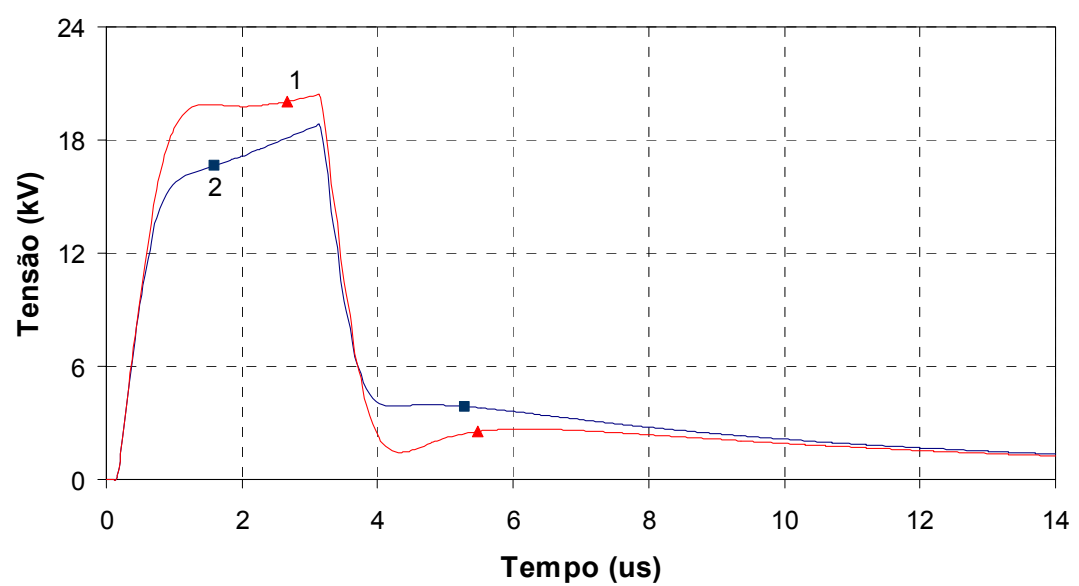

(a)

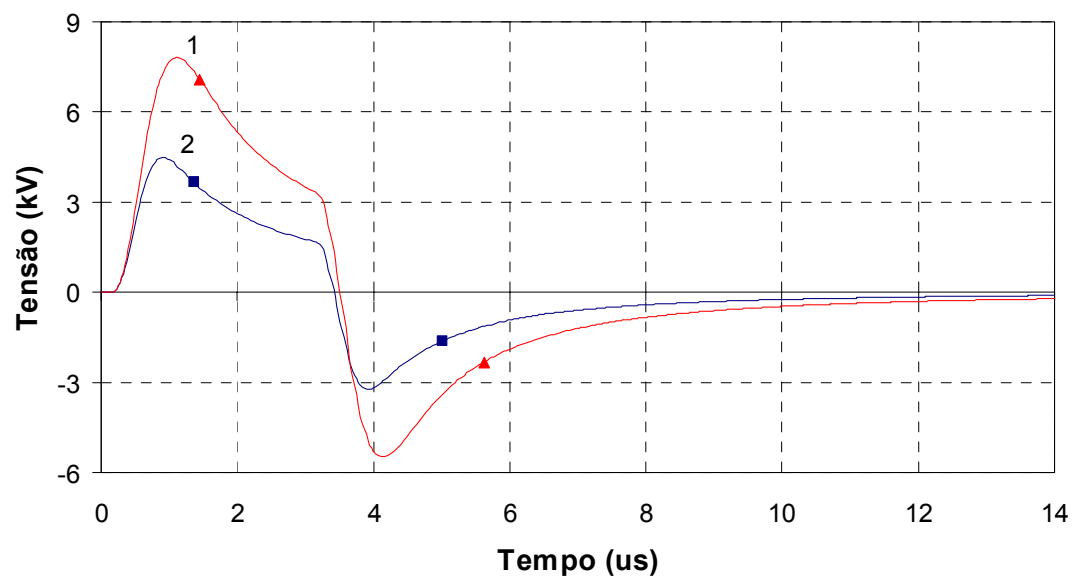

(b)

Fig. 4.20: Tensões induzidas no ponto $\mathrm{P}$ indicado na Figura 4.19.

1- Linha sem carga 2- Linha com carga no ponto central
a) tensões fase-terra
b) tensões fase-neutro

Em outra situação considerada, verificou-se o comportamento das tensões induzidas quando se considera na linha apenas uma carga indutiva (como respectivo ramal de ligação), representada por uma indutância de 3,5 $\mu \mathrm{H}$, desprezando-se a impedância do secundário do transformador indicado na Figura 4.19. As tensões induzidas no ponto P da Figura 4.19, sem e com a presença do transformador, são apresentadas na Figura 4.21. Todos os parâmetros restantes da linha e da corrente de descarga foram mantidos inalterados, variando apenas a carga conectada entre a fase e o neutro no ponto de cálculo da tensão induzida. 


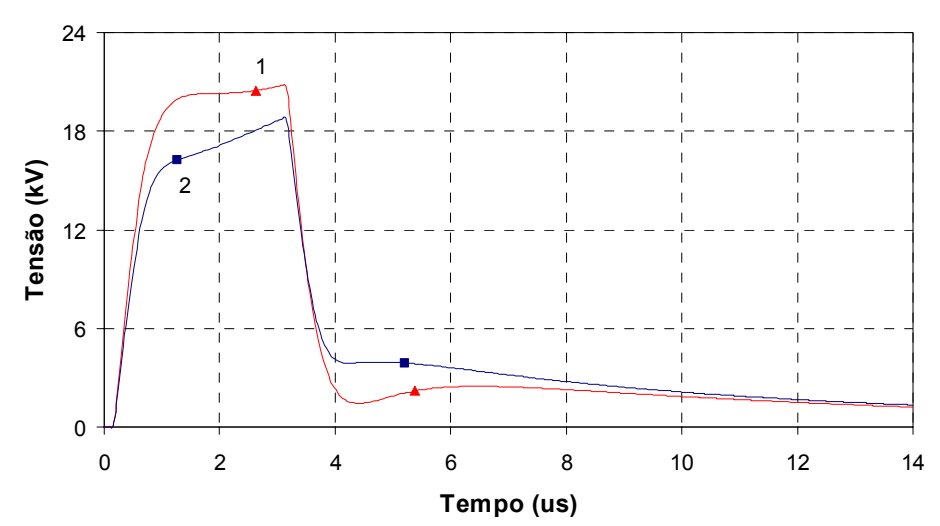

(a)

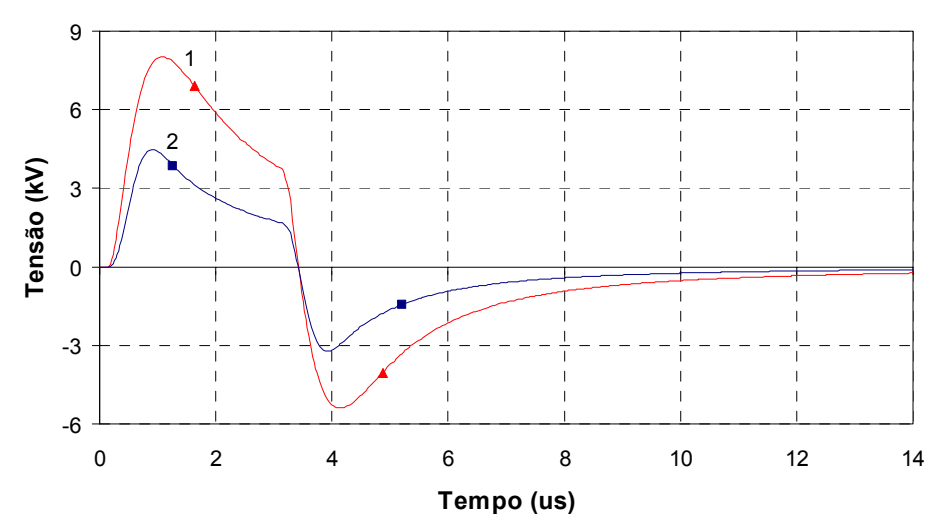

(b)

Fig. 4.21: Tensões induzidas no ponto P indicado na Figura 4.19.

1 - Linha apenas com carga (sem transformador)

2 - Linha com transformador e carga

a) tensões fase-terra

b) tensões fase-neutro

As amplitudes das tensões induzidas fase-terra e fase-neutro mostraram-se superiores às respectivas tensões calculadas no caso anterior, em que se tem carga em paralelo com transformador. Isso é explicado porque a amplitude e forma de onda dessas tensões são fortemente dependentes do valor e tipo de carga. Como neste caso a carga apresenta impedância maior que no caso anterior, as tensões induzidas apresentam amplitudes maiores. A tensão neutro-terra praticamente não sofreu alterações, tanto em amplitude quanto em forma de onda. Verificou-se também que, comparando as tensões fase-terra e fase-neutro na configuração indicada na Figura 4.19 considerando linha somente com transformador ou somente com carga, as tensões são praticamente iguais. Essa similaridade também foi observada quando se repetiu essa comparação para uma corrente de descarga com tempo de frente mais curto $-1 \mu \mathrm{s}-$, com os valores dos demais parâmetros idênticos às simulações 
anteriores. O resultado dessa nova comparação é apresentado na Figura 4.22, onde é possível observar que as tensões induzidas apresentam taxas de crescimento e decaimento mais altas que na comparação anterior (Fig. 4.21). Mesmo nesse caso, em que os espectros de freqüências das tensões induzidas possuem mais componentes de altas freqüências, as tensões induzidas na linha considerando somente $\mathrm{o}$ transformador foram muito próximas às tensões induzidas na linha somente com carga indutiva de $3,5 \mu \mathrm{H}$ (considerando também a indutância de $50 \mu \mathrm{H}$ do ramal de ligação). Conclui-se então que, para efeito de simulação, o modelo do transformador pode ser substituído por uma carga de $53,5 \mu \mathrm{H}$. Esse resultado facilita as simulações de linhas de baixa tensão levando-se em conta o efeito das cargas e do transformador.

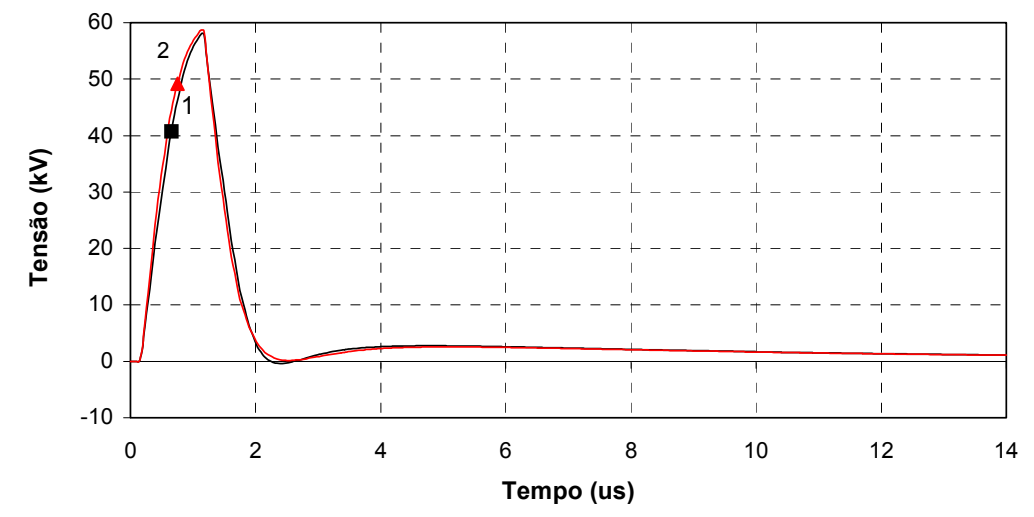

(a)

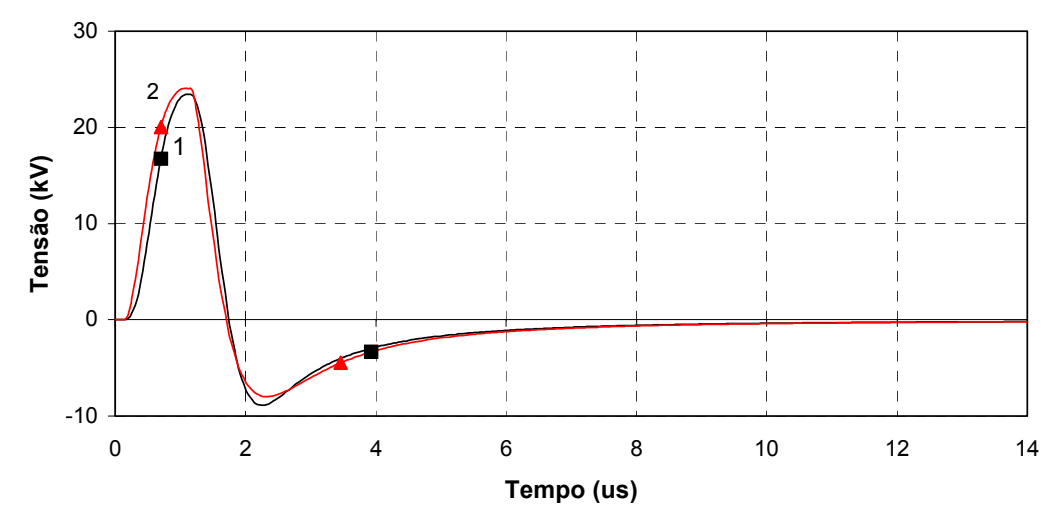

(b)

Fig. 4.22: Tensões induzidas no ponto $P$ indicado na Figura 4.19. Considerando a corrente da descarga com tempo de frente $\mathrm{tf}=1 \mu \mathrm{s}$.

1 - Linha apenas com transformador

a) tensões fase-terra
2 - Linha apenas com carga

b) tensões fase-neutro 
As cargas utilizadas nas simulações anteriores (indutor de $3,5 \mu \mathrm{H}$ ) são uma aproximação do modelo da carga avaliada em [8] e sugeridas pelo próprio autor do trabalho. Na simulação apresentada a seguir, é considerada a configuração de linha indicada na Figura 4.23, sendo a carga representada através do circuito mostrado na Figura 2.26-a. Assim, como nos casos anteriores, a indutância do ramal de ligação $(50 \mu \mathrm{H})$ também é levada em consideração. Os demais parâmetros são idênticos aos das simulações anteriores, sendo o tempo de frente da corrente da descarga igual a $3 \mu \mathrm{s}$.

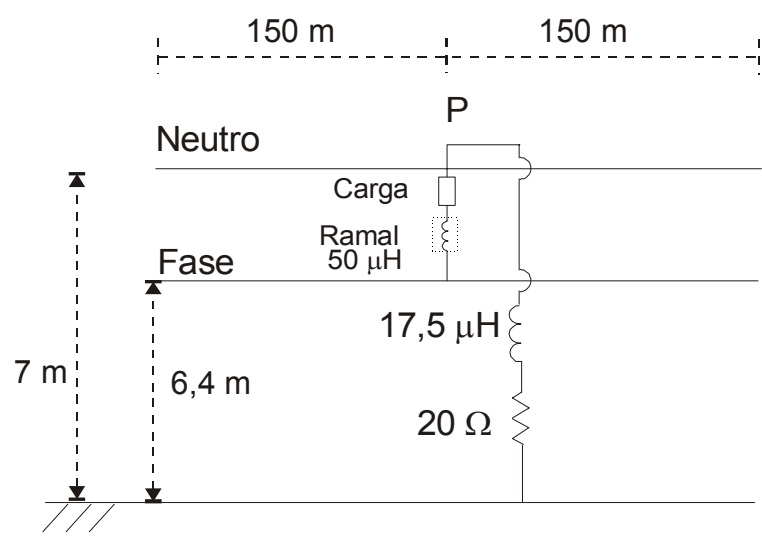

(a)

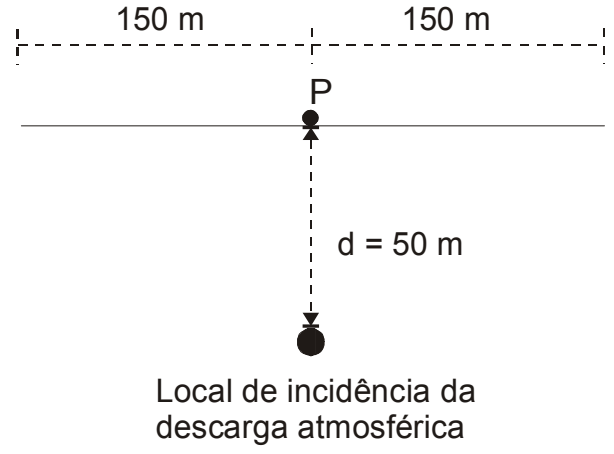

(b)

Fig. 4.23: Configuração da linha para diferentes modelos de carga. • - carga.
a) vista lateral
b) vista superior

A comparação entre as tensões induzidas na linha, considerando as representações completa e simplificada para a carga é feita na Figura 4.24. Como visto, para a situação analisada a adoção do modelo mais completo para a carga da instalação consumidora não leva a grandes diferenças nas amplitudes e formas de onda das tensões induzidas. É possível que, para uma outra condição da linha (resistência de terra, comprimento, etc.) ou da corrente de descarga (como o tempo de frente), maiores diferenças nas tensões induzidas possam ser encontradas. De qualquer modo, nas simulações realizadas deste ponto em diante utilizou-se o modelo mais apurado (circuito indicado na Figura 2.6-a) para a carga da instalação consumidora. 


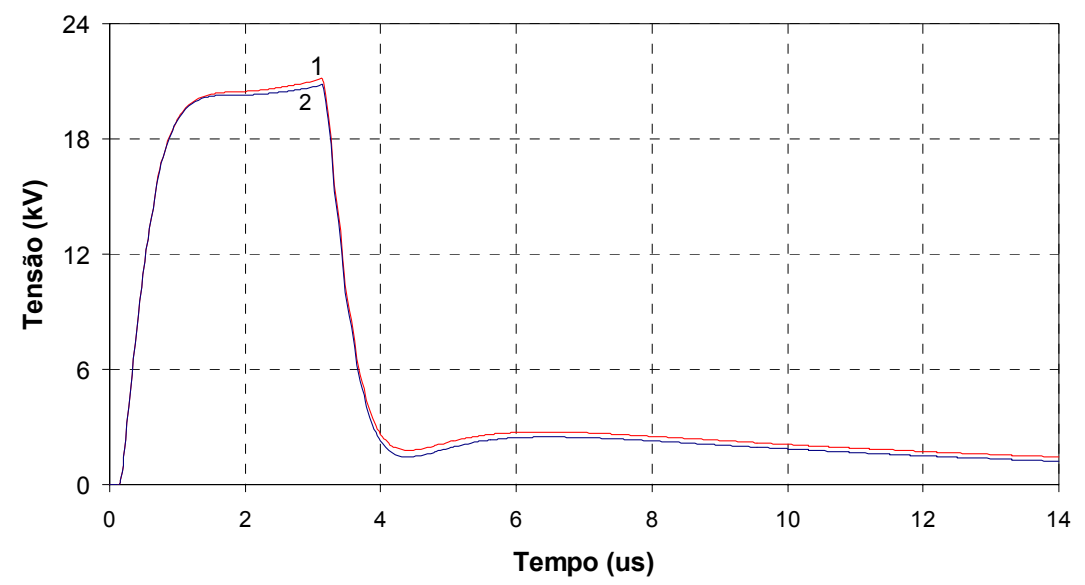

(a)

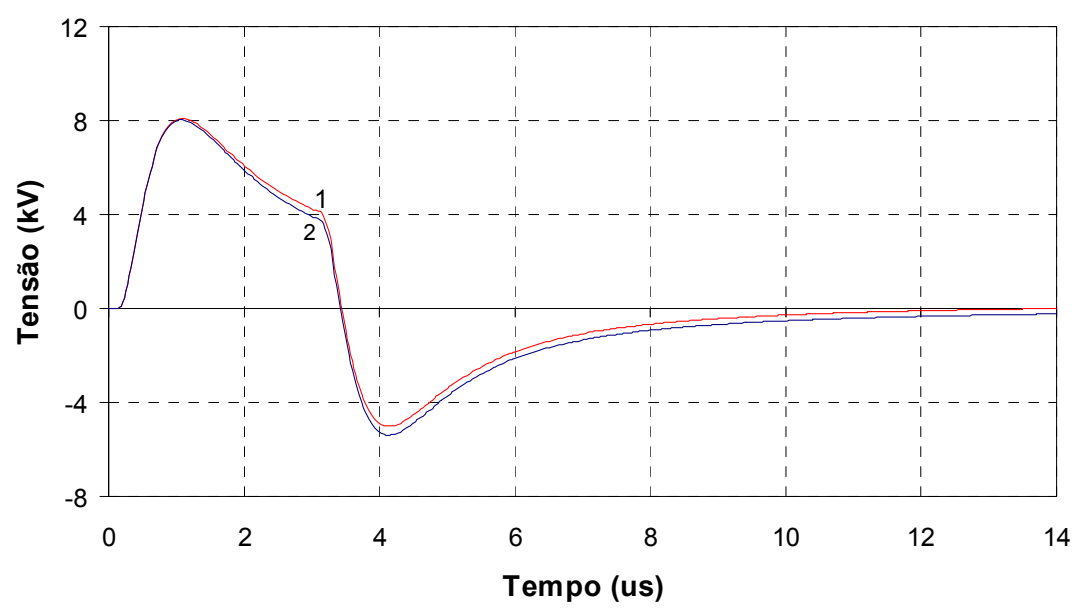

(b)

Fig. 4.24: Comparação entre tensões induzidas na configuração mostrada na Fig. 4.23 para diferentes tipos de carga.

1 - Carga indicada na Fig. 2.26-a 2 - Carga simplificada (indutor de 3,5 $\mu \mathrm{H}$ )
a) tensões fase-terra
b) tensões fase-neutro

A partir das simulações anteriores definiu-se a configuração básica da linha a ser utilizada na análise paramétrica das tensões induzidas. Essa configuração, denominada Caso Base, é mostrada na Figura 4.25. A linha tem $300 \mathrm{~m}$ de comprimento, um transformador (modelado através de uma indutância de 53,5 $\mu \mathrm{H}$ ) no centro e 4 cargas consumidoras espaçadas de $60 \mathrm{~m}$. É considerada a indutância do ramal de ligação concentrada entre o terminal fase da carga e o condutor fase da linha. O aterramento do condutor neutro é efetuado em todos os pontos onde estão conectadas as cargas e o transformador. A altura do condutor neutro foi fixada em 
7,0 m e o condutor fase, no Caso Base, em 6,8 m. Os parâmetros restantes da linha são mantidos inalterados, assim como a localização, amplitude e forma de onda da corrente de descarga, sendo listados a seguir:

- amplitude da corrente de descarga I igual a $45 \mathrm{kA}$;

- tempo de frente tf da corrente de descarga igual a $3 \mu \mathrm{s}$;

- tempo até o zero to da corrente de descarga igual a $150 \mu \mathrm{s}$;

- distância entre pontos de aterramento do neutro xat igual a $60 \mathrm{~m}$ (coincidente com a separação entre cargas/carga-transformador);

- resistência de terra do neutro rat igual a $20 \Omega$;

- altura do condutor neutro hg igual a $7 \mathrm{~m}$;

- altura do condutor fase $\mathbf{h}$ igual a $6,8 \mathrm{~m}$;

- distância entre o ponto de cálculo da tensão induzida na linha e o ponto de aterramento do neutro mais próximo $\mathbf{x d}=0 \mathrm{~m}$;

- distância entre o ponto de cálculo da tensão induzida e o ponto da linha mais próximo ao local de incidência da descarga atmosférica $\mathbf{x}=0 \mathrm{~m}$;

- razão entre a velocidade de propagação da onda de corrente no canal de descarga e a velocidade da luz no vácuo $\mathbf{b}=0,3$;

- comprimento do canal de descarga igual a $3 \mathrm{~km}$;

- indutância do ramal de ligação igual a $50 \mu \mathrm{H}$.

Na Figura 4.26 são mostradas as tensões induzidas calculadas no ponto P indicado na Figura 4.25. Neste caso, todas as amplitudes foram reduzidas quando comparadas com as tensões obtidas na configuração de linha apresentada na Figura 4.23 (e mostradas na Fig. 4.24). Observa-se também que as tensões possuem característica mais oscilatória que as anteriormente apresentadas. Isso ocorre pelo fato de existir um maior número de cargas ligadas à linha e, conseqüentemente, um maior número de pontos de aterramento do condutor neutro. A forma de onda e a amplitude das tensões induzidas depende dos parâmetros da linha, das cargas consumidoras e dos parâmetros das descargas atmosféricas. Como observado através da simulação, as tensões induzidas (fase-terra, fase-neutro, neutro-terra) apresentam valores de 
amplitude elevados, variando entre $6 \mathrm{kV}$ e aproximadamente $17 \mathrm{kV}$, que podem acarretar disrupção em algum ponto da rede.

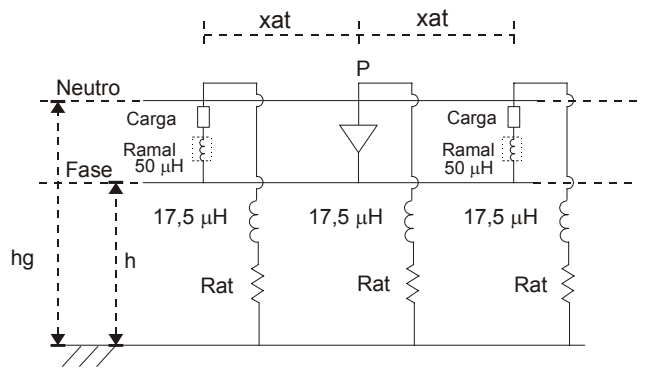

(a)

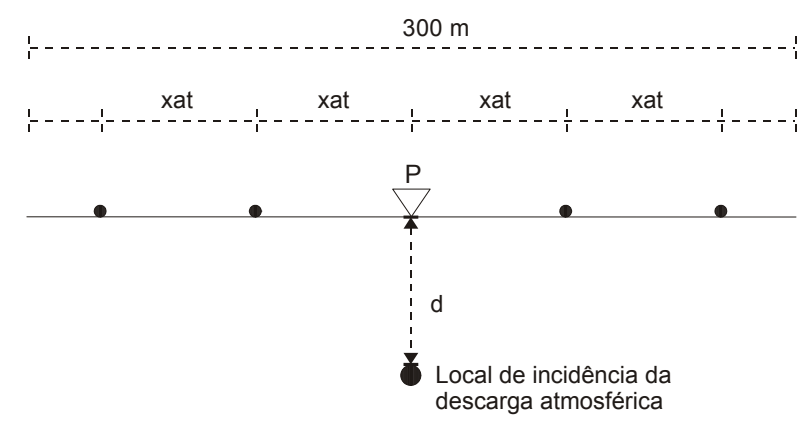

Fig 4.25: Configuração da linha - Caso Base $(x a t=60 \mathrm{~m})$.

$$
\nabla \text { - transformador } \quad \bullet \text { - carga }
$$
a) vista lateral
b) vista superior

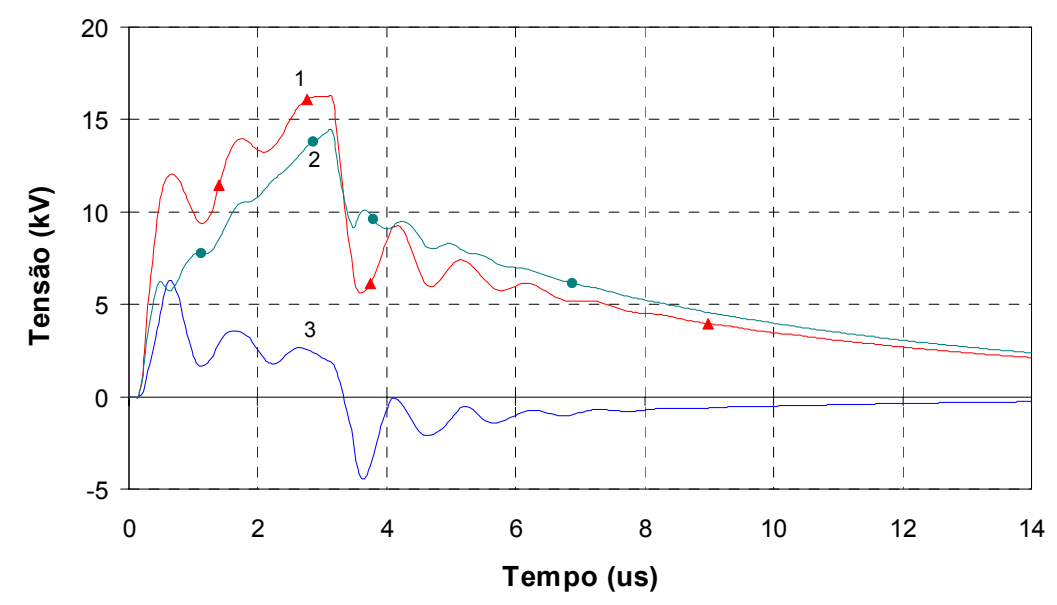

Fig. 4.26: Tensões induzidas no ponto P indicado na Fig. 4.27. Caso Base.

1 - tensão fase-terra $\quad 2$ - tensão neutro-terra $\quad 3$ - tensão fase-neutro

\subsubsection{Altura do condutor fase}

Como visto nas simulações anteriores à definição do Caso Base, a tensão induzida é proporcional à altura do condutor (efeito da altura do condutor ao solo). Quando um condutor não aterrado (fase) está localizado nas proximidades de um condutor aterrado (neutro), a tensão induzida no condutor fase diminui com a redução da distância entre eles (mantendo-se os demais parâmetros inalterados), devido ao efeito 
do acoplamento entre os condutores. Como na rede secundária convencional os condutores são instalados verticalmente, a mudança do afastamento dos condutores fase em relação ao neutro provoca a alteração da altura do condutor fase. Assim, a redução na altura do condutor fase de $6,8 \mathrm{~m}$ (Caso Base) para $6,4 \mathrm{~m}$ pode diminuir ou aumentar a tensão fase-terra, dependendo de qual dos efeitos é predominante. Com o objetivo de avaliar a influência da altura do condutor fase, foram realizadas duas simulações da configuração de rede apresentada na Figura 4.25, uma com $\mathrm{h}=6,8 \mathrm{~m}$ e outra com $\mathrm{h}=6,4 \mathrm{~m}$. O único parâmetro alterado nas simulações foi a altura $\mathbf{h}$ do condutor fase, sendo os restantes iguais aos do Caso Base. As tensões induzidas nesses dois casos são mostradas na Figura 4.27. Embora as diferenças não sejam significativas, observa-se nessas simulações que, para a menor altura do condutor $(\mathrm{h}=6,4 \mathrm{~m})$ a tensão induzida é maior, o que leva à conclusão que, para essa configuração de linha, o efeito do acoplamento entre os condutores fase e neutro é predominante em relação ao efeito de redução da altura do condutor fase.

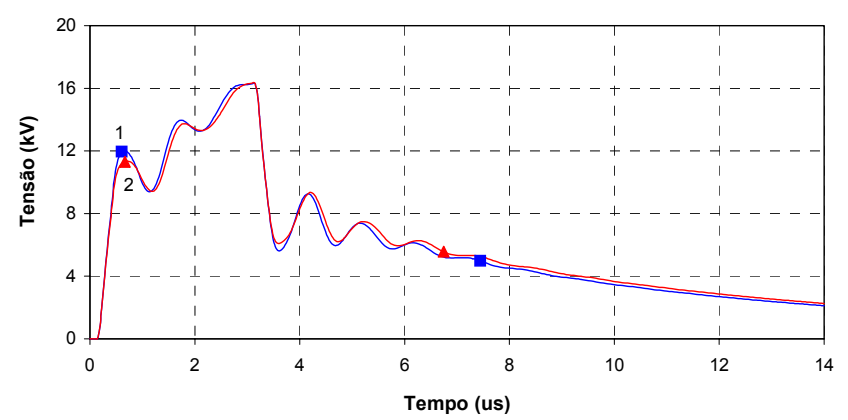

(a)

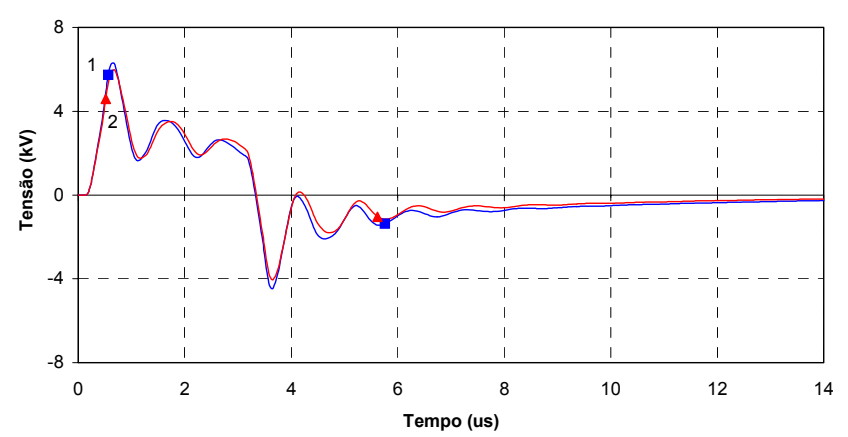

(b)

Fig. 4.27: Comportamento da tensão induzida em função da altura $\mathbf{h}$ do condutor fase.

Configuração da linha mostrada na Fig. 4.25.

$$
1-\mathrm{h}=6,4 \mathrm{~m} \quad 2-\mathrm{h}=6,8 \mathrm{~m} \text { (Caso Base) }
$$
a) tensões fase-terra
b) tensões fase-neutro 


\subsubsection{Posição ao longo da linha}

Para essa análise foram realizadas simulações das configurações de linha apresentadas na Figura 4.28, onde o ponto de cálculo da tensão induzida e o ponto de incidência da descarga atmosférica foram variados. As tensões induzidas fase-terra e fase-neutro no ponto P da Figura 4.28, assim como aquelas obtidas para o Caso Base $(x=0 \mathrm{~m}$ e $\mathrm{xd}=0 \mathrm{~m})$, são mostradas na Figura 4.29. Comparando as tensões induzidas fase-terra nas três configurações, verifica-se que a maior amplitude ocorre quando $\mathrm{xd}=30 \mathrm{~m}$ e $\mathrm{x}=0 \mathrm{~m}$ (curva 1 na Figura 4.29-a). Neste caso, a amplitude é maior devido à maior distância entre o ponto de cálculo das tensões induzidas ao ponto de aterramento do condutor neutro $(x d=30 \mathrm{~m})$. A menor amplitude da tensão induzida fase-terra ocorre para a situação representada na Figura 4.28-b, onde $\mathrm{xd}=0 \mathrm{~m}$ e $\mathrm{x}=30 \mathrm{~m}$. Isso ocorre porque o ponto de cálculo das tensões induzidas está em um local de aterramento do condutor neutro e o ponto de incidência da descarga atmosférica está mais afastado $(x=30 \mathrm{~m})$ que no Caso Base, em que $\mathrm{x}=0 \mathrm{~m}$. $\mathrm{O}$ comportamento das tensões induzidas neutro-terra (não mostradas) é análogo ao das tensões fase-terra. Por esse motivo, as diferenças nas tensões fase-neutro para as situações analisadas não são tão significativas, como pode ser observado na Figura 4.29-b.

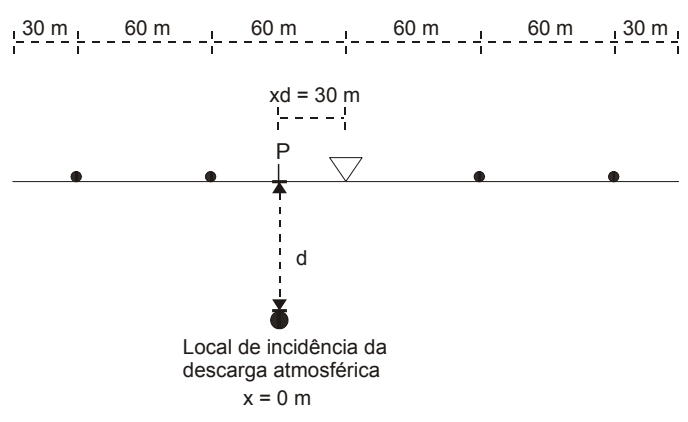

(a)

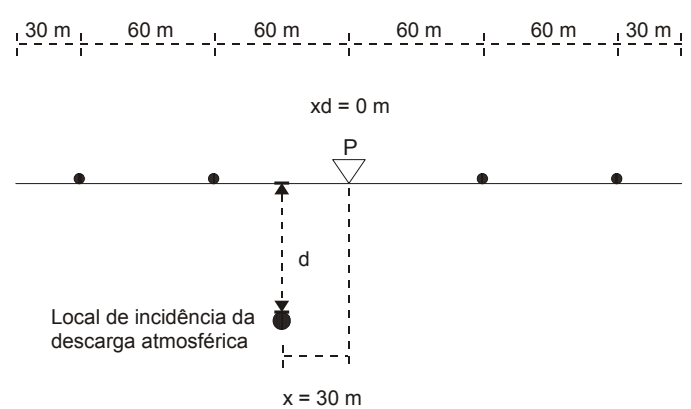

(b)

Fig 4.28: Configuração da linha - Caso base. Análise das tensões induzidas ao longo na linha.

$$
\nabla \text { - transformador } \quad \bullet \text { - carga }
$$
a) $\mathrm{x}=0 \mathrm{~m}$ e $\mathrm{xd}=30 \mathrm{~m}$ (vista superior)
b) $\mathrm{x}=30 \mathrm{~m}$ e $\mathrm{xd}=0 \mathrm{~m}$ (vista superior) 


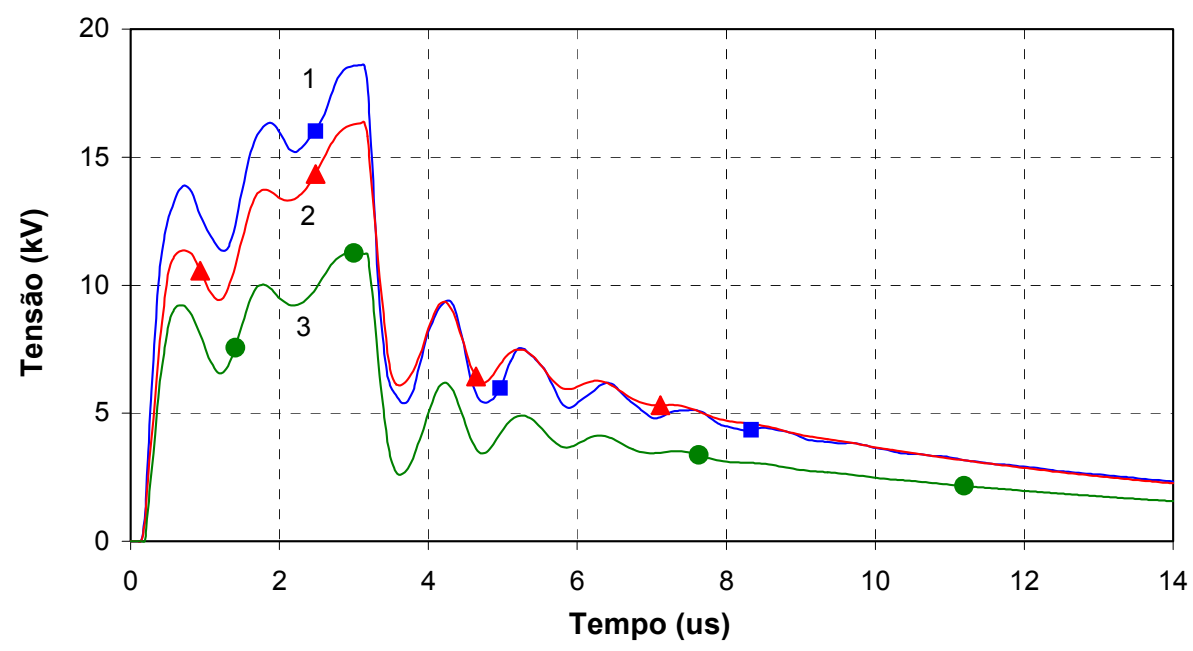

(a)

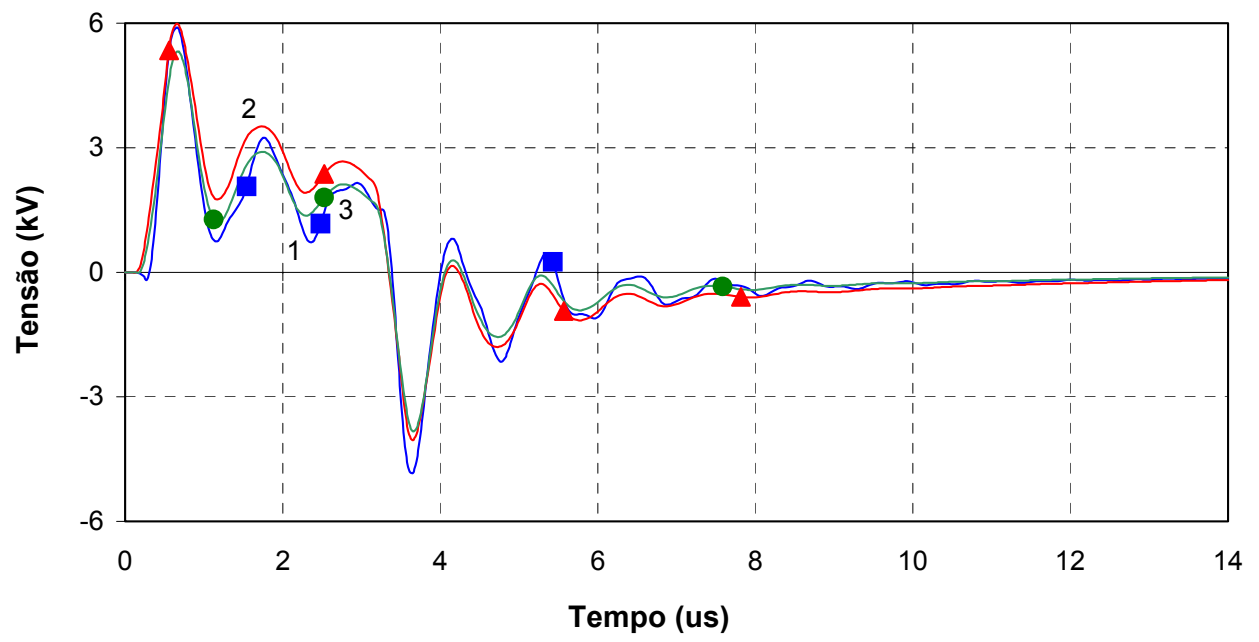

(b)

Fig. 4.29: Comportamento da tensão induzida em função das distâncias xd e x.

1) $x d=30 \mathrm{~m} \mathrm{e} x=0 \mathrm{~m}$ (Fig 4.28-a)

2) $x d=0 \mathrm{mex}=0 \mathrm{~m}$ (Fig. 4.25) - Caso Base

3) $\mathrm{xd}=0 \mathrm{~m} \mathrm{e} \mathrm{x}=30 \mathrm{~m}$ (Fig. 4.28-b)
a) tensões fase-terra
b) tensões fase-neutro

\subsubsection{Amplitude da corrente da descarga de retorno}

Neste item, comparou-se as tensões obtidas no Caso Base às obtidas quando se altera a amplitude da corrente da descarga de $45 \mathrm{kA}$ para $90 \mathrm{kA}$. Os demais parâmetros da configuração da linha não foram alterados. A comparação entre as tensões induzidas é feita na Figura 4.30. Observa-se que as tensões induzidas são proporcionais à 
amplitude da corrente de descarga. Nota-se também que as tensões fase-terra atingem seus valores máximos em aproximadamente $3 \mu \mathrm{s}$, que é o tempo de frente da corrente de descarga. Já nas tensões fase-neutro os valores de crista ocorrem em aproximadamente $0,7 \mu$ s. Apesar da alteração na amplitude da tensão induzida, não foram verificadas mudanças significativas na sua forma de onda com a variação da amplitude da corrente da descarga.

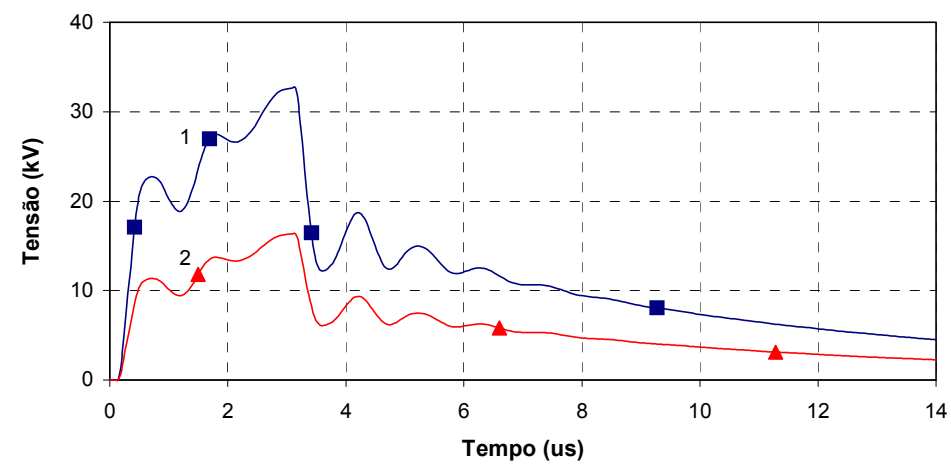

(a)

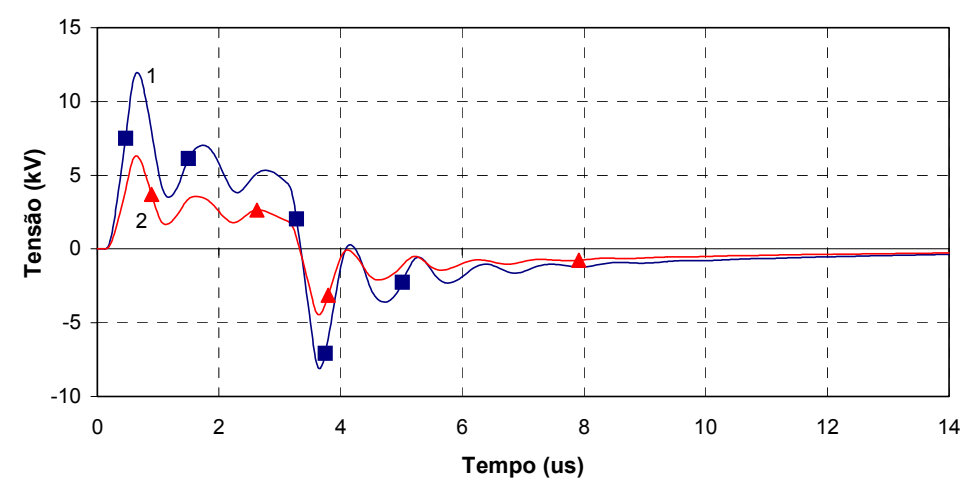

(b)

Fig. 4.30: Comportamento das tensões induzidas em função da amplitude I da corrente de descarga. Tensões calculadas no ponto P indicado na Fig. 4.25.
1) $\mathrm{I}=90 \mathrm{kA}$
2) $\mathrm{I}=45 \mathrm{kA}$ (Caso Base)
a) tensões fase-terra
b) tensões fase-neutro

\subsubsection{Tempo de frente da corrente de descarga}

Neste item o parâmetro analisado é o tempo de frente da corrente da descarga atmosférica. Um menor tempo de frente de onda implica numa variação mais brusca no campo eletromagnético gerado pela descarga, que acarreta uma maior amplitude 
das tensões induzidas na linha, conforme observado na Figura 4.31. É interessante notar que os picos de tensão induzida fase-terra ocorrem próximos aos instantes de tempo em que as correntes atingem os seus valores máximos, sendo que para tempos maiores que $8 \mu$ s as diferenças entre as tensões induzidas fase-terra são mínimas para os três casos. Entretanto, o comportamento das tensões fase-neutro é diferente: os valores máximos dessas tensões ocorrem praticamente no mesmo instante, independente do tempo de frente da corrente da descarga. Isto mostra que o tempo de frente de onda de corrente tem grande influência nas amplitudes e formas de onda das tensões induzidas na linha.

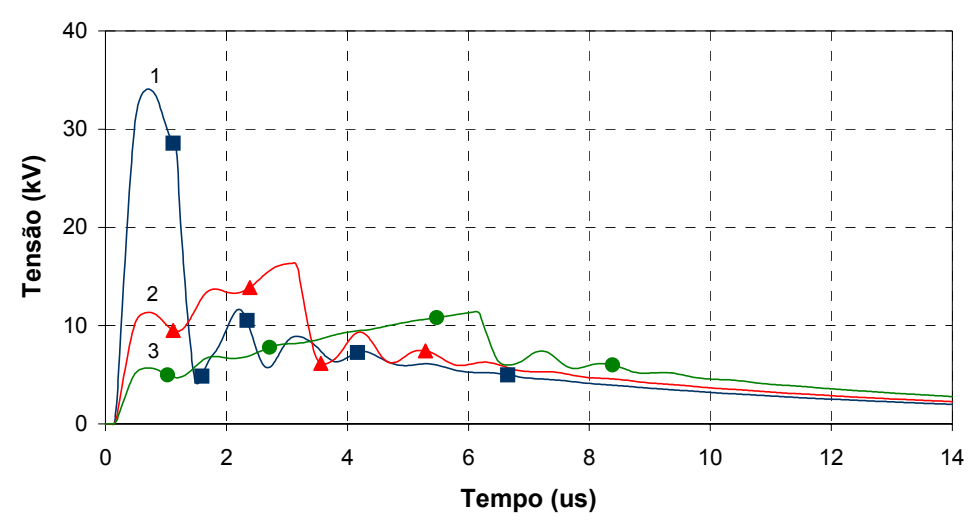

(a)

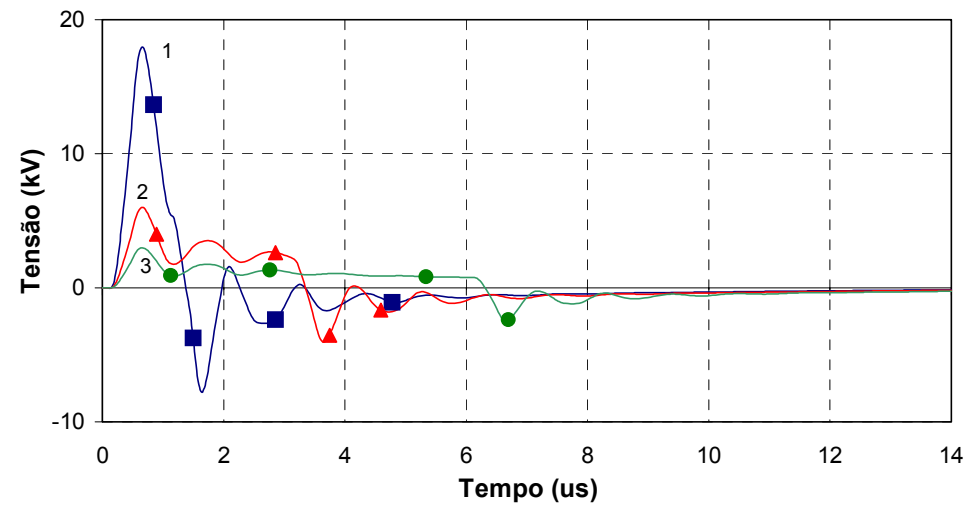

(b)

Fig. 4.31: Variação das tensões em função do tempo de frente tf da corrente de descarga. Tensões calculadas no ponto $P$ indicado na Fig. 4.25 . $\mathrm{I}=45 \mathrm{kA}$, to $=150 \mu \mathrm{s}$.
1) $\mathrm{tf}=1,5 \mu \mathrm{s}$
2) $\mathrm{tf}=3 \mu \mathrm{s}$ (Caso Base)
3) $\mathrm{tf}=6 \mu \mathrm{s}$
a) tensões fase-terra
b) tensões fase-neutro 
4.3.1.6 Tempo de queda da corrente de descarga

Foram realizadas simulações considerando a configuração usada como Caso Base para verificar o comportamento das tensões induzidas em função do tempo de queda to (tempo em que a amplitude da corrente de descarga é nula), sendo as tensões calculadas no ponto $\mathrm{P}$ indicado na Figura 4.25. Exceto to, todos os demais parâmetros são iguais aos usados no Caso Base. Os tempos escolhidos foram $75 \mu \mathrm{s}$ e $300 \mu$ s que correspondem, respectivamente, à metade e ao dobro do valor utilizado no Caso Base. As tensões induzidas fase-terra e fase-neutro são mostradas na Figura 4.32 para os diferentes tempos de queda da corrente. Como pode-se observar, os valores de crista das tensões induzidas (tanto as tensões fase-terra quanto as tensões fase-neutro) não sofreram alterações com a modificação do tempo de queda to. A variação da tensão induzida fase-terra em função do tempo de queda da corrente da descarga é observada em instantes de tempo superiores a 4,5 $\mu \mathrm{s}$, o mesmo ocorrendo com as tensões fase-neutro e, conseqüentemente, neutro-terra. De modo geral, pode-se dizer que as tensões induzidas tendem a diminuir mais rapidamente com a diminuição do tempo de cauda da corrente de descarga, embora essa variação não seja normalmente significativa quando se leva em conta as formas de onda típicas das correntes. 


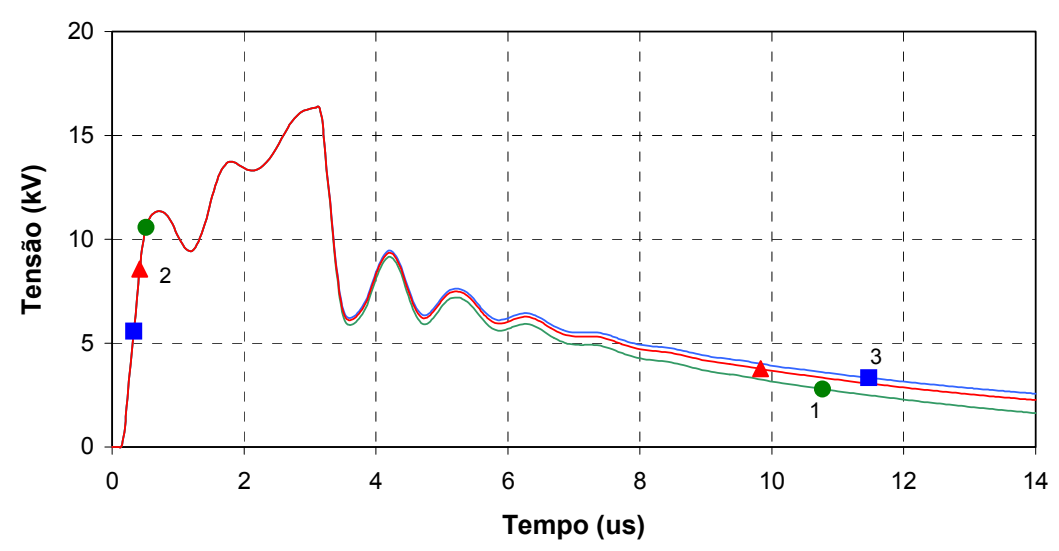

(a)

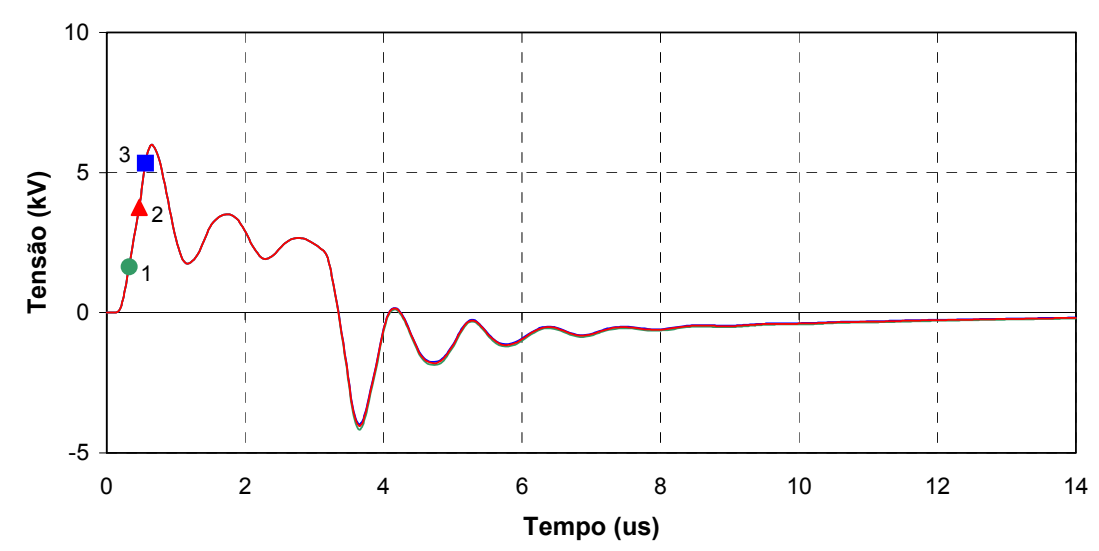

(b)

Fig. 4.32: Variação das tensões induzidas em função do tempo de frente to da corrente de descarga.

$$
\mathrm{I}=45 \mathrm{kA}, \mathrm{tf}=3 \mu \mathrm{s} .
$$
1) to $=75 \mu \mathrm{s}$
2) to $=150 \mu \mathrm{s}($ Caso Base $)$
3) to $=300 \mu \mathrm{s}$
a) tensões fase-terra
b) tensões fase-neutro

\subsubsection{Velocidade de propagação da corrente de descarga no canal}

Neste caso o parâmetro analisado foi a relação entre a velocidade de propagação da corrente no canal da descarga e a velocidade da luz no vácuo. Na Figura 4.33 são apresentadas as tensões induzidas no ponto P da Figura 4.25 (configuração utilizada como base) para diferentes valores da relação (b) entre as velocidades. Pode-se notar através dos gráficos que, para os casos analisados, quanto maior a velocidade de propagação da corrente, maior a tensão induzida. Esta relação pode ser explicada pelo fato de o maior valor de velocidade indicar uma variação mais rápida da corrente no canal, que corresponde a uma variação mais abrupta do campo 
eletromagnético gerado pela descarga, ocasionando assim uma maior amplitude de tensão induzida. É importante destacar, contudo, que existem situações onde ocorre o contrário, ou seja, a tensão diminui com o aumento da velocidade, conforme verificado em $[25,61,88]$ para o caso de tensões induzidas em linhas de média tensão.

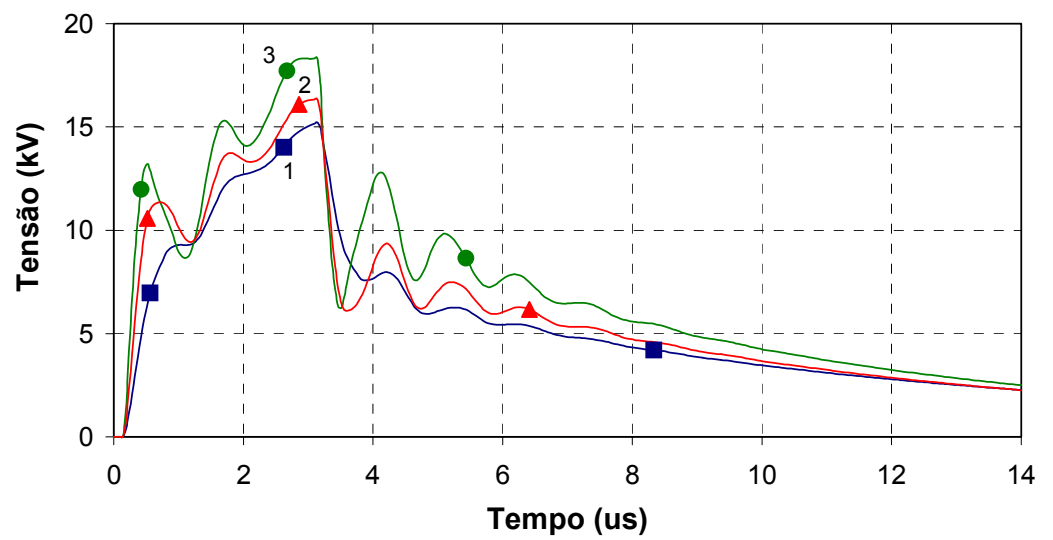

(a)

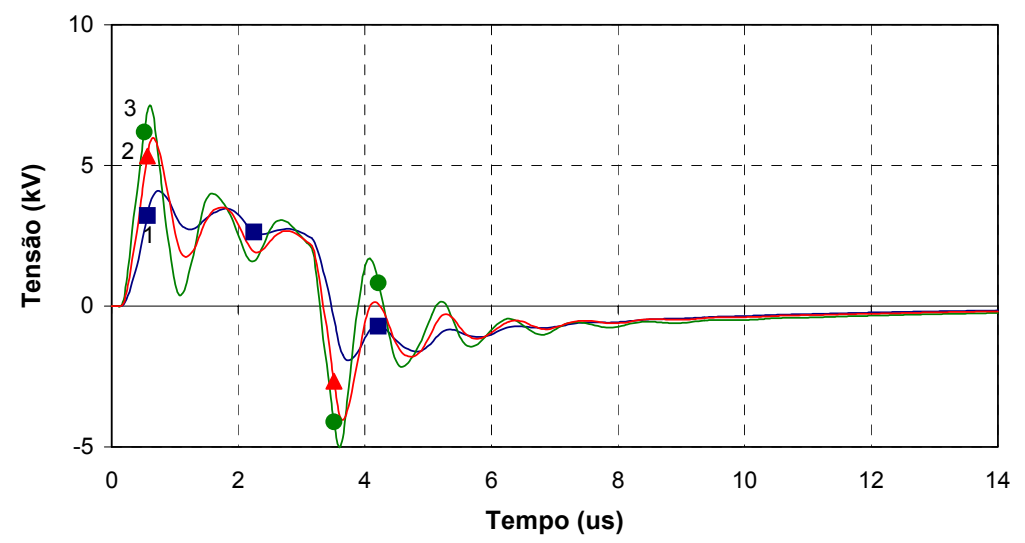

(b)

Fig. 4.33: Variação das tensões induzidas em função da relação b.

$$
\mathrm{I}=45 \mathrm{kA}, \mathrm{tf}=3 \mu \mathrm{s}, \text { to }=150 \mu \mathrm{s} .
$$
1) $b=0,15$
2) $b=0,3$ (Caso Base)
3) $b=0,6$

a) tensões fase-terra

b) tensões fase-neutro 


\subsubsection{Distância do local de incidência da descarga à linha}

Para analisar a influência da distância d do local de incidência da descarga atmosférica ao ponto central da linha de BT (Figura 4.25), foram comparadas as tensões obtidas no Caso Base $(\mathrm{d}=50 \mathrm{~m})$ àquelas obtidas quando se alterou a distância d para $25 \mathrm{~m}$ e para $100 \mathrm{~m}$. As tensões induzidas para essas distâncias são mostradas na Figura 4.34, podendo-se observar que suas amplitudes foram reduzidas aproximadamente à metade quando se dobrou a distância d. Observa-se, então, que a distância entre o ponto de ocorrência da descarga e a linha tem influência significativa na tensão induzida. Por outro lado, essa influência não é tão marcante na forma de onda da tensão, que pouco se altera.

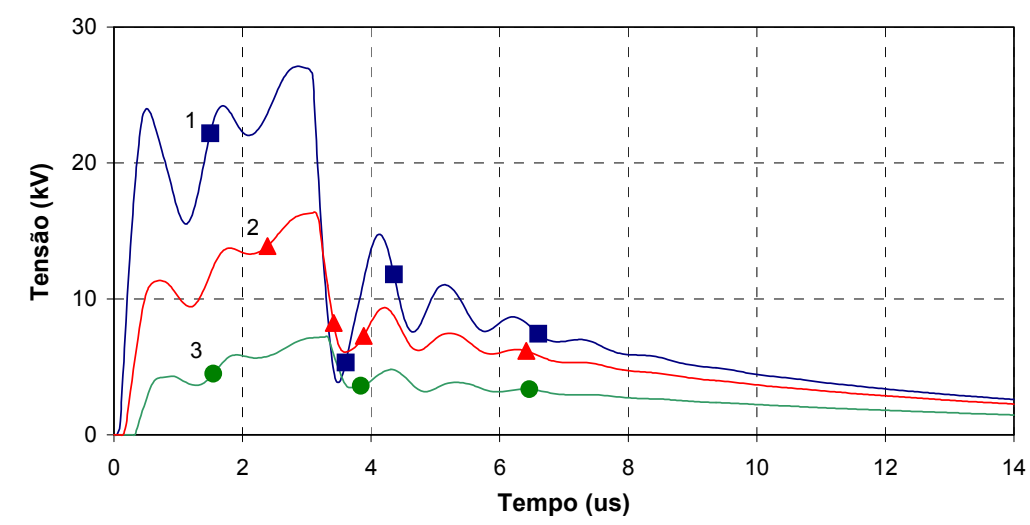

(a)

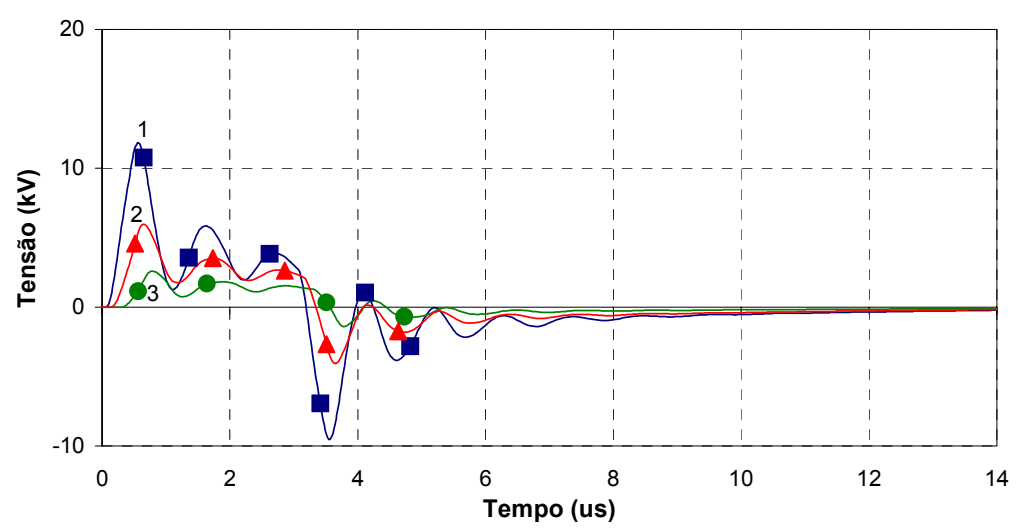

(b)

Fig. 4.34: Variação das tensões induzidas em função da distância d da linha ao ponto de incidência da descarga atmosférica. $\mathrm{I}=45 \mathrm{kA}, \mathrm{tf}=3 \mu \mathrm{s}$, to $=150 \mu \mathrm{s}$.
1) $d=25 \mathrm{~m}$
2) $d=50 \mathrm{~m}$ (Caso Base) 3) $d=100 \mathrm{~m}$

a) tensões fase-terra

b) tensões fase-neutro 


\subsubsection{Resistência de terra}

O valor da resistência de terra foi alterado com o objetivo de verificar o comportamento das tensões induzidas frente a esse parâmetro. A análise consistiu em simulações da configuração utilizada como base com os seguintes valores de resistência de terra: $10 \Omega, 20 \Omega$ (Caso Base), $80 \Omega$ e $200 \Omega$. A comparação das tensões induzidas (fase-terra e fase-neutro) é mostrada na Figura 4.35. Verifica-se que as tensões fase-terra, indicadas na Figura 4.35-a, aumentam com o aumento da resistência de terra. As tensões neutro-terra (não mostradas) têm comportamento semelhante, porém esse efeito é mais pronunciado que nas tensões fase-terra. Isso ocorre porque as tensões neutro-terra são mais fortemente afetadas pela resistência de terra que as tensões fase-terra. Por esse motivo, as tensões fase-neutro (Figura 4.35-b) diminuem com o aumento da resistência de terra. Embora isso ocorra com a tensão fase-neutro, é desejável que as resistências de terra de uma linha de distribuição sejam as menores possíveis, tendo em vista a segurança dos usuários e o próprio desempenho da linha, uma vez que tensões fase-terra menores diminuem a possibilidade de disrupção em algum ponto da linha. 


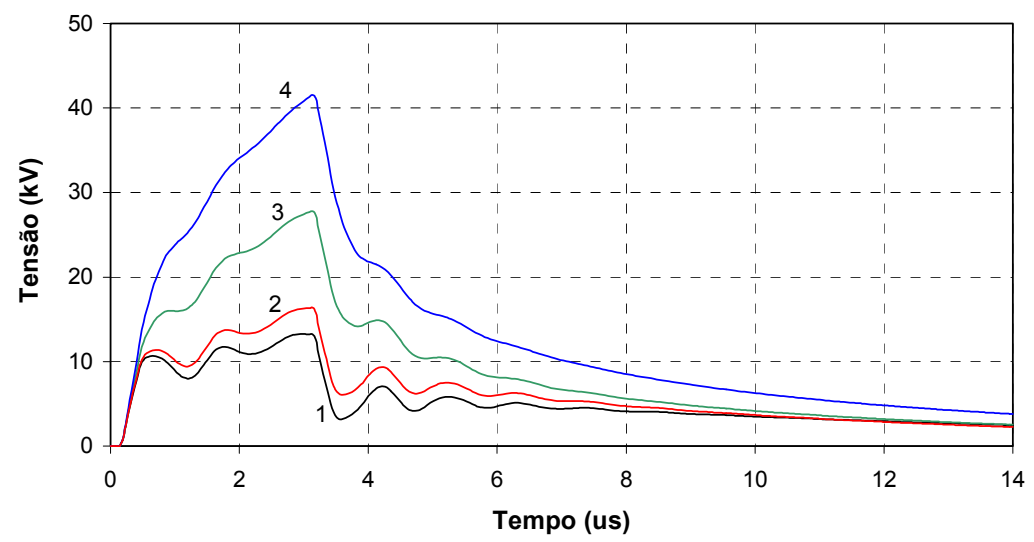

(a)

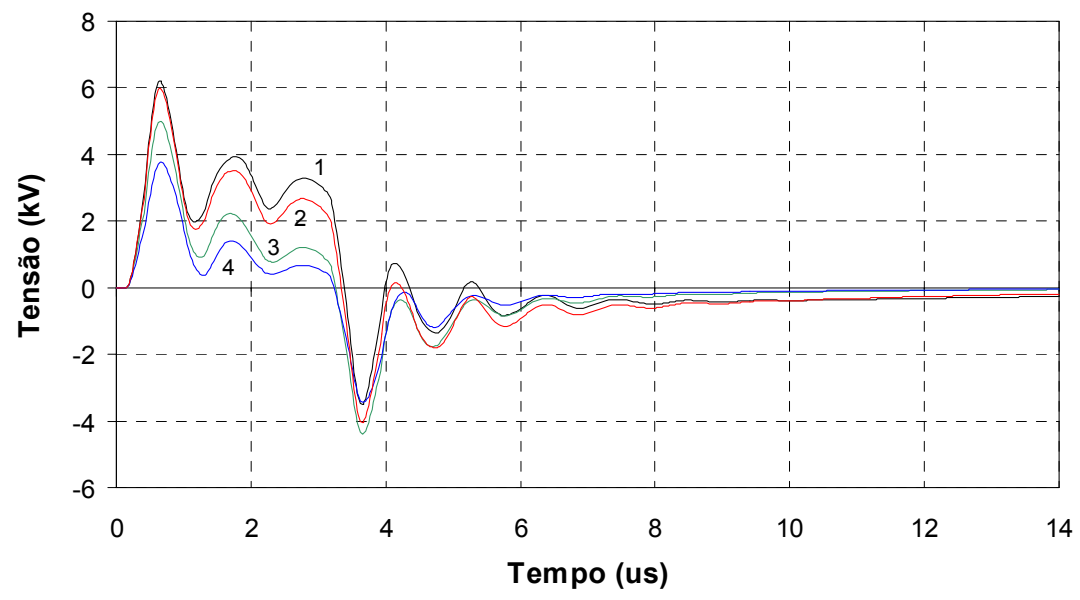

(b)

Fig. 4.35: Variação das tensões induzidas em função da resistência de terra Rat.
1) Rat $=10 \Omega$
2) Rat $=20 \Omega$ (Caso Base)
3) $\mathrm{Rat}=80 \Omega$
4) $\mathrm{Rat}=200 \Omega$
a) tensões fase-terra
b) tensões fase-neutro

\subsubsection{Comprimento da linha}

A análise da variação das tensões induzidas em função do comprimento da linha foi realizada para a configuração mostrada na Figura 4.36, onde y representa a distância entre a carga e a extremidade da linha. Os demais parâmetros da linha e da corrente da descarga atmosférica são iguais aos do Caso Base. Com essa configuração, consideraram-se nas simulações comprimentos de $120 \mathrm{~m} \quad(\mathrm{y}=0 \mathrm{~m}), 140 \mathrm{~m}$ $(\mathrm{y}=10 \mathrm{~m})$ e $400 \mathrm{~m}(\mathrm{y}=140 \mathrm{~m})$. As tensões induzidas no ponto $\mathrm{P}$ para os diferentes valores de y (Figura 4.36) são apresentadas na Figura 4.37. 
Observa-se pelos gráficos que para as situações consideradas as amplitudes das tensões induzidas fase-terra aumentam pouco com o aumento do comprimento da linha. Isto ocorre pelo fato de o ponto de cálculo da tensão estar localizado no centro da linha, onde existe um ponto de aterramento do condutor neutro junto ao transformador, e também por esse local sofrer influências das cargas ligadas à linha. Já as tensões fase-neutro praticamente não se alteram com o comprimento da linha.

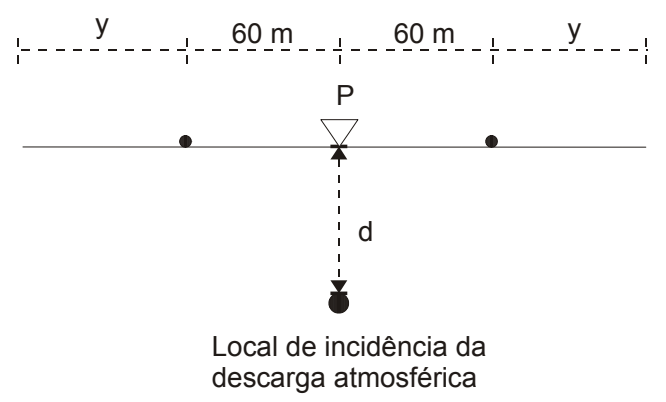

Fig 4.36: Configurações de linha para análise da influência do seu comprimento (vista superior).

$$
\nabla \text { - transformador } \quad \bullet \text { - carga }
$$

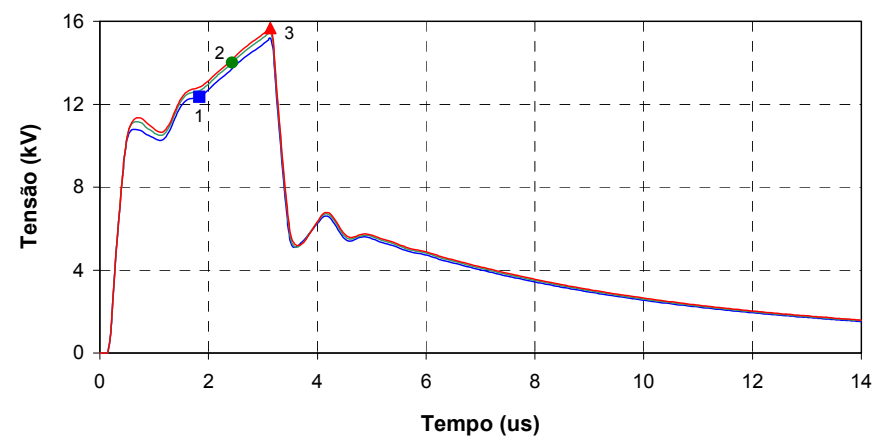

(a)

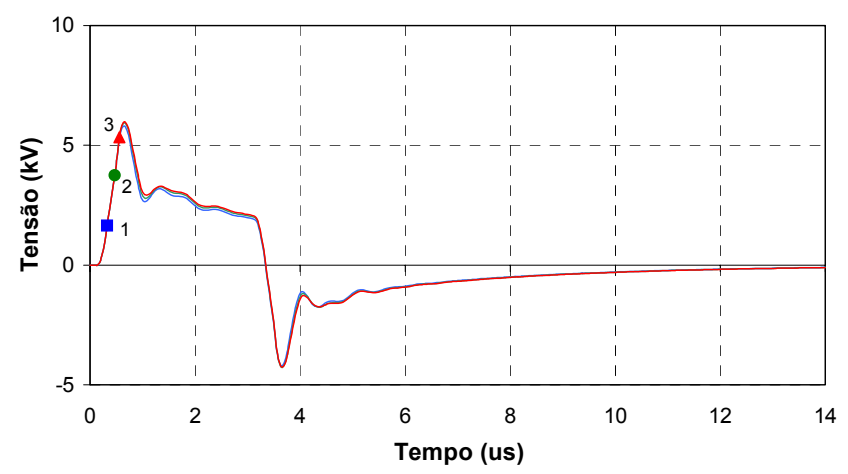

(b)

Fig. 4.37: Variação das tensões induzidas (no ponto P) em função do comprimento da linha.
1) $\mathrm{y}=0 \mathrm{~m}$
2) $y=10 \mathrm{~m}$
3) $\mathrm{y}=140 \mathrm{~m}$

a) tensões fase-terra

b) tensões fase-neutro 


\subsubsection{Distância entre pontos de aterramento do neutro}

Neste caso a análise é feita com base na Figura 4.38, em que o comprimento da linha é igual a $450 \mathrm{~m}$, com distância xat entre pontos de aterramento do condutor neutro. Variou-se então a distância entre os pontos de aterramentos com o objetivo de estudar sua influência na tensão induzida. As distâncias utilizadas foram 30 m, 60 m e 90 m. As tensões induzidas para essas configurações são mostradas na Figura 4.39. Pode-se observar que para o caso em que xat é igual a $30 \mathrm{~m}$, a amplitude de tensão induzida é menor, se comparada às das tensões correspondentes às outras distâncias. A diferença entre as tensões fase-terra é de aproximadamente $44 \%$ em relação ao caso de xat $=60 \mathrm{~m}$ e de aproximadamente $56 \%$ em relação ao caso de xat $=90 \mathrm{~m}$. Para o caso das tensões fase-neutro essa diferença é de aproximadamente $56 \%$ e $96 \%$ em relação aos casos xat $=60 \mathrm{~m}$ e xat $=90 \mathrm{~m}$, respectivamente, mantendo o caso $x a t=30 \mathrm{~m}$ como referência. Fica evidente assim que, quanto menor o espaçamento entre os pontos de aterramento do condutor neutro, menor a amplitude da tensão induzida, podendo essa variação ser significativa dependendo dos valores dos demais parâmetros.

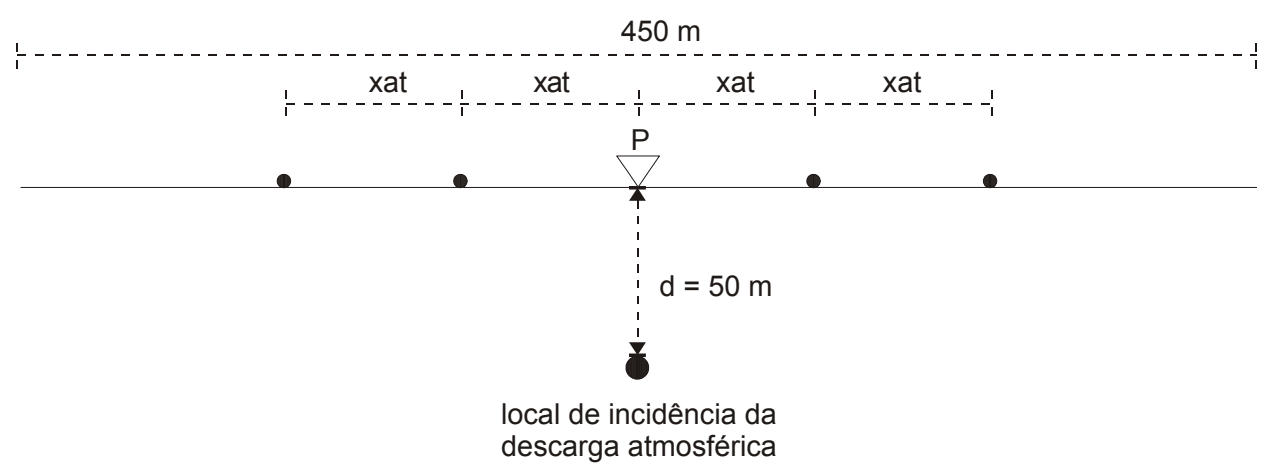

Fig 4.38: Configurações de linha para análise da influência da distância entre pontos de aterramento do condutor neutro.

$$
\nabla \text { - transformador } \quad \bullet \text { - carga }
$$




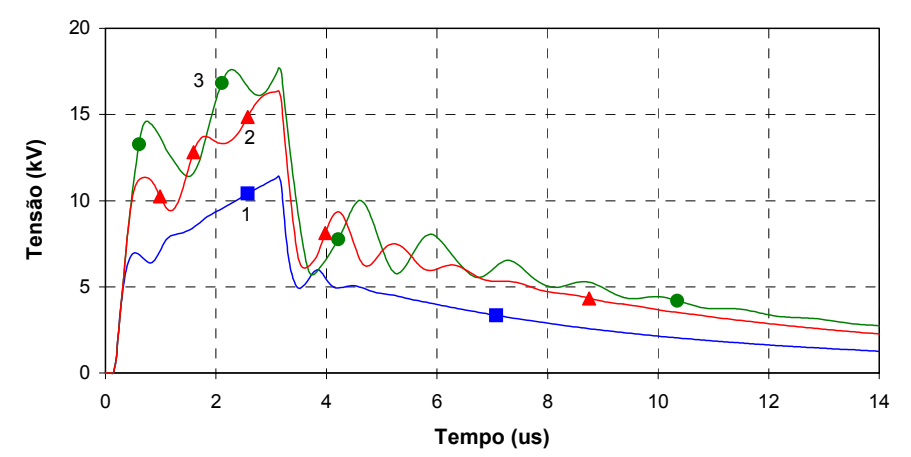

(a)

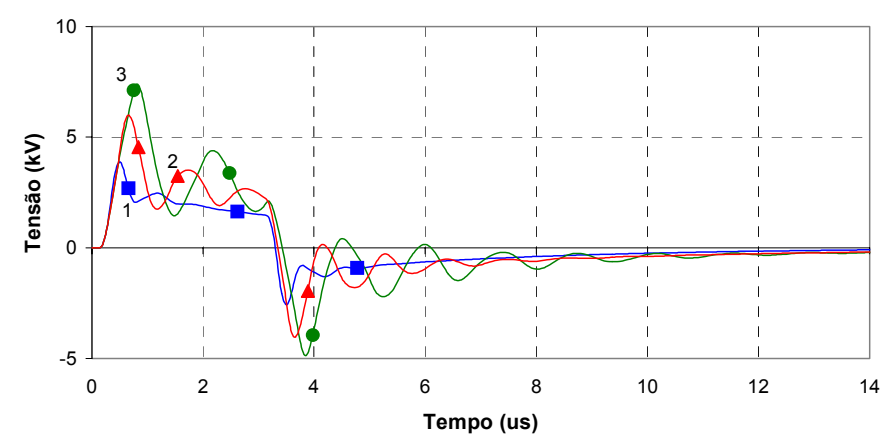

(b)

Fig. 4.39: Variação das tensões induzidas em função do intervalo de aterramento do condutor neutro.

$$
\text { 1) } \mathrm{xat}=30 \mathrm{~m}
$$

a) tensões fase-terra
2) $x a t=60 \mathrm{~m}$

3) $x a t=90 \mathrm{~m}$

b) tensões fase-neutro

\subsubsection{Carga indutiva}

Neste caso, a impedância total considerada entre fase e neutro consiste em um indutor com valor de $50 \mu \mathrm{H}$ (que representa a indutância do ramal de ligação) em série com um resistor de $1 \Omega$ (que representa as perdas no ramal) e um indutor $\mathbf{L}$ (representando a carga), que terá seu valor alterado para analisar o comportamento das tensões induzidas na linha. Foram escolhidos dois valores de indutância: $2 \mu \mathrm{H} \mathrm{e}$ $20 \mu \mathrm{H}$. As tensões induzidas no ponto $\mathrm{P}$ da configuração usada como base (Figura 4.25) são apresentadas na Figura 4.40. Pode-se observar que, para um valor de indutância maior $(20 \mu \mathrm{H})$, tem-se uma tensão induzida maior devido ao aumento da impedância entre fase e neutro. Com o valor menor de indutância não houve mudança significativa em relação ao Caso Base. Isto pode ser explicado pelo fato 
deste valor de indutância $(2 \mu \mathrm{H})$, assim como o valor da indutância do Caso Base $(3,5 \mu \mathrm{H})$, serem muito pequenos se comparados com o valor da indutância do ramal de ligação $(50 \mu \mathrm{H})$, não alterando significativamente o valor da impedância total entre os dois condutores.

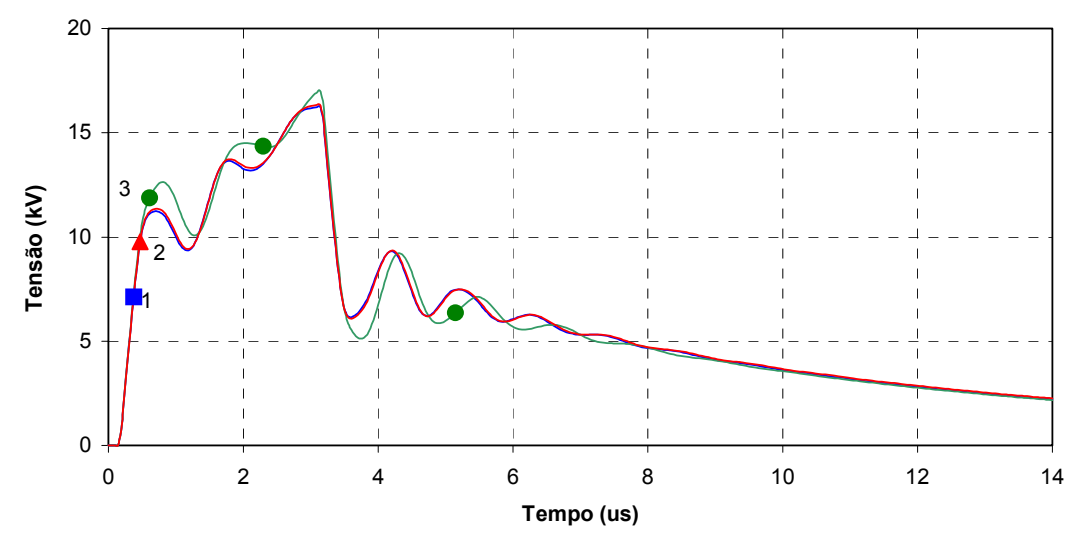

(a)

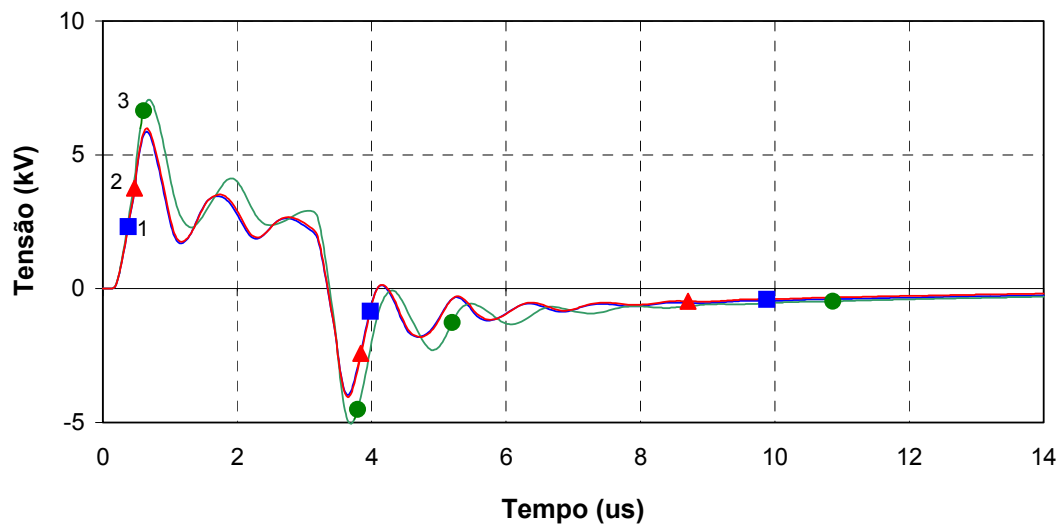

(b)

Fig. 4.40: Variação das tensões induzidas em função da carga indutiva.
1) $\mathrm{L}=2 \mu \mathrm{H}$
2) $\mathrm{L}=3,5 \mu \mathrm{H}$ (Caso Base)
3) $\mathrm{L}=20 \mu \mathrm{H}$
a) tensões fase-terra
b) tensões fase-neutro 


\subsubsection{Carga resistiva}

Para avaliar o efeito de uma carga resistiva foram considerados três valores de resistência $\mathrm{R}(12 \Omega, 60 \Omega$ e $120 \Omega)$ em série com a indutância do ramal de ligação $(50 \mu \mathrm{H})$ e suas perdas (representadas pelo resistor de $1 \Omega$ ), considerando a configuração de linha usada como base (Figura 4.25). As tensões induzidas no ponto P, indicado na Figura 4.25, são mostradas na Figura 4.41. Pode-se perceber que, quanto maior o valor da resistência da carga, maior o valor da tensão induzida. Isto pode ser explicado pelo fato de que uma maior resistência implica numa maior impedância entre fase e neutro, e desta maneira uma menor parcela da energia contida na onda de tensão induzida no condutor fase é desviada para o condutor neutro e, conseqüentemente, para o ponto de aterramento. Em relação à forma de onda das tensões fase-terra, verifica-se que seus os tempos de crista ocorrem em tempo semelhantes aos observados nas tensões fase-terra da análise de carga indutiva (Figura 4.40-a), que corresponde ao tempo em que a corrente da descarga atinge o seu máximo valor. Já as tensões fase-neutro apresentaram diferenças nas suas formas de onda em relação ao caso de carga indutiva (Figura 4.40-b). Os tempos de máximo valor das tensões fase-neutro nessa análise são coincidentes com os tempos de crista das tensões fase-terra, enquanto que para o caso anterior os tempos de crista são mais rápidos, da ordem de $1 \mu \mathrm{s}$. Observa-se também que a variação do valor da carga resistiva (valores de $12 \Omega, 60 \Omega$ e $120 \Omega$ ) provocou uma alteração significativa nas amplitudes das tensões induzidas. No caso anterior não nota-se variações significativas nas tensões induzidas com a variação do valor da indutância da carga. Isso se deve ao fato da indutância do ramal de ligação $(50 \mu \mathrm{H})$ exercer uma grande influência na impedância total da carga. 


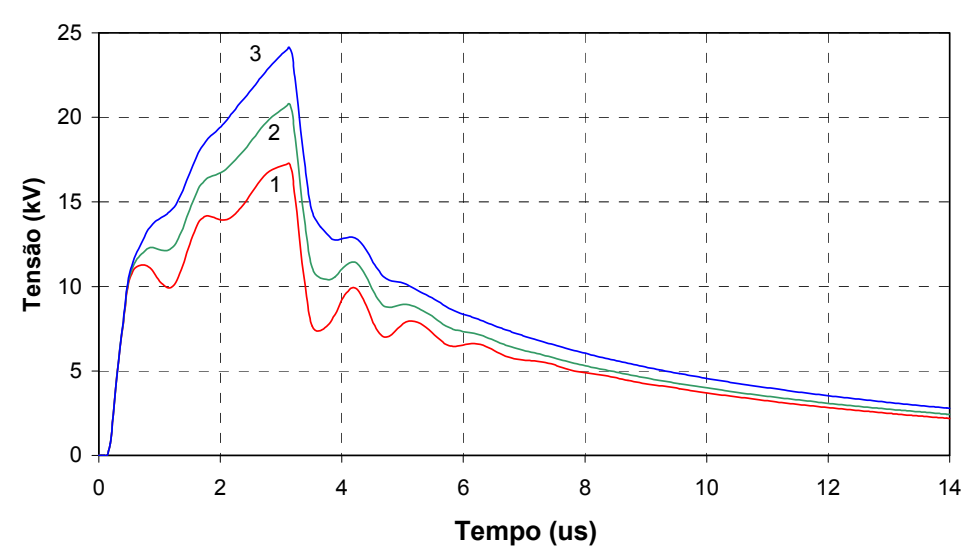

(a)

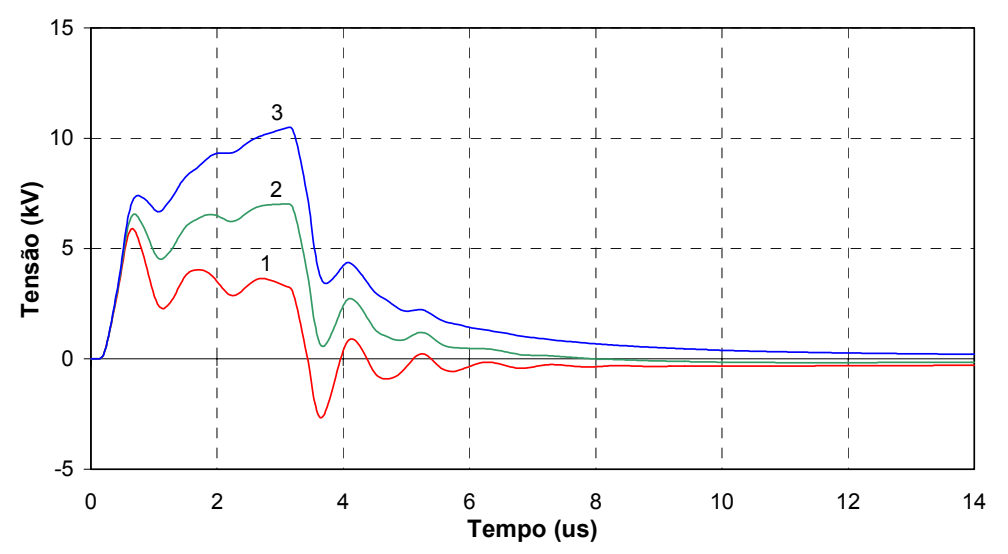

(b)

Fig. 4.41: Variação das tensões induzidas em função da carga resistiva.
1) $R=12 \Omega$
2) $R=60 \Omega$
3) $R=120 \Omega$

a) tensões fase-terra

b) tensões fase-neutro

\subsubsection{Carga capacitiva}

Considerou-se a seguir uma carga capacitiva de valor $\mathrm{C}$ também em série com a indutância do ramal de ligação $(50 \mu \mathrm{H})$ e com a resistência associada às suas perdas $(1 \Omega)$. Os valores escolhidos de capacitância foram $2 \mathrm{nF}, 4 \mathrm{nF}$ e $20 \mathrm{nF}$. As tensões induzidas no ponto $\mathrm{P}$ (configuração indicada na Figura 4.25) são mostradas na Figura 4.42. Pelos gráficos obtidos, verifica-se que um menor valor de capacitância implica numa maior tensão induzida na rede de distribuição. A inclusão do capacitor no circuito faz com que o mesmo se torne uma carga RLC ressonante. Com menor valor de capacitância, a carga apresenta maior impedância nas regiões mais importantes do espectro de freqüência das tensões induzidas, resultando então em 
uma tensão induzida de maior amplitude. Quanto às formas de onda, verifica-se que as tensões não apresentam os decaimentos abruptos no instante de tempo igual a $3 \mu \mathrm{s}$ como os observados nos casos de cargas indutiva e resistiva mostrados anteriormente. No caso de carga capacitiva ocorre uma pequena oscilação da tensão nesse instante de tempo, sendo que a partir de $4 \mu$ s as tensões começam a cair mais lentamente que nos casos anteriores. Nota-se também que para o caso de carga capacitiva de $20 \mathrm{nF}$ a tensão induzida sofre uma inversão da tendência de queda e aumenta sua amplitude a partir de $9 \mu$ s até aproximadamente $13 \mu \mathrm{s}$.

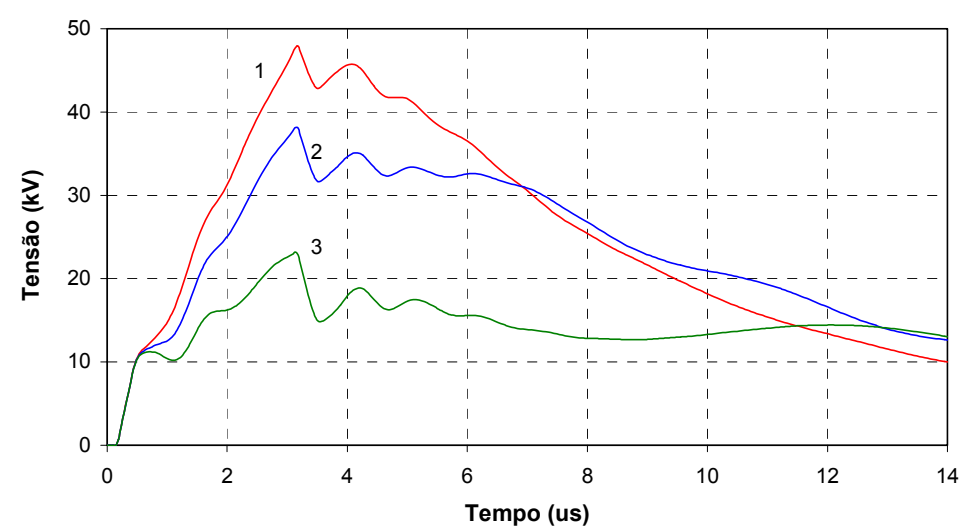

(a)

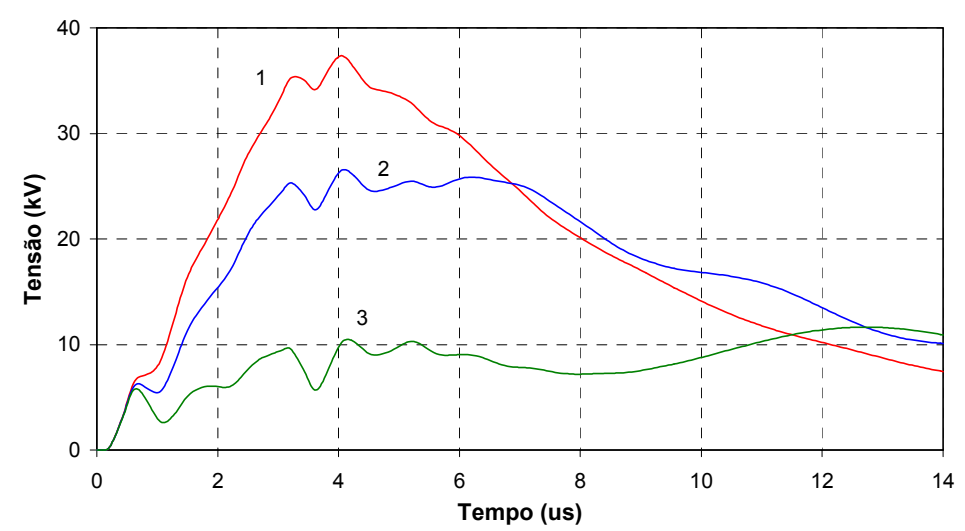

(b)

Fig. 4.42: Variação das tensões induzidas em função da carga capacitiva.
1) $\mathrm{C}=2 \mathrm{nF}$
2) $\mathrm{C}=4 \mathrm{nF}$
3) $\mathrm{C}=20 \mathrm{nF}$

a) tensões fase-terra

b) tensões fase-neutro 


\subsubsection{Comprimento do ramal de ligação}

Nas simulações anteriores a impedância do ramal de ligação foi considerada igual a $50 \mu \mathrm{H}$, que corresponde à indutância de um condutor de $10 \mathrm{~mm}^{2}$ de seção transversal e com 40 m de comprimento. Com o objetivo de avaliar o efeito do comprimento $\mathbf{~ r r}$ do ramal de ligação nas tensões induzidas na linha de BT foi realizada outra simulação, considerando as duas configurações indicadas na Figura 4.28 porém adotando o comprimento de $20 \mathrm{~m}$ para os ramais de ligação, o que equivale a uma indutância de $25 \mu \mathrm{H}$. As tensões induzidas (fase-terra e fase neutro) no ponto P das duas configurações mostradas na Figura 4.28 para os comprimentos de $40 \mathrm{~m}$ e $20 \mathrm{~m}$ são comparadas nas figuras 4.43 e 4.44. Como observado, as tensões induzidas não apresentam diferenças significativas quanto às amplitudes e formas de onda quando se consideram comprimentos menores dos ramais de ligação, tanto para o caso em que as tensões foram calculadas entre o ramal e o transformador $(x=0 \mathrm{~m}$ e $\mathrm{xd}=30 \mathrm{~m}$, Figura 4.28-a) quanto para o caso em que foram calculadas no transformador ( $\mathrm{x}=30 \mathrm{~m}$ e $\mathrm{xd}=0 \mathrm{~m}$, Figura $4.28-\mathrm{b})$.

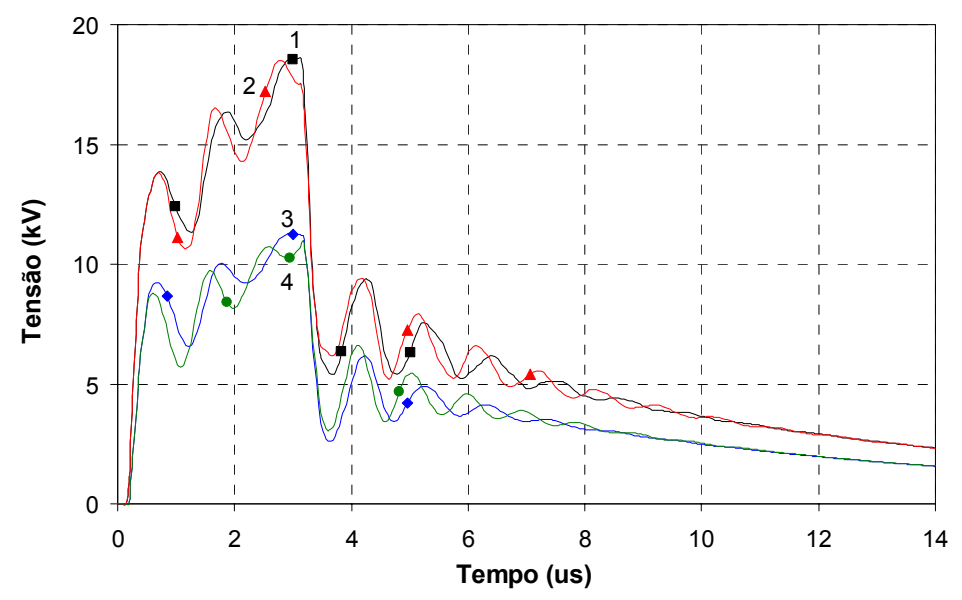

Fig. 4.43: Tensões induzidas (fase-terra) em diferentes pontos da linha em função do comprimento Ir do ramal de ligação.
1) $\operatorname{lr}=40 \mathrm{~m}(\mathrm{x}=0 \mathrm{~m}$ e $\mathrm{xd}=30 \mathrm{~m}$, Fig. $4.28-\mathrm{a})$
2) $1 \mathrm{r}=20 \mathrm{~m}(\mathrm{x}=0 \mathrm{~m}$ e $\mathrm{xd}=30 \mathrm{~m}$, Fig. $4.28-\mathrm{a})$
3) $l r=40 \mathrm{~m}(x=30 \mathrm{mexd}=0 \mathrm{~m}$, Fig. 4.28-b)
4) $1 \mathrm{r}=20 \mathrm{~m}(\mathrm{x}=30 \mathrm{~m}$ e $x d=0 \mathrm{~m}$, Fig. 4.28-b) 


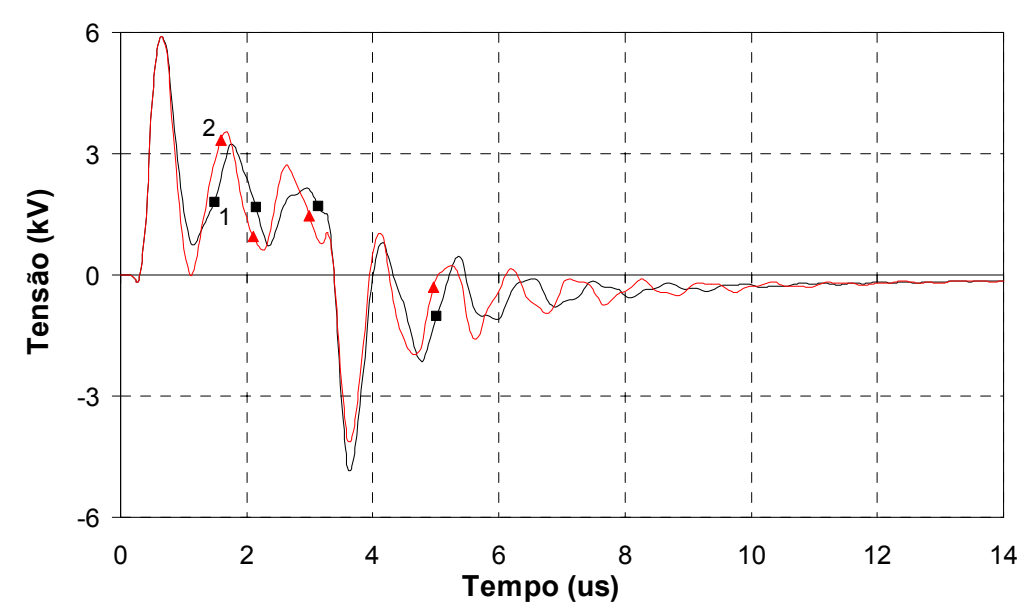

(a)

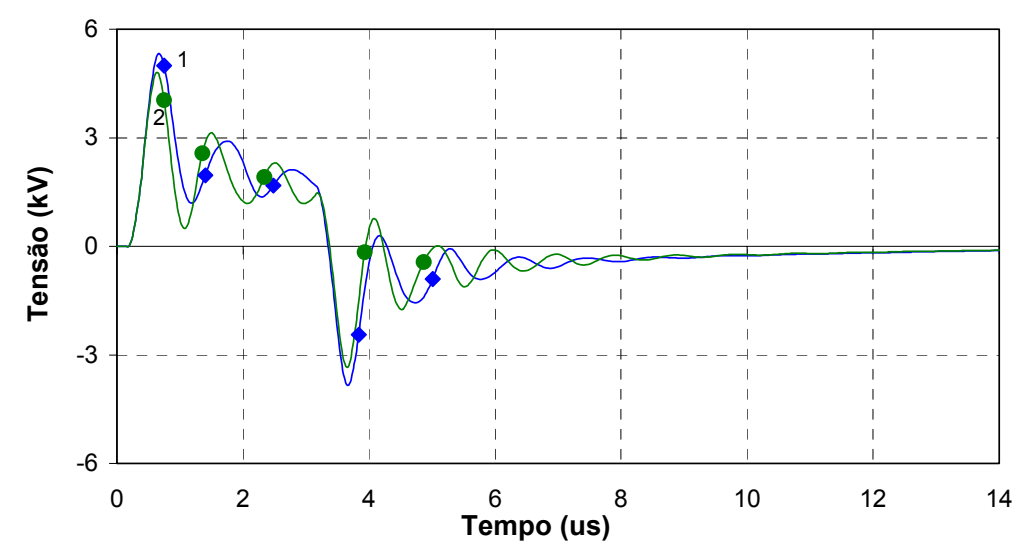

(b)

Fig. 4.44: Variação das tensões induzidas fase-neutro em função do comprimento do ramal de ligação em diferentes pontos da linha. Onda 1) $\mathrm{lr}=40 \mathrm{~m}$; onda 2) $\mathrm{lr}=20 \mathrm{~m}$.
a) $x=0 \mathrm{mexd}=30 \mathrm{~m}$ (Fig. 4.28 -a)
b) $x=30 \mathrm{me} x d=0 \mathrm{~m}$ (Fig. 4.28-b)

\subsubsection{Rede multiplexada}

A rede multiplexada é formada por um ou mais condutores isolados enlaçados ao redor do condutor neutro, que também possui a função de sustentação da rede. A rede multiplexada é recomendada em regiões muito arborizadas devido a várias vantagens em relação à rede convencional, como por exemplo menor freqüência de desligamentos provocados por toques em árvores e menores custos de manutenção. Em relação ao seu desempenho em descargas atmosféricas, há poucas publicações [89]. O objetivo deste item é comparar, em algumas situações, as tensões 
induzidas em redes convencionais e em redes multiplexadas. Novamente o estudo é feito inicialmente para casos mais simples e, posteriormente, são considerados transformador e cargas ao longo da linha. A influência de alguns parâmetros da linha e da corrente de descarga são depois analisados. Os parâmetros da descarga atmosférica (tempo de frente, tempo até o zero e amplitude da corrente, comprimento do canal de descarga, velocidade de propagação da corrente no canal, distância do local de queda da descarga à linha, etc.) utilizados nas simulações apresentadas a seguir são idênticos aos utilizados no Caso Base na rede convencional, salvo quando indicado em contrário.

Na Figura 4.45 é apresentada a configuração de uma rede de baixa tensão multiplexada, trifásica, com condutor neutro a 7,0 $\mathrm{m}$ de altura. A altura dos condutores fase foi adotada como sendo igual a 6,99 $\mathrm{m}$ e as tensões induzidas foram calculadas no ponto $\mathrm{P}$ central da linha, sendo que as tensões de fase referem-se à fase externa mais próxima ao canal da descarga atmosférica. A rede mostrada na Figura 4.45 também é casada em ambas as extremidades e não possui transformador ou cargas. Os condutores possuem diâmetro igual a $1 \mathrm{~cm}$.

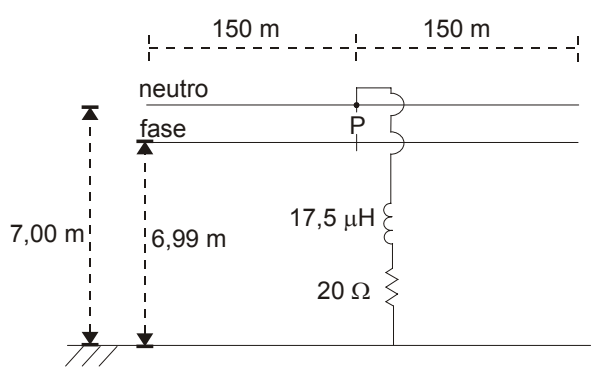

(a)

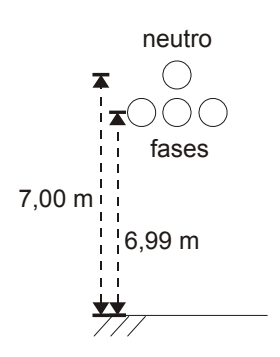

(b)

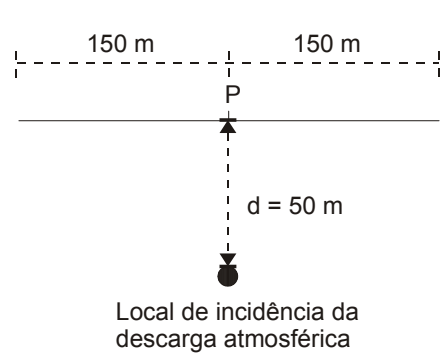

(c)

Fig. 4.45: Configuração de uma rede de BT multiplexada sem carga ou transformador instalado na linha.
a) vista lateral
b) vista frontal
c) vista superior (monofilar)

As tensões induzidas no ponto $\mathrm{P}$ indicado na Figura 4.45, utilizando os mesmos parâmetros da descarga utilizados na simulação do Caso Base da rede convencional, são mostradas na Figura 4.46 junto com as correspondentes tensões induzidas na rede convencional (configuração indicada na Figura 4.12). 


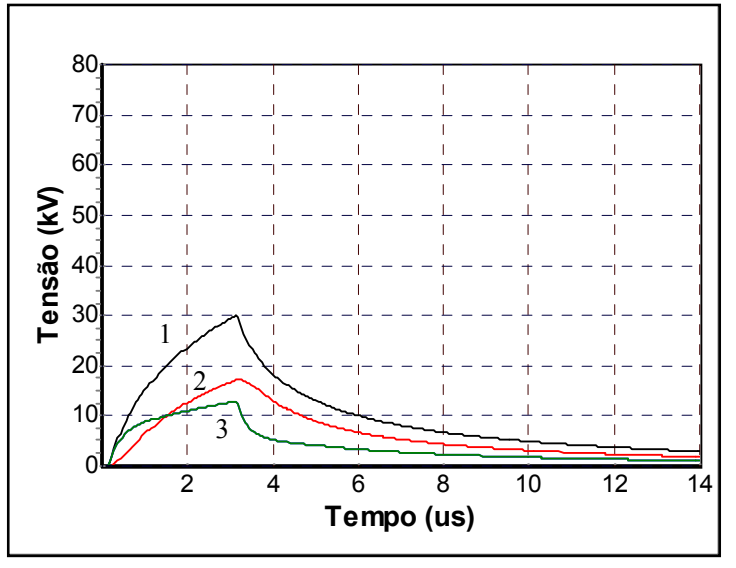

(a)

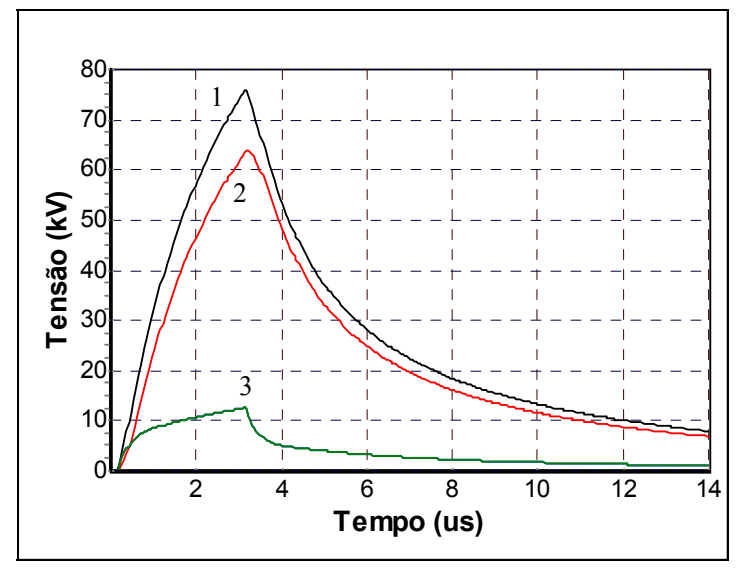

(b)

Fig. 4.46: Comparação entre tensões induzidas no ponto $\mathrm{P}(\mathrm{xd}=0 \mathrm{~m})$ das redes multiplexada (Fig. 4.45) e convencional (Fig 4.12). Caso simples, sem transformador ou cargas na linha.
1) Tensões fase-terra
2) Tensões fase-neutro
3) Tensões neutro-terra
a) rede multiplexada
b) rede convencional

Embora os condutores neutro das redes multiplexada e convencional estejam respectivamente a alturas de $7 \mathrm{~m}$ e $6,8 \mathrm{~m}$ em relação ao solo, pode-se comparar as tensões induzidas nas duas configurações. Ambas as redes são simples, não possuindo transformador ou cargas. Como visto na Figura 4.46, a rede multiplexada apresenta tensões induzidas fase-terra e fase-neutro com amplitudes bem mais baixas que as correspondentes à rede convencional (reduções de aproximadamente $61 \% \mathrm{e}$ $73 \%$ nas tensões fase-terra e fase-neutro, respectivamente). A tensão induzida neutro-terra na rede multiplexada sofreu um aumento de $2,6 \%$ em relação à da rede convencional. Isso ocorreu pelo fato de o condutor neutro da rede multiplexada estar $0,2 \mathrm{~m}(2,9 \%)$ acima do condutor neutro da rede convencional. Como a tensão induzida é diretamente proporcional à altura dos condutores, a rede multiplexada apresenta tensão neutro-terra com amplitude maior. A amplitude da tensão fase-terra na rede multiplexada apresentou uma redução significativa em relação à da rede convencional. Isso é explicado pelas menores distâncias entre os condutores fase e neutro (aproximadamente $1 \mathrm{~cm}$ ) na rede multiplexada, às quais correspondem maiores acoplamento entre os mesmos. Apesar desse resultado sugerir um melhor desempenho da rede multiplexada frente a tensões induzidas, o resultado observado na Figura 4.44 é válido apenas para o caso específico simulado. 
Para verificar o comportamento das tensões induzidas na rede multiplexada com a presença de um transformador de $30 \mathrm{kVA}$, foi realizada uma simulação considerando a configuração de linha mostrada na Figura 4.47. O modelo do transformador utilizado na simulação é o circuito RLC paralelo utilizado no item 4.3.1. As tensões induzidas foram calculadas no ponto $\mathrm{P}$, a $100 \mathrm{~m}$ do transformador (o neutro é aterrado neste ponto) e são mostradas na Figura 4.48 juntamente com as tensões obtidas na rede aberta de configuração equivalente (configuração mostrada na Figura 4.15 para $\mathrm{xd}=100 \mathrm{~m}$ ).

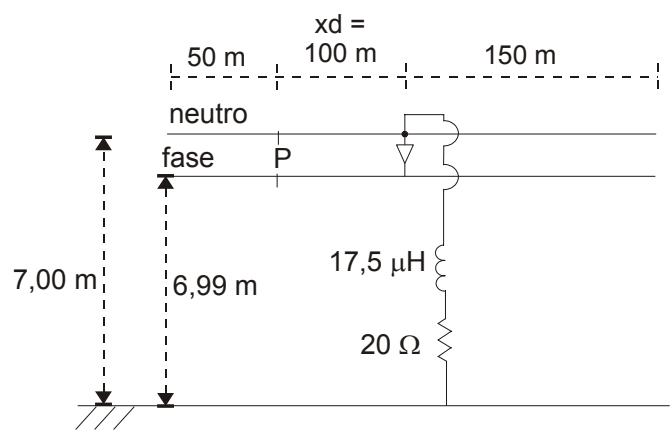

(a)

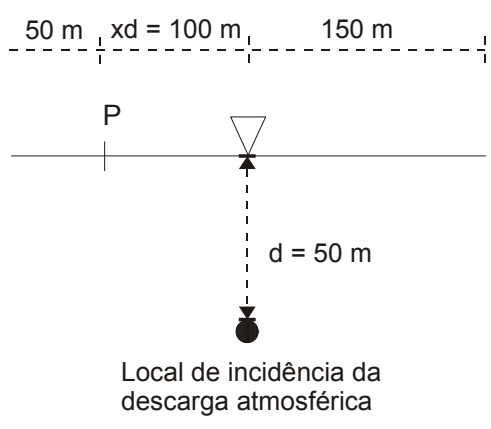

(b)

Fig. 4.47: Configuração da linha de BT multiplexada com transformador de $30 \mathrm{kVA}$ instalado em seu ponto central. $\mathrm{P}$ - ponto de cálculo das tensões induzidas. $\nabla$ - transformador.
a) vista lateral
b) vista superior (monofilar)

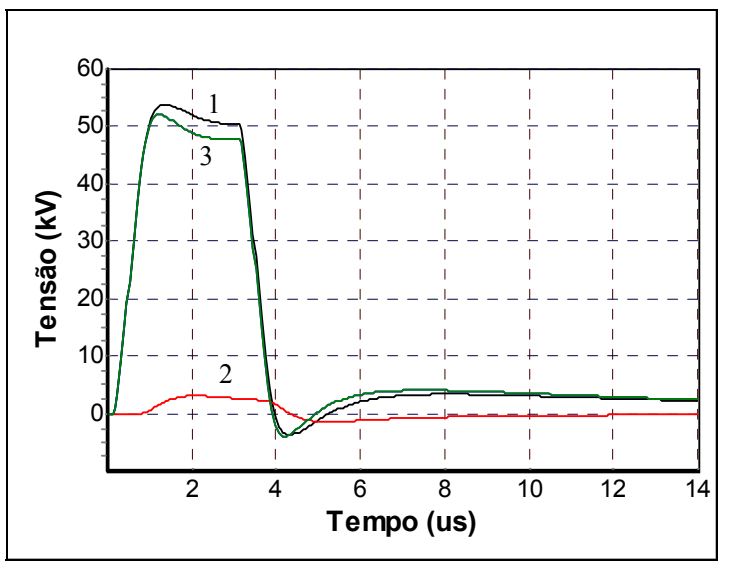

(a)

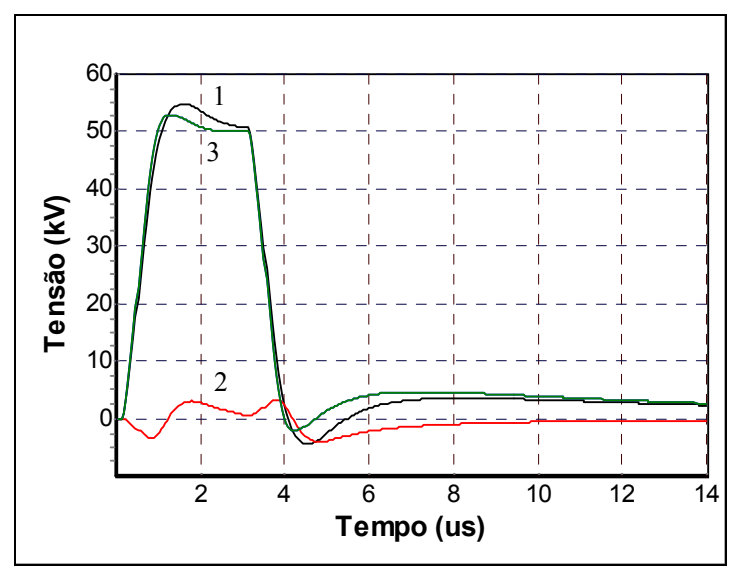

(b)

Fig. 4.48: Comparação entre tensões induzidas no ponto $\mathrm{P}(\mathrm{xd}=100 \mathrm{~m})$ na rede com transformador para as configurações multiplexada (Fig. 4.47) e convencional (Fig 4.15).
1) Tensões fase-terra
2) Tensões fase-neutro
3) Tensões neutro-terra
a) rede multiplexada
b) rede convencional 
Pode-se observar que na rede multiplexada com transformador as diferenças entre os valores de crista das tensões induzidas fase-terra e neutro-terra são muito pequenas. Em relação à rede convencional, as diferenças também são pequenas, inferiores a $2 \%$, com as tensões na rede multiplexada apresentando valores mais baixos. A comparação entre tensões induzidas fase-neutro para as duas redes analisadas é melhor visualizada na Figura 4.49. Conforme pode-se observar, a tensão induzida na rede multiplexada apresenta menor amplitude e menos oscilações. A tensão induzida fase-neutro na rede convencional apresenta incursão inicial negativa devido ao fato de o condutor neutro estar $0,2 \mathrm{~m}$ acima do condutor fase e o local de aterramento do neutro estar a $100 \mathrm{~m}$ do ponto de cálculo da tensão induzida. Neste caso (rede convencional), a diferença de altura entre os condutores é suficiente para que a tensão induzida neutro-terra seja maior, nos instantes iniciais, que a tensão induzida fase-terra. Como na rede multiplexada os condutores fase e neutro estão muito próximos (diferença de altura dos condutores igual a $1 \mathrm{~cm}$ ), essa diferença é muito menor, praticamente imperceptível para o caso em questão.

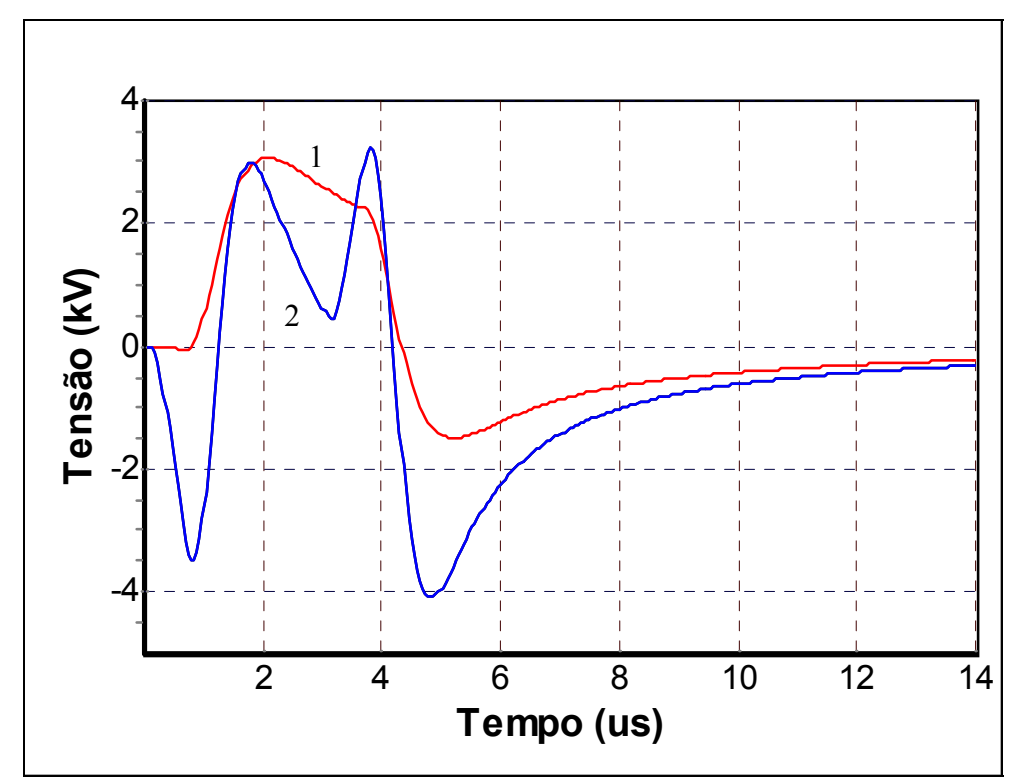

Fig. 4.49: Comparação entre tensões induzidas fase-neutro no ponto $\mathrm{P}(\mathrm{xd}=100 \mathrm{~m})$ na rede com transformador de $30 \mathrm{kVA}$ para as configurações multiplexada (Fig. 4.47) e convencional (Fig 4.15).

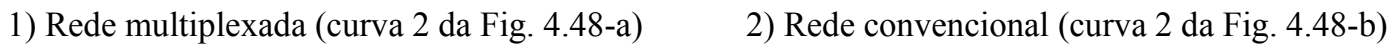


Observou-se então que as amplitudes e formas de onda das tensões induzidas faseterra e neutro-terra praticamente não foram alteradas com a mudança do tipo de rede, principalmente pela ligação existente entre os condutores fases e neutro através do circuito secundário do transformador de distribuição e também pelo fato de a tensão induzida ter sido calculada a $100 \mathrm{~m}$ do ponto de aterramento do neutro. Com a presença do transformador na linha, ocorre uma injeção de corrente no ponto de aterramento do condutor neutro, elevando assim o seu potencial. Quando se calcula a tensão induzida na linha em um ponto onde o neutro não é aterrado, a tensão no condutor neutro é praticamente igual à tensão no condutor fase nos primeiros instantes. Somente a partir do tempo $\mathrm{xd} / \mathrm{c}$ é que começam a chegar as ondas de tensão refletidas no ponto de aterramento do condutor neutro. Por esses motivos, a tensão no condutor neutro sofre uma grande variação quando comparada nessas duas situações. Conforme mostrado na Tabela 4.2, a tensão neutro-terra sofre um aumento significativo em relação ao caso anterior (aproximadamente $313 \%$ e $309 \%$ para as redes multiplexada e convencional, respectivamente).

Tabela 4.2: Amplitudes máximas das tensões induzidas no condutor neutro (ponto P) para as configurações de redes multiplexada (Figs. 4.45 e 4.47) e convencional (Figs.4.12 e 4.15).

\begin{tabular}{|l|c|c|c|}
\hline \multirow{2}{*}{ Tipo de Rede } & \multicolumn{2}{|c|}{$\begin{array}{c}\text { Valor de pico da tensão induzida no condutor } \\
\text { neutro }(\mathrm{kV})\end{array}$} & \multirow{2}{*}{ Variação (\%) } \\
\cline { 2 - 3 } & $\begin{array}{c}\text { Sem transformador e } \\
\text { com xd }=0 \mathrm{~m}\end{array}$ & $\begin{array}{c}\text { Com transformador e } \\
\text { com xd }=100 \mathrm{~m}\end{array}$ & \\
\hline Multiplexada & $12,6 \mathrm{kV}$ & $52,1 \mathrm{kV}$ & $313 \%$ \\
\hline Convencional & $12,9 \mathrm{kV}$ & $52,9 \mathrm{kV}$ & $309 \%$ \\
\hline
\end{tabular}

Outra comparação realizada envolveu o Caso Base da rede convencional (mostrado na Figura 4.25) com seu equivalente na rede multiplexada, indicado na Figura 4.50. Em ambas as configurações de rede a altura do condutor neutro é fixada em 7,0 m. Essa simulação tem por objetivo verificar o comportamento de uma rede multiplexada frente a surtos atmosféricos induzidos, considerando transformador e cargas instaladas ao longo da linha. Os modelos da carga e do transformador utilizados nessa simulação são idênticos aos utilizados na simulação do Caso Base da rede convencional, assim como todos os demais parâmetros utilizados nas 
simulações. As tensões induzidas na rede multiplexada são apresentadas na Figura 4.51. Como pode-se observar, a rede multiplexada para essa configuração de rede já não apresenta redução significativa nas amplitudes das tensões induzidas quando comparada à rede convencional, o que pode ser explicado pela existência de cargas conectadas ao longo da linha. Em relação às formas de onda das tensões, verifica-se que na rede multiplexada elas apresentam menos oscilações que as observadas na rede convencional. Observa-se também que os tempos de crista e cauda das ondas praticamente não se alteram para as duas configurações.

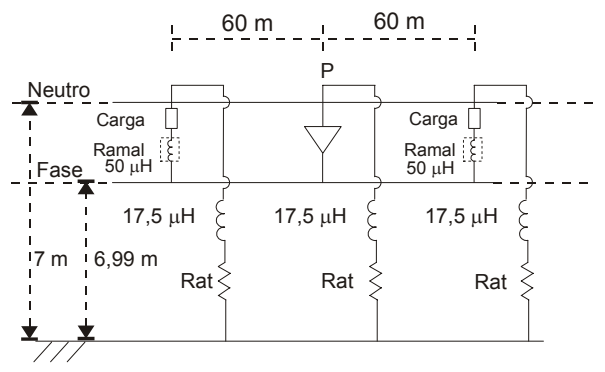

(a)

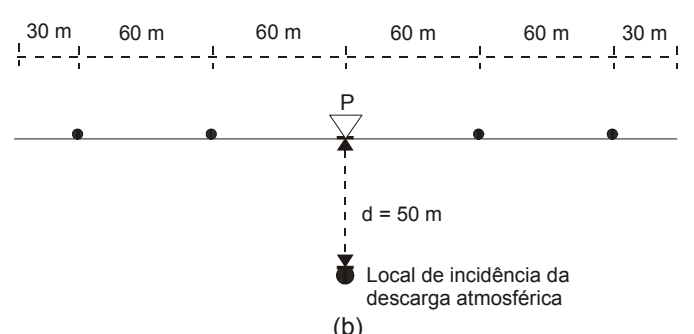

(b)

Fig. 4.50: Configuração da linha de BT multiplexada com transformador de $30 \mathrm{kVA}$ instalado no seu ponto central e cargas ao longo da linha (configuração equivalente à mostrada na Fig. 4.25).

$\mathrm{P}$ - ponto de cálculo das tensões induzidas. $\nabla$ - transformador. $\bullet$ - carga
a) vista lateral
b) vista superior (monofilar)

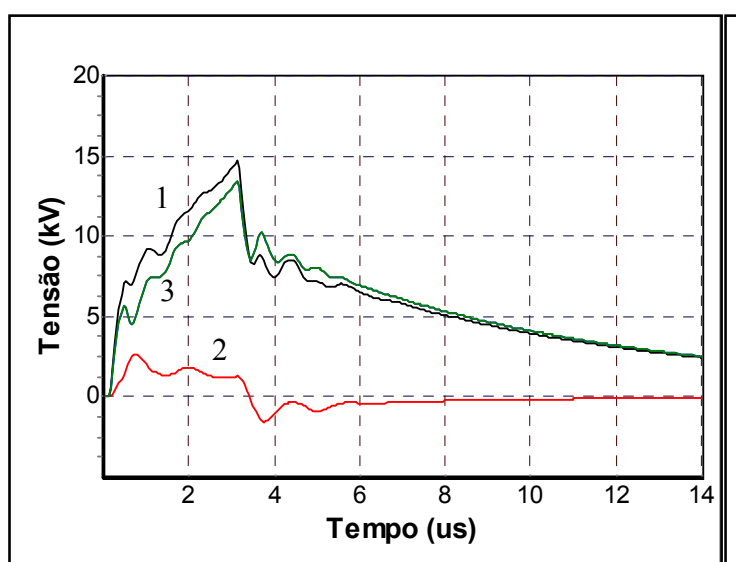

(a)

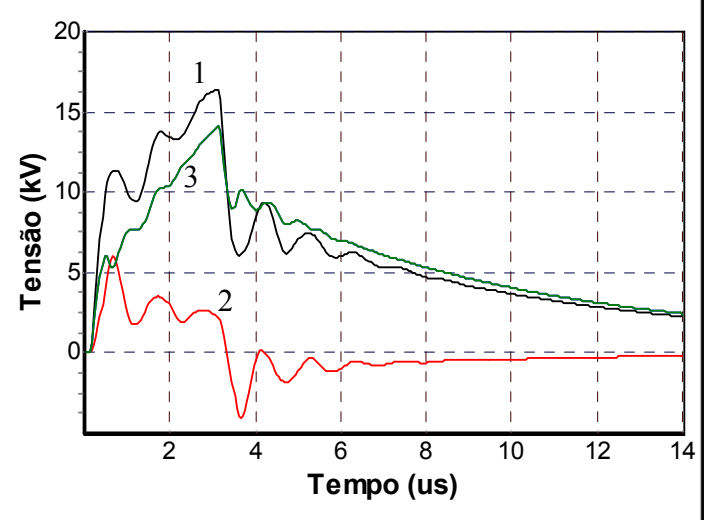

(b)

Fig. 4.51: Comparação entre tensões induzidas no ponto P na rede com transformador de $30 \mathrm{kVA} \mathrm{e}$ cargas para as configurações multiplexada (Fig. 4.50) e convencional (Fig 4.25).

Resistência de terra Rat $=20 \Omega$.
1) Tensões fase-terra
2) Tensões fase-neutro
3) Tensões neutro-terra
a) rede multiplexada
b) rede convencional 
No item 4.3.1 foi realizada uma análise paramétrica das tensões induzidas em redes convencionais considerando diferentes tipos de configuração de linha, onde os efeitos dos principais parâmetros da linha e das descargas atmosféricas foram analisados. A seguir são comparadas as tensões induzidas nas redes multiplexada e convencional considerando algumas das situações estudadas na análise realizada no item anterior.

\subsubsection{Posição ao longo da linha}

A configuração da rede multiplexada mostrada na Figura 4.50 foi modificada de modo a permitir a observação das tensões induzidas em um local da linha distante $30 \mathrm{~m}$ de um ponto de aterramento do condutor neutro, como indicado na Figura 4.52. Essa configuração é equivalente à utilizada na análise da rede convencional (Figura 4.28-a) e as tensões induzidas no ponto $\mathrm{P}$ para os dois tipos de rede são mostradas na Figura 4.53. Pode-se observar que as amplitudes das tensões induzidas fase-terra e neutro-terra nas duas redes são semelhantes. Já a amplitude da tensão fase-neutro da rede multiplexada apresenta maior variação percentual se comparada à respectiva tensão na rede convencional, devido ao fato de uma pequena variação nas tensões fase-terra e neutro-terra acarretar maior variação em sua amplitude. Nesse caso, a relação entre as amplitudes das tensões fase-neutro nas redes multiplexada e convencional foi de aproximadamente $42 \%$. Quanto às formas de onda, observa-se que as tensões induzidas na rede multiplexada apresentam oscilações menores que na rede convencional. 


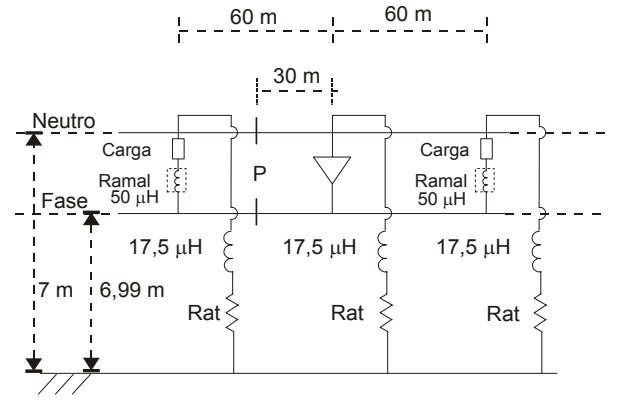

(a)

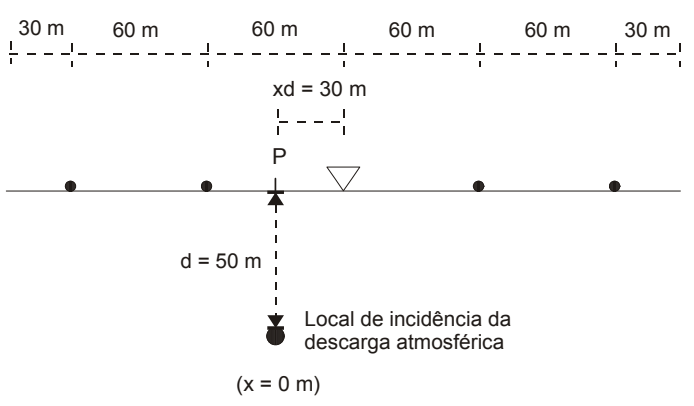

(b)

Fig. 4.52: Configuração de linha multiplexada para análise das tensões induzidas a $30 \mathrm{~m}$ de um ponto de aterramento do neutro. Configuração equivalente à mostrada na Fig. 4.28-a.

$\mathrm{P}$ - ponto de cálculo das tensões induzidas. $\nabla$ - transformador. $\bullet$ - carga
a) vista lateral
b) vista superior (monofilar)

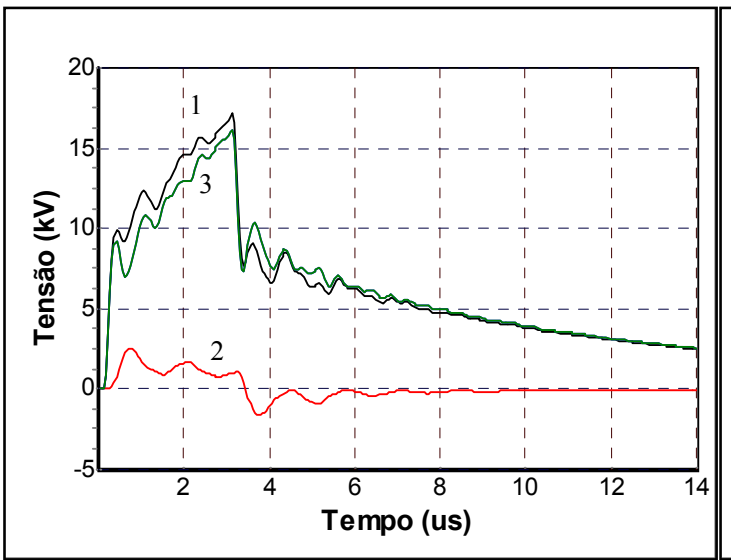

(a)

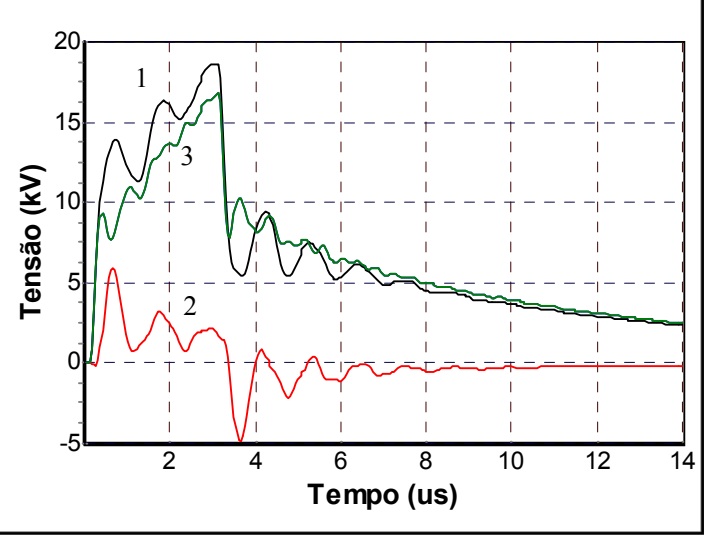

(b)

Fig. 4.53: Comparação entre tensões induzidas na rede com transformador e cargas para as configurações multiplexada (Fig. 4.52) e convencional (Fig 4.28-a).
1) Tensões fase-terra
2) Tensões fase-neutro
3) Tensões neutro-terra
a) rede multiplexada
b) rede convencional

\subsubsection{Amplitude da corrente de descarga}

Foram simuladas as configurações do Caso Base da rede multiplexada (Figura 4.50) e da rede convencional (Figura 4.25) com amplitude da corrente de descarga I igual a 90 kA. A comparação das tensões obtidas no ponto P para esses dois tipos de rede, utilizando os parâmetros restantes iguais ao Caso Base da rede convencional, é 
mostrada na Figura 4.54. Assim como no caso anterior, verifica-se que as amplitudes das tensões induzidas fase-terra e neutro-terra na rede multiplexada são semelhantes às observadas na rede convencional (as reduções de amplitude da rede multiplexada em relação à rede convencional foram de aproximadamente de $6 \%$ e $10 \%$, respectivamente). Por outro lado, o valor máximo da tensão fase-neutro na rede multiplexada sofreu redução de aproximadamente $56 \%$ em relação à rede convencional. Observa-se também que as formas de onda não sofreram alterações significavas nos dois casos considerados.

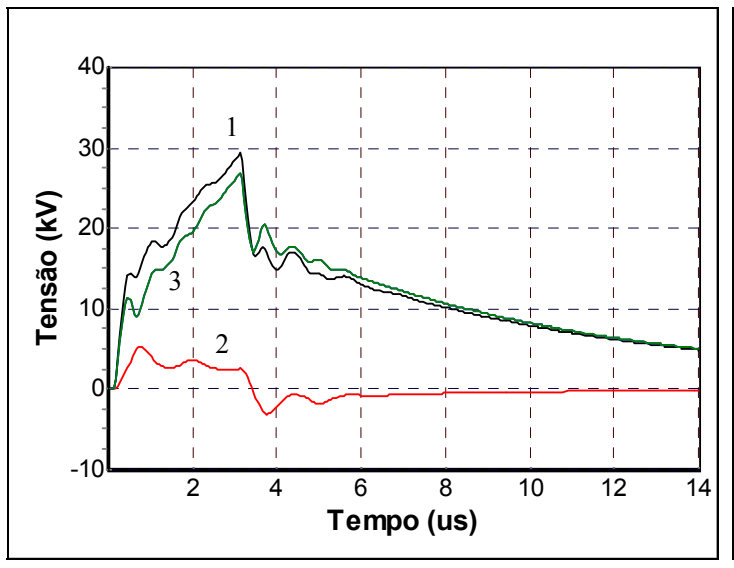

(a)

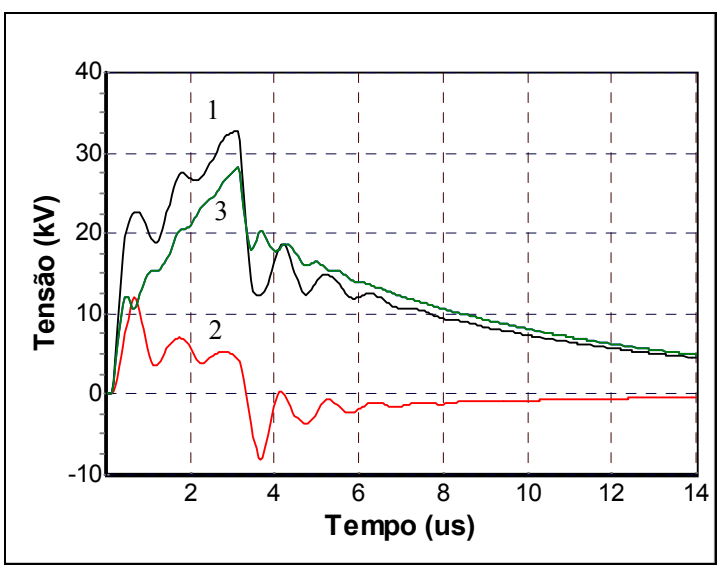

(b)

Fig. 4.54: Comparação entre tensões induzidas no ponto $\mathrm{P}$ da rede com transformador para as configurações multiplexada (Fig. 4.50) e convencional (Fig 4.25). Amplitude da corrente I = $90 \mathrm{kA}$.
1) Tensões fase-terra
2) Tensões fase-neutro
3) Tensões neutro-terra
a) rede multiplexada
b) rede convencional

\subsubsection{Tempo de frente da corrente de descarga}

O tempo de frente tf da corrente de descarga foi alterado para 1,5 $\mu$ s de modo a comparar as tensões induzidas nos dois tipos de rede para esta condição. Os demais parâmetros utilizados na simulação não foram alterados em relação ao Caso Base. As tensões induzidas no ponto $\mathrm{P}$ das figuras 4.25 e 4.50 são mostradas na Figura 4.55. As tensões induzidas na rede multiplexada apresentaram amplitudes reduzidas quando comparadas com as da rede convencional. A tensão fase-neutro da rede multiplexada sofreu maior redução (aproximadamente $70 \%$ ), enquanto para as tensões fase-terra e neutro-terra as reduções ficaram em torno de $39 \%$ e $22 \%$, 
respectivamente. Ao contrário dos outros casos comparados, as formas de onda das tensões na rede multiplexada são diferentes daquelas observadas na rede convencional. Os tempos de crista das tensões fase-terra e neutro-terra na rede convencional são menores que os observados na rede multiplexada (diferenças de $0,93 \mu$ s e $0,53 \mu$ s respectivamente). Já as tensões fase-neutro atingem o seu máximo valor aproximadamente no mesmo instante. Nota-se então que para correntes com tempos de frente curtos o tipo de rede (multiplexada ou convencional) tem influência nas amplitudes e formas de ondas das tensões induzidas.

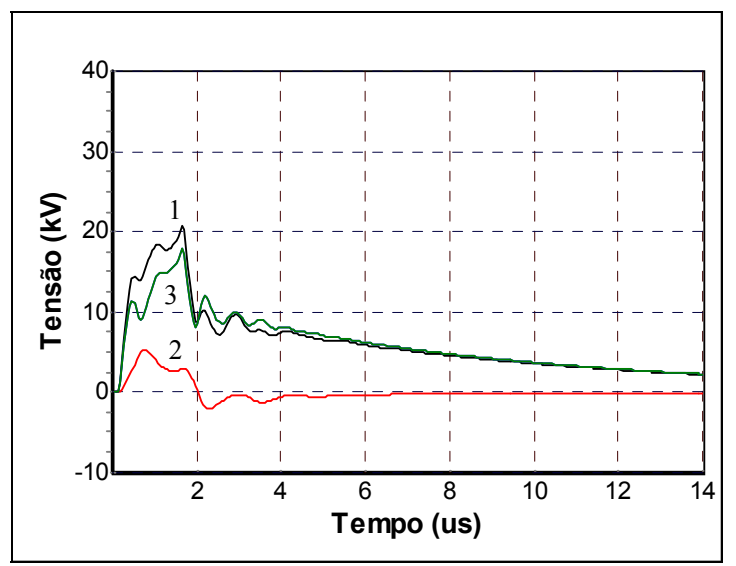

(a)

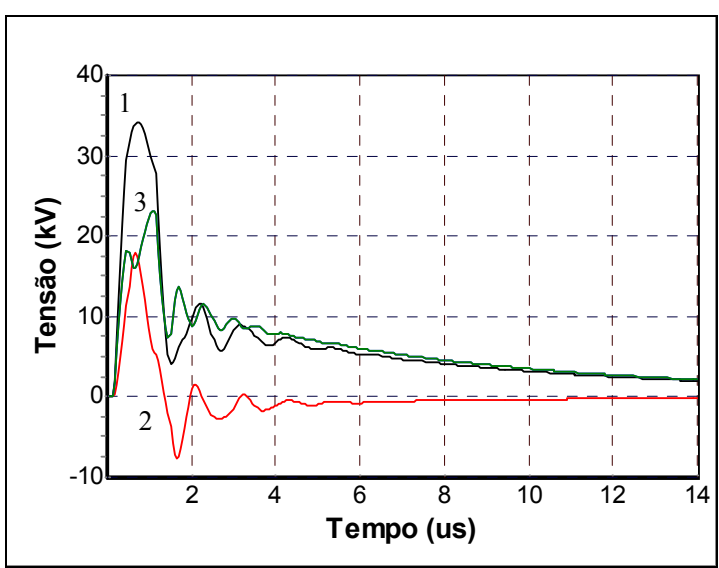

(b)

Fig. 4.55: Comparação entre tensões induzidas no ponto P na rede com transformador para as configurações multiplexada (Fig. 4.50) e convencional (Fig 4.25).

Tempo de frente da corrente da descarga $\mathrm{tf}=1,5 \mu \mathrm{s}$.
1) Tensões fase-terra
2) Tensões fase-neutro
3) Tensões neutro-terra
a) rede multiplexada
b) rede convencional

\subsubsection{Resistência de terra}

$\mathrm{Na}$ análise paramétrica realizada na rede convencional mostrou-se que a resistência de terra tem grande influência nas amplitudes das tensões induzidas. Para verificar o comportamento das tensões induzidas na rede multiplexada frente a esse parâmetro, foi realizada uma simulação da configuração de rede apresentada da Figura $4.50 \mathrm{com}$ valor de resistência de terra igual a $200 \Omega$. As tensões induzidas calculadas no ponto $\mathrm{P}$ das figuras 4.25 e 4.50 (rede convencional e multiplexada, respectivamente) são 
apresentadas na Figura 4.56. Observa-se que as diferenças entre as tensões induzidas não foram significativas (principalmente nas tensões fase-terra e neutro-terra), a exemplo do que se verificou para o caso de Rat $=20 \Omega$ (Figura 4.51). Conclui-se então que a resistência de terra pode afetar significativamente as tensões induzidas também para redes multiplexadas.

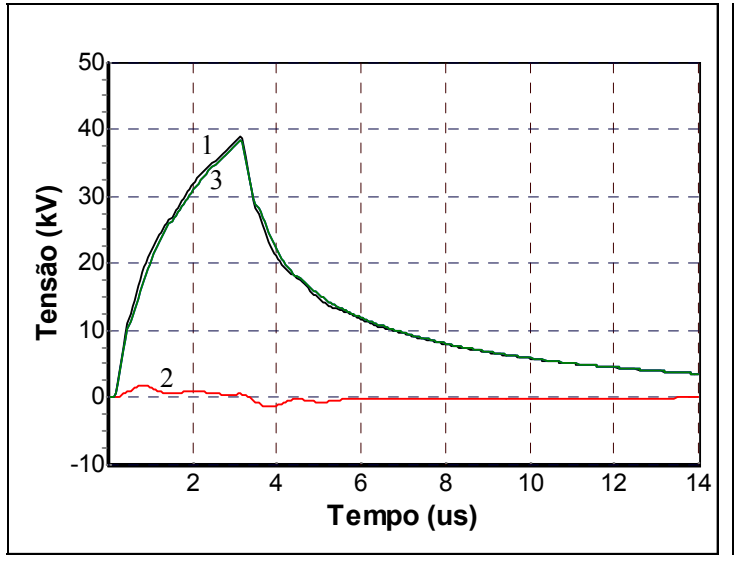

(a)

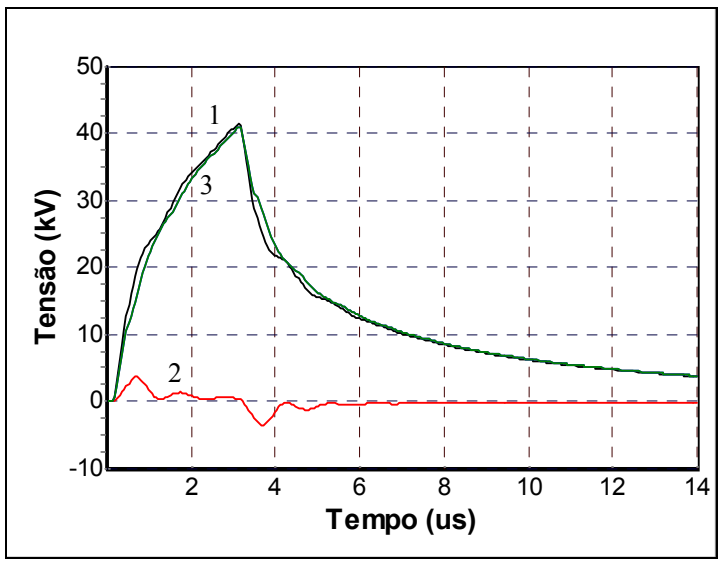

(b)

Fig. 4.56: Comparação entre tensões induzidas no ponto $\mathrm{P}$ na rede com transformador para as configurações multiplexada (Fig. 4.50) e convencional (Fig 4.25). Resistência de terra Rat $=200 \Omega$.
1) Tensões fase-terra
2) Tensões fase-neutro
3) Tensões neutro-terra
a) rede multiplexada
b) rede convencional

Nesse item foram apresentadas comparações entre tensões induzidas em redes multiplexadas e convencionais. Para o caso de uma linha simples, sem cargas ou transformador, as diferenças entre as amplitudes das tensões induzidas nas duas configurações é significativa - da ordem de $60 \%$ a $70 \%$ de redução na linha multiplexada. Como pode-se observar, para os casos onde se encontram instalados na linha transformador ou cargas, as amplitudes das tensões fase-terra e neutro-terra nas redes multiplexadas são, em geral, um pouco inferiores que as observadas na rede convencional (até aproximadamente $10 \%$ ). Por outro lado, as diferenças nas amplitudes das tensões fase-neutro são bem maiores, observando-se reduções da ordem de $50 \%$. Essas diferenças tendem a aumentar à medida que diminui o tempo de frente da corrente da descarga. 


\subsubsection{Tensões induzidas em linhas com dispositivos de proteção contra surtos}

Nas redes de distribuição os pára-raios são usados principalmente no primário transformador e nos finais da linha primária. Nas redes de baixa tensão os dispositivos de proteção contra surtos (DPS) geralmente não são utilizados, o que pode provocar a queima do transformador devido a surtos oriundos da baixa tensão [15]. O objetivo desse item é verificar a eficiência dos DPSs na redução das amplitudes de tais surtos e, conseqüentemente, no aumento da confiabilidade do sistema. Para tal foram simuladas duas configurações de linha de baixa tensão multiplexada, apresentadas na Figura 4.57. Os demais parâmetros da linha são idênticos aos utilizados no item 4.3.2. Vale ressaltar que essas configurações consideradas representam um grande avanço na análise das tensões induzidas em linhas de BT por descargas atmosféricas. Ao longo da pesquisa bibliográfica realizada não foram encontradas publicações tratando de configurações com esse grau de complexidade.

As tensões induzidas são calculadas no ponto $\mathrm{P}$, a $75 \mathrm{~m}$ do transformador, para uma descarga atmosférica incidente a $50 \mathrm{~m}$ da linha, em frente ao ponto P. Os parâmetros da descarga atmosférica são iguais ao utilizados no Caso Base da rede convencional no item 4.3.1. Anteriormente foi mostrado que o modelo da carga que representa a unidade consumidora utilizado nesse trabalho pode ser simplificado por um indutor de 3,5 $\mu \mathrm{H}$. Neste item essa simplificação foi adotada, sendo utilizado um indutor de $53,5 \mu \mathrm{H}$ entre os condutores fase e neutro da linha, sendo 3,5 $\mu \mathrm{H}$ referente à própria carga e $50 \mu \mathrm{H}$ referente à indutância do condutor fase do ramal de ligação. Assim como nas cargas, o secundário do transformador também foi modelado por uma indutância de $53,5 \mu \mathrm{H}$, conforme discutido no item 4.3.1. Nos pontos da linha onde existe carga ou transformador o condutor neutro é aterrado, sendo a resistência de terra assumida igual a $20 \Omega$ e a indutância do condutor de descida do aterramento do neutro igual a 17,5 $\mu \mathrm{H}$ (iguais ao Caso Base - rede multiplexada). A utilização de DPS no modelo ERM se dá por meio da curva característica VxI do dispositivo, sendo esta obtida por meio de ensaios em laboratório a partir da aplicação de impulsos normalizados de corrente (onda $8 / 20 \mu$ s). Nas simulações foi utilizada a 
curva VxI indicada na Figura 4.58. O DPS é instalado diretamente na linha, entre os condutores fase e neutro, e utiliza o mesmo condutor de aterramento do neutro para desviar as correntes de surto. As tensões induzidas no ponto $\mathrm{P}$ considerando amplitudes de correntes de descarga I iguais a $45 \mathrm{kA}$ e $90 \mathrm{kA}$ para as duas configurações simuladas são mostradas nas figuras 4.59 e 4.60 respectivamente (ambas correntes com $\mathrm{tf}=3 \mu$ s e to $=150 \mu \mathrm{s}$ ).

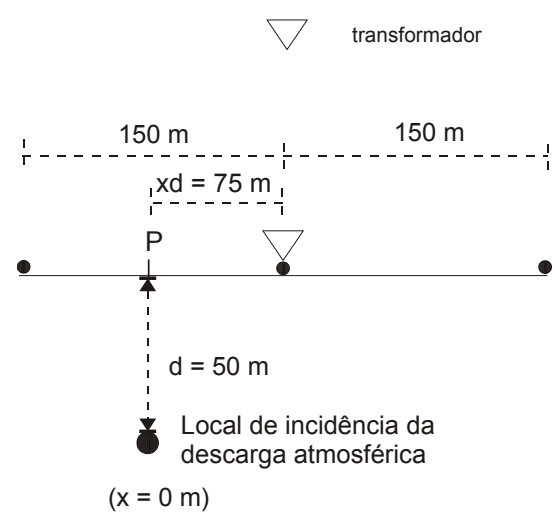

(a)

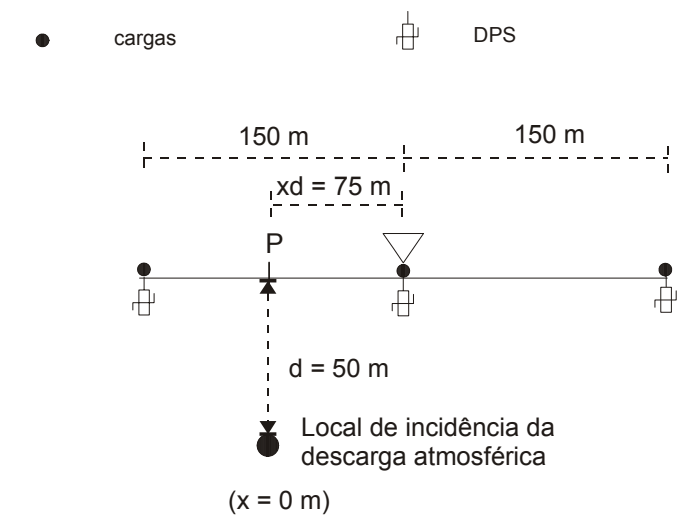

(b)

Fig. 4.57: Configurações de rede multiplexada simuladas.

a) Linha sem DPS

b) DPS no secundário do transformador e nas extremidades da linha

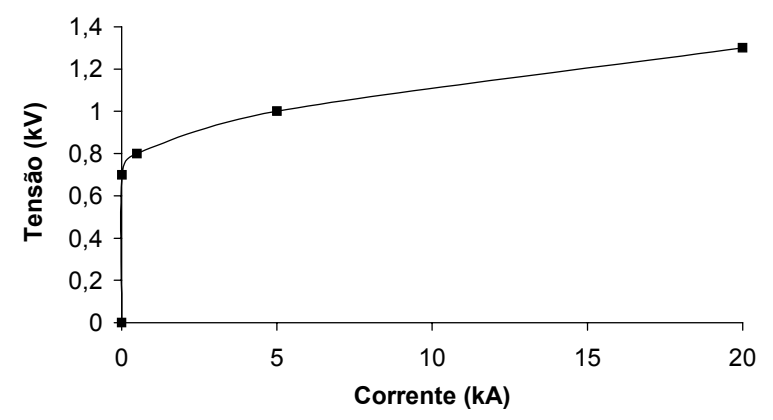

Fig. 4.58: Curva VxI de um DPS típico de baixa tensão.

Como pode-se observar, as amplitudes das tensões fase-terra pouco variaram com a presença de DPSs na linha, tanto para correntes com amplitudes de $45 \mathrm{kA}$ como para 90 kA. Por outro lado, a redução de amplitude das tensões fase-neutro na linha com DPSs são mais visíveis, tendo sido obtidas reduções de aproximadamente 54 \% e $77 \%$ para correntes com amplitudes de $45 \mathrm{kA}$ e $90 \mathrm{kA}$, respectivamente. 
Verificou-se também que as amplitudes das tensões fase-terra praticamente dobraram quando a corrente de descarga foi alterada de $45 \mathrm{kA}$ para $90 \mathrm{kA}$, fato este não observado nas tensões fase-neutro devido à presença do dispositivo de proteção entre os condutores. Como o DPS é instalado na linha entre os condutores fase e neutro e ligado à terra por meio de um aterramento com impedância não nula, as reduções de amplitude das tensões fase-terra são menores que as verificadas nas tensões faseneutro. Em relação às formas de onda, nota-se poucas alterações nas tensões faseterra para os dois casos analisados. Já as tensões fase-neutro apresentam mais oscilações na linha com proteção devido à atuação dos DPSs.

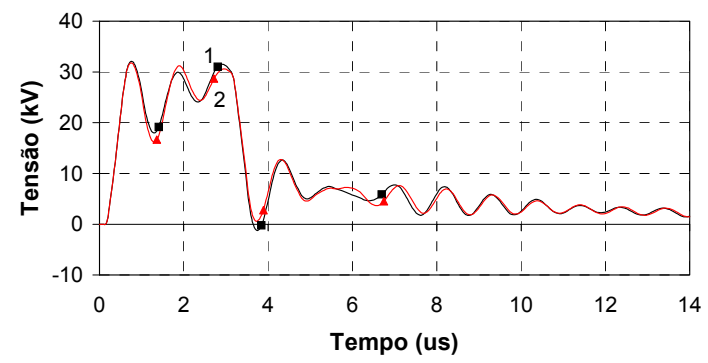

(a)

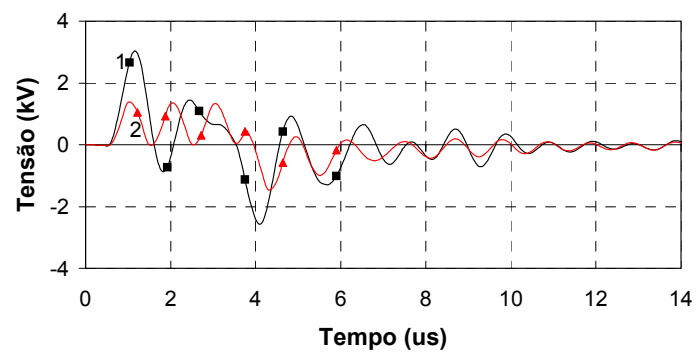

(b)

Fig. 4.59: Tensões induzidas no ponto P para as duas configurações de linha mostradas na Fig. 4.57. Amplitude da corrente de descarga $\mathrm{I}=45 \mathrm{kA}, \mathrm{tf}=3 \mu \mathrm{s}$, to $=150 \mu \mathrm{s}$.

1) Linha sem DPS (configuração indicada na Fig. 4.57-a)

2) Linha com DPS no transformador e nos finais da linha (configuração indicada na Fig. 4.57-b)
a) tensões fase-terra
b) tensões fase-neutro

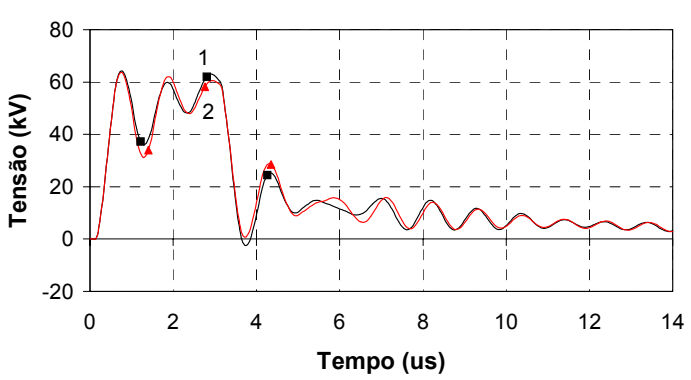

(a)

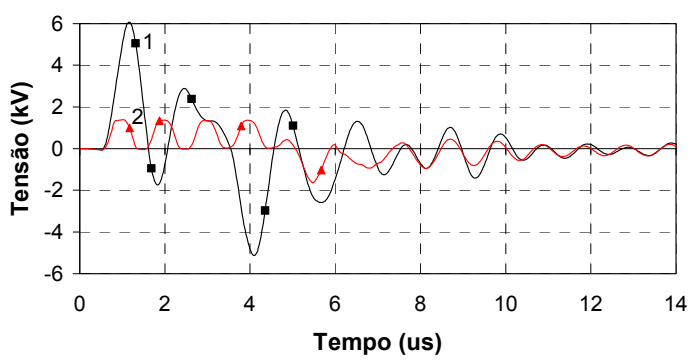

(b)

Fig. 4.60: Tensões induzidas no ponto P para as três configurações de linha mostradas na Fig. 4.57. Amplitude da corrente de descarga $\mathrm{I}=90 \mathrm{kA}, \mathrm{tf}=3 \mu \mathrm{s}$, to $=150 \mu \mathrm{s}$.

1) Linha sem DPS (configuração indicada na Fig. 4.57-a)

2) Linha com DPS no transformador e nos finais de linha (configuração indicada na Fig. 4.57-b)
a) tensões fase-terra
b) tensões fase-neutro 
As tensões induzidas no ponto $\mathrm{P}$ e também nos terminais de BT do transformador, no caso de uma descarga atmosférica incidente no ponto indicado na Figura 4.57-b, com amplitude de corrente igual a $90 \mathrm{kA}$, são mostradas na Figura 4.61. Como era de se esperar, as amplitudes das tensões no transformador são significativamente menores que no ponto $\mathrm{P}$ (a $75 \mathrm{~m}$ de distância dos DPSs). A tensão fase-terra foi reduzida em aproximadamente $76 \%$, enquanto que para a tensão fase-neutro essa redução ficou ao redor de $48 \%$. No caso das tensões no secundário do transformador, pode-se observar a grande redução da amplitude da tensão fase-terra e a forma de onda da tensão fase-neutro, limitada à tensão residual do DPS. A amplitude da tensão fase-terra sofre uma redução acentuada porque a impedância do DPS (quando de sua atuação) é muito baixa - da ordem de $1 \Omega$.

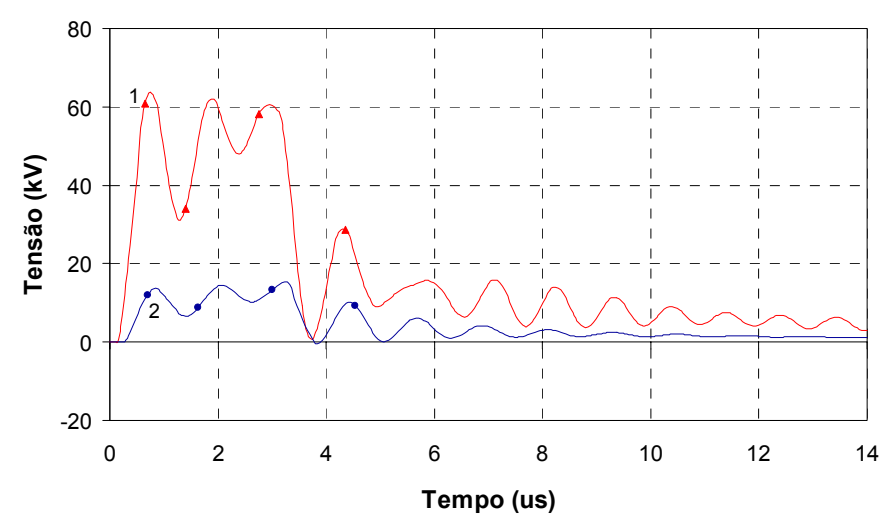

(a)

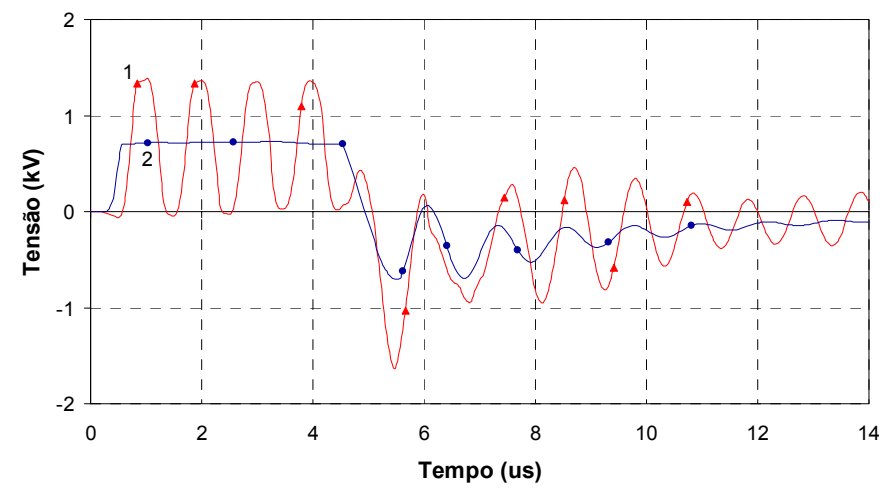

(b)

Fig. 4.61: Tensões induzidas no ponto P e nos terminais de BT do transformador para a configuração de linha mostrada na Fig. 4.57-b.

Amplitude da corrente de descarga igual a $90 \mathrm{kA}, \mathrm{tf}=3 \mu \mathrm{s}$, to $=150 \mu \mathrm{s}$.

1) Tensões no ponto $P$

a) tensões fase-terra
2) Tensões nos terminais de BT do transformador

b) tensões fase-neutro 


\subsection{Comparação entre tensões transferidas ao secundário do transformador e tensões induzidas em redes de baixa tensão}

No Capítulo 3 foram calculadas as tensões transferidas à rede de baixa tensão através do transformador devido a descargas atmosféricas próximas à linha. Neste item é realizada a comparação entre tensões transferidas e tensões induzidas na rede baixa tensão. Para isso são calculadas (com o uso do ERM) as tensões induzidas em uma determinada configuração de rede para a mesma descarga atmosférica incidente em suas proximidades, podendo assim ser comparadas diretamente as tensões induzidas com as transferidas pelo transformador. A Figura 4.62 mostra a configuração utilizada no cálculo das tensões induzidas nas linhas primária e secundária.

A rede primária é trifásica, com $6 \mathrm{~km}$ de extensão, condutores situados a $10 \mathrm{~m}$ do solo e com um transformador típico de distribuição de $30 \mathrm{kVA}$ instalado no centro da linha. Foi utilizado o modelo apresentado no Capítulo 3 (Figura 3.12) para representar a impedância do transformador vista pela linha de média tensão e para os cálculos da tensão transferida. A rede de baixa tensão é multiplexada, trifásica, com $300 \mathrm{~m}$ de comprimento e condutores neutro e fases a $7 \mathrm{~m} \mathrm{e} 6,99 \mathrm{~m}$ do solo, respectivamente. $\mathrm{O}$ condutor neutro segue toda a extensão da linha primária e é aterrado no transformador e a cada $150 \mathrm{~m}$, com resistência de terra assumida igual a $20 \Omega$ e indutância do condutor de descida do aterramento igual a $17,5 \mu \mathrm{H}$. O diâmetro dos condutores da rede primária e secundária é de $1 \mathrm{~cm}$. Uma carga consumidora de $3,5 \mu \mathrm{H}$ e seu ramal de ligação $(50 \mu \mathrm{H})$ são considerados em cada extremidade da linha de BT e também no secundário do transformador de distribuição. As tensões induzidas calculadas nos pontos $\mathrm{P}_{1}$ e $\mathrm{P}_{2}$ indicados na Figura 4.62 (linhas primária e secundária) são mostradas nas figuras 4.63 e 4.64 para uma descarga atmosférica incidente a $50 \mathrm{~m}$ da linha, e em frente ao transformador, com amplitude de corrente de $45 \mathrm{kA}$ e tempos de frente iguais a $3 \mu \mathrm{s}$ e $1,5 \mu \mathrm{s}$ respectivamente. Os demais parâmetros das descargas atmosféricas são idênticos aos utilizados no Caso Base do item 4.3.1. 


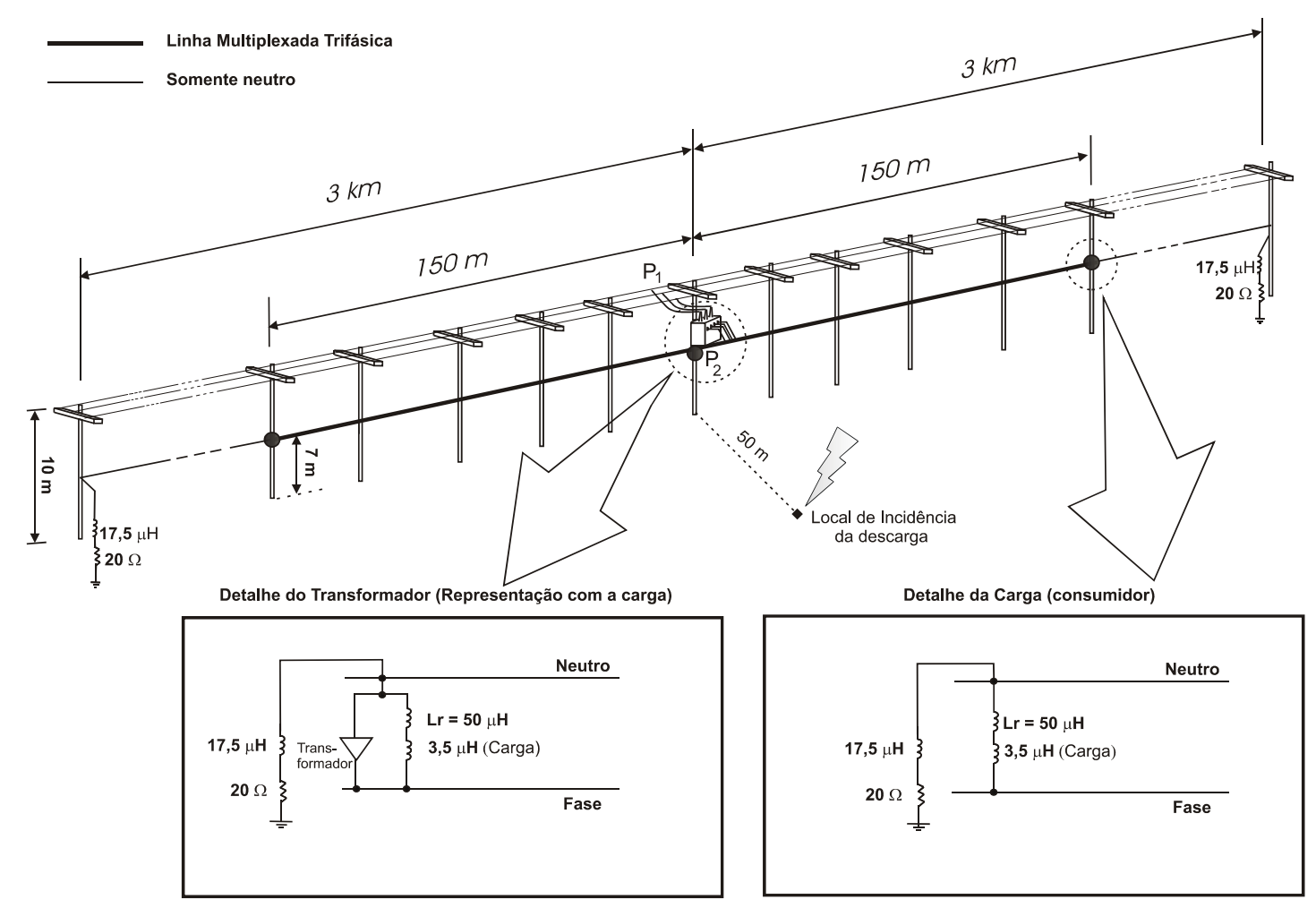

Fig. 4.62: Configurações das linhas primária e secundária.

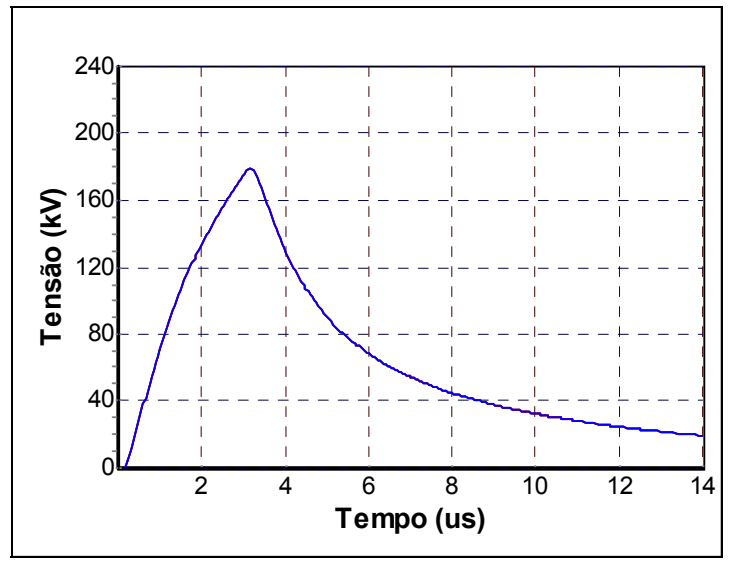

(a)

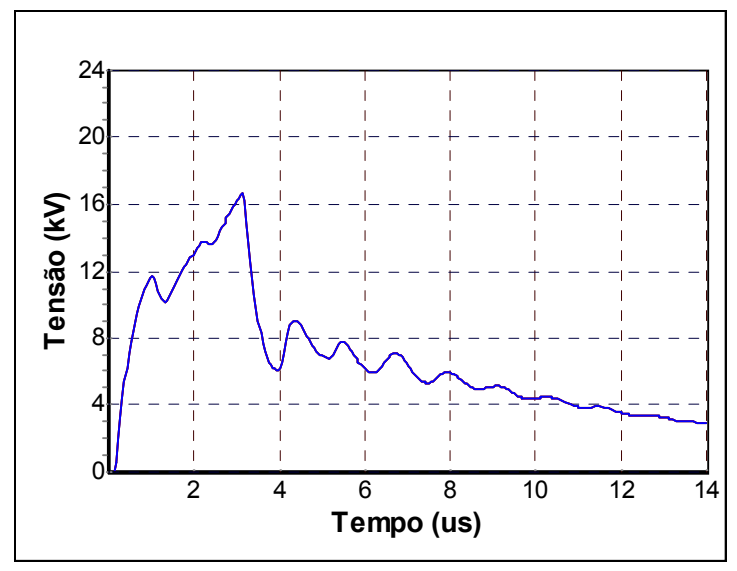

(b)

Fig. 4.63: Tensões induzidas fase-terra nos pontos $\mathrm{P}_{1}$ e $\mathrm{P}_{2}$ das linhas primária e secundária (configuração mostrada na Fig. 4.62) para corrente de descarga com tempo de frente $\mathrm{tf}=3 \mu \mathrm{s}$.
a) tensão na linha primária (ponto $P_{1}$ )
b) tensão na linha secundária (ponto $\mathrm{P}_{2}$ ) 


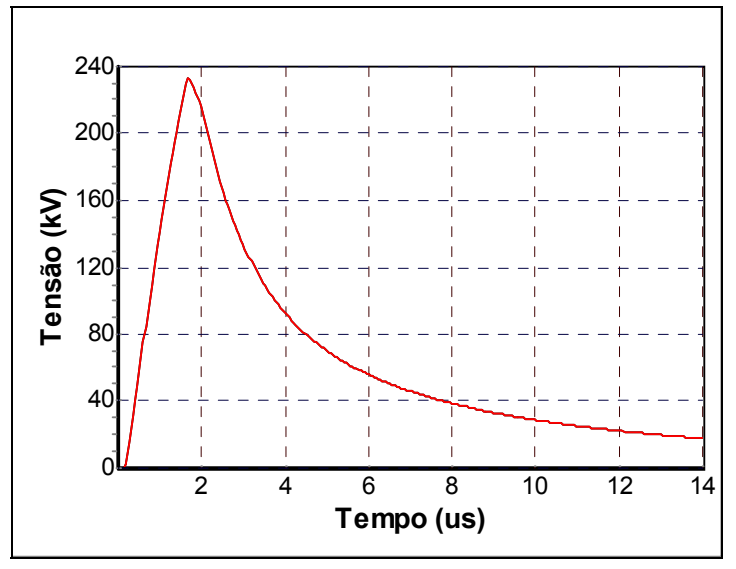

(a)

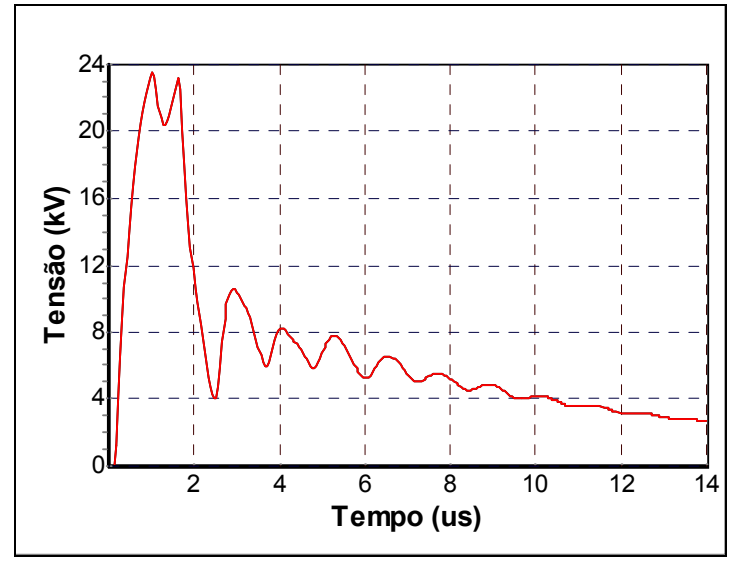

(b)

Fig. 4.64: Tensões induzidas fase-terra nos pontos $\mathrm{P}_{1}$ e $\mathrm{P}_{2}$ das linhas primaria e secundária (configuração mostrada na Fig. 4.62) para corrente de descarga com tempo de frente tf $=1,5 \mu \mathrm{s}$.
a) tensão na linha primária (ponto $\mathrm{P}_{1}$ )
b) tensão na linha secundária (ponto $\mathrm{P}_{2}$ )

As tensões fase-terra induzidas na linha primária alcançam amplitudes elevadas, aproximadamente $180 \mathrm{kV}$ e $230 \mathrm{kV}$, para correntes com tempos de frente de $3 \mu$ s e 1,5 $\mu$ s, respectivamente. As formas de onda não apresentam oscilações e os tempos de frente são aproximadamente iguais aos das correntes da descarga. As tensões faseneutro da rede primária são muito próximas às tensões fase-terra apresentadas, uma vez que a tensão neutro-terra é significativamente menor (aproximadamente $91 \%$ menor) que as tensões fase-terra da linha primária. As tensões fase-terra na linha de baixa tensão apresentam amplitudes e formas de onda semelhantes às mostradas no item 4.3.2. Observa-se que as formas de onda das tensões na baixa tensão apresentam quedas mais acentuadas e mais oscilações em relação às tensões induzidas no primário, devido à presença de cargas na linha.

A partir das tensões induzidas fase-neutro nos terminais de alta tensão do transformador, foram calculadas as tensões transferidas à linha de BT utilizando o programa "Alternative Transients Program" (ATP), considerando a configuração mostrada na Figura 4.62. Nas simulações não se considerou a ocorrência de disrupções. As tensões transferidas ao secundário do transformador e as tensões induzidas no ponto $\mathrm{P}_{2}$ da linha de $\mathrm{BT}$ são mostradas nas figuras 4.65 e 4.66 para correntes com tempos de frente iguais a $3 \mu \mathrm{s}$ e 1,5 $\mu \mathrm{s}$, respectivamente. Vale lembrar que no local de cálculo das tensões transferidas existe a ligação de um consumidor 
(modelado por uma indutância de 3,5 $\mu \mathrm{H}$ ) por meio de um ramal (indutância de $50 \mu \mathrm{H})$. Observa-se que as tensões transferidas apresentam característica oscilatória, com freqüência fundamental entre $770 \mathrm{kHz}$ e $910 \mathrm{kHz}$ nesses casos analisados. As amplitudes das tensões transferidas atingem baixos valores, aproximadamente $1 \mathrm{kV}$ para corrente de descarga com $\mathrm{tf}=3 \mu \mathrm{s}$ e $2,5 \mathrm{kV}$ para o caso de $\mathrm{tf}=1,5 \mu \mathrm{s}$. Comparadas com as tensões induzidas fase-neutro na linha de baixa tensão, as amplitudes das tensões transferidas via transformador são menores, embora não desprezíveis.

A tensão total na linha de baixa tensão devido a descargas indiretas é a composição dessas duas parcelas: tensões induzidas e tensões transferidas pelo transformador. A título de ilustração a tensão total é mostrada na Figura 4.67 para os dois casos analisados. Nota-se também que as características básicas das tensões transferidas ao secundário (amplitudes e formas de onda) são semelhantes às verificadas no Capítulo 3, quando se utilizou dados de tensões induzidas medidas em linhas primárias em experimentos realizados tanto em escala real como em modelo reduzido.

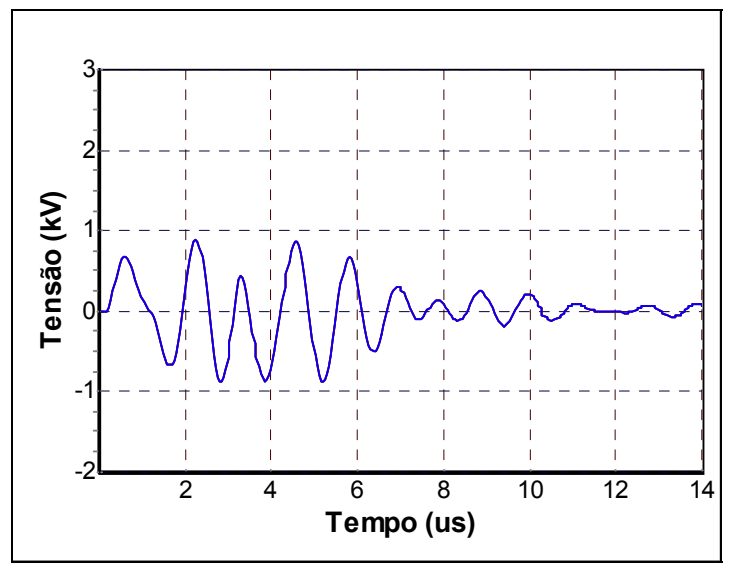

(a)

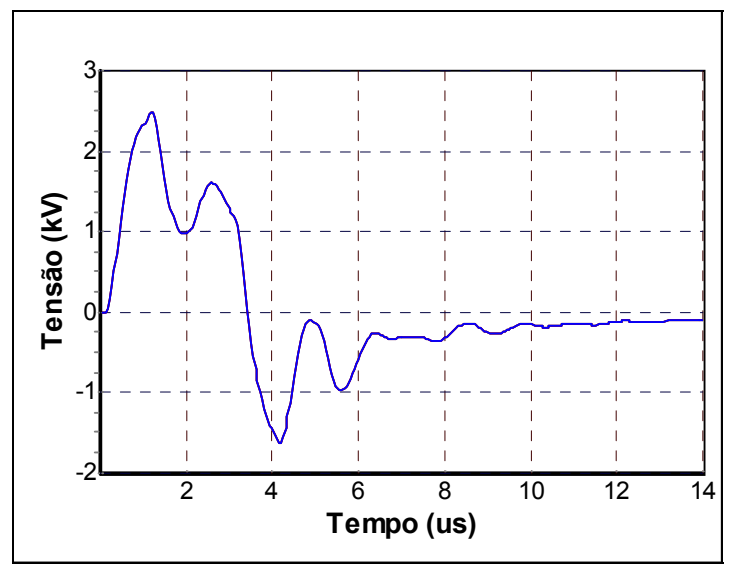

(b)

Fig. 4.65: Sobretensões fase-neutro na rede secundária (ponto $\mathrm{P}_{2}$ ) devido a descarga nas proximidades da linha. Amplitude da corrente da descarga igual a $45 \mathrm{kA}, \mathrm{tf}=3 \mu \mathrm{s}$.
a) tensão transferida via transformador
b) tensão induzida na linha de baixa tensão 


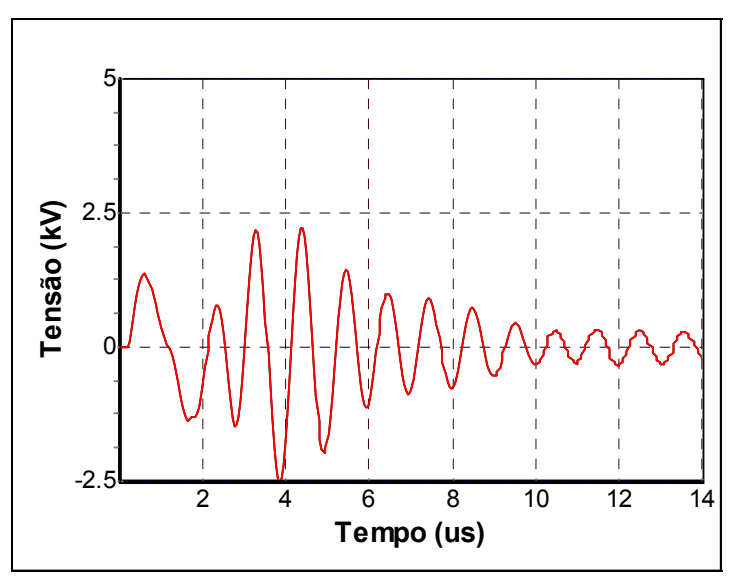

(a)

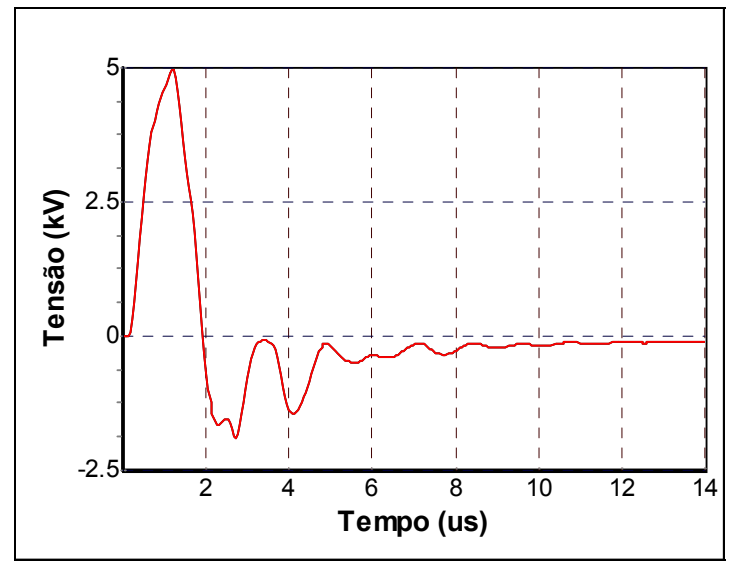

(b)

Fig. 4.66: Sobretensões fase-neutro na rede secundária (ponto $\mathrm{P}_{2}$ ) devido a descarga nas proximidades da linha. Amplitude da corrente da descarga igual a $45 \mathrm{kA}, \mathrm{tf}=1,5 \mu \mathrm{s}$.

a) tensão transferida via transformador

b) tensão induzida na linha de baixa tensão

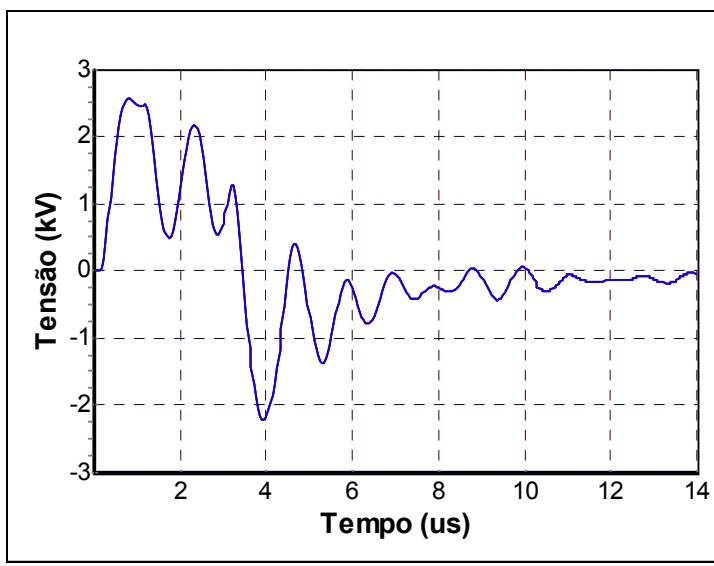

(a)

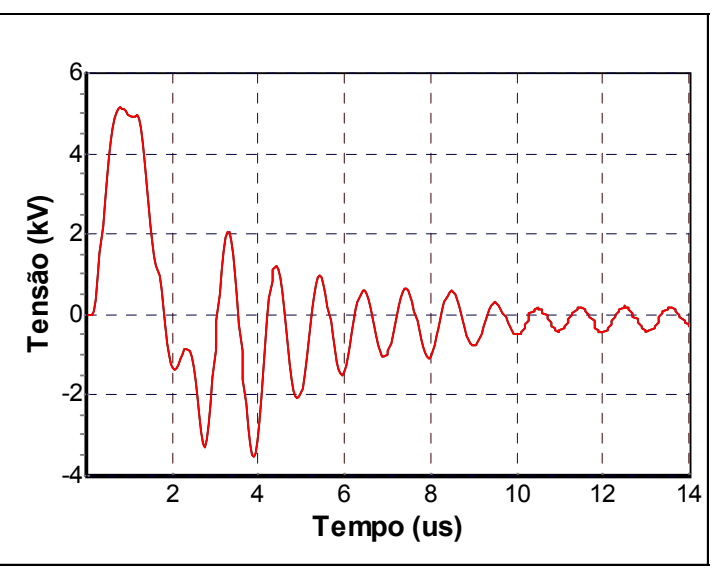

(b)

Fig. 4.67: Sobretensões fase-neutro totais (tensões transferida mais induzida) no secundário do transformador (ponto $\mathrm{P}_{2}$ ) devido a descarga nas proximidades da linha.

Amplitude da corrente da descarga igual a $45 \mathrm{kA}$.
a) $\mathrm{tf}=3 \mu \mathrm{s}$ (referente à Fig. 4.65)
b) $\mathrm{tf}=1,5 \mu \mathrm{s}$ (referente à Fig. 4.66) 


\section{CAPÍTULO 5}

\section{CONCLUSÕES E PROPOSTAS DE TRABALHOS FUTUROS}

O objetivo desse trabalho foi caracterizar as tensões induzidas na rede secundária em decorrência de descargas próximas à linha. Essa caracterização consistiu na verificação das amplitudes e formas de onda das tensões induzidas considerando a variação de diversos parâmetros da linha e das descargas atmosféricas. Além disso, foram também analisadas as tensões transferidas à rede de baixa tensão via transformador, através de simulações computacionais utilizando o modelo de transformador de distribuição desenvolvido pelo GATDA/USP. Esse modelo foi validado por meio de várias comparações entre tensões transferidas medidas e calculadas para diferentes formas de onda de tensão impulsiva na entrada e também para diversas condições de carga. As tensões induzidas na rede primária, utilizadas nos cálculos das tensões transferidas, foram obtidas por meio de experimentos em escalas reais e reduzida. Observou-se que as tensões transferidas ao secundário do transformador apresentam característica oscilatória, em geral com freqüência fundamental na faixa de $300 \mathrm{kHz}$ a $1 \mathrm{MHz}$. As amplitudes dessas tensões são fortemente dependentes da forma de onda da tensão no primário do transformador e geralmente apresentam valores de amplitude da ordem de alguns quilovolts.

As tensões induzidas em linhas de baixa tensão com configurações convencional e multiplexada foram calculadas por meio do modelo ERM ("Extended Rusck Model"). Foram abordados aspectos importantes quando do cálculo dessas tensões, como por exemplo a impedância do transformador vista pela linha de BT, a modelagem de instalações elétricas dos consumidores e dos ramais de ligação, linhas sem e com dispositivos de proteção. Com relação ao transformador de distribuição, verificou-se que a sua presença afeta as amplitudes e formas de onda das tensões induzidas na rede secundária. Pela análise paramétrica realizada para a linha convencional foi possível determinar como cada parâmetro da linha e das descargas atmosféricas influencia as tensões induzidas. As amplitudes das tensões fase-terra na rede secundária apresentaram valores elevados, da ordem de $15 \mathrm{kV}$ para uma linha 
com cargas instaladas e até aproximadamente $70 \mathrm{kV}$ quando não foram consideradas as presenças das cargas e do transformador. Esses valores podem ser altos o suficiente para acarretar a queima de equipamentos e disrupções elétricas em pontos susceptíveis da rede. Em relação às formas de onda, verificou-se que as tensões induzidas na linha de baixa tensão não apresentam a característica oscilatória observada em $[6,7]$ devido à diferença entre os intervalos de aterramento do neutro considerados. A forma de onda das tensões induzidas fase-terra na rede de BT é dependente das cargas conectadas a ela e apresentam, em geral, tempos de frente semelhantes ao da corrente da descarga. Por outro lado as tensões possuem tempos de queda muito mais curtos que os da corrente da descarga (da ordem de $5 \mu \mathrm{s}$ ). No caso de cargas capacitivas nota-se tempos de queda da tensão induzida maiores que os relativos aos casos de carga indutiva.

Foram estudadas ainda algumas configurações de linhas multiplexadas trifásicas, tendo sido observada grande redução nas amplitudes das tensões induzidas, em relação à rede convencional, apenas na condição de ausência de cargas e do transformador. Para situações mais realistas, quando são consideradas as ligações com os consumidores e o transformador de distribuição, as diferenças entre as tensões induzidas são bem menores, da ordem de $5 \%$ a $10 \%$, dependendo do caso. Conclui-se, portanto, que o desempenho das redes multiplexadas frente a descargas atmosféricas é comparável ao das redes convencionais, sendo o seu emprego justificado devido a outros fatores, como por exemplo custos de manutenção e redução do número de desligamentos provocados por toques de árvores nas linhas.

O uso de DPS na linha, junto ao transformador de distribuição e nas extremidades da mesma, também foi considerado. As análises realizadas foram feitas para linhas de BT multiplexadas trifásicas com cargas e transformadores. Foi utilizada uma curva característica VxI típica de um DPS para os cálculos das tensões induzidas. Verificou-se que tal dispositivo possibilita a redução das amplitudes das tensões na linha, principalmente no local onde ele está instalado, aumentando o grau de proteção dos equipamentos situados nas suas proximidades. Mesmo para pontos mais distantes do DPS pode-se notar, em alguns casos, uma redução considerável nas 
tensões induzidas fase-neutro, o que contribui para a melhoria do desempenho da linha.

As comparações realizadas entre as tensões induzidas fase-neutro na linha de baixa tensão com aquelas transferidas ao secundário via transformador, na mesma condição (mesma descarga), mostraram que essas últimas não são desprezíveis. Nos casos considerados as amplitudes das tensões transferidas atingiram valores da ordem de $35 \%$ a $45 \%$ das tensões induzidas. Esse resultado reforça a importância do estudo do comportamento dos transformadores frente a solicitações impulsivas.

Embora os modelos de redes de BT utilizados neste trabalho representem um avanço em relação a estudos anteriores, é importante destacar que a modelagem do fenômeno das tensões induzidas é complexa, principalmente no caso de linhas secundárias, em que se tem diversas configurações possíveis e parâmetros difíceis de se conhecer com precisão, como as impedâncias das cargas e as características do transformador de distribuição. Propõe-se, como temas para trabalhos futuros, uma investigação mais detalhada das impedâncias das unidades consumidoras e a determinação dos níveis de proteção de equipamentos eletroeletrônicos, como por exemplo televisores, aparelhos de som e vídeo, microondas, microcomputadores, etc. Em relação aos surtos transferidos, propõe-se estudos experimentais envolvendo medições em campo das tensões no primário e no secundário de transformadores de distribuição típicos. 


\section{REFERÊNCIAS BIBLIOGRÁFICAS}

[1] PINTO JR, O.; PINTO, I. R. A. Tempestades e relâmpagos no Brasil. São José dos Campos: Instituto de Pesquisas Espaciais, 2000. 194p.

[2] INSTITUTO DE PESQUISAS ESPACIAIS, AGÊNCIA ESPACIAL AMERICANA. Apresenta informações sobre o impacto das descargas atmosféricas. Disponível em: http://noticias.uol.com.br/inovacao/. Acesso em: 08/08/2003.

[3] COUTO, E. C.; DUARTE, J. V.; SOARES, M. R. Análise da taxa de falha de transformadores aéreos de distribuição. Revista Eletricidade Moderna, São Paulo, abr. 1995. p.54-74.

[4] PIANTINI, A.; CARVALHO, T. O. DE; SILVA NETO, A.; JANISZEWSKI, J. M.; ALTAFIM, R. A. C.; NOGUEIRA, A. L. T. A system for lightning induced voltages data acquisition - preliminary results. In: INTERNATIONAL SYMPOSIUM ON LIGHTNING PROTECTION, 7., Curitiba, 2003. Proceedings. VII SIPDA. São Paulo: IEE/USP, 2003. p.156-161.

[5] PIANTINI, A.; JANISZEWSKI, J. M. Use of surge arrester for protection of overhead lines against nearby lightning. In: INTERNATIONAL SYMPOSIUM ON HIGH VOltage ENGINEERING, 10., Montreal, 1997. Proceedings. ISH., Montreal, 1997.

[6] JOINT CIRED/CIGRE WORKING GROUP 05. Protection of MV and LV networks against lightning: basic information. In : INTERNATIONAL CONFERENCE ON ELECTRICITY, Birmingham, 1997. Proceedings. CIRED'97. Birmingham 1997. CONFERENCE PUBLICATION n. 438. p.2.19.1-2.19.6.

[7] MIRRA, C.; PORRINO, A.; ARDITO, A.; NUCCI, C. A. Lightning overvoltages in low voltage networks. Proc. of the Int. conference on Electricity 
Distribution. In : INTERNATIONAL CONFERENCE ON ELECTRICITY, Birmingham, 1997. Proceedings. CIRED'97. Birmingham 1997. CONFERENCE PUBLICATION n.438. p.2.19.1-2.19.6.

[8] HOIDALEN, H. K. Lightning-induced voltages in low-voltage systems and its dependency on overhead line terminations. In: INTERNATIONAL CONFERENCE ON LIGHTNING PROTECTION, 24., Birmingham, 1998,. Proceedings. ICLP 1998. Stafford: Staffordshire University, 1998. p.287-292.

[9] PIANTINI, A; BASSI, W.; JANISZEWSKI, J. M.; MATSUO, N. M.

Sobretensões na rede secundária, ocasionadas por descargas atmosféricas. São Paulo, Centro de Excelência em Distribuição de Energia Elétrica. CED 294/STRA002/RL 002/OR, fev. 1998.

[10] PIANTINI, A. Sobretensões induzidas na rede secundária devido a descargas atmosféricas. In: III CONGRESSO LATINO AMERICANO DE DISTRIBUIÇÃO DE ENERGiA ELÉTRICA, 1998, São Paulo. Anais. III CONLADIS. São Paulo: EPUSP, 1998. p. 468-472.

[11] PIANTINI, A.; JANISZEWSKI, J. M. Lightning induced voltages on lowvoltage lines. In: V INTERNATIONAL SYMPOSIUM ON LIGHTNING PROTECTION, 5,. São Paulo, 1999. Proceedings. V SIPDA. São Paulo: IEE/USP, 1999. p. 234-239.

[12] PIANTINI, A.; JANISZEWSKI, J. M. Tensões induzidas na rede secundária por descargas atmosféricas indiretas. Revista Eletricidade Moderna, São Paulo, v.27, n.308, nov. 1999. p.92-104.

[13] HOIDALEN, H. K.; HUSE, J.; DAHLSLETT, F.; AALBORG, T. Impacts of lightning-induced overvoltages on power quality in low-voltage distribution systems. In: INTERNATIONAL CONFERENCE ON LIGHTNING PROTECTION, 25., 
Rhodes, 2000. Proceedings. ICLP 2000. Patras, University of Patras, 2000. p.564569.

[14] SILVEIRA, H. F.; VISACRO FILHO, S. Lightning induced overvoltages: the influence of lightning and line parameters. In: INTERNATIONAL CONFERENCE ON GROUNDING AND EARTHING \& 3RD BRAZILIAN WORKSHOP ON ATMOSFERIC ELECTRICITY, 3., Rio de Janeiro, 2002. Proceedings. GROUND'2002 \& 3rd WAE. Rio de Janeiro: SB-RAI: Brazilian Society for Electrical Protection, 2002. p.105-110.

[15] BASSI, W. Estudo de surtos em redes secundárias de distribuição devido a descargas atmosféricas diretas na rede primária. 1999. 135p. Dissertação (Mestrado) - Escola Politécnica, Universidade de São Paulo. São Paulo, 1999.

[16] BASSI, W.; MATSUO, N. M.; PIANTINI, A. Currents and charge absorbed by low-voltage SPDs in overhead distribution systems due to lightning. In: INTERNATIONAL SYMPOSIUM ON HIGH VOLTAGE ENGINEERING, 11., London, 1999. Proceedings. ISH., London: Institution of Electrical Engineers, 1999. v. 2, p.2349-2352.

[17] PIANTINI, A.; MALAGODI, C. V. S. Voltage surges transferred to the secondary of distribution transformers. In: INTERNATIONAL SYMPOSIUM ON High VOltage EnGINeERING, 11., London, 1999. Proceedings. ISH., London: Institution of Electrical Engineers, 1999. v. 1, p.1.365-1.368.

[18] BASSI, W.; PIANTINI, A.; MATSUO, N. M. Evaluation of currents and charge in surge protective devices in low-voltage distribution networks due to direct lightning strikes. In: INTERNATIONAL CONFERENCE ON ELECTRICITY DISTRIBUTION (CIRED), 16., Amsterdam, 2001. CIRED 2001 - Technical Papers. London: IEE - Institution of Electrical Engineers, 2001. v. 2, p.52-55. 
[19] CONTI, A. R. DE Proteção de redes elétricas de baixa tensão contra descargas atmosféricas: transferência de surtos através de transformadores de distribuição. 2001. 163p. Dissertação (Mestrado) - Universidade Federal de Minas Gerais - UFMG, Minas Gerais, 2001.

[20] PIANTINI, A.; KANASHIRO, A. G.; CARNEIRO, J. C. Surtos transferidos à rede de baixa tensão via transformador - influência da carga conectada ao secundário. In: SEMINÁRIO NACIONAL DE DISTRIBUIÇÃO DE ENERGIA ELÉTRICA, 15, Salvador, 2002. XV SENDI. 2002. 1 CD-ROM.

[21] PIANTINI, A.; KANASHIRO, A. G.; OBASE, P. F. Lightning Surges transferred to the low-voltage network. In: INTERNATIONAL SYMPOSIUM ON LIGHTNING PROTECTION, 7., Curitiba, 2003. Proceedings. VII SIPDA. São Paulo: IEE/USP, 2003. p.216-221.

[22] PIANTINI, A; BASSI, W.; JANISZEWSKI, J. M; MATSUO, N. M. A simple transformer model for analysis of transferred lightning surges from MV to LV lines. In: INTERNATIONAL CONFERENCE ELECTRICITY DISTRIBUTION, 15., 1999, Nice. CIRED’NICE 99. Technical Papers. Liege: AIM, 1999 p. sec.2.18/ 16.

[23] OBASE, P. F. Surtos atmosféricos transferidos à rede secundária via transformador. Dissertação (Mestrado) - Escola Politécnica, Universidade de São Paulo. São Paulo. Dissertação em desenvolvimento.

[24] KANASHIRO, A. G.; PIANTINI, A. The effect of the secondary loads on the voltage surges transferred through distribution transformers. In: INTERNATIONAL SYMPOSIUM ON HIGH VOLTAGE ENGINEERING, 13., Delft, 2003. Proceedings. ISH. Rotterdam: 2003. p.216-221. 
[25] PIANTINI, A. Contribuição ao estudo das tensões induzidas em linhas de distribuição por descargas atmosféricas indiretas. 1991. 205p. Dissertação (Mestrado) - Escola Politécnica, Universidade de São Paulo. São Paulo, 1991.

[26] PIANTINI, A. Tensões induzidas por descargas atmosféricas indiretas em linhas aéreas, rurais e urbanas, considerando diferentes métodos de proteção modelagens teórica e experimental e aplicação ao cálculo de interrupções. 1997. 316p. Tese (Doutorado) - Escola Politécnica, Universidade de São Paulo. São Paulo, 1997.

[27] PIANTINI, A.; JANISZEWSKI, J. M. Induced voltages on distribution lines due to lightning discharges on nearby metallic structures. IEEE Transactions on Magnetics, v.34, n.5, p.2799 - 2802, Sep.1998.

[28] PIANTINI, A.; JANISZEWSKI, J. M. The Extended Rusck Model for calculating induced voltages on overhead lines. In: INTERNATIONAL SYMPOSIUM ON LIGHTNING PROTECTION, 7., Curitiba, 2003. Proceedings. VII SIPDA. São Paulo: IEE/USP, 2003. p.151-155.

[29] KANASHIRO, A. G. Modelagem de transformadores de distribuição para altas freqüências. 2001. 174p. Tese (Doutorado em Engenharia Elétrica) - Escola Politécnica, Universidade de São Paulo. São Paulo, 2001.

[30] PIANTINI, A.; KANASHIRO, A. G. A distribution transformer model for calculating transferred voltages. In: INTERNATIONAL CONFERENCE ON LiGHTNING PROTECTION, 26., Cracow, 2002,. Proceedings. ICLP 2002. Cracow: Association of Polish Electrical Engineers, 2002. p.429-434.

[31] KANASHIRO, A. G.; PIANTINI, A.; BURANI, G. F. A methodology for transformer modelling concerning high frequency surges. In: INTERNATIONAL SYMPOSIUM ON LIGHTNING PROTECTION, 6., Santos, 2001. Proceedings. VI SIPDA. São Paulo: IEE/USP, 2001. p.275-280. 
[32] KANASHIRO, A. G.; PIANTINI, A.; BURANI, G. F. Modelo de transformador de distribución trifásico para estudios de máximos de tensión ocasionados por descargas atmosféricas. Revista Información Tecnológica del Chile, v. 15, n. 1, p.67-73, 2004. La Serena, Chile, 2004.

[33] NUCCI, C. A.; RACHIDI, F.; MICHEL, V. Lightning induced voltages on overhead lines. IEEE Transaction on Electromagnetic Compatibility, v. 35, n. 1, p.75-86, Feb. 1993.

[34] NUCCI, C. A.; BORGHETTI, A.; PIANTINI, A.; JANISZEWSKI, J. M. Lightning-induced voltages on distribution overhead lines: comparison between experimental results from a reduced-scale model and most recent approaches. In: INTERNATIONAL CONFERENCE ON LIGHTNING PROTECTION, 24., Birmingham, Sep. 1998. Proceedings. ICLP 1998. Birmingham: 1998. p.314-320.

[35] UMAN, M. A. The lightning discharge. New York, Academic Press, 1987. (International Geophysics, v. 39).

[36] RUBINSTEIN, M.; UMAN, M. A. Review of the University of Florida research on lightning induced voltages on power distribution lines. In: INTERNATIONAL CONFERENCE ON LIGHTNING PROTECTION, 21, Berlin, 1992. Proceedings. ICLP 1992 , Berlin, 1992. p.189-193.

[37] AGRAWAL, A. K.; PRICE, H. J.; GURBAXANI, S. H. Transient response of multiconductor transmission lines excited by a nonuniform electromagnetic field. IEEE Transaction on Electromagnetic Compatibility, v. 22, n. 2, p.119-129. May 1980.

[38] HEIDLER, F.; CVETIC, J. M.; STANIC, B. V. Calculation of lightning current parameters. IEEE Transaction on Power Delivery, v. 14, n. 2, p.399-404. Apr. 1999. 
[39] BABA, Y.; RAKOV, V. A. On the transmission line model for lightning return stroke representation. Geophysical Research Letters, v. 30, n. 24, 2294, 2003.

[40] CONTI, A. R.DE; VISACRO FILHO, S.; SILVEIRA, F. H.; PEREIRA, C.; VICENTE, J. P. D. Lightning overvoltages on low voltage networks: analysis and protection. In: INTERNATIONAL CONFERENCE ON GROUNDING AND EARTHING \& 3RD BRAZILIAN WORKSHOP ON ATMOSFERIC ELECTRICITY, 3., Rio de Janeiro, 2002. Proceedings. GROUND’2002 \& 3rd WAE. Rio de Janeiro: SB-RAI: Brazilian Society for Electrical Protection, 2002. p.285-209.

[41] SILVEIRA, F. H.; MESQUITA, C. R.; VISACRO FILHO, S. Evaluation of the influence of lightning channel and return current characteristics on induced overvoltages. In: international conference on lightning protection, 26., Cracow, 2002. Proceendings. ICLP 2002. Cracow: Association of Polish Electrical Engineers, 2002. p.191-196.

[42] VISACRO FILHO, S., SOARES, A. J., SCHROEDER, M. A. O. An interactive computational code for simulation of transient behavior of electric system components for lightning currents. In: INTERNATIONAL CONFERENCE ON Lightning PROteCtiOn, 26., Cracow, 2002. Proceedings. ICLP 2002. Cracow: Association of Polish Electrical Engineers, 2002. p.732-737.

[43] GRUBER, P. X.; JANDRELL, I. R.; BRITTEN, A. C.; COLLER, V. J. M. Comparison of measured and predicted induced overvotages on LV ABC due to adjacent lightning. In: INTERNATIONAL SYMPOSIUM ON HIGH VOLTAGE ENGINEERING, 10., Montreal, 1997. Proceedings. ISH , Montreal, IEEE-PES / Cigré / Hydro Quebec, 1997. p.25-29

[44] GALVÁN, A.; COORAY, V.; THOTTAPPILLIL, R. Effects of lightning electromagnectic field pulses (LEMP) in low voltage power installations. In: INTERNATIONAL CONFERENCE ON LIGHTNING PROTECTION. 24., 
Birmingham, 1998. Proceedings. ICLP 1998. Staffordshire University, 1998. p.729-734.

[45] GALVÁN, A.; COORAY, V.; THOTTAPPILLIL, R. A Technique for the evaluation of lightning-induced voltages in complex low-voltage power-installation networks. IEEE Transactions on Electromagnetic Compatibility, v. 43, n. 3, Aug. 2001, p.402-409.

[46] GALVÁN, A.; COORAY, V. Analytical simulation of lightning induced voltage in low voltage power installation. In: INTERNATIONAL CONFERENCE ON Lightning PROTECTION, 15., Rhodes, 2000. Proceedings. ICLP 2000. Patras, University of Patras, 2000. p.290-295.

[47] SILFVERSKIÖLD, S.; THOTTAPPILLIL, R.; COORAY, V.; SCUKA, V. Induced voltages in a low-voltage power installation network due to lightning electromagnetic fields: an experimental study. IEEE Transaction on Electromagnetic Compatibility, v. 41, n. 3, p.265-271, Aug. 1999.

[48] SILVEIRA, F.; VISACRO FILHO, S.; CONTI, A. R. DE Tensões induzidas por descargas atmosféricas em circuitos de baixa tensão: influência na qualidade de energia. In: ENCUENTRO REGIONAL LATINOAMERICANO DE LA CIGRÉ, 10, 2003, Puerto Iguazu. Trabalhos Técnicos. ERLAC. CIGRÉ, 2003

[49] PIANTINI, A.; JANISZEWSKI, J. M.; KAMEYAMA, F. H.; MALIMPENSA FILHO, G.; OLIVEIRA, J. J. DE; MATSUO, N. M.; YUMIO, S.; NASAKI, S.; PINHEIRO, W. Estudo experimental de tensões induzidas por descargas atmosféricas através de modelo reduzido. In: SEMINÁRIO NACIONAL DE DISTRIBUIÇÃO DE ENERGIA ELÉTRICA, 11, Florianóponis, 1992. Anais. XI SENDI. 1992.

[50] CARVALHO, T. O. DE. Desenvolvimento de sistema para estudo de tensões induzidas em linhas de media tensão por descargas atmosféricas. 2004. 137p. 
Dissertação (Mestrado) - Escola Politécnica, Universidade de São Paulo. São Paulo, 2004.

[51] PIANTINI, A.; CARVALHO, T. O. DE; SILVA NETO, A.; JANISZEWSKI, J. M.; ALTAFIM, R. A. C.; NOGUEIRA, A. L. T. A system for simultaneous measurements of lightning induced voltages on lines with and without arresters. Artigo aprovado para publicação In: INTERNATIONAL CONFERENCE ON Lightning PROTECTION, 27., Proceedings. ICLP 2004.

[52] PIANTINI, A.; MALAGODI, C. V. S. Voltages transferred to the low-voltage side of distribution transformers due to lightning discharges close to overhead lines. . In: INTERNATIONAL SYMPOSIUM ON LIGHTNING PROTECTION, 5., São Paulo, 1999. Proceedings. V SIPDA. São Paulo: IEE/USP, 1999. p.201-205.

[53] MALOGODI, C. V. S.; PIANTINI, A; JANISZEWSKI, J. M. Programa computacional para determinação de tensões transferidas à rede secundária. São Paulo, Centro de Excelência em Distribuição de Energia Elétrica. CED 274/STRA002/NT 003/OR. jun. 1997.

[54] OrCAD PSpice A/D, evaluation version 9.1. Cadence Design System, Inc. [S.I.] Conjunto de programas.

[55] NUCCI, C. A.; RACHIDI, F. Lightning induced overvoltages. IEEE Transmission and Distribution Conference, Panel Session "Distribution Line Protection”, New Orleans, Apr. 1999.

[56] CHOWDHURI, P. Response of overhead lines of finite length to nearby lightning strokes. IEEE Transaction on Power Delivery, v. 6, n. 1, p.343-351, Jan. 1991. 
[57] LIEW, A. C.; MAR, S. C., Extension of the Chowdhuri - Gross model for lightning induced voltage on overhead lines. IEEE Transaction on Power Systems, v. 1, n. 2, p.240-247, Apr. 1986.

[58] RUSCK, S. Induced lightning over-voltages on power-transmission lines with special reference to the over-voltage protection of low-voltage networks. Transactions of the Royal Institute of Technology, n. 120, p.1-118, 1958.

[59] YOKOYAMA, S.; MIYAKE, K.; MITANI, H. Advanced observations of lightning induced voltage on power distribution lines. IEEE Transaction on Power Delivery, vol. 1, n. 2, p.129-139, Apr. 1986.

[60] YOKOYAMA, S.; MIYAKE, K.; MITANI, H. Simultaneous measurement of lightning induced voltages with associated stroke currents. IEEE Transaction on Power Apparatus and Systems, v. 102, n. 8, p.2420-2427, Aug. 1983.

[61] PIANTINI, A.; JANISZEWSKI, J. M. Analysis of three different theories for computation of induced voltages on distribution lines due to nearby lightning. In: INTERNATIONAL CONFERENCE ON ELECTRICITY DISTRIBUTION , Buenos Aires, 1996. Proceedings. CIRED. Buenos Aires, Dec. 1996. p.127-132.

[62] PIANTINI, A.; JANISZEWSKI, J. M. The influence of the upward leader on lightning induced voltages. In: INTERNATIONAL CONFERENCE ON LIGHTNING PROTECTION, 23., Florence, 1996. Proceedings. ICLP 1996., v. 1, p.352-357, Florence, 1996.

[63] CHOWDHURI, P. Estimation of flashover rates of overhead power distribution lines by lightning strokes to nearby ground. IEEE Transaction on Power Delivery, v. 4, n. 3, p.1982-1989, July 1989.

[64] CENTRAIS ELÉTRICAS DE GOIÁS S/A . CELG NTD-08: Critérios de projetos de redes de distribuição aéreas urbanas - Classes de 15 e 36,2 kV. 1996. 
[65] CENTRAIS ELÉTRICAS DE GOIÁS S/A. CELG NTD-18: Estruturas para Redes Aéreas Isoladas em Tensão Secundária de Distribuição. 2001.

[66] EMPRESA ENERGÉTICA DO MATO GROSSO DO SUL. ENERSUL TDE 107: Rede aérea de distribuição urbana. 1998.

[67] EMPRESA ENERGÉTICA DO MATO GROSSO DO SUL. ENERSUL INS COM -13: Estruturas para redes de distribuição secundárias aéreas isoladas. 1998.

[68] COMPANHIA ENERGÉTICA DE BRASÍLIA. CEB 1.02: Critérios para projetos de redes aéreas urbanas convencionais. 2002.

[69] COMPANHIA ELÉTRICA DE TOCANTINS. CETINS NTD 12: Montagem de redes aéreas secundárias isoladas com cabos multiplexados. 2002.

[70] COMPANHIA ELÉTRICA DO PARÁ. CELPA NTD 09: Padrão de estruturas de rede aérea secundária com cabos multiplex. 2002.

[71] CENTRAIS ELÉTRICAS MATO-GROSSENSES. CEMAT - NTE 26:

Montagem de redes de distribuição aérea urbana trifásica - 13,8 e 34,5 kV. 2003.

[72] CENTRAIS ELÉTRICAS MATO-GROSSENSES. CEMAT NTE 23: Norma de montagem de redes aéreas secundárias isoladas com cabos multiplexados . 2003.

[73] COMPANHIA ELÉTRICA DA BAHIA. COELBA PDR 00.01: Instrução de serviço para sistema de projeto e montagem de rede aérea de distribuição urbana em poste duplo $t$ - condutores nus. 1998.

[74] COMPANHIA ELÉTRICA DA BAHIA. COELBA PDR 00.06: Instrução de serviço para montagem de rede aérea de distribuição urbana antifurto. 1998. 
[75] COMPANHIA PARANAENSE DE ENERGIA. COPEL NTC 841001: Projeto de redes de distribuição urbana. 1999.

[76] METROPOLITANA ELETRICIDAdE DE SÃO PAULO S.A. ELETROPAULO Fascículo: Especificações e montagens de materiais e equipamentos - rede aérea. 2002.

[77] METROPOLITANA ELETRICIDADE DE SÃO PAULO S.A.

ELETROPAULO Fascículo: Condições gerais para o fornecimento. 2002.

[78] COMPANHIA PAULISTA DE FORÇA E LUZ. CPFL GED - 3602: Rede secundária com condutores nus - montagem. 2003.

[79] COMPANHIA PAULISTA DE FORÇA E LUZ. CPFL PT 122: Estruturas padronizadas para redes aéreas de distribuição urbana - volume 1. 2001.

[80] COMPANHIA PAULISTA DE FORÇA E LUZ. CPFL 574: Estruturas

padronizadas para redes aéreas secundárias isoladas com cabos multiplexados. 2001.

[81] COMPANHIA PAULISTA DE FORÇA E LUZ. CPFL Orientação Técnica: Aterramentos na distribuição. 2000.

[82] ELETRICIDADE E SERVIÇOS S.A.. ELEKTRO NTU - 01: Fornecimento de energia elétrica em tensão secundária a edificações individuais. São Paulo 1999.

[83] COMPANHIA BANDEIRANTE DE ENERGIA. BANDEIRANTE Norma:

Fornecimento de energia elétrica em tensão secundária de distribuição.

[84] ASSOCIAÇÃO BRASILEIRA DE NORMAS TÉCNICAS. Redes de distribuição aérea rural de energia elétrica - padronização - NBR 5433. Rio de Janeiro. 1982. 
[85] ASSOCIAÇÃO BRASILEIRA DE NORMAS TÉCNICAS. Redes de distribuição aérea urbana de energia elétrica - padronização - NBR 5434. Rio de Janeiro. 1982.

[86] RODRIGUES, J. L. Módulo - Materiais Elétricos. 2003. Apostila Curso Técnico em Eletrotécnica - $1^{\circ}$ Semestre 2003 - ESCOLA TÉCNICA ELETROMECÂNICA DA BAHIA.

[87] LEITE, D. M.; LEITE, C. M. Proteção contra descargas atmosféricas. 3 ed. São Paulo: Officina de Mydia, 1977. 294p.

[88] PIANTINI, A.; JANISZEWSKI, J. M. Surtos induzidos por descargas atmosféricas: influência da velocidade de propagação da corrente. In: II CONGRESSO BRASILEIRO DE ELETROMAGNETISMO, 1996, Ouro Preto. CBMAG'96: Anais. Belo Horizonte: UFMG, 1996. p. 51-54.

[89] PIANTINI, A; BASSI, W.; MATSUO, N. M.; NOSAKI, S. Sobretensões e sobrecorrentes em redes de baixa tensão com cabo multiplexado causadas por descargas atmosféricas. In: I CONGRESSO DE INOVAÇÃO TECNOLÓGICA EM ENERGIA ELÉTRICA, 1., Brasília, 2001. Anais. I CITENEL. p. 68-71. 